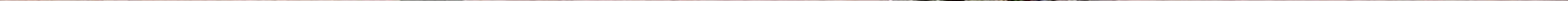


The Journal of Public Space

2016 | Vol. I, n. I

https://www.journalpublicspace.org

Queensland University

of Technology

\title{
Founding Editors
}

Luisa Bravo, City Space Architecture, Italy

Mirko Guaralda, Queensland University of Technology, Australia

\section{Scientific Board}

Davisi Boontharm, Sophia University, Japan

Simone Brott, Queensland University of Technology, Australia

Julie-Anne Carroll, Queensland University of Technology, Australia

Margaret Crawford, University of California Berkeley, United States

Philip Crowther, Queensland University of Technology, Australia

Simone Garagnani, University of Bologna, Italy

Pietro Garau, University of Rome "La Sapienza”, Italy

Carl Grodach, Queensland University of Technology, Australia

Miquel Marti, Universitat Politècnica de Catalunya, Spain

Darko Radovic, Keio University, Japan

Estanislau Roca, Universitat Politècnica de Catalunya, Spain

Joaquin Sabate, Universitat Politècnica de Catalunya, Spain

Robert Saliba, American University of Beirut, Lebanon

Claudio Sgarbi, Carleton University, Canada

Hendrik Tieben, The Chinese University of Hong Kong, Hong Kong

\section{Editorial Board}

Glenda Caldwell, Queensland University of Technology, Australia Linda Carroli, Queensland University of Technology, Australia Debra Cushing, Queensland University of Technology, Australia Severine Mayere, Queensland University of Technology, Australia

\section{Editorial Support}

Paul Donehue, Queensland University of Technology, Australia Michael Marriott, Queensland University of Technology, Australia Marisha McAuliffe, Queensland University of Technology, Australia

\section{Journal Manager}

Luisa Bravo, City Space Architecture, Italy

\section{Correspondents}

Konstantinos loannidis, Aristotle University of Thessaloniki, Greece Massimo Santanicchia, Iceland Academy of the Arts, Iceland Lakshmi Priya Rajendran, Lancaster University, United Kingdom Matthew D. Lamb, The Pennsylvania State University, USA

\section{Editorial offices}

Queensland University of Technology

2 George Street, Brisbane

QLD 4000, AUSTRALIA

jps@qut.edu.au

\author{
City Space Architecture \\ Via Paolo Giovanni Martini 26/d \\ 40I34 Bologna, ITALY \\ jps@cityspacearchitecture.org
}

\section{Publication Ethics Statement}

The Journal of Public Space aligns itself with the Committee on Publication Ethics (COPE) best practice guidelines for dealing with ethical issues in journal publishing.

http://publicationethics.org/

Cover image by Leonardo Parra-Agudelo. 


\section{TABLE OF CONTENTS}

\section{EDITORIAL}

An open access forum for the discussion and advancement

of research about public space

Luisa Bravo \& Mirko Guaralda, Queensland University of Technology, Brisbane, Australia

Public Space and the New Urban Agenda

5-10

Cecilia Andersson, UN Habitat

\section{OVERVIEW}

Public Space Update. Report from the United States

Margaret Crawford, University of California Berkeley, USA

Measuring the Magic of Public Space

Pietro Garau, "La Sapienza" University in Rome, Italy

Public Space Trends in Hong Kong. A view from the New Territories

Hendrik Tieben, The Chinese University of Hong Kong, Hong Kong

Learning, Thinking and Living Tokyo.

About doing urban research in cultures radically different to that of our own

Darko Radovic, Keio University, Tokyo, Japan

Mapping the lived experiences of Bangkok's soi

Davisi Boontharm, Sophia University, Tokyo, Japan

SPACE

Urban morphology and the post-industrial city: commercial space in Manchester

Eamonn Canniffe, Manchester School of Architecture, UK

Temporary Public Spaces: A Technological Paradigm

Philip Crowther, Queensland University of Technology, Brisbane, Australia

\section{SOCIETY}

The Social Life of Gas Stations

Giulio Giovannoni, University of Florence, Italy

Guerilla East and Bicycle Espresso.

The Changing Contemporary Food Culture of Urban Helsinki

Mika Savela, Canadian Centre for Architecture, Canada

Public Space for Street-Scape Theatrics. Guerrilla Spatial Tactics

and Methods of Urban Hacking in Brisbane, Australia

Christopher Cox, Mirko Guaralda, Queensland University of Technology, Brisbane, Australia

\section{SYSTEMS}

Private control and public openness.

$129-146$

The development of London's public spaces since the Mayor's 2009 manifesto

Camilo Vladimir de Lima Amaral, University of East London, UK

\section{VIEWPOINT}

This is My City

Leonardo Parra-Agudelo, Queensland University of Technology, Australia

Magic Carpet. Re-envisioning Community Space in Hong Kong

Hendrik Tieben, The Chinese University of Hong Kong, Hong Kong

Pop-up City. Searching for instant urbanity

Luisa Bravo, City Space Architecture, Bologna, Italy 


\title{
An open access forum for the discussion and advancement of research about public space
}

\author{
Luisa Bravo \& Mirko Guaralda \\ Queensland University of Technology \\ Creative Industries Faculty, School of Design \\ luisa.bravo@qut.edu.au|m.guaralda@qut.edu.au
}

Human beings are social beings and public spaces have always been the stage of interaction, socialization and representation of a society as well as of a culture (Carmona, Heath, Oc, \& Tiesdell, 20l0). The role of public space has changed throughout history; the profound changes our cities have undergone during the industrial and technological revolution have modified the way people access and engage in the public domains (Gehl, 2010). The introduction of motorized vehicles and mass consumption commercial centres challenged the traditional view of publics and new types of public spaces in time have emerged. More recently, at the outset of the digital revolution, some analysts predicted that information technology would have sanctioned the death of public place, but the introduction of mobile technologies is instead fostering a renaissance of social public spaces (Foth, 20l I). The way citizens relate to the public dominion has also deeply changed in recent decades with more and more bottom-up, pop-up and temporary interventions taking place in the public realms (Caldwell \& Guaralda, 20I6). Public space is still the centre of the contemporary social life; its forms and types have evolved in time and today we are facing with a variety, complexity and richness in public spaces rarely experienced in the past. The traditional role of the square as gathering and social place has evolved in a multitude of location, uses and interactions. Streets, parks, commercial centres, cultural precincts, techno-parks, libraries, but also infrastructures, stations or parking lot today accommodate publics in different ways. What in the 1990s was labelled as a 'non-place' (Auge, 1995) today has resulted in a 'new-place'.

The discourse about public spaces is generally dominated by exempla coming mainly from Europe and North America, where in the 1960s and 1970s main theories about use and navigation of the built environment have been developed (Arefi, 2004). If on one side cases from these cultural areas are more accessible, on the other side interesting and relevant experiences are today developed all over the world, starting with the innovative and highly socially relevant intervention in South American cities. New types of public spaces are also emerging in the Asia-Pacific region, due to the digital revolution, or in Africa, in consideration of the massive urbanisation this continent is undergoing. 
Whilst there are several dedicated publications to cities, urban morphologies, urban dynamics and urban design, a forum where to discuss and share research, experiences and projects about public space so far was not provided in a structured and clear way. The Journal of Public Space aims to be the first international, open access journal, integrally dedicated to the discussion of public space in all its different forms and incantations. The objective is to provide a platform where academics and practitioners can share ideas and debate publics breaking traditional disciplinary boundaries. We are willing to engage also artists, to provide a different point of view.

The Journal of Public Space, as a true public space, is meant to be an inclusive forum where people from different backgrounds can present their work and access other people's experiences. This is possible through the use of an open access platform (Open Journal System), where authors publish their work and readers can download articles without the payment of any fees. The open access platform could be also used to comment articles and to send requests to authors and editors. Nowadays academic knowledge is often not easily accessible; most of the leading journals require a subscription fee to access contents. Universities, institutions or individual researchers have often to deal with the substantial cost of knowledge in the form of fees to publishers, not only to be able to read contents, but in some cases even to have one's research reviewed and published. Publish or perish, they say, but how? A recent on line petition "The Cost of Knowledge", signed by more than 15.000 researchers, is discussing the way knowledge is produced and disseminate in academia. Some illegal actions - like Sci-Hub, the first pirate website in the world to provide mass and public access to tens of millions of research papers - are standing against commercial enterprises. We promote a different approach to academic knowledge. We want a journal different from most of the leading journals that are currently available. Knowledge is a common good, in the same way public space in cities is a common good.

As a project, The Journal of Public Space was born as a collaboration between the nonprofit cultural association 'City Space Architecture', based in Bologna, Italy', and the Queensland University of Technology, Brisbane, Australia ${ }^{2}$. Discussions about the need of a new journal started after the first 'Past Present and Future of Public Space' International conference on Art, Architecture and Urban Design organised by 'City Space Architecture' that took place in Bologna on June 25-27, 20143. After two years of brainstorming, discussion and planning, The Journal of Public Space commences now its journey, paying tribute to the international conference that has fostered its conception. The partnership with UN Habitat, the United Nations Agency for Cities and Human Settlements is a promising wish that the journal will be able to attract attention and interest not only of the academic environment but also of global institutions involved in the process of create, transform and manage public space all around the world. The Journal is committed to foster international collaboration and knowledge transfer from academia into industry and society and to facilitate better practice in the design and management of public spaces through access to knowledge and international exempla.

In this first issue, the variety and richness of public space is discussed presenting some of the papers initially presented in 2014 , revised, on a double blind peer review process, and expanded to suit the broad audience the journal aims to reach.

We present in this first issue a selection of five overviews that leading academics in the field of architecture have kindly provided in order to start rendering the complexities of 
the discourse on public space. Margaret Crawford, Pietro Garau, Hendrik Tieben, Darko Radovic and Davisi Boontharm provide their view from different geographical and cultural perspectives. The journal is then organised in three sections covering Space, Society and Systems: six different papers discuss topics in design, such as urban form and temporary spaces; social dynamics, for example urban hacking or the emergence of new places; and complex topics related to publicness and openness. The viewpoint section closes the first issue providing an artist's point of view on his city, Bogota, a report on an on-going research project in Hong Kong and a report of a photography research project on instant urbanity initiated in Bologna.

Overall, this first issue gives voice to experiences across five different continents and provide points of view from different disciplines and cultural positions. As a first issue, the tone and structure of the Journal is still developing, but its vision as a public inclusive forum is clear.

After the 2014 conference in Bologna, City Space Architecture and the Queensland University of Technology are currently establishing the 'Past Present and Future of Public Space' research group, intended to engage academic scholars from multidisciplinary fields in the advancement of knowledge and understanding of the complexity and relevance of public space in our cities. The Journal of Public Space was presented on September 23, 2016, in Venice, Italy, during an international seminar, in the frame of Biennale Sessions, a special educational project of La Biennale di Venezia. This symposium was the first meeting of the 'Past Present and Future of Public Space' research group.

The Journal of Public Space will be officially launched at the Habitat III conference, the United Nations Conference and Sustainable Urban Development, that will take place in Quito, Ecuador, on October 17-20, 20164. City Space Architecture, the Queensland University of Technology and UN Habitat will held a talk at the Urban Library on October 19, 5.00-5.45pm at the main venue of the conference, Casa de la Cultura Ecuatoriana 'Benjamín Carrión'. This talk is included in the main programme of the conference.

Habitat III is a major global summit that takes place every twenty years ${ }^{5}$, to decide the future of cities. More than 45.000 participants already registered. We hope to provide a valuable contribution.

Bologna/Brisbane, October 13, 2016

\section{Acknowledgments}

The Editors would like to thank the Queensland University of Technology, QUT Library and QUT - Creative Industries Faculty for the support to this editorial project. We would like also to acknowledge the support of QUT ejournal Community of Practice for their input in finalising this first issue. Finally we wish to thank every one who has collaborated to this first number; the Scientific and Editorial Boards our Correspondants and particularly all the academics who have volountered their time to peer-review the articles. 
Notes

(I) http://www.cityspacearchitecture.org

(2) http://www.qut.edu.au

(3) The 'Past Present and Future of Public Space' International Conference on Art, Architecture and Urban Design (2014) was organised by City Space Architecture under the patronage of the Municipality of Bologna, the Department of Architecture of the University of Bologna, the Italian Institute of Urban Planners (INU), the Institute of Cultural Heritage of the Emilia-Romagna Region, the Academy of Fine Arts in Bologna, the Professional Association of Architects and Engineers in Bologna, the Italian Council of Architectural Libraries and the International Society of Biourbanism, with the collaboration of several relevant Italian Institutions. Conference details are available here: http://www.cityspacearchitecture.org/?p=past-present-future-of-public-space

(4) Official website of the conference: https://habitat3.org/. More details on the conference are available here: http://citiscope.org/habitatlll/explainer/what-habitat-iii

(5) The first one was in Vancouver in 1976, the second one was in Istanbul in 1996.

\section{Bibliography}

Arefi, M. (2004). The pedagogy of the American city: revisiting the concepts of place, non-place, and placelessness. Urban Design Int, 9(I), 103 - II 17.

Auge, M. (1995). Non-places: Introduction to an anthropology of supermodernity. (J. Howe, Trans.). London: Verso.

Caldwell, G. A., \& Guaralda, M. (2016). Blurring the physical boundaries of the city: Media architecture and urban informatics for community engagement. In G. A. Caldwell, C. H. Smith, E. M. Clift \& G. Cairns (Eds.), Digital Futures and the City of Today New Technologies and Physical Spaces (pp. 235-250). Bristol, UK: Intellect.

Carmona, M., Heath, T., Oc, T., \& Tiesdell, S. (2010). Public Places Urban Spaces: The Dimensions of Urban Design. New York: Taylor \& Francis Ltd.

Foth, M. (20I I). From social butterfly to engaged citizen: urban informatics, social media, ubiquitous computing, and mobile technology to support citizen engagement. Cambridge, Mass: MIT Press.

Gehl, J. (2010). Cities for People. Washington DC: Island Press.

\section{To cite this Editorial:}

Bravo, L. \& Guaralda, M. (20I6), An open access forum for the discussion and advancement of research about public space, The Journal of Public Space, I(I), I-4, DOI: 10.5204/jps.vlil.3

Please see the Editorial Policies under the 'About' section of the journal website for further information.

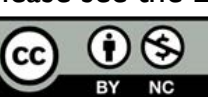

This work is licensed under a Creative Commons Attribution - Non Commercial 4.0 International License. https://creativecommons.org/licenses/by-nc/4.0/ 


\title{
EDITORIAL
}

\section{Public Space and the New Urban Agenda ${ }^{(*)}$}

\author{
Cecilia Andersson \\ UN Habitat | United Nations Human Settlements Programme \\ Programme on Public Space. Urban Planning \& Design Branch \\ cecilia.andersson@unhabitat.org
}

\section{Public Space led urban development}

Cities that improve the quality of life for their citizens experience higher levels of prosperity; they are also likely to find themselves more advanced in terms of sustainability. Such cities strive towards social equity and gender equality by increasing access to the urban commons and public good, preventing private appropriation and expanding the scope for improved quality of life for all. Cities that have a strong notion of the 'public' demonstrate a commitment to an improved quality of life for their citizens by providing adequate street space, green areas, parks, recreation facilities and other public spaces.

Public spaces are a vital ingredient of successful cities. They help build a sense of community, civic identity and culture. Public spaces facilitate social capital, economic development and community revitalisation. The liveliness and continuous use of public space as a public good leads to urban environments that are well maintained, healthy and safe, making the city an attractive place in which to live and work. It is important for local governments to invest in public space:

- $\quad$ Public space $=$ quality of life

- Public space supports the economy

- Public Space contributes to a sense of civic cohesion and citizenship

- Public space fosters social and cultural interaction

- Public space enhances safety

- Public space improves health and well-being

- Public space increases mobility

- Public space improves the environment

Public space can lead urban development by ensuring that building will only be permitted if public space has been organized prior to development. The link between public space and urban development needs to be understood in each context and legal framework in order to prevent the creation of unmanaged and/or public space deficiencies common to many cities. Particularly in recent decades, many cities have put public space at the core of urban development, for example Bogota in Colombia.

Ensuring city-wide distribution of public spaces is a way for governments to reduce inequalities and reallocate benefits. The benefit of preparing a city-wide strategy/policy is the protection and creation of a network of high-quality public spaces. City-wide policies 
and strategies should ensure planning, design and management of public spaces at different scales. Without a clear strategy/policy, it is difficult for local governments to prioritise, spend and plan resources and to show how much public space is valued, and to mitigate the negative impacts of site specific interventions (e.g. gentrification).

\section{The Relevance of Public Space and global mandate}

Globally, the growing attention to public space informed the 23rd Session of the Governing Council of The United Nations Human Settlements Programme (UN-Habitat) in 20 II, where member states mandated UN-Habitat to consolidate agency-wide work on public space, to develop and promote public space policy, coordination, disseminate knowledge and directly assist cities in public space initiatives'. In addition, UN-Habitat established in 2012, a Global Programme on Public Space now working in 30 cities. In 20I3-15, the Future of Places (FoP) initiative also significantly contributed to raising awareness around the public space agenda on a global level. A multi-stakeholder initiative which was established by Ax:son Johnson Foundation, UN-Habitat and Project for Public Spaces (PPS) brought together a large and diverse network of stakeholders around the issues of public space through a series of annual conferences. The Future of Places gathered global thinkers, academia, decision-makers, practitioners, UN Agencies, media, communities and private sector that subscribe to the transformative power that good quality public spaces can have in a city. The initiative has shown the commitment of a wide range of actors with a stake in public space, as well as highlighted the global importance of this theme.

\section{The opportunity: the global SDG and the New Urban Agenda}

Another great milestone is the adoption of the 2016-2030 Sustainable Development Goals which adopted a Goal II 'Build cities and human settlements inclusive, safe, resilient and sustainable.' One of the proposed targets set out is 'by 2030 , provide universal access to safe, inclusive and accessible, green and public spaces, particularly for women and children, older persons and persons with disabilities". Support for SDG II, and in particular public space Target II.7, is important to ensure adequate means of implementation and a sound monitoring framework that will be necessary to catalyse action on public space as a contribution to sustainable cities and human settlements. The adoption of SDG II.7 and the elaboration of the New Urban Agenda provide significant recognition of the importance of public space to sustainable development and whilst it is a critical first step, on its own it will have little impact without an appropriate follow up mechanism. Therefore, there is a need for supporting local and national governments in developing legislation, policy, norms and practices, which support governments in adopting a holistic and integrated approach to the planning, design development, creation, protection and management of public space. This will require that cities invest in public space and in the spirit of the new urban agenda cities and local governments should take a trans-disciplinary approach by working in partnership with a range of stakeholders and organizations, including civil society, academia and the private sector to ensure inclusive, safe and accessible public spaces for all. 


\section{Towards Habitat III: the road from Vancouver to Quito}

In 1976, the United Nations General Assembly convened the first United Nations Conference on Human Settlements (Habitat I) in Vancouver, Canada. Governments had just begun to recognize the consequences of rapid urbanization driven by rural poverty, growing urban economies, reduced infant mortality and longer life spans. Along with this shift came unplanned urbanization and in some cities urban slums and evictions became commonplace, whilst others struggled with urban sprawl and decaying inner cities. While Habitat I was notable for bringing urban issues to an international stage for the first time, the Second United Nations Conference on Human Settlements (Habitat II) which took place in Istanbul, Turkey in 1996 was notable for being the first UN conference to invite NGOs and civil society organizations to provide input and participate in drafting recommendations. The result of the conference was the Habitat Agenda containing 600 recommendations organized around five central objectives meant to guide UN policy regarding cities: (I) adequate shelter for all, (2) security of tenure, (3) support for vulnerable groups and women, (4) adequate and equitable access to services, and (5) promotion of decentralization and good urban governance. Despite the success of bringing urban issues to the global stage and the inclusion of a broad range of stakeholders, Habitat II was criticized for failing to produce a lasting and meaningful impact on urban policy.

In the period since Habitat II, cities have become centres of unprecedented wealth and prosperity. As Habitat III approaches, the New Urban Agenda (NUA) is being articulated. The NUA is guided by the following interlinked principles: (a) Leave no one behind, (b) Sustainable and inclusive urban economies, and (c) Environmental sustainability as well as reflecting the Sustainable Development Goal II. Promoting socially inclusive, integrated, connected, accessible, gender-responsive, environmentally sustainable and safe public spaces is key in achieving the New Urban Agenda. Good quality public space provides connectivity and access, protection from crime, shelter from climate, seclusion from traffic and the opportunity to rest, work and meet. Through its multifunctional and multidisciplinary nature, public space offers a holistic view of the city, such as social inclusion, gender equality, the benefits of nature and green spaces, governance, health, safety, education, climate change, transport, energy and the local urban economy. Therefore, in the spirit of the new urban agenda, cities and local governments should take a transdisciplinary approach by working in partnership with a range of stakeholders and organizations, which should include civil society (taking into consideration indigenous people, women's and grass roots women's organizations), academia and the private sector to ensure inclusive, safe and accessible public spaces for all.

The enabling components of the New Urban Agenda are mutually reinforcing and vital in ensuring prosperous cities. Rules and legislation protect access to public spaces, urban planning and design provides adequate quantity and good quality public space and urban finance and economy share values, promotes income, investment, wealth creation and provides employment and decent job opportunities for all. When planning focuses on providing an adequate public space structure in terms of supply and connectivity, it is possible to move forward with infrastructure, land subdivision and development in a much more efficient and sustainable way. Streets and public spaces need to be planned first with a view of supporting adequate urban density and connectivity. Furthermore, 
public space can lead the implementation of the new urban agenda and urban growth. This link between public space and urban development is critical and needs to be understood in each context and legal framework in order to prevent the creation of unmanaged and unimproved open spaces and/or public space deficiencies common to many cities.

Public space offers an integrated and holistic approach to sustainable urban development. Building on the interlinked principles of the New Urban Agenda:

a) public space lends itself well to participatory, gender and age -responsive approaches, and to landscape planning that catalyzes on the benefits of ecosystems to health and quality of life, providing equal access and making sure to leave no one behind. Adequately planned and designed public space raise issues regarding the right of people to freedom of artistic expression, political assembly and civic empowerment, to enjoy, engage and exchange with each.

b) public space creation, protection, management and enjoyment are ideal opportunities for the involvement of all citizens, ensuring that individual and differentiated interests are transformed into collaborative practices. The commons provides the space for participation of urban stakeholders from different classes of the society to advance sustainable and inclusive urban economies. Investments in streets and public space infrastructure improve urban productivity, livelihoods and allows better access to markets, jobs and public services, especially in developing countries where over half of the urban workforce is informal.

c) Public space is critical for environmental sustainability. Adequately planned and designed public spaces play a critical role in mitigation and adaptation strategies to climate change. Green open spaces can minimise carbon emissions by absorbing carbon from the atmosphere. Green spaces can act as sustainable drainage system, solar temperature moderator, source of cooling corridors, wind shelter and wildlife habitat.

\section{Key drivers for action: implementation of the New Urban Agenda}

Some of the key driver that have been distilled from the issue paper on public space and the dialogues leading up to the adoption of the New Urban Agenda include:

I. At regional and city level, city-wide strategies need to focus not only on places and spaces but on the form, function and connectivity of the city as a whole.

2. Local authorities should be able to design the network of public space as part of their development plans.

3. At neighbourhood level, urban design should work with communities to foster social inclusion, gender equality, celebrate multiculturalism and biodiversity, and enable urban livelihoods, thus creating rich, vibrant spaces in the urban commons.

4. Laws and regulations need to be reviewed, to establish enabling systems to create, revitalise, manage, and maintain public space, including participatory processes to define their use and manage access to public spaces.

5. Land value sharing and land readjustment tools to be widely adopted and promoted for municipalities to capture private values generated by better public spaces to sustain investment in public space. 
6. Investing in public space needs to be harnessed as a driver for economic and social development, as well as for gender equality, taking into consideration urban-rural linkages.

7. As cities expand, the necessary land for streets and public spaces as well as public infrastructure networks must be secured. Urban projects need to ensure adequate public space in planned city extensions, planned city infills and participatory slum upgrading projects. Instruments to enable the creation of public space from private owned land are of critical importance.

8. Debate on targets, indictors and principles on measuring the distribution, quantity, quality and accessibility of public space.

\section{Note}

(I) UN-Habitat Resolution 23/4 on Sustainable Urban Development through Access to Public Spaces.

(*) Some contents of this paper are a summary of articles and documents already published on line, available at: www.habitat3.org; www.unhabitat.org; www.futureofplaces.com.

\section{To cite this Editorial:}

Andersson, C. (2016), Public Space and the New Urban Agenda, The Journal of Public Space, I(I), 5-I0, DOI: 10.5204/jps.vlil.4

Please see the Editorial Policies under the 'About' section of the journal website for further information.

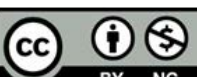

This work is licensed under a Creative Commons Attribution - Non Commercial 4.0 International License. https://creativecommons.org/licenses/by-nc/4.0/ 


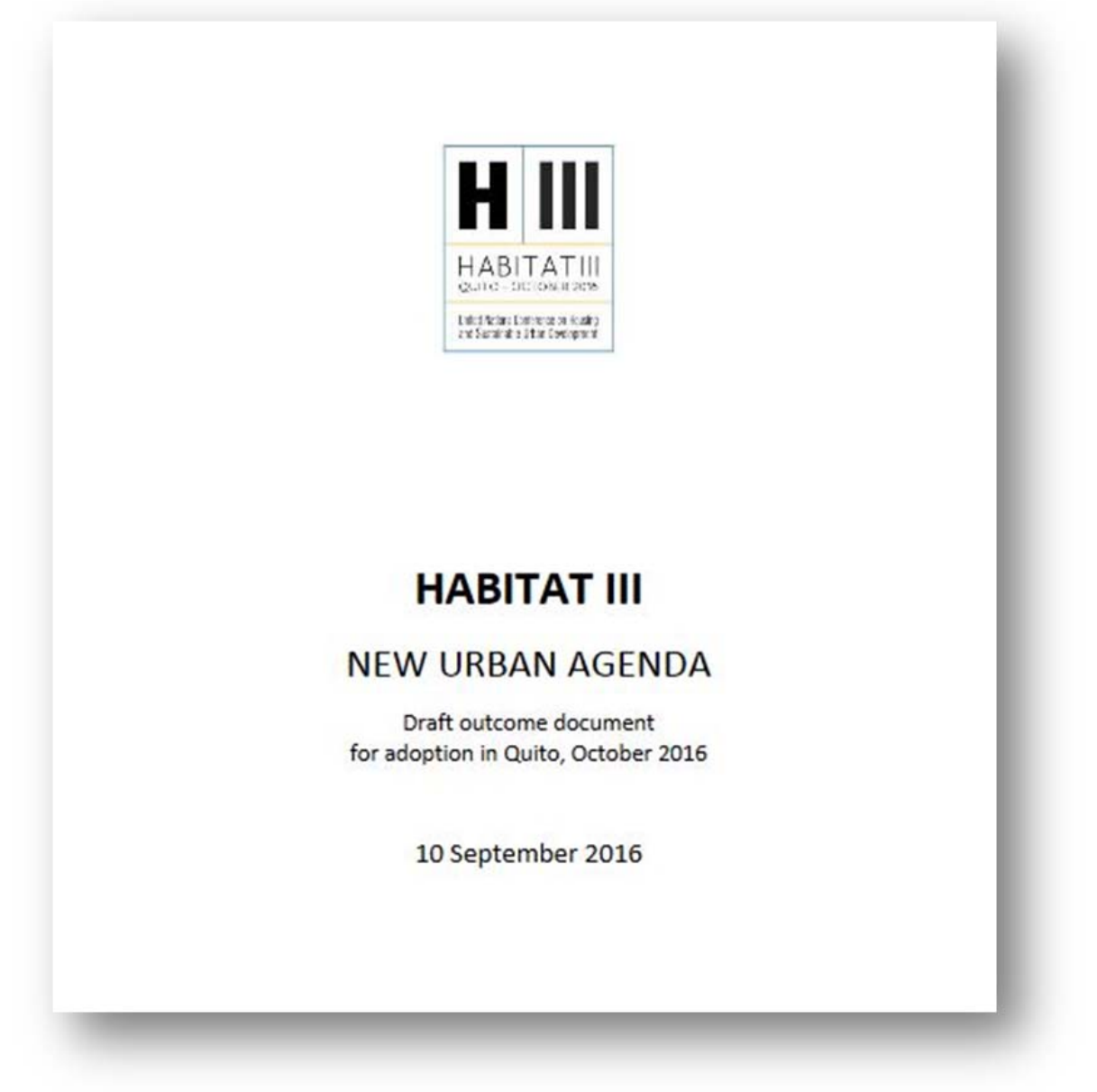

View the agreed draft of the New Urban Agenda - 10 September 2016 http://habitat3.org/the-new-urban-agenda

The Habitat III Conference has, as its mission, the adoption of a New Urban Agenda - an action-oriented document which will set global standards of achievement in sustainable urban development, rethinking the way we build, manage, and live in cities through drawing together cooperation with committed partners, relevant stakeholders, and urban actors at all levels of government as well as the private sector.

After the release of the Surabaya Draft of the New Urban Agenda at the third session of the Preparatory Committee for the Habitat III Conference in Surabaya, Indonesia in July 2016, the New Urban Agenda has been agreed on at the Habitat III Informal Intergovernmental Meeting which took place at the United Nations Headquarters in New York from 7 to 10 September 2016, and it will be adopted in Quito, Ecuador, in October 2016.

View also the Habitat III Issue Paper on Public Space (Area 3. Spatial Development, issue paper n. II): http://unhabitat.org/wp-content/uploads/2015/04/Habitat-III-Issue-PaperII_Public-Space-2.0.compressed.pdf 


\title{
Public Space Update. Report from the United States
}

\author{
Margaret Crawford \\ University of California Berkeley, USA \\ College of Environmental Design \\ mcrawfor@berkeley.edu
}

\begin{abstract}
Like everything else in this large and disparate country, public space, as a movement and as a collection of physical places is highly varied and unequally distributed. Even so, over the last decade public space in both senses has moved to the forefront of American urbanism. In terms of academic debates, the narratives of decline that dominated discussions of public space since the 1990s have been replaced with expanded definitions of public space. The number of actual new public spaces, public events and support for them has grown exponentially over the last decade. These spaces continue to attract large numbers of people. For design professionals, this has meant new opportunities to connect their practices with the larger public realm. At the same time, however, critics have raised important questions about their inclusivity and ability to promote genuine social interaction.
\end{abstract}

Keywords: Public Space; United States; New Urbanism; Occupy Movement; Black Lives Matter.

\section{To cite this article:}

Crawford, M. (2016). Public Space Update. Report from the United States. The Journal of Public Space, I(I), II-I6, DOI: I0.5204/jps.vliI.5

This article has been peer-reviewed and accepted for publication in The Journal of Public Space. Please see the Editorial Policies under the 'About' section of the journal website for further information.

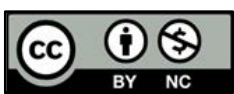

This work is licensed under a Creative Commons Attribution - Non Commercial 4.0 International License. https://creativecommons.org/licenses/by-nc/4.0/ 


\section{Introduction}

Like everything else in this large and disparate country, public space, as a movement and as a collection of physical places is highly varied and unequally distributed. Even so, over the last decade public space in both senses has moved to the forefront of American urbanism. In terms of academic debates, the narratives of decline that dominated discussions of public space since the 1990s have been replaced with expanded definitions of public space. The number of actual new public spaces, public events and support for them has grown exponentially over the last decade. These spaces continue to attract large numbers of people. For design professionals, this has meant new opportunities to connect their practices with the larger public realm. At the same time, however, critics have raised important questions about their inclusivity and ability to promote genuine social interaction.

In order to understand both the conceptual and the physical dimensions of public space, we need to clarify what public space is. Until recently, theorists held to a very pure notion of public space. Drawing a firm line between public and private, they argued that only spaces that were open to everyone and collectively owned (usually through the state) were "true" public spaces'. Current definitions of public space have become more expansive and nuanced, recognizing their multiplicity and complexity. This acknowledges public spaces where public and private are blurred, such as "quasi-public" spaces such as shopping malls, or semi-public spaces such as POPS (privately owned public spaces) which are usually corporately sponsored plazas, the best known of which is Zuccotti Park in Lower Manhattan, where the Occupy Movement began. There are also publically owned, but privately managed (usually by non-profit organizations) spaces such as Central Park, funded and supervised by the Central Park Conservancy.

The migration of much political debate on-line to virtual public spaces has helped clarify the differences between the public sphere of civic engagement (an arena of debate and discussion) and physical spaces whose civic benefits are still being debated. In a nation without a long tradition of the commons and spaces historically associated with collective use, no universal model of public space has emerged. Continuous influxes of immigrants from around the globe, whose experiences of public space vary widely, insure that the meanings of public space will remain in flux, as new uses and demands continue to reshape society and space.

\section{New Landscapes of Public Space}

In spite of these complications, we can identify a broad array of organizations, people, activities, events, times and places that have recently come together to create and constitute contemporary public spaces in the U.S. Although the General Services Administration, which manages federal properties, issued a guide urging "great federal public spaces", and the National Endowment for the Arts funds Creative Placemaking, individual cities have taken the lead in supporting, producing and maintaining public spaces $^{2}$. Their efforts vary widely according to city size budget and, most importantly, the commitment of the mayor and city officials. One of the most notable and best-publicized efforts was that of Michael Bloomberg, mayor of New York from 200I to 2014. His planning director, Amanda Burden, a former employee of William $\mathrm{H}$. Whyte and who claimed Jane Jacobs as her greatest influence, constantly emphasized the importance of 
public space ${ }^{3}$. Burden was instrumental in producing not only highly designed places such as the High Line and Brooklyn Bridge Park, but also the lower Manhattan and Brooklyn waterfronts, as well as upgrading smaller urban plazas such as Madison Square Park and Union Square. Similarly, Bloomberg's Transportation Commissioner, Janette Sadik-Khan, implemented a dramatic pedestrianization of city streets, converting streets, disused traffic triangles, parking lots and other under-utilized sites across the five boroughs into more than 300 new plazas and squares. To speed up their transformation, she began by designating the plazas with traffic cones, paint, and hauling in lawn chairs. Once the places became populated, potted trees, chairs, tables, and Wi-Fi were installed.

The best known of these projects was the series of new plazas along Broadway, taking advantage of the triangular spaces produced by the street's diagonal path. Making Times Square, one of the most heavily trafficked areas in the world, into a pedestrian mall was the program's main event. Along a 5-block area, from 42nd to 47th streets, the DOT designated multiple plazas. Their popularity with both locals and tourists improved pedestrian and driver safety, and higher commercial rents in the area prompted the city to hire the well-known Norwegian architectural firm Snoetta to redesign them as permanent spaces ${ }^{4}$. Since then, not all of these plazas have been well maintained or supported by City Hall. But the most successful made immediate differences in reducing crime, boosting local commerce, and improving street life. Bloomberg's commitment to public space was exceptional, however. Few American cities have high enough density or budgets to justify such large investments in public life.

As a result, numerous non-profits and other advocacy groups have stepped into this breach. In many cases, their concepts and proposals have filtered upwards to inform and shape city governments and planners' policy recommendations. Organizations such as the Project for Public Spaces, the Design Trust for Public Space, the Canadian Foundation for Indoor Public Spaces, and others across the country conduct research, sponsor design competitions, and publish books and websites to raise awareness and interest about public space among government officials, urban planners, and the general public. They can be seen as benevolent lobbyists for public spaces, often commissioning surveys and generating designs that cash-strapped city governments typically can't afford. Public space also plays an important role in larger organizations whose goal it is to transform the American built environment. The Congress for the New Urbanism, Making Cities Livable and Smart Growth America have each crafted their own versions of public space advocacy. Pedestrian spaces and public squares and plazas, often following traditional models are central elements in the CNU design principles, while Smart Growth America sponsors the Complete Streets program, which encourages municipalities to redesign streets to better accommodate pedestrians and bicyclists. Supplying municipal governments with detailed engineering and planning manuals makes it easy for cities to adopt their recommendations. They claim that these changes improve not only safety but also health, livability, and community cohesion ${ }^{5}$.

Another growing but very different approach to public space comes from artists and art organizations. Public art, public performances, social practice art, and "creative placemaking" all emphasize creative uses of public space without specifying form, duration or content. This has engendered an enormous range of artists' interventions into urban space, a category that can include everything from graffiti to government-commissioned art in public spaces. A new genre of art organization, such as New York's Creative Time, 
has emerged to support this approach. A well-funded non-profit, Creative Time sponsored artist Paul Chan's community-centered production of Waiting for Godot, performed in the middle of an intersection in New Orleans' flood devastated Ninth Ward. Another important work was feminist artist Suzanne Lacy's Between the Door and the Street. Lacy asked 400 people, mostly women, to sit on the stoops of a single block in Brooklyn and discuss gender issues for an afternoon. Thousands of people showed up to walk down the street and listen to their conversations ${ }^{6}$.

Smaller, less expensive and more concerned with the built environment are DIY (Do It Yourself) urban projects known as tactical urbanism or temporary urbanism. They also cover a vast range of activities, temporalities, and scale. The American pavilion at the 2012 Venice Biennale, Spontaneous Intervention: Design Actions for the Common Good, cataloged 126 of these small, pop-up temporary and mobile interventions into urban public life, ranging from guerrilla gardening and yarn bombing, to free mini-libraries in phone booths and, most famously, Park(ing) Day, which encouraged anyone to turn a parking space into a temporary park. In many cases, ordinary people rather than designers or artists undertook these projects ${ }^{8}$.

Finally, designers have been enormous beneficiaries of all of these efforts. Although quick and inexpensive projects have received a lot of attention, more permanent public spaces require professional expertise. The increasing number of commissions for public parks, plazas, and other communal places has prompted many architects, urban designers and landscape architects to add public space design to their portfolios. These new opportunities also attracted European designers experienced in working on public projects. The Danish architect, Jan Gehl, whose firm specializes in urban public spaces, and who has written several books on the subject, recently opened offices in New York and San Francisco. The French landscape firm Agence Ter, working with local partners, just won an important competition to redesign Los Angeles' historic Pershing Square. All of these activities, ranging from amateur efforts such as yarn bombing to sophisticated professional park designs, have led public space advocates to assert that we live in a golden age of public space. Bicycle lanes, upgraded public plazas designed for human comfort, farmers markets and pedestrianized streets all demonstrate growing investments in high-quality urban spaces. Furthermore, new planning policies encourage sidewalk cafes, festivals and street performers, and more and more cities adopt "complete streets" programs. While not all of these advocates agree on every point, they all assert that "vibrant" public spaces are fundamental in humanizing contemporary cities, and cite the increasing number of people enjoying these spaces as evidence of their success.

Underlying the broad array of practices described above is an assumption that the goal of creating public spaces is to bring "everyone" together in safe and pleasant places. This, they argue, fosters social unity and supports democracy'. Important exceptions to this approach are critical artists such as Chan and Lacey. Their work is intended to do the opposite: to focus on specific social groups, such as African-Americans or women and to unsettle rather than comfort the users of public space.

\section{Questions about Pubic Space}

In spite of such apparent success, critics have challenged their aspirations toward inclusiveness and claims to appeal to the desires and values of a single unified public, 
arguing that these spaces have clear limits. This is particularly visible when we examine them in the American context. Focusing on central cities, they neglect the suburbs, where more than $50 \%$ of Americans live. Emphasizing pedestrians and bicyclists over cars, they privilege the young and able-bodied. Assuming that highly diverse populations are a single universal group of "users" without significant differences, they fail to consider and even mask the troubling social, racial and spatial inequalities that have long characterized the United States. Scholars have pointed out that there is no single "public" but a myriad of publics, each with differing identities and interests. Some publics, such as white men, claim powerful rights to urban space, while the claims of others, such as AfricanAmericans and the homeless are far weaker ${ }^{10}$. Public spaces invariably reflect these differences. Bloomberg's celebrated public spaces, for example have been criticized as primarily benefitting tourists and wealthy Manhattan residents. There are racial implications to approaches that assume a generic public, disregarding the fact that many whites automatically link the presence of blacks with danger and criminality. Studies have shown that sharing public spaces with more than a limited percentage of non-whites makes white people uncomfortable".

A more serious accusation is the contradiction between New York's new public plazas and squares and another signature Bloomberg public space initiative: "Stop and Frisk." Highly controversial, this policy allowed the New York Police Department to stop, question and search any "suspicious" pedestrian. In $201 \mathrm{I}$ alone, police stopped nearly 700,000 people, nearly all African-American or Latino males, essentially depriving them of equal rights to be in public ${ }^{12}$. Most of these stops occurred in neighborhoods far from those with newly improved public spaces. Across the country, the "Black Lives Matter" movement has demonstrated that African-American men are not safe in public, risking death from police or other members of the public as they conduct their daily lives. The fatal shooting of Travon Martin, a black teenager on the way to his mother's house, by a white neighbor who was acquitted of any crime was only one example of racially restricted access to space ${ }^{13}$.

Even the apparently benign complete streets movement can be seen as dangerously "incomplete", imposing privileged, usually white, narratives that drown out the voices of low-income and minority communities. Street vending, a largely immigrant economic activity, or Chicano low riding and other car-centered public activities are completely absent from their concept of street life. This bias has led African-American communities to organize against bike lanes in their neighborhoods, identifying hipster bikers as the first wave of gentrification ${ }^{14}$.

These critiques are important, and, as the Black Lives Matter movement shows, the stakes are high. By focusing on the popularity and "vibrancy" of a limited number of designated spaces, public space advocates and designers avoid very real issues of access, use and identity present in other kinds of public spaces. Often influenced by European examples, they ignore America's continuing problems of segregation and racial violence, assuming a spatial equality that in fact does not exist. In order for American public spaces to become truly public, both discourse and design need to confront their actual social content. This means acknowledging inequality and exclusion, conflict, and contestation. A more expansive view of public space would include protests such as the Occupy Movement and Black Lives Matter demonstrations, sidewalk livelihoods such as street vending and day labor, and even the presence of homeless people, whose domestic lives 
take place in public, on city streets. This definition of public space would be far more challenging than current versions, but ultimately more productive in connecting public spaces with real issues of democracy and citizenship.

\section{Notes}

(I) See, for example: Don Mitchell (2003), The Right to the City: Social Justice and the Fight for Public Space, New York: Routledge.

(2) See: http://www.gsa.gov/graphics/pbs/pmg_partl_intro.pdf, Accessed 7/28/16. And https://www.arts.gov/partnerships/creative-placemaking, accessed 7/28/16.

(3) William H. Whyte's book (1980) and film, The Social Life of Small Urban Spaces is a classic of public space design.

(4) http://www.pps.org/reference/broadway-boulevard-transforming-manhattans-most-famousstreet-to-improve-mobility-increase-safety-and-enhance-economic-vitality/. Accessed I I/5//4 4.

(5) http://www.smartgrowthamerica.org/complete-streets. Accessed 7/28/16.

(6) http://creativetime.org. Accessed 7/28/16.

(7) http://www.spontaneousinterventions.org/interventions

(8) www.architectmagazine.com/Design/spontaneous-interventions. Accessed 4/20/16

(9) http://gehlarchitects.com. Accessed 10/20/I5.

(10) Nancy Fraser (1990), "Rethinking the Public Sphere: A Contribution to the Critique of Actually Existing Democracy”, Social Text, No. 25/26, pp. 56-80.

(I I) See, for example: Dovidio, John F.; Gaertner, Samuel E.; Kawakami, Kerry; Hodson, Gordon (2002), "Why can't we just get along? Interpersonal biases and interracial distrust,", Cultural Diversity and Ethnic Minority Psychology, Vol 8(2), May, Pp. 88-I02.

(12) http://www.nytimes.com/interactive/2014/09/19/nyregion/stop-and-frisk-is-all-but-gone-fromnew-york.html? r=0. Accessed I I/I5/I4. On August II, 2013, Federal judge Shira Scheindlin declared that Bloomberg's "stop and frisk" policy was unconstitutional. http://www.nytimes.com/2013/08/I3/nyregion/stop-and-frisk-practice-violated-rights-judgerules.html?.pagewanted=all\& $r=0$. Accessed Nov. II, 2014.

(32) http://www.nytimes.com/interactive/2012/04/02/us/the-events-leading-to-the-shooting-oftrayvon-martin.html? $r=0$, Accessed 7/28/16.

(14) See Stephen Zavestoski and Julian Agyeman (eds.) (2014) Incomplete Streets, processes, practices, and possibilities, New York: Routledge. 


\title{
Measuring the Magic of Public Space. Le Piazze di Roma
}

\author{
Pietro Garau \\ University of Rome "La Sapienza", Italy \\ INU - Italian Institute of Urban Planners \\ pietro.garau@gmail.com
}

\begin{abstract}
The concept of public space, and particularly of civic public space, is certainly a constitutive element of Italy's urban culture. The design and spatial configuration of public spaces have always been a synthesis between deeply rooted models and political functions (the piazza, the palazzo, the church, the civic buildings), and of local circumstances and design inspiration. Hence the fascination of the piazza: while all piazze perform similar functions, they take very different spatial and architectural characteristics, thus adding to the variety and the "magic", as it were, of public space experience.

The main purpose of this article is to celebrate the piazza as the core symbol of public space magic. In doing so, I set a modest linguistic goal: to discourage non-Italian speaking piazza fans from using the plural "piazzas" and to impose the Italian "piazze". As to the success of this endeavour, only future will tell.
\end{abstract}

Keywords: public space; Italy; Roma; piazze; urban magic.

To cite this article:

Garau, P. (2016). Measuring the Magic of Public Space. Le Piazze di Roma. The Journal of Public Space, I(I), 17-24, DOI: I0.5204/jps.vlil.6

This article has been peer-reviewed and accepted for publication in The Journal of Public Space. Please see the Editorial Policies under the 'About' section of the journal website for further information.

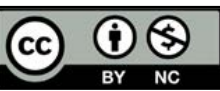

This work is licensed under a Creative Commons Attribution - Non Commercial 4.0 International License. https://creativecommons.org/licenses/by-nc/4.0/ 


\section{Introduction}

The concept of public space, and particularly of civic public space, is certainly a constitutive element of Italy's urban culture. The design and spatial configuration of public spaces have always been a synthesis between deeply rooted models and political functions (the piazza, the palazzo, the church, the civic buildings), and of local circumstances and design inspiration. Hence the fascination of the piazza: while all piazze (the Italian plural of "piazza") perform similar functions, they take very different spatial and architectural characteristics, thus adding to the variety and the "magic", as it were, of public space experience.

Needless to say, no pre-determined norms or standards ever applied to the design of the piazza as the centrepiece of Italian urbanism. Only less than a century ago was public space mentioned in the first piece of comprehensive national legislation on urbanism: the Legge Urbanistica Statale 17 agosto 1942, n. I I 50. This law prescribed that all master plans had to indicate, in addition to transportation networks, expansion and redevelopment zones, and sites for community services, all areas designed to "form spaces for public use": basically, gardens, parks and piazze.

However, with the notable exception of comprehensive public housing projects, public spaces were almost totally neglected during the rapid, speculative and disorderly expansion process of urban areas in post-world war II Italy. Hence, the national decree of 1968 (Decreto Ministeriale 1444/1968) imposed for all new developments, a minimum of 18 square meters per inhabitant for "public spaces or spaces reserved for communal activities, public green spaces or parking spaces excluding spaces reserved for roads and streets". Of these, 9 square meters per inhabitant had to be provided for "public spaces equipped for play and sports, not counting green spaces alongside road infrastructure".

Despite the fact that it might have been relatively simple to impose on developers, the implementation of this decree encountered many difficulties, such as the alienation of the required public spaces in exchange for permission to build.

Therefore, the full implementation of the decree became the exception, rather than the rule. Later on, plans and planning legislation became a responsibility of regional governments, and in turn municipalities acquired greater powers in drawing and adopting municipal master plans. This became, however, a case of decentralization without empowerment. More recently, restrictive spending policies resulting from the adoption of the common European currency created severe limitations to state expenditure. At the same time, and even more recently, a crucial source of revenue for municipalities, the property tax, was both eliminated in the case of owner-occupier households and its reduced flow re-appropriated in large measure by central government. Consequently, municipalities found themselves confronted with the need to reserve scarce resources for basic day-to-day needs including current expenditure, and left with very little latitude for management and proper maintenance, let alone investment in land acquisition or public space projects. As a result, the qualitative and quantitative public space gap between the consolidated city and new urban expansion areas increased. This gap is certainly a cause, if not necessarily the only one, behind the sense of neglect and isolation many inhabitants of metropolitan Italy feel today as a result of poor transportation, chronic lack of physical maintenance of public infrastructure, urban decay, population aging, widespread youth unemployment, and difficulties between established and immigrant populations. 
As always, there is a renowned national talent for coping, intervened by introducing practices, often successful, of "active citizenry" initiatives in improving or maintaining public spaces at the neighbourhood level'. However, the fragile, small-scale and remedial nature of these practices cannot be ignored. Until the country can again count on financially viable local governments, there will be little hope for a proper supply, distribution and quality of public spaces.

On the positive side, there is a notably increasing interest in public space in Italy. Whilst summer schools and master courses have been devoted to the subject, seminars and meetings on public space, also of an international nature, have multiplied in recent years. Most notably, Architect Mario Spada's intuition to organize under the $\mathrm{INU}^{2}$ flag a "Biennial of Public Space" starting from 20I I has led to an increasingly popular, and increasingly international, event which is nothing but a virtual piazza - a place where people can meet, listen, and intervene to discuss ideas, experiences, and plans. The Biennial, with its Charter of Public Space adopted in 2013, also contributed to filling a gap in the understanding, definition, and guiding principles of successful public spaces.

Going back to the lamentable current conditions and prospects for public space in Italy, we have to underscore the increasing asymmetry between the supply, quality and distribution of public spaces in newly developed urban areas compared to those in the "historic city". This leads to the bittersweet task of celebrating the financially viable, reasonably well maintained and eminently enjoyable public spaces one can still find everywhere in the country: the historic piazze.

\section{Why piazza is more than "square"}

The Italian piazza is not simply the translation of the term "square", in itself a brutish approximation of the spatial variety of public spaces that for so many years, and in so many different cultures, have symbolized and embodied public life.
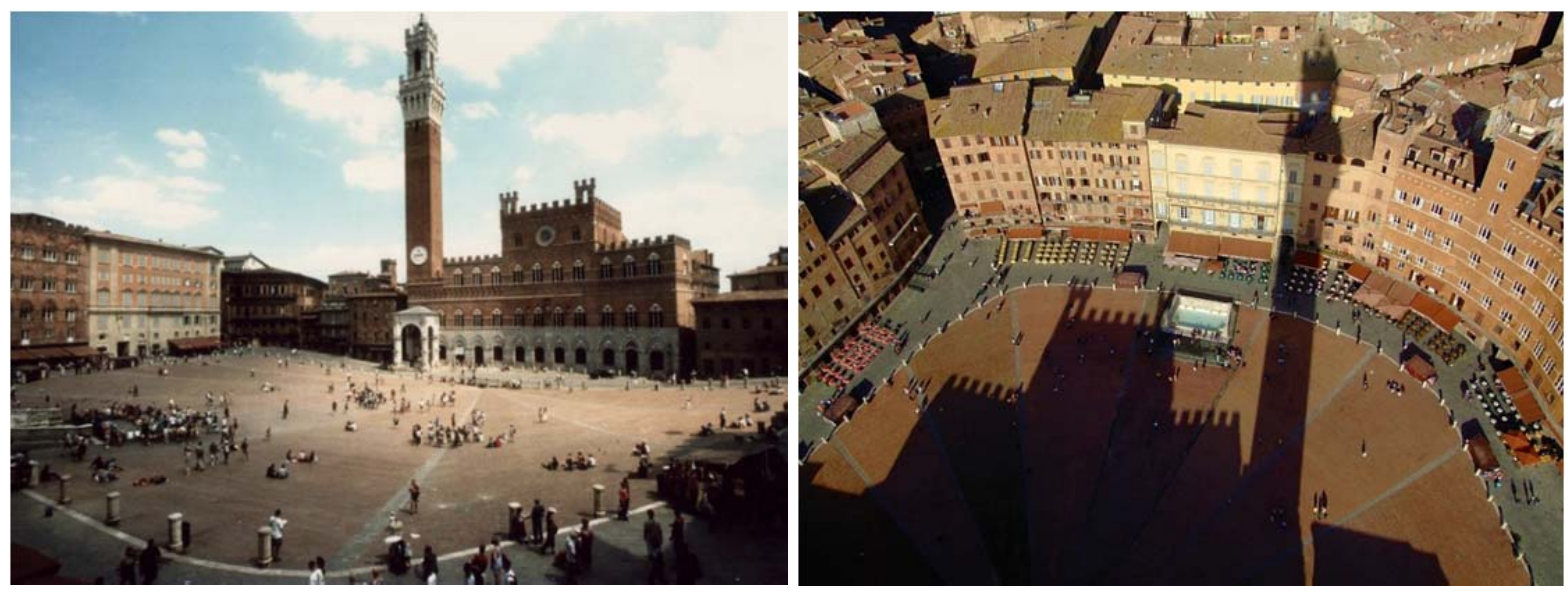

Fig. I-2. Piazza del Campo, Siena.

Sources: on the left https://villaroseto.files.wordpress.com/2013/03/siena3.jpg and on the right https://it.wikipedia.org/wiki/Piazza_del_Campo

Part of the term's attractiveness is certainly due to its history. In Italy the piazza assumed a very important meaning in medieval times, when it became the urban space of the three fundamental functions of western urban civilization during the middle ages: religious, civic, 
commercial. Luigi Piccinato remarks that at the beginning piazze were spaces devoted specifically to one of the above three functions (piazza della chiesa, piazza del comune, piazza del mercato). With reference to its civic function, it is important to note that the piazza became the place where citizens congregated to affirm their newly conquered independence embodied in the comune (a term still in use in Itay to denote municipalities, and which simply means "shared","commonly held").

The Italian piazza is loaded with a rich array of historic and architectural meanings pointing to it as the "public space par excellence". Here are some:

- piazza as testimony of historical events;

- piazza d'armi; piazza del mercato; piazza del duomo;

- piazza as a political container (rallies, speeches);

- piazze as places of elocution and execution;

- piazza as a marketplace;

- Piazza as an architectural background (e.g. Navona, Piazza San Marco)

- piazze as architecture (e.g. San Pietro)

- piazza as the quintessence of "public".

The piazza is also an inspirer of commonly used Italian idioms such as: "Mettere in piazza" meaning to "make known something that it might be better to maintain private"; "Scendere in piazza" which means taking action to seize political advantage; "La pubblica piazza" which means a place where any action or activity could not possibly be more manifest; "Spiazzato" which refers to losing one's point of reference and "Fare una piazzata" meaning coming out with an unexpected action, often accompanied by strong expressions, of an unwelcome vigour.

\section{An exploratory sample: le piazze di Roma}

Of all Italian cities, Rome possibly presents the greatest variety of piazza; its piazze storiche" (historic piazze) presents an extreme example of the public-space asymmetry remarked above. Further, Rome's piazze storiche mark a sharp contrast with their epigones in newly developed peripheral areas because they are points of attraction for the whole city and, of course, for all visitors, national and international.

\section{Measuring the Magic of Rome's piazze storiche}

Whilst in its plainest sense, the piazza is simply a paved urban surface, surrounded by buildings, and connected to the city's street network; it is also a quaint, respectable and valuable urban space. Therefore, it is inevitable that the piazza's "urban value" be connected to a number of measurable parameters.

Five of them were selected for the purpose of this brief review. They are:

I) Absence, or severe limitation, of motorized traffic;

2) Functional variety, i.e. the ability of the urban space to perform different functions, either at the same time or during different times of the day;

3) Architectural value, keeping in mind that the quality of the architectural scenery and stagecraft that "forms" the piazza has an impact on its use and functions. In some cases, imposing architecture can have a discouraging effect (Boston's city hall, for example, a celebrated architectural masterpiece, is not exactly an encouraging factor for spontaneous social congregation); 
4) Locational value - an admittedly more vague indicator signifying the synergy the piazza has with functions and uses in its adjacency;

5) Historic interest - an aspect indicating the unfair advantage that "old" piazze enjoy over "new" piazze ${ }^{3}$.

These five parameters are the result of the analysis of a few Roman examples sketched below. Many others could, and perhaps, should have been added such as safety,, or intensity of use. Most of them, in fact, are linked to the "software" of public space (users) as opposed to its hardware (the built environment). But for the time being, these five might suffice.
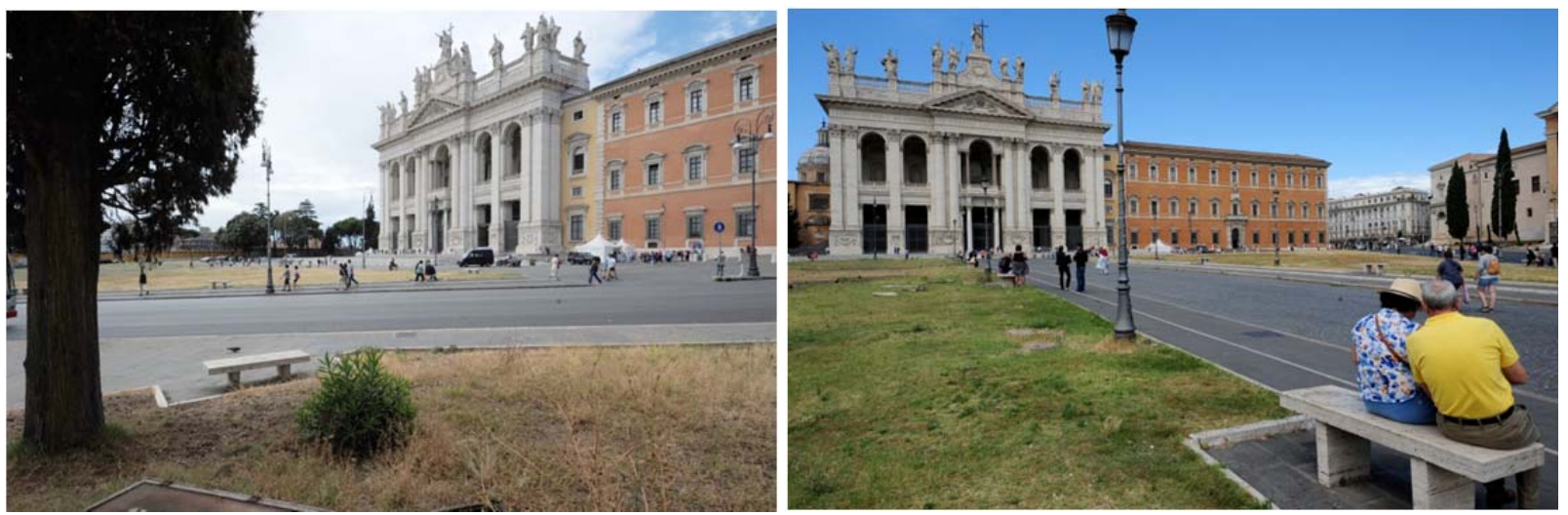

Fig. 3-4 . Piazza San Giovanni, Rome. Pictures by: Eugenio Monti

Piazza San Giovanni: snails and rallies

\begin{tabular}{l|l|l|l|l}
\hline $\begin{array}{l}\text { Free of } \\
\text { motorized traffic }\end{array}$ & Functional variety & $\begin{array}{l}\text { Architectural } \\
\text { value }\end{array}$ & Locational value & Historic interest \\
\hline & & & & \\
\hline
\end{tabular}

While of less than astonishing architectural appeal, Piazza san Giovanni is the largest enclosed public open space in Rome. At the centre of a popular working class neighbourhood, San Giovanni was famous both for hosting its Saint's Summer Day and rallies of the $\mathrm{PCl}$, the Italian Communist Party (the saint remains, but the party does not). With the demise of the $\mathrm{PCl}$ and the decline of popular political participation, the piazza became a challenge to those who dared repeating the mass gatherings of the past. The last time the piazza hosted a party rally was in 2013, when the populist "Movimento Cinque Stelle" managed to fill the square in a gesture of defiance that meant to celebrate the end of the established political parties' political domination. The heirs of the communist party decided instead to give up San Giovanni for their closing event and to hold it in a former vaudeville theatre.

The irony was not missed by the voters. Today, the piazza continues to owe its prestige to its size and the basilica it hosts more than to any degree of pleasantness, plagued as it is to this day by hosting more motorized traffic than it should.

A harmonious redesign of the eighteenth century, Piazza del Popolo achieved new significance in recent times. As a result of a comprehensive $18^{\text {th }}$ century design to create a grand northern entry to the city connected to the above Pincio gardens, which later turned into a roundabout cum parking lot, it gained new life after being pedestrianized. It 
has also become a passage for all visitors exiting the nearby subway stop and flocking to the via del Corso's elegant shopping district. For a while, its appeal attracted semipermanent exhibition infrastructure, a habit thankfully discontinued in recent times. To this day, the piazza (see photograph) also hosts a variety of spontaneous street happenings and events.
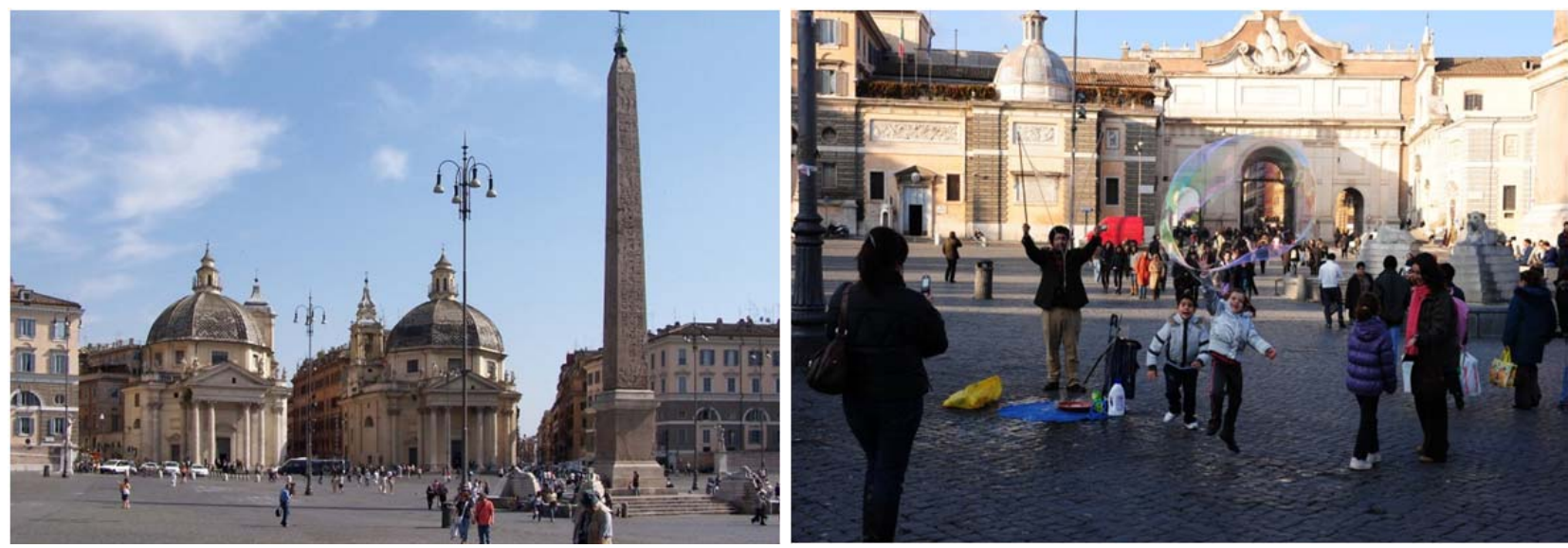

Fig. 5-6. Piazza del Popolo, Rome. On the left, source: https://it.wikipedia.org/wiki/Piazza_del_Popolo_(Roma)\#/media/File:Roma_Piazza_del_Popolo_BW_I.JPG On the right, picture by: Eugenio Monti

Piazza del Popolo: from parking lot to urban oasis

\begin{tabular}{|c|c|c|c|c|}
\hline $\begin{array}{l}\text { Free of motorized } \\
\text { traffic }\end{array}$ & $\begin{array}{l}\text { Functional } \\
\text { variety }\end{array}$ & $\begin{array}{l}\text { Architectural } \\
\text { value }\end{array}$ & Locational value & Historic interest \\
\hline$\checkmark$ & & $\checkmark$ & $\boldsymbol{V}$ & $v$ \\
\hline
\end{tabular}

Marking the eastern boundary of the tiny Vatican state, Piazza San Pietro is one of the few squares of the world reserved exclusively for religious events. While it can be negotiated on foot during weekdays, it is often partitioned to a point where visitors cannot even stand on the foci of the Bernini ellipsed portico to savour a joy of the past - seeing the columns as one. In addition, the northern portico has become a corral for the queues of the faithful waiting to be admitted into the basilica, while access can be granted only at the end of an exhausting security check.

The magnificent Bernini enclosure designed to provide a spectacular spatial introduction to the church, literally exploding from the dense mass of popular tenements immediately preceding it, is in stark contrast with the stubborn clumsiness of the via della Conciliazione, the avenue created in the middle of the twentieth century to provide a grand motorized access to St. Peter's. To this day, the avenue feeds the temptation to consider everything that is old -worthy of respect, and everything that is new - largely worthless.

The use of the square presents an interesting public space riddle. It is a vast and open urban place, no doubt; but it only holds gatherings linked to Catholic events. One could argue, therefore, that it is not a veritable public space. It is the total randomness and unpredictability of use that makes a true public space. 

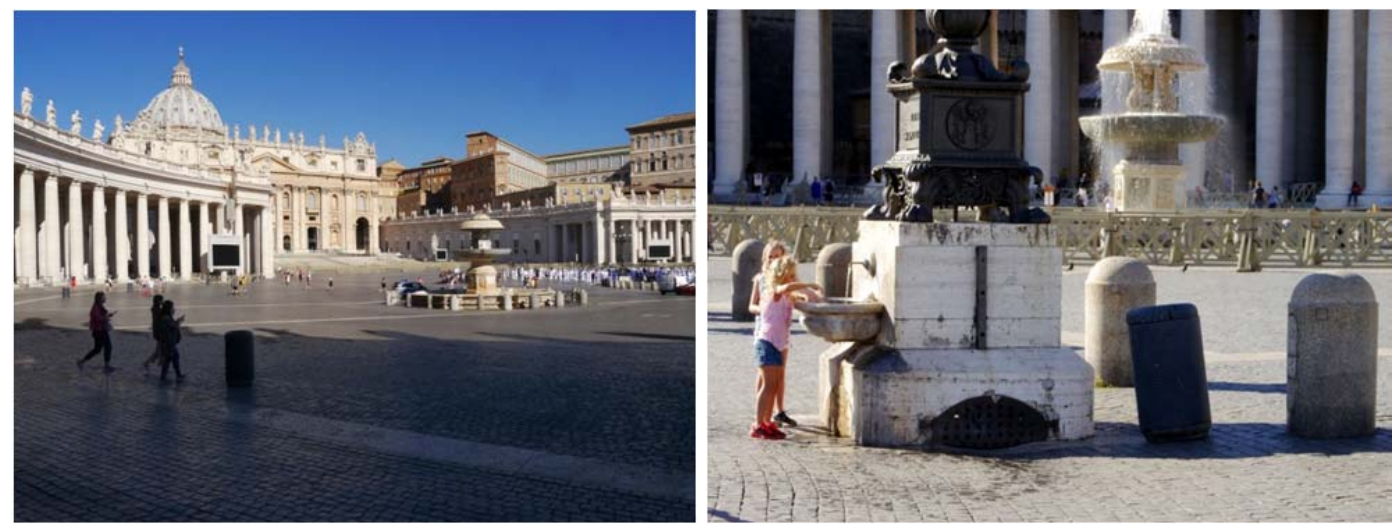

Fig. 7-8. Piazza San Pietro, Rome. Pictures by: Eugenio Monti

Piazza San Pietro: an imposing public space not quite so public

\begin{tabular}{|c|c|c|c|c|}
\hline $\begin{array}{l}\text { Free of motorized } \\
\text { traffic }\end{array}$ & $\begin{array}{l}\text { Functional } \\
\text { variety }\end{array}$ & $\begin{array}{l}\text { Architectural } \\
\text { value }\end{array}$ & Locational value & Historic interest \\
\hline$\checkmark$ & & $\checkmark$ & & $\checkmark$ \\
\hline
\end{tabular}

One of the Rome piazzas taking its name from a patrician family, Piazza Farnese is strongly characterized by the renaissance façade of the palazzo, now hosting the French Embassy. It is perhaps too solemn and too square (literally and figuratively) for Romans and visitors alike, who tend to prefer the contiguous Campo de Fiori.
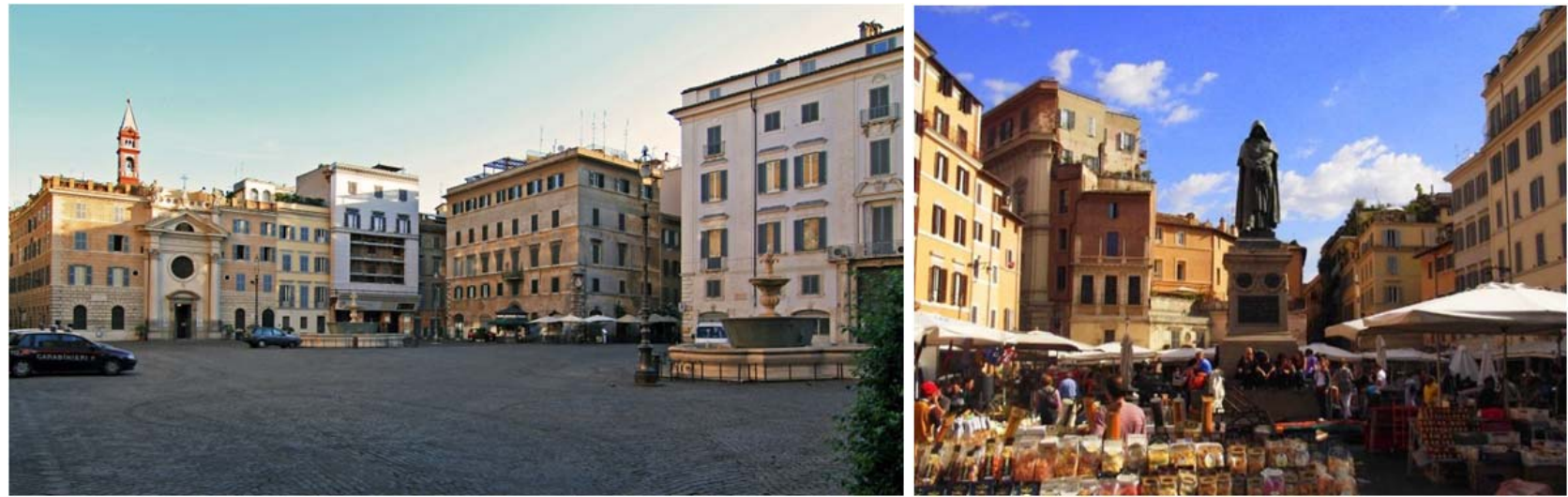

Fig. 9-10. On the left: Piazza Farnese, Rome. Source:

https://it.wikipedia.org/wiki/Piazza_Farnese\#/media/File:Piazza_Farnese_Rome.jpg

On the right: Piazza Campo de' Fiori, Rome. Source: http://www.prolocoroma.it/piazza-campo-de-fiori/

Piazza Farnese: order and beauty, but little magic

\begin{tabular}{l|l|l|l|l}
$\begin{array}{l}\text { Free of } \\
\text { motorized traffic }\end{array}$ & Functional variety & $\begin{array}{l}\text { Architectural } \\
\text { value }\end{array}$ & Locational value & Historic interest \\
\hline $\boldsymbol{V}$ & $\boldsymbol{V}$ & $\boldsymbol{}$ & \\
\hline
\end{tabular}

This might also due to the fact that Campo de' Fiori does not have a dominating architectural presence. The favour it enjoys is also due to the daily succession of prevalent 
uses (vegetable market in the morning, eating and gathering place in the afternoon, favourite spot of the young drinking classes in the evening) and its unique historical significance, with its statue of the reformist cleric Giordano Bruno on the very spot where he was burned at the stake half a millennium ago.

Another reason of the Campo de Fiori prevalence over Piazza Farnese is its closeness to some of the most popular retail shops in the city as opposed to the patrician upper crust of the Piazza Farnese streets, notably the sanitized, elegant and fairly lifeless via Giulia.

Campo de' Fiori: a popular favourite

\begin{tabular}{l|l|l|l|l}
$\begin{array}{l}\text { Free of } \\
\text { motorized traffic }\end{array}$ & Functional variety & $\begin{array}{l}\text { Architectural } \\
\text { value }\end{array}$ & Locational value & Historic interest \\
\hline $\boldsymbol{V}$ & $\boldsymbol{V}$ & $\boldsymbol{V}$ & $\boldsymbol{V}$ & $\boldsymbol{\checkmark}$ \\
\hline
\end{tabular}

\section{Conclusions}

This brings us to the end of our cursory and culpably limited review. We omitted important examples like Piazza Venezia, the traffic exchange at the opposite end of Piazza del Popolo, former location of the rallies of the infamous fascist regime, and surrounded by a host of architectural horrors; and Piazza del Pantheon, a gem that can be only enjoyed in the week hours of the morning due to the fact that it is now strangled by huge numbers of tourists, vendors, space-gobbling restaurateurs, and many others.

So, we come back to our initial question: in what way can the piazza embody the "urban magic"?

The question is as baffling as its subject. But we have found that there is no single element that makes a great piazza. Getting rid of motorized traffic is important, but not decisive, as in the case of Piazza Farnese. Architectural props and heroics are important as well, but not decisive either, as in the cases of Saint Peter's and San Giovanni. Certainly, what is important is the harmony of space and use, as in Campo de' Fiori. Whenever we manage to have a pleasant urban space enriched by variety and life, we can be confident in its success.

Unfortunately, this apparently simple combination is hard to create in outer urban areas, where the frequently combined lack of history, care and good design militate against that important success factor for public space sustainability - attractiveness.

\section{Notes}

(I) Many of them are described in the archive section of the Biennial of Public Space's web site.

(2) INU is the acronym of "Istituto Nazionale di Urbanistica". Of late this non-profit institute, born in 1930 to cultivate and disseminate the culture of urbanism, has internationalized its mandate through the dissemination of the Charter of Public Space, the preparation of UNHABITAT's "Global Public Space Toolkit" and the coordination, in partnership with the China Society of Urban Planners, of the Habitat III Policy Paper on Urban Spatial Strategies.

(3) "Vetustas", a powerful magnifier of architectural glory that would merit becoming a companion to Vitruvius's "venustas", is the winning veneer that transforms all but the poorest architectural expressions into something commanding respect - perhaps a result of living beings' dismay about human frailty. 


\title{
Public Space Trends in Hong Kong. A view from the New Territories
}

\author{
Hendrik Tieben \\ The Chinese University of Hong Kong, Hong Kong \\ School of Architecture \\ hktieben@cuhk.edu.hk
}

\begin{abstract}
Hong Kong's vertical urban landscape, bustling street markets, and multi-layered urban spaces have attracted a range of scholars (Cuthbert and McKinnell, 1997; Smith, 2005; Frampton [et al.], 20I0; Shelton [et al.], 20II). Therefore, this paper focuses on aspects of Hong Kong's public spaces', which so far have caught less attention, but affect the majority of its residents today. The paper starts with the following observations: (I) More than half of Hong Kong's population $(52,2 \%)$ lives today in the New Territories, an area usually outside of international attention (Census 20I I) ${ }^{2}$; (2) Here, most people live in public and private housing estates, constructed over the last 40 years; (3) Individual estates can reach a population size of entire European towns and their "public spaces" - if one can name them as such - follow strict rules and have their own spatial conditions; (4) The street patterns, which connect these estates with their surrounding are fundamentally different from those of the older urban areas on Hong Kong Island and the Kowloon Peninsula. Basically, in these new developments we don't find the bustling street markets or the complex multi-layered spatial conditions anymore, which have caught most international attention (e.g. Frampton [et al.], 20I0); and, (5) through urban renewal and redevelopment these new spatial conditions are introduced also to the older urban areas. As a response, there have been a growing number of initiatives by civil society groups to recapture the original role of streets as public spaces to offer more opportunities for economic and social activities, and re-enable expressions different cultural identities, life styles, and political views ${ }^{3}$.
\end{abstract}

Keywords: Public Space; Hong Kong; Streets; New Territories.

\section{To cite this article:}

Tieben, H. (2016). Public Space Trends in Hong Kong. A view from the New Territories. The Journal of Public Space, I(I), 25-34, DOI: 10.5204/jps.vliI.7

This article has been peer-reviewed and accepted for publication in The Journal of Public Space. Please see the Editorial Policies under the 'About' section of the journal website for further information.

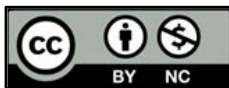

This work is licensed under a Creative Commons Attribution - Non Commercial 4.0 International License. https://creativecommons.org/licenses/by-nc/4.0/ 


\section{Background}

In 2013 UN-Habitat published the report Streets as Public Spaces and Drivers of Urban Prosperity, in which Hong Kong ranked highest among all studied cities in Africa, Asia and Latin America and the Caribbean, in regards to the amount of land allocated to streets and density of street intersections (UN Habitat, 20I3, 72 \& 77). In the preface of the report, Joan Clos, Under-Secretary-General and Executive Director of UN-Habitat, highlighted the fundamental importance of street patterns for five dimensions of prosperity: Productivity, infrastructure development, environmental sustainability, quality of life, and equity/social inclusion (UN-Habitat, 20I3, IV). The exceptional high ranking of Hong Kong's core areas, seems to be supported by other data regarding its economic performance ${ }^{4}$, and by the urban experience of bustling street spaces, short walking distances and numerous businesses and activities in the older urban areas on Hong Kong Island and Kowloon Peninsula.

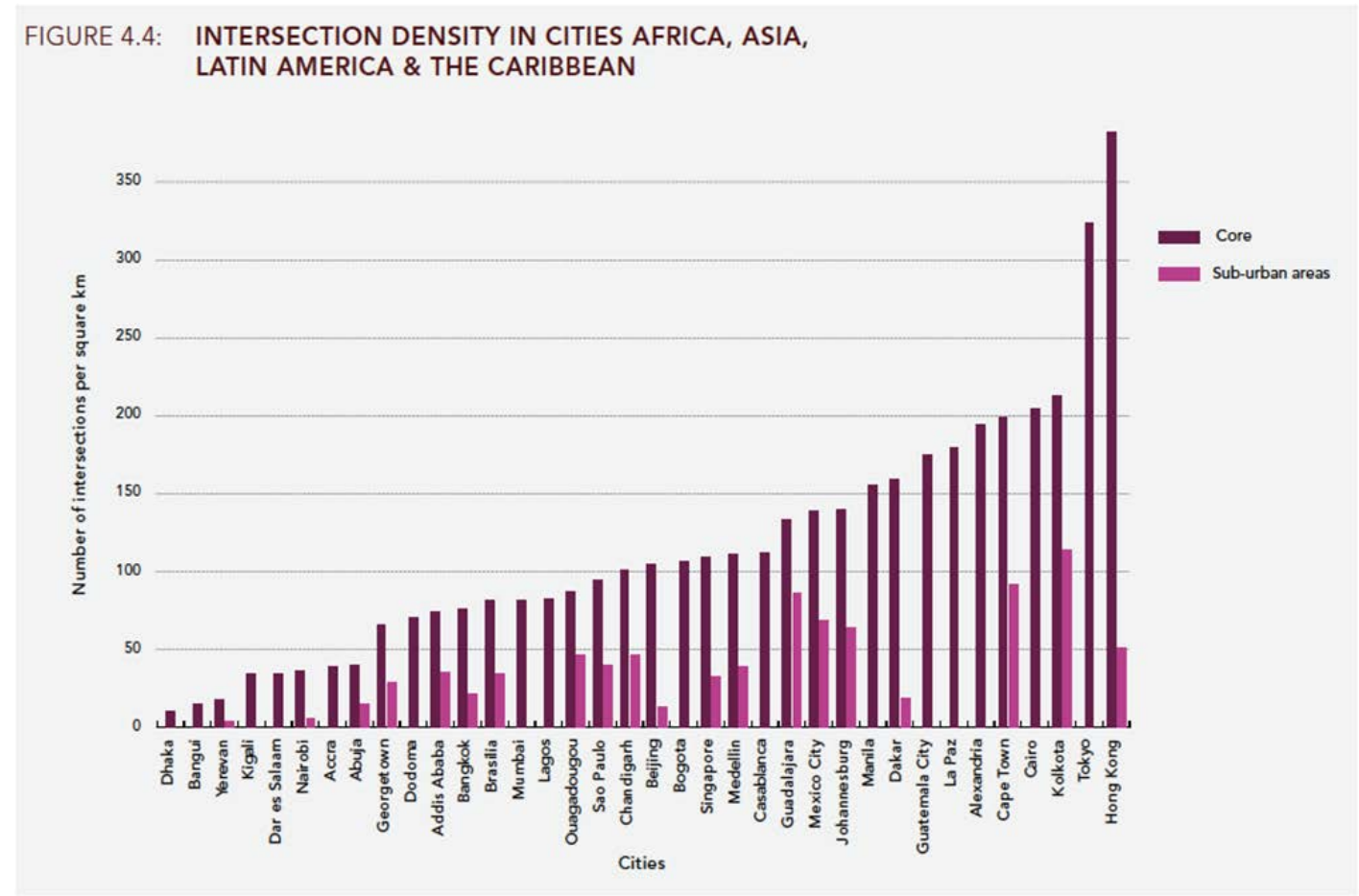

Fig. I. Intersection Density in Cities Africa, Asia, Latin America \& The Caribbean (UN Habitat, 2013, 77).

However, the UN-Habitat report presents also another remarkable result: The great gap between the data for Hong Kong's core and suburban areas. Here in suburbia, Hong Kong's results are among the lowest. For instance, its intersection density compares with those of the suburban areas of Brasilia and Johannesburg (UN-Habitat, 20I3, 72), places usually discussed for their lack of vibrancy (Brasilia) and high level of social inequality (Johannesburg). The report doesn't specify the location and boundaries of the core and suburban areas used for the calculations. Also, the study doesn't consider the impact of rail-based public transport and population density on urban prosperity, which could present Hong Kong's suburban areas in a better light. But, as this paper aims to show, there exist fundamental differences between the street patterns of the older urban areas 
on Hong Kong Island and Kowloon and those in the New Territories, and they should be addressed seriously for their range of effects ${ }^{5}$.

Until World War II, most people in the British colony lived on Hong Kong Island and in Kowloon. The New Territories became part of the colony only in 1898, when they were leased from China. Their urbanization started only after World War II, with the arrival of many refugees and migrants from China.

In the older urban areas, streets were laid-out between 1842 and the 1930s and were organized as small grids and street blocks. Size and orientation of the grids was based on the movements of pedestrians and horse- and streetcars, as well as the trading activities around the harbor. At that time, streets were the centers of everyday life and accommodated a range of additional functions such as street markets and eateries, informal extensions of shops and workshops, occasional theatre performances and religious rituals. The shop-tenement houses built along the streets offered flexible spaces for living and working. Their ground floor spaces were opened to the sidewalks to attract customers, and, sidewalks were covered to protect pedestrians from too much sun and rain (Tieben, 2013). In Central and Admiralty, there existed a small number of purposedesigned public spaces for the representation of the colonial government and the social elites; and after the outbreak of the bubonic plague (I893) several open spaces were added, to improve people's health; but, the street spaces kept their role as centers of everyday life 6 .

When urbanization of the New Territories started in the 1960s, streets were laid-out here according to the new paradigm of separating pedestrian and vehicular traffic in anticipation of increasing road traffic. According to the modernist idea of functional zoning, areas were demarcated as "residential" and assigned for the development of public and private housing estates.

The following paragraphs discuss the public spaces of these public and private estates as well as their integration into the larger spatial plans of the New Towns in the New Territories. The paper concludes with preliminary conclusions and arising questions for the urban design and planning of Hong Kong and those cities, which consider Hong Kong as a potential urban model.

\section{Public Spaces in Public Housing Estates}

In 2006, 48.8 percent of Hong Kong's population lived in rental and subsidized-sale units of public housing estates, provided by the Hong Kong Housing Authority and Hong Kong Housing Society. With the massive construction of public housing, the colonial government responded to the high numbers of migrants from China (after World War II approximately one million per decade) and to the fast growing informal settlements. The first resettlement estate was built in 1954, accommodating the residents of the Shek Kip Mei squatter settlement, which had become homeless after a fire in 1953 (Castells, 1990). In 1973, the colonial government launched a comprehensive new town program and thus started the large-scale urbanization of the New Territories (Bristow, 1989).

The layout of the public housing estates made use of the architectural types prefigured by European modernism in the 1920-30s and the new planning paradigms of the 1960s, calling for the separation of pedestrians and road traffic (Buchanan, 2015). With average housing units not bigger than I3.Isqm per person (Public Housing Authority, 2015), the public spaces of the estates are important extensions of the individual living space and as 
places to socialize with neighbors. Aware of the important role of these spaces, the Housing Authority and Housing Society put a significant effort into their design. For instance, in the public rental estate Upper Ngau Tau Kok (opened in 200I), residents can reach from their homes all public spaces and transport nods with universal access and protected from the weather. The placement of buildings ("Harmony l" and "Non-Standard" tower types) and open spaces followed the digital simulation of the microclimate, to capture natural ventilation and provide shading where needed. Plants and trees were added to further improve the environment; and seating and playgrounds were arranged according to inputs of residents in a seven years-long participation process. Furthermore, design details and artworks were added to evoke memories of the earlier - now redeveloped - estate and to strengthen residents' sense of belonging (Image 2).

The high quality of the public spaces in the Upper Ngau Tau Kok Estate resulted from the joint effort of professionals and academics and the input of residents. While not all public spaces in the public housing estates reach this quality, the general use of an interdisciplinary and participatory approach is helping to create more integrated solutions, considering accessibility, activities, comfort, and sociability at the same time ${ }^{7}$.

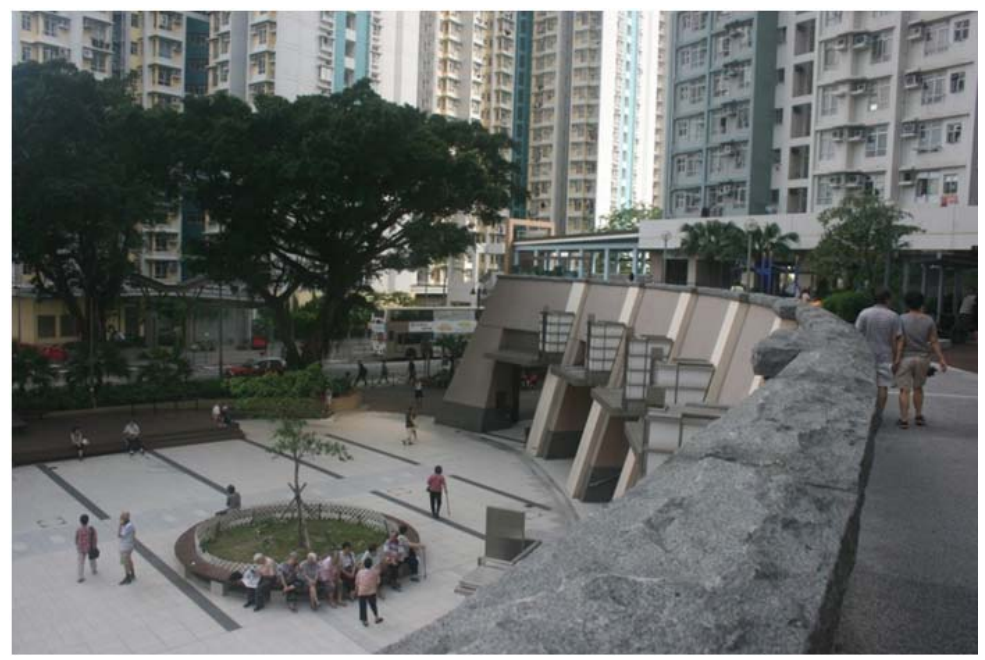

Fig. 2. Public space at Upper Ngau Tau Kok Estate. Photo: H. Tieben.

However, despite these efforts and achievements, the public space design of these estates has important limitations: (I) Due to the limited repertoire of building typologies and open spaces, as well as limited ground floor activities and strict management rules, opportunities for self-organized economic and creative activities are strongly restricted (Tieben [et al.], 20I3); (2) The main attention in the design is given to the spaces within the estates, while the outer perimeter is defined by blank walls and fences; (3) Streets surrounding the estates are planned for vehicles, which surprises, as over $90 \%$ of daily trips in Hong Kong are made by public transport (Hong Kong Government's Travel Characteristics Survey) and most residents of public housing estates don't own a car ${ }^{8}$. Due to the general lack of active street spaces, the one half of Hong Kong's population, which is living in public housing estates, has almost no opportunity to develop entrepreneurial skills or create own employment in the area where they live (Tieben [et al.] 2013). And, as today an increasing number of people is only temporarily or self- 
employed, it is particular problematic if creating and sustaining a network to other businesses and clients is made so difficult. With the lack of street spaces also the opportunities to express and experience different cultural identities, lifestyles or political views are strongly restricted, affecting particularly young people and migrants who are still in the process of finding their own place in society.
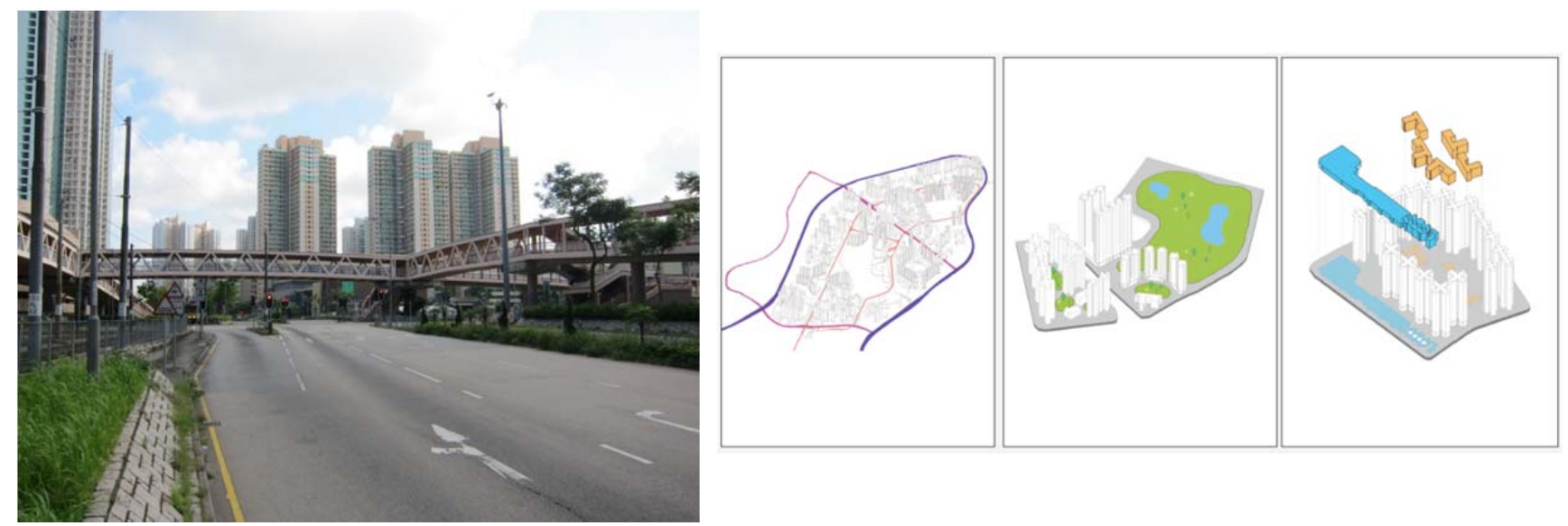

Fig. 3. On the left: road-spaces in the center of Tin Shui Wai, New Territories. Photo: H. Tieben. Fig. 4. On the right: organization of Tin Shui Wai New Town.

While each public housing estate usually has its own commercial center, these do not provide such opportunities. Before the millennium, the Hong Kong Housing Authority had been responsible for these centers. At that time, some of them still offered a small number of shops and restaurants with direct street access (e.g. see Chevalier Garden). Other estates, such as the Heng On Estate, offered carefully designed transition zones between commercial areas and gathering spaces, which linked economic activities and social interaction.

In 2004, these commercial centers were privatized and now are owned and managed by Link REIT. Since then, there has been growing criticism regarding the increase of rents and the replacement of local shops by chain stores. There also were conflicts involving hawkers, who responded to the new difficulties with the management, by offering goods outside of the malls.

In addition to these controversies, there are spatial issues, related to the new inward looking mall design. A fundamental problem for new business ideas or businesses related to ethnic minorities is, that they face difficulties to expand their customer base and thrive within these small malls. Why should residents from neighboring estates come here? They would need to pass along long footbridges over vehicular roads, just to arrive in shopping malls, which offer the same small assortment shops as the mall in their own estate. While small businesses thus struggle to survive in the mall, their presence is missing along the monotonous vehicular roads, to make them more vibrant.

\section{Public Spaces in Private Housing Estates}

The other residents of the New Territories, who do not live in the public housing estates, most likely live in private estates. 
While today's private estates tend to be gated, this has not always been this way in Hong Kong. For instance, Mei Foo Sun Chuen Estate, built between 1968 and 78 in New Kowloon, was well integrated into its surrounding and accessible to the general public. It was organized along a central street space for pedestrian, with shops and restaurants on two levels and a green central spine with resting and play areas. However, such solutions are no more built today.

The new gated communities, however, provide a wide range of in- and outdoor spaces, which remind on the amenities of luxurious holiday resorts. To those who can afford to live here, they offer spas and swimming pools, children playgrounds and study areas, as well as music rooms and event spaces. These amenities make the living in Hong Kong's increasingly dense urban environment more acceptable. They also provide a range of opportunities to socialize - although only with the residents of the same estate.

Similar to the public estates, also the private estates can reach very large scales. Already Mei Foo Sun Chuen Estate covered an area of 161,874 sqm for around 70,000-80,000 inhabitants. The recently built private estate, LOHAS Park occupies 330,000 sqm and in it's final state will have 2I,500 apartments in fifty towers for around 58,000 residents. LOHAS Park is developed by the MTR Corporation in collaboration with Hong Kong's biggest real-estate developers and arranged on-and-around a train depot of the metroline. The name LOHAS Park stands for "Lifestyle of Health and Sustainability" and encourages the use of public transport and reduction of fossil energy consumption. The marketing of the housing and commercial units recaptures the costs for the public infrastructure construction. However, such new models of private housing estates present similar problems to the public housing estates:

Despite their generally excellent connections to the public transport system and thus to other parts of Hong Kong, they remain often cut-off from their direct surrounding. Also here we find by walls and fences followed by wide vehicular roads. If retail spaces are provided, they are usually organized in shopping malls without direct access of stores to a public street. Businesses here have to follow the strict management rules of the developers and pay high rents for their vicinity to the metro-station. This system favor well-established brands and super market chains, while other businesses and services have difficulties to pay the rents or simply are excluded here. In addition, they also cannot move in the adjacent towers, as they are exclusively planned for housing. Similar to New York, there exists in Hong Kong a bonus system, granting developers higher plot-ratios for the provision of public spaces within their developments. Over the last two decades this bonus system has been criticized, regarding the accessibility, design, legal status, and permitted uses of the spaces it produced (Rossini, 20I4). In addition there were concerns regarding the lack of transparency how much bonus space would be granted (Cuthbert and McKinnell, 1997). As a response, in 20I I, Hong Kong SAR Government published the Public Open Space in Private Development Design and Management Guideline (Hong Kong SAR Development Bureau, 20I I). It is still too early to evaluate its long-term effect. Currently, still hurdles have to overcome to make these public spaces in private developments more attractive. The application processes to provide outdoor seating for cafes and restaurants or organize events are seen as complicated, time consuming and costly and such initiatives face resistance of residents in the estates (Yeung, 20I5). 


\section{Road-scapes of the New Territories}

The above-discussed public and private housing estates are the essential components for urban development in the New Territories today. After the discussion of the public spaces within the estates, the following question is: How are these internal public spaces estates connected with the surrounding street pattern? This question brings us back to the remarkable contrast between the street patterns of Hong Kong core and suburban areas, presented in the UN-Habitat study (UN-Habitat, 20I3).

One of the most striking cases in this regard was the planning of Tin Shui Wai New Town since the 1980s. This new town for around 300,000 people is based on the abovediscussed functional units of public and private housing estates, shopping malls, etc. As each of the estates was designed as an inward-looking unit, the entire new town has basically only roads and no streets. Residents in Tin Shui Wai are faced with serious problems to find jobs and usually have to make a one-hour travel to work in the older urban areas. The lack of street spaces and flexible building typologies means, that it is almost impossible in the entire 300,000 people town to find a place to open a simple bicycle or car repair shop, carpentries or a new 3d-printing shop. There are also no spaces for law or architecture offices, as well as for restaurants or grocery shop, which would allow recent migrants to create their own jobs and become part of the local society.

As mentioned above, the most recent developments, such as LOHAS Park, can assume large sizes of $330,000 \mathrm{sqm}$. The entire area is organized without any public street. There increasingly large developments with few or no streets are linked to the economic logic of land development in Hong Kong. Since its early days, Hong Kong's government relied on private investors for the construction of large public infrastructure and land reclamations projects. Developments such as LOHAS Park without public streets are more profitable the government and the private developers. The government saves its expenditures for the construction, maintenance and policing of streets and shifts them to the developer. For the private developer, fewer or no streets mean a larger undivided piece of land with significantly higher development density, as the permitted plot ratio increases proportionally with the land size. This, in return, brings also proportionally higher government revenue for the land lease. As a side effect, the surrounding roads become wider, according to the calculated higher road traffic; and, the wider roads have to comply with higher safety standards, further enforcing the separation of pedestrians and cars.

Such tendencies are neither new, nor only specific to Hong Kong. Much more important is the question: Which efforts are made to counter such tendencies to create a more socially and spatially integrated city. In the 1970s when the Sha Tin New Town was planned, the colonial government formulated the specific ambition to create a socially balanced and self-sufficient New Town (Bristow, 1989). This effort followed the destabilizing experience of the 1967 Hong Kong Riots and the international political climate of the time. The main step to realize this ambitious goal was to link all individual developments of Sha Tin New Town with an intricate public space network, which was conceived across different scales and dimensions. The network was anchored at the railway and bus stations and extended from here through a central shopping mall to the waterfront of the Shing Mun River, where a concert hall, outdoor arena, a park and a museum were placed. The main pedestrian path through the mall leads over a highway 
and local streets, and is then extending into a system of elevated walkways and outdoor spaces to both sides, integrating different private and public housing estates.

The grain of the street network remained small and was combined with an additional multilevel pedestrian system. Urban design guidelines were inscribed in the lease documents and helped to realize these multilevel pedestrian connections despite the involvement of many different public authorities and private developers (Bristow, 1989). Following the design guidelines, also building heights were stepped down towards the river space and views protected to the surrounding hills with a Christian monastery and Buddhist temple. Along the waterfront, also a cycling track was provided.

Besides the central shopping mall for international brands, which became the "High Street" of the new town, further malls and markets were added, offering a broader range of shop sizes to more affordable rents. The facades of these malls were opened to the streets and the pedestrian walkways. In the public housing estates, places for Dai Pa Dongs (local street eateries) were provided as social gathering points, which with their vibrant atmosphere not only attract residents from the public housing estates. Most importantly, public and private housing estates were treated with equal care as essential parts of an integrated spatial and social fabric. The essential strategy for integration was the carefully designed and programmed public spaces network. Similar spatially and socially inclusive approaches are missing today. Thus, based on the underlying logic of land development and the types of current urban models, Hong Kong urban and social fabric becomes increasingly fragmented.

\section{Preliminary Conclusions}

The UN-Habitat study Streets as Public Spaces and Drivers of Urban Prosperity underlined the central relevance of street patterns in regards to productivity, infrastructure development, environmental sustainability, quality of life, and equity/social inclusion. In this study the old core areas of Hong Kong ranked highest in terms of the amount of land allocated to streets and density of street intersections. However, the results for Hong Kong's suburban areas were very low.

The difficulties for more integrative street patters in the New Territories started with the division of urban life in distinct functions and building types for public and private housing estates, shopping malls etc. Their connection was then entrusted mainly rail-based masstransit and buses using large vehicular roads. With these decisions, Hong Kong abandoned the backbone of its earlier prosperity and socio-spatial integration: Its vibrant and interconnected street spaces. Which results in an increasingly fragmented urban fabric, with substantial lack of opportunities for small and innovative businesses, and the expression of different cultural identities, life styles and political views.

But, the example of Mei Foo and Sha Tin showed, that under similar political and economic conditions, much better integrated solutions could be produced. These solutions didn't copy simply the traditional street spaces of the older urban areas of Hong Kong, but used contemporary urban typologies and planning approaches, to create wellconnected and vibrant public spaces on multiple levels. In the case of Sha Tin, the public space network linked public transport hubs with public and private housing, besides providing commercial areas ranging from "high-street" shopping and to street eateries. This example could be a positive lesson for Hong Kong's current New Development Areas planned in the New Territories. 
At the same time, the results of the UN-Habitat study should be a warning that current tendencies in Hong Kong are going in the opposite direction and that recent urban renewal projects might destroy exactly those street spaces, which so far were the backbone for a broader shared prosperity and social inclusion?.

\section{Notes}

(I) The term "public space" has its limitations in regards to the here-discussed examples. A recent publication proposes the term "urban space" to capture the hybridity of the contemporary spaces in Asian high-density cities (Cho [et al.], 2016). However, recent protest movements in Hong Kong and Taipei reiterated the relevance of the original concept of public space as the place to negotiate different political views. This aspect had been the most essential achievement of the Greek agora, and the Greek idea of the polis. To acknowledge this important aspect as a central demand in the current movements, the paper continues to use the term "public space", while acknowledging its recent critique.

(2) The development of Hong Kong under the British Colony Government started I842 on Hong Kong Island after the first Opium War. After the second Opium War, the Kowloon Peninsula became part of the Colony. In 1898, The British Government leased the "New Territories" from the China. From 7.072,000 million people living in 20II in the Hong Kong Special Administrative Region, only I.270,876 lived on Hong Kong Island, 2,019,533 million in Kowloon, but 3,69I,093 people (52.2\%) in the New Territories (Census20I I.gov.hk).

(3) Such groups are for instance: Civic Exchange, Clean Air, Designing Hong Kong, Hong Kong Public Space Initiative, Very Hong Kong. These issues are also addressed by the author's project Magic Carpet - Re-envisioning Community Space (magiccarpet.hk).

(4) Hong Kong also performs very high in other data related to prosperity, for instance the ease of doing business measured by the World Bank (worldwide rank 5 ,

www.doingbusiness.org/rankings) and its economic freedom measured by the Heritage Foundation (worldwide rank I, www.heritage.org/index/). However, the author is not aware of any study, which would have related these aspects.

(5) The Census and Statistics Department of Hong Kong SAR Government uses the boundaries of these historically and geographically distinct areas to organize its data. Therefore they are also used for this paper.

(6) A counter example is Centre Street in Sai Ying Pun (Hong Kong Island), which lost this role after the removal the street market on this street (Tieben, Baniassad, Govada, \& Grace, 20I4).

(7) For the discussion of the public spaces, the author uses the criteria accessibility, activities, comfort and sociability, established by the Project for Public Space (http://www.pps.org) as they allow a more holistic understanding.

(8) According to the Public Housing Recurrent Survey 2008, there were only around 154000 car users in public housing, comprising some 80300 in PRH, 19600 in TPS estates and 54200 in HOS flats. Many of the used cars are company cars (for instance Taxi's). Only around 58000 are using the car parking facilities in the estates.

(9) Hong Kong regularly figures as one of the most expensive cities in the world. For instance the 2016 survey by Mercer ranked Hong Kong as the most expensive city for expatriates. http://www.mercer.com/newsroom/continued-demand-for-mobility-in-the-global-workforcechallenged-by-cost-of-expatriate-packages.html 


\section{References}

Bristow, M. R. (1989). Hong Kong's new towns: a selective review, Hong Kong: Oxford University Press.

Buchanan, C. (2015). Traffic in Towns: A Study of the Long Term Problems of Traffic in Urban Areas (Ist edition 1964), New York \& Milton Park Abingdon: Routledge.

Canhem, S. and Wu, R. (20I0). Portrait from Above, Hong Kong's informal rooftop communities, Hong Kong: Peperoni Books / MCCM.

Castells, M., Goh, L., Kwok, R.Y.W. (1990). The Shek Kip Mei syndrome: economic development and public housing in Hong Kong and Singapore, London: Pion Ltd.

Christ, E. [et al], eds. (2010). Hong Kong typology: an architectural research on Hong Kong building types, Zurich: GTA.

Cho, I.S., Heng, C.K., Trivic, Z. (2016). Re-framing Urban Space: Urban Design for Emerging Hybrid and High-Density Conditions, New York \& Milton Park Abingdon: Routledge.

Cuthbert, A.R. and K.G. McKinnell (1997). "Ambiguous space, ambiguous rights - corporate power and social control in Hong Kong". Cities I4:5.

Frampton, A., Solomon, J.D., and C. Won (2010). Cities Without Ground: A Hong Kong Guidebook, ORO Editions.

Grahame Shane D. (20II). Urban Design Since 1945: A Global Perspective, New York: Wiley.

Kayden, J. (2000). Privately Owned Public Space: The New York City Experience New York, New York Dept. of City Planning, The Municipal Art Society of New York, John Wiley \& Sons.

Mathews, G. (20I I). Ghetto at the Center of the World: Chungking Mansions, Hong Kong, Chicago: University of Chicago Press.

Pearson, V. and T.K. Ko, eds. (2008). A sense of place: Hong Kong West of Pottinger Street, Hong Kong: Joint Pub. Co.

Rossini, F. (20I4). Nuevos espacios colectivos de la ciudad vertical contemporánea: el caso de Hong Kong, Dissertation at the Departament d'Urbanisme i Ordenació del Territori. Barcelona: Universitat Politècnica de Catalunya.

Saunders, D. (20I I). Arrival City: How the Largest Migration in History is Reshaping our World. London: Windmill.

Shelton B., Karakiewicz J. and T. Kvan (20II). The Making of Hong Kong From Vertical to Volumetric. Abingdon, Oxfordshire: Routledge.

Smith, P.C. (2006). The urban design of impermanence: streets, places and spaces in Hong Kong, Hong Kong, MCCM Creations.

Tieben, H., Baniassad, E., Govada, S. \& Grace, H. (20I4). "Measuring community benefit in public space transformation: A case study of Centre Street, Sai Ying Pun, Hong Kong," in: Roberto Cavallo [et al.] (eds.), New Urban Configurations, Delft: IOS Press \& Delft University Press, 535 $-544$.

Tieben, H. (2013). "Public/Private Interfaces in Hong Kong: Observations in the Sai Ying Pun District," in: Darko Radović (ed.), Density \& Intensity: Measuring the Non-Measurable, Work Book I, Flick Studio \& IKI- International Keio Institute for Architecture and Urbanism, Tokyo, 36-43.

Tieben, H., Baniassad, E., Govada, S. \& Grace, H. (20I3). "How to Create Sustainable

Communities in Hong Kong? Inherent Problems of Recent Urban Layouts for Microeconomic Opportunities and Quality of Living," presentation and paper at the SB/3 Hong Kong Regional Conference "Urban Density and Sustainability". https://www.irbnet.de/daten/iconda/CIB_DC26582.pdf

UN-Habitat (2013). Streets as Public Spaces and Drivers of Urban Prosperity, Nairobi: UN-Habitat. Yeung, M.L. (2015). Postgraduate Thesis: Privately owned public space in Hong Kong, Hong Kong: University of Hong Kong. 


\title{
Learning, Thinking and Living Tokyo. Doing urban research in cultures radically different to that of our own
}

\author{
Darko Radović \\ Keio University, Tokyo, Japan \\ IKI \& co+labo Radović | Smart Communities \\ radovic@sd.keio.ac.jp
}

\begin{abstract}
In 20I I, at Keio University, Tokyo, we launched Measuring the non-Measurable, with academic and practitioners involved in production of space in ten cities of Asia (Tokyo, Bangkok, Beijing, Hong Kong, Singapore), Australia (Melbourne) and Europe (Barcelona, Belgrade, Copenhagen, Florence).

The intention of Mn'M was never to question the importance of quantifiable dimensions of life. One of its critical aims was to argue for an equally respectful treatment of other dimensions of knowing, as neither the quantifiable not the non-quantifiable alone can fully cover the key dimensions of the synthetic quality which we seek to live. The cities are always in and of a particular place, in and of a particular time. That double contextualisation makes their realities enormously dynamic and complex. The complexity itself and the groundedness in concrete, unique situations are the key aspects of being urban.
\end{abstract}

Keywords: Public Space; Tokyo; non-measurable; subjectivity; urbanity.

To cite this article:

Radovic, D. (2016). Learning, Thinking and Living Tokyo. Doing urban research in cultures radically different to that of our own. The Journal of Public Space, I (I), 35-42, DOI:

10.5204/jps.vlil.8

This article has been peer-reviewed and accepted for publication in The Journal of Public Space. Please see the Editorial Policies under the 'About' section of the journal website for further information.

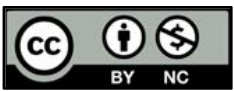

This work is licensed under a Creative Commons Attribution - Non Commercial 4.0 International License.

https://creativecommons.org/licenses/by-nc/4.0/ 
Learning, Thinking and Living Tokyo.

Doing urban research in cultures radically different to that of our own

I.

Several years ago, I took part in a very interesting event, a conference organised by one of the best European universities. Perfectly managed, the conference allowed plenty of time for spontaneous interaction and authentic discussions. One of the main threads focused at interim results of the research project, which was meticulously crafted by a local team, was an attempt to compare development patterns in a number of cities across the globe. The core team distributed research method guidelines and a pre-established presentation format, which facilitated easy and interesting comparisons. Having on mind the complexity of the themes addressed and opened within, and by that project, the discussions at the conference were wide-ranging, often provocative, and even truly polemological.

A then young researcher presented the sub-project which he headed in his home town, one of the provocative cases from Africa. When asked about the relevancy of the method, and how sensitive to local conditions (which were, of course, dramatically different from those in European, American, Asian and Australian examples) the predefined and finely crafted research methods were, his answer was unqualified; "Not at all!" he replied.

The local university was approached and funded by the reputable foreign institution. Research methods and communication tools were pre-established, based on the best of current urban theory and rigorously applied. As the focus was on comparisons, the comparisons were made, but the issues addressed and the themes raised locally had less then little relevance. For those who really knew the place and the problems facing it, the research questions were not relevant at all.

We all know that, as the Invisible Committee has succinctly summarised, "the past has given us far too many bad answers (...) not to see that the mistakes were in the questions themselves" (2009). The questions of this perfectly intended, decidedly rebellious and truly critical research project, as those of many similar projects before, were still crafted within the ruling, "dominant paradigm, which determines the very nature of questions asked and problems posed" (Kuhn, 1970). It was clouded by an a priori belief that the rich World we inhabit is one. And, while ticking off all the boxes that the officially sanctioned research practices demand, in terms of its ultimate relevance and usefulness - it failed.

2.

In 20II, at Keio University, Tokyo, we launched the project Measuring the non-Measurable, one of the most important aims of which was to address precisely that issue. Mn'M included academic and practitioners involved in production of space in ten cities of Asia (Tokyo, Bangkok, Beijing, Hong Kong, Singapore), Australia (Melbourne) and Europe (Barcelona, Belgrade, Copenhagen, Florence). The broad framework was critically informed by Lefebvre's call to address the irreducible oeuvre (1996), while never losing sight of de Certeau's understanding of the city is the most immoderate of human texts (Highmore, 2006). 
As such, the project has explicitly not celebrated efficiency. That made us able to find allies in the depths of thinking such as those of Hélène Cixous, whose ways of reading (which can be translated into the ways of reading that immoderate urban text of ours) deliberately focus "not on a strategically selected detail but on the text in its entirety" (Andermatt Conley, 1992). Such an unorthodox approach to urban research, in which we openly argued for inclusion of the summarily proscribed subjectivity of the researcher, has also found strong support in the latest developments in life sciences. As Sandra Mitchell eloquently explains, in order "to begin to understand many aspects of our complex world ... we need to expand our conceptual frameworks to accommodate contingency, dynamic robustness, and deep uncertainty" (Mitchell, 20I2). Complex realities, "simply", need an intellectual apparatus of matching complexity.

The intention of Mn'M was never to question the importance of quantifiable dimensions of life. One of its critical aims was to argue for an equally respectful treatment of other dimensions of knowing, as neither the quantifiable, not the non-quantifiable alone can fully cover the key dimensions of the synthetic quality which we seek to live. The cities are always in and of a particular place, in and of a particular time. That double contextualisation makes their realities enormously dynamic and complex. The complexity itself and the groundedness in concrete, unique situations are the key aspects of being urban.

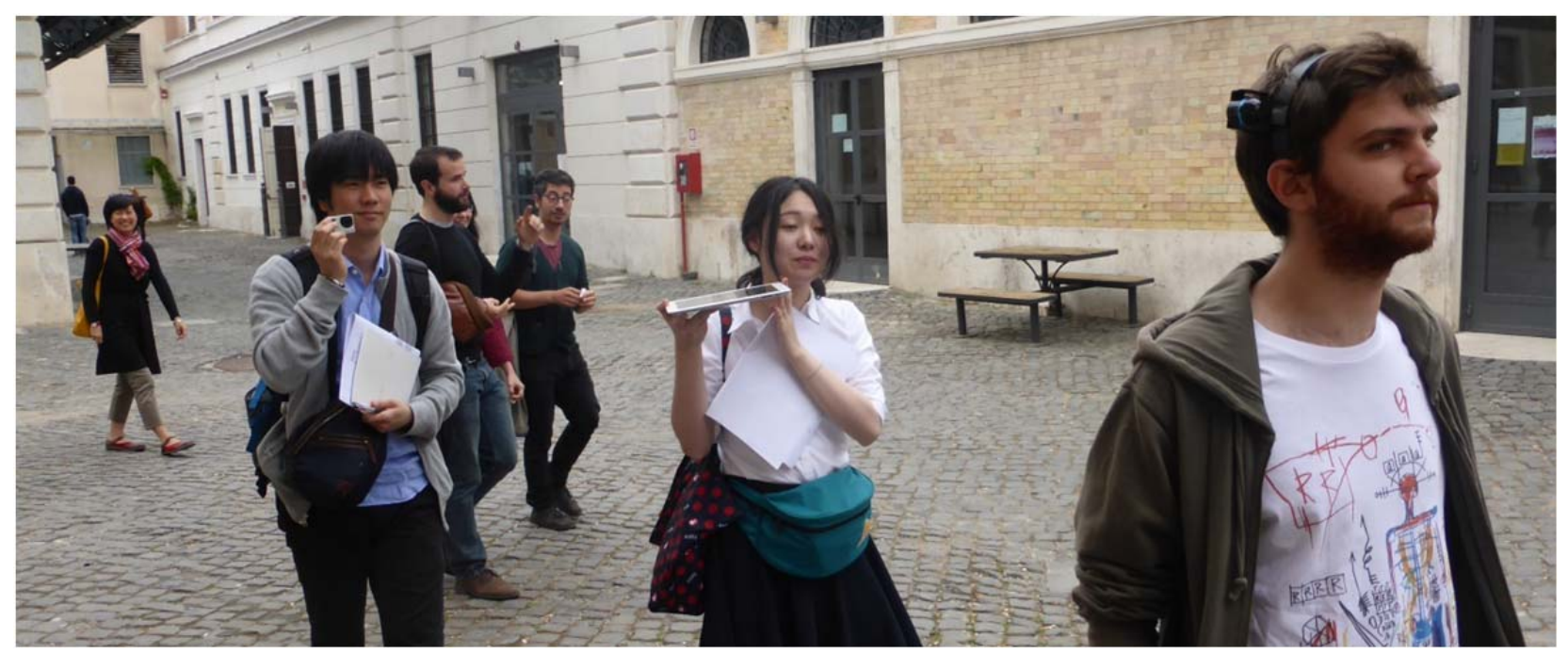

Fig. I co+labo Radović and Mitsukura Laboratory, Keio - urban research fieldwork (Rome, 20I5): confronting recordings of subjective appreciation of urban quality (through interviews, observations, artistic impressions etc.) and the latest in EEG technology

Until recently, much of sciences, "adopted strategies involving reductive explanations designed to simplify the many complexities of nature, in order to understand them" (ibid.). Life sciences have found such limitations too restrictive and unsustainable. The problem is, of course, even more pronounced in the studies of built environments, as they include both the complexities of ecological systems and those of human and social 
Learning, Thinking and Living Tokyo.

Doing urban research in cultures radically different to that of our own

power relations, where precisely the latter produce that crucial quality, the layer that makes human text amazingly immoderate.

If we allow ourselves to lose sight of the untameable complexity of urban phenomena, as well as of the complexity as, in itself, one of the key urban features, if we agree to reduce our understanding of and our interaction with cities, if we narrow them to sets of fragments and fragmentary solutions, we will lose the ability to think, to make, and to live the urban. We will lose urbanity, which cannot be fragmented, and we will, ultimately, lose the human dimension of our habitat.

In that sense, the complexity of the approaches means a better chance to (re)discover fully human ways towards comprehension and, in production of environments, good urbanism, profoundly humane environments.

3.

On the side-lines of Mn'M, we investigated which aspects of urban complexity tend to get excluded from the officially sanctioned practices. Briefly summarised (from Radović, 2014), rigorous application of rigid research frameworks exclude precisely the subtleties which make some of the most fragile, most beautiful and most precious dimensions of the urban. The concepts such as beauty, which are so important, which are part of what makes our species special, came under suspicion. As ultimately subjective, they could not be subjected to pedantic definition and accurate accounting. The same applies to multisensory experiences. The previous knowledges were totally excluded. The singular replaced the plural, in order to enthrone new, pure epistemological framework, an exclusive paradigm of modernity. The emphasis started to move from cumulative and evolutionary, towards futuristic and revolutionary.

In production of space, in urbanism and architecture, the loss of experiential depth (Harvey, 1990), which came from an ever-increasing domination of the modernist urge, remains favoured and generously supported by the power of Spectacle. "The only sense which is fast enough to keep pace with the astounding increase of speed in the technological world is sight" (Pallasmaa, 2005). The Spectacle prefers "the world of the eye", as it is "causing us to live increasingly in a perceptual present, flattened by speed and simultaneity" (ibid.), in which the artificial realities of money and financial power operate best. Domination of the optical introduced a particular kind of "hygiene" which fears complexity. "The contemporary city is increasingly the city of the eye", which has superseded the "haptic city" of the past (ibid.), producing the shopping-centre-like sterilities, which get confused for the new urban(ism). Even the universal and, at the same time, also always culture-and place-specific shadows of Junichiro Tanizaki, Rembrandt or Caravaggio, those of the interiors of the Mediterranean house, vanish to give way and open our realities to pornographic gaze, surveillance, and characterless neon and LED lighting.

Since economy was proclaimed a science, and especially after it became equated with politics, its logic has conquered (much of the) world. Such economy-cum-politics is governed by the Spectacle which seeks power for the few, and (whenever reasonably achievable), panem at circenses, enough food and entertainment to its subjects. That 
power has constructed its own language that, in that historically proven way, rhetorically (re)organized the world in keeping with its (new, always new) views, and set out to convert others to their program. The unconverted ones are - the heretics.

When emphasising how the events and processes 'necessarily exceed our capacity to know them', Law actually stresses the 'beauty of being in the world', the very existence of the unknowable - the search for which, besides cogito, makes us human.

Sentio ergo sum'.

Facing the limits of our ability to rationalise needs courage, the courage of even higher order than what is necessary to unveil the truths (or - the "truths"), scientific - or otherwise.

An ability to appreciate, in parallel, and in addition to (and absolutely not as replacement for) the need to comprehend, is exactly what has been lost by application of exclusive, progressist methods in addressing the aporias of the urban.

4.

That which comes from an overall unease to face situations, cannot be tamed and conquered to fit dominant epistemological frameworks. Despite the rhetoric, the power which fuels current globalisation has difficulties to acknowledge even the existence, let alone the importance of Derridean tout autre, of true and radical difference. That is because such otherness "cannot be made transparent to the understanding and thereby dominated and controlled" (Hillis Miller, 2000). As any heresy, it is subversive and, consequently, highly undesirable. On the other hand, the urban, as an essential theatre of co-presences, is exactly where the very Otherness of the Other plays out one of the most significant roles in creating the magic, irrepressible complexity of cities. It includes some of the most subversive (urban rights) - such as Lefebvrian droit à la ville, the renewed right to the city, le droit a la difference, the right to difference ie. the right to be empowered and to be different, and rights to (each particular) city and to (each particular) urbanity, as fullydeveloped local cultures (Radović, 2008).

Subjectivity and sensuality are political and subversive. As Mack puts it, "the contemporary exclusion of subjectivity amounts to the increasing abrogation of democracy and politics [...] In a society wherein we can appeal to nothing else but the calculating processes of law and economics, individuality as well as diversity lose their political foundations" (Mack, 2014). The Spectacle (Debord, 1994, 1998) thus, banalises and reduces sensuality to sexuality, and sexuality to pornography - in the way it reduces everything to the (monetary) numerical. The opposing project is in search for the complexity lost.

The Spectacle leaves a false impression that "anything goes", while the realities it produces tells exactly the opposite. The power which fuels globalisation of the neo-liberal kind is very efficient in exterminating ideological opposition. The kind of inclusiveness of looking at cities which we advocate here is not an extension of the Post Modern "nonideological", banal pastiche. On the contrary, it has to be based on a strong value system, which is in opposition to the ruling doctrine. This is a value system which rejects its own 
Learning, Thinking and Living Tokyo.

Doing urban research in cultures radically different to that of our own

ossification into a new totalitarian ideology. Getting there, demands a new kind of thinking, and decisive individual responsibility.

The urban is inevitably ideological and political. Ideology and politics of the urbane are those of the common good. Over the last several decades, the urban has been reduced to urbo-economic, in parallel to, and as yet another expression of the reduction of citizens to the consumers.

Therefore, what gets taken out from urban research and action is the fullness of our humanity, and the awareness that, in order to meet our individual and social needs, we seek humane environments which can nourish the best we can all give and live. We will focus on two dimensions of urban research which have been neglected and ostracized, as they cannot fit the insatiable growth machine of the Spectacle - our subjectivities and our sensualities.

5.

Some situations enhance the sense of self and make one extremely aware of own subjectivity, and the inevitability, necessity, and potential of our reliance on deeply personal insights. Such is the condition of extreme cultural foreignness (of the researcher).

For more than two decades now, I have lived in cultures which are profoundly different from that of my own. I do much of my research in the exact places where I live, with focus wide (or narrow) enough to include my own vécu. That makes inroads into objects of my investigation inevitably (self) referential, forming the fields of potential (dis)similarities, causing inspirational (mis)understandings and diverse cross-cultural resonances. Attempts at reconciling my own external and increasingly internalised views opens often conflicting new perspectives, and hints at the various possibilities and degrees of entry. In any case, when exploring the cultures and thought of the Other, "only crossing thresholds and 'entering"' (Jullien, 2015) might be possible.

Research demands definite terms. In cross-cultural research we have to accept an impossibility of having them. Often, there simply is no equivalence, and we need to defy the orthodoxy by specifying contextual definitions.

For instance, to me, initially, the realisation that Japanese language (along many other nonWestern languages, including East and South East Asia) has no words equivalent to the term "public" (Radović, 2010, 20I4) was not easy to comprehend. That absence indicates an absence of, or at least a very unusual situation with, the very concept of public - which is one of the cornerstones of my cultural, professional and academic frameworks. Neither the transcribed paburiku [パブリック], nor the Japanese indigenous kōkyo [公共の] encapsulate the meaning of public. We have to accept that that concept is simply among those "in which other cultures have shown hardly any interest, to the extent that often they do not even have name for it" (Jullien, 20I4). The West has proclaimed its own concept universal, and imposed them on the socio-cultural contexts of the rest. And "we" continue to expect the acceptance; "we" continue to impose them. Similar is the 
situation with a number of other, equally foundational terms and concepts, such as culture, philosophy, aesthetics, logic, rights, or even beauty (Jullien, 20I6).

The terms considered simple and easy, such as piazzas, squares, lanes, or alley are also not easy to translate to many languages. That is because they do not stand for any exact scientific constructs, but for spatial expressions of lived, ephemeral, culturally-specific, social phenomena. There is no universal "alley as such". Urban type which we name "alley" is a product of particular patterns of inhabitation and life. It would be surprising if anything similar, let alone the same, has spontaneously developed in a faraway Japan, or China. We need to ask if connotations of the word alley (can) correspond to those of roji, or sokak, or soi, or calle, or kala, or ... Such questions should not be asked in the name of empty political correctness, but because of the need to recognise the reality of cultural diversity, authenticity, uniqueness, arising from the loci of our projects. The placed identity identifies place.

Living in places of radical cultural difference develops an ability to doubt. The life itself puts to test even "what I can not imagine doubting" (Jullien, 20I5), and one needs to be(come) able to embrace the unease which such doubts cause. Living within the environments of the Other, we first have to "begin to question ourselves" (ibid.), according to local perspective and "according to its implications and expectations" (ibid.).

6.

Ferrarotti's decision "that I prefer not to understand, rather than to colour and imprison the object of analysis with conceptions that are, in the final analysis, preconceptions" (Daley, 1986) is a worthy aim, and a must for the much-needed foreigner-researcher of a new kind (the one who does not seek to educate, but to observe and engage). That is a worthy aim, both hard and rewarding to live.

\section{Note}

(I) Adapted from "Cogito, ergo sum", a philosophical proposition by René Descartes, namely "I think, therefore I am". The author is using the expression "Sentio, ergo sum", namely "I fell, therefore I am" to emphasize the human sensitivity to understand the urban environment.

\section{References}

Andermatt Conley, V. (1992), Hélène Cixous, Toronto: University of Toronto Press. Dale, R. 1986, The Myth of Japanese Uniqueness, Oxford: University of Oxford. de Certeau, M. (1984), The Practice of Everyday Life, Berkeley: University of California Press. Debord, G. (1994), Society of the Spectacle, New York: Zone Books.

Debord, G. (1998), Comments on the Society of the Spectacle, London: Verso. Harvey, D. (1990), The Condition of Post-Modernity, Molden: Blackwell Publishing. Hillis-Miller, J. (200I), Others, Princeton and Oxford: Princeton University Press. Highmore, B. (2006), Michel de Certeau, Analyzing Culture, London, New York: Continuum Publishing. Invisible Committee (2009), The Coming Insurrection, Semiotext(e), Intervention series. 
Learning, Thinking and Living Tokyo.

Doing urban research in cultures radically different to that of our own

Jullien, F. (20I4), On the Universal, Cambridge: Polity Press.

Jullien, F. (2015), The Book of Beginnings, New Heaven:Yale University Press.

Jullien, F. (2016), The Strange Idea of the Beautiful, London: Seagull Press.

Kuhn. T. (1970), The Structure of Scientific Revolutions, Chicago: University of Chicago Press.

Lefebvre, H. (1996), Writings on Cities, Cambridge, MA." Blackwell.

Mack, M., (20I4), Philosophy and Literature in Times of Crisis, Challenging our Infatuation with Numbers, New York, London: Bloomsbury Publishing.

Mitchell, S. (2012), Unsimple Truths: Science, Complexity, and Policy, Chicago: University of Chicago Press.

Pallasmaa, Y. (2005), The Eyes of the Skin, Chichester: John Wiley \& Sons Ltd.

Radović, D. (2008), Another Tokyo - places and practices of urban resistance, University of Tokyo, ichii Shobou.

Radović, D., Boontharm, D. (20I4a), In the Search of Urban Quality: 100 maps of Kuhonbutsugawa Street, Tokyo: flick Studio.

Radović, D. (20I4b), Subjectivities in Investigations of the Urban: the Scream, the Mirror, the Shadow, Tokyo: flick Studio. 


\title{
Mapping the lived experiences of Bangkok's soi
}

\author{
Davisi Boontharm \\ Sophia University, Tokyo, Japan \\ Centre for Global Discovery \\ davisi@sophia.ac.jp
}

\begin{abstract}
One of the most distinctive urban characteristics of Bangkok is its sois. Soi is an alley that branches out from the main thoroughfares. This terminology applies to both the artery system of streets and canals. Soi is considered as a sub-street or a tertiary type in the hierarchy of the streets of Bangkok, the spatial layout of which follows old agricultural patterns of the water based settlement. They produce the labyrinth-like spatial and social configurations initiated by various agreements and practices between the landowners and residents. The public investment in road infrastructure couldn't cope with the speed of urbanisation in Bangkok. Apart from the main roads constructed by the public authorities, the soi where the majority of population in Bangkok lives is created by private initiative. For this paper, I only present part of the bigger project, which is still on going. In this very initial state of my investigation, I focus only on one family; mine.
\end{abstract}

Keywords: public space; Bangkok; superblock; soi; mapping.

To cite this article:

Boontharm, D. (2016). Mapping the lived experiences of Bangkok's soi, The Journal of Public Space, I(I), 43-52, DOI: 10.5204/jps.vlil.9

This article has been peer-reviewed and accepted for publication in The Journal of Public Space. Please see the Editorial Policies under the 'About' section of the journal website for further information.

\section{(c) (P)}

This work is licensed under a Creative Commons Attribution - Non Commercial 4.0 International License. https://creativecommons.org/licenses/by-nc/4.0/ 
One of the most distinctive urban characteristics of Bangkok is its sois. Soi is an alley that branches out from the main thoroughfares. This terminology applies to both the artery system of streets and canals. Soi is considered as a sub-street or a tertiary type in the hierarchy of the streets of Bangkok, the spatial layout of which follows old agricultural patterns of the water based settlement. Soi branches away from the main street bringing access into the innermost parts of the superblocks (Boontharm, 2013). They produce the labyrinth-like spatial and social configurations initiated by various agreements and practices between the landowners and residents.

Bangkok used to be known as the "Venice of the East," with life orientated towards its complex water system of Chaophraya river and its canals and irrigation structures.

Throughout 234 years of development, the city has undergone a tremendous change, evolving from its traditional, aquatic roots (Jumsai, 1997) and distinctly tropical green city character into a megacity of artificial topographies of concrete.

The end of the nineteenth century was the period when Bangkok still maintained the feel of an amphibious city. Starting from the end of the nineteenth century, it evolved into a sprawling system of land-based settlements, while the mid-twentieth century until today marked of the most drastic urban transformations. For the last five decades, despite the great effort of producing urban planning documents by the authorities to shape Bangkok, none of those plans were successfully implemented. Reasons are the lack of statutory force and law enforcement, the inability of government agencies to coordinate and cooperate, and the supremacy of property interests in the fast growing city ( $\mathrm{Nim}, \mathrm{1963}$; Askew, 2002).

The public investment in road infrastructure couldn't cope with the speed of urbanisation in Bangkok. Apart from the main roads constructed by the public authorities, the soi where the majority of population in Bangkok lives is created by private initiative. In the peri-urban of Bangkok, where more than tens of square kilometres are occupied by hundreds of thousands of people, the process of urbanisation happened exclusively by the juxtaposition of private allotment projects. Very few of the secondary streets link to the main public roads, to relieve the surcharge of traffics on those main public corridors. (Charmes, 2002). Bangkok followed an erratic expansion of the soi system and dependence on automobiles, which caused seemingly endless ribbon developments, often leaving huge enclaves of inaccessible land locked within the heart of the unplanned superblocks. Seen from this perspective, soi is the result of the opportunistic private land market made by and for affordable middle class society. At the same time soi is socially produced urban fabric, issued from the negotiation of right to access which leads to right to construct and accumulative lived experiences. The production of soi is a progressive phenomenon, and took a long time to process.

Superblock and soi are typical Bangkok's suburban landscapes. There are common characteristics among the soi in Bangkok, such as the width of approximately 4-6 meters, enough for two cars to pass in opposite directions. This narrowness conditions the speed of the traffic to slow movement. However, each soi has its own pattern, its own turns and its own dead-ends. Each soi has its particular history, its way of life and its local social construct. The main roads and the soi are the juxtaposition of two completely different worlds. Pichard-Bertaux expressed these phenomena as "Soi is generally described as narrow, winding and dark while the main road is the symbol of progress, opulence and bright. However these two worlds are far from opposing each other, they complement 
each other and can't be dissociated (Pichard-Bertaux, 20I I). The spot where the two worlds connect is pak soi (mouth of the soi). It is a strategic place which acts as the gate to the hidden community inside. It is also the node of activities, one can find the concentration of shops catered to everyday activities, such as newsstands, drugstores, convenience stores, food and drink stands, and public transport nodes. This location also attracts several informal push-carts offering diverse food and goods.

Within the context of relentless, uncontrolled, rapid and heavy transformation of Bangkok, a number of local readjustments were taking place. Within such contexts, one can identify a number of ideas and examples of situation-, time- and place-specific inventiveness. For example, the self-organized transportation system - such as motorbiketaxi services which facilitate residents' travel within the soi, or the minivan bus system, which helps people move from the centre to their suburb without many stops, or diverse types of mobile vendors who serve the residents who live deep in the soi (Polakit and Boontharm, 2008).

The vast superblock with its complex labyrinth-like pattern of soi creates a tapestry of neighbourhoods, with a different sense of belonging by their residents. Soi indeed can be like a business street or thoroughfare or even an intimate lane of a quiet residential compound depending on its location, configuration and practices. Soi are complex, offering many things to diverse groups of people. For residents, they are the stages at which fully lived local lives and urban practices unfold, they are produced in an interplay of those lives and their other characters. Soi, as any other urban phenomenon in Bangkok, are not "purely" lanes, they are conflictual frameworks of an unfolding complexity. For this reason, the investigation of soi urbanism cannot be achieved by the knowledge of a single discipline alone (Arkaraprasertkul, 2010). The purpose of this paper is to argue for the trans-disciplinary methods of investigating the realm of a neighbourhood in the specific context of Bangkok's superblock and its soi from the perspective of the residents' lived experience. For those with lived experiences in this environment, soi are never the background notion of concrete everyday lives and memories of concrete people. By referring to Lefevbre's trialectics, exploring those spaces as conceived, perceived and lived, I discuss the complexity of socio-spatial production of the concrete neighbourhood. As I want to emphasise the importance of concrete, real lives of concrete, real people in concrete, real situations, my particular emphasis will be on vécu, the lived experiences which I can unpack both as an academic and as a long-time resident - those of my own family members, including myself, and acquaintances in the soi.

For this paper, I only present part of the bigger project, which is still on going. In this very initial state of my investigation, I focus only on one family; mine. Lefebvre (1974) suggests that the body is one useful way to locate and understand how space is socially produced. In this particular case the "body" is me and each of my family members'. I am aware of the limitations that I and my family can only establish part of the whole representation of soi Aladin. My complete research is aimed at capturing multiple stories from broader groups with a deep level of local involvement and knowledge.

By addressing the vécu, the approach to an individual's living experience is necessary, and the subjectivity in the method of enquiry is unavoidable. Human experience is important in urban research; it is always situated in a social, cultural, and spatial context. Individuals directly and indirectly are subjects of conditions of their social milieu. To record and communicate the deep meaning and the sense of neighbourhood, I combine the method of narrative and mapping as an attempt to present the non-measurable and qualitative 
aspects of the place. The story of my neighbourhood cannot be told without the presence of the soi. Soi is not only the spatial structure of the neighbourhood, it is also the physical and mental space where body movements and social interactions occur. I hope that through layering different individual stories of diverse experiences of the past and present we can reassemble the content (physical, spatial and social) and their relationships and achieve some kind of reading of this concrete neighbourhood.

At this initial stage of research, I only attempt to experiment with this method through my own family. The results are not intended to offer a complete understanding of the neighbourhood social construct, but my aim is to start with "one of" the complex whole and the most meaningful. In this paper, I value the subjective views of each family member's experience. Those subjective views could constitute important parts of the significantly understandable picture of soi Aladin neighbourhood.

Radović $(2014,2016)$ argues for the legitimacy of subjectivities in the investigation of the urban:

[...] in urban research we need to multiply subjectivities, to both ... flatten subjectivities - to make a statistical sample, or far more interesting... and ... layer subjectivities - to keep each and every of them simultaneously individual and contextual

I challenge the layer of subjectivities and avoid flattening them. For this paper, I have selected three narrative maps of my siblings and mine who were born and grew up in this neighbourhood. The maps describe the living experiences in the neighbourhood of soi Aladin. I let them tell their personal stories and express their feelings, thought and emotions about this neighbourhood, including how they describe the boundary or the realm of this neighbourhood. The record of their and my experience is done through writing. I advocate the "sketch and script" methods (Boontharm, 20I2; 20I5), in this particular case "mapping and narrative, graphical/artistic representations and texts. This spatial narrative would let the reader freely perceive. They are a patch-work of facts and feelings.

I use mapping techniques to translate those narratives to spatial form. Through this process, an active engagement between me and the texts have occurred. There is a challenge in mapping subjectivities. Mapping the narrative is to give another dimension of understanding the built environment; it could link the stories to space or just an illustration, a chart, a picture or a work of art on its own. I deliberately do not seek the dull, systematic and informative mapping, but push it towards thought, emotions and aesthetic. Do I map the reality or my imaginary? Or map the unmappable? (Radovic, 2016)

[...] I can only be sure (and even that only to a certain degree) that that I can know what matters - to me...(subjectivity... subjectivities) ... mapping is process of spatial representation of thoughts, emotions, feelings... spatial expression of somebody's ... some - body's (individual or collective body) experience, thought, hunch...[...]

[...] Mapping subjectivities opens fascinating fields for urban research... the subjectivity of the researcher... the subjective of the researched... the subjectivities of the researched $[\ldots]$

(Radović, 2016)

The aim of employing the sketch and script methods isn't only about subjectively and 
forcefully glorifying and bringing excitement to my unexciting and mundane soi. This method is an open field which invites readers to subjectively read and contemplate these representations, as one of the dimensions, the long neglected dimension in urban research (Radović 20I4, 2016).

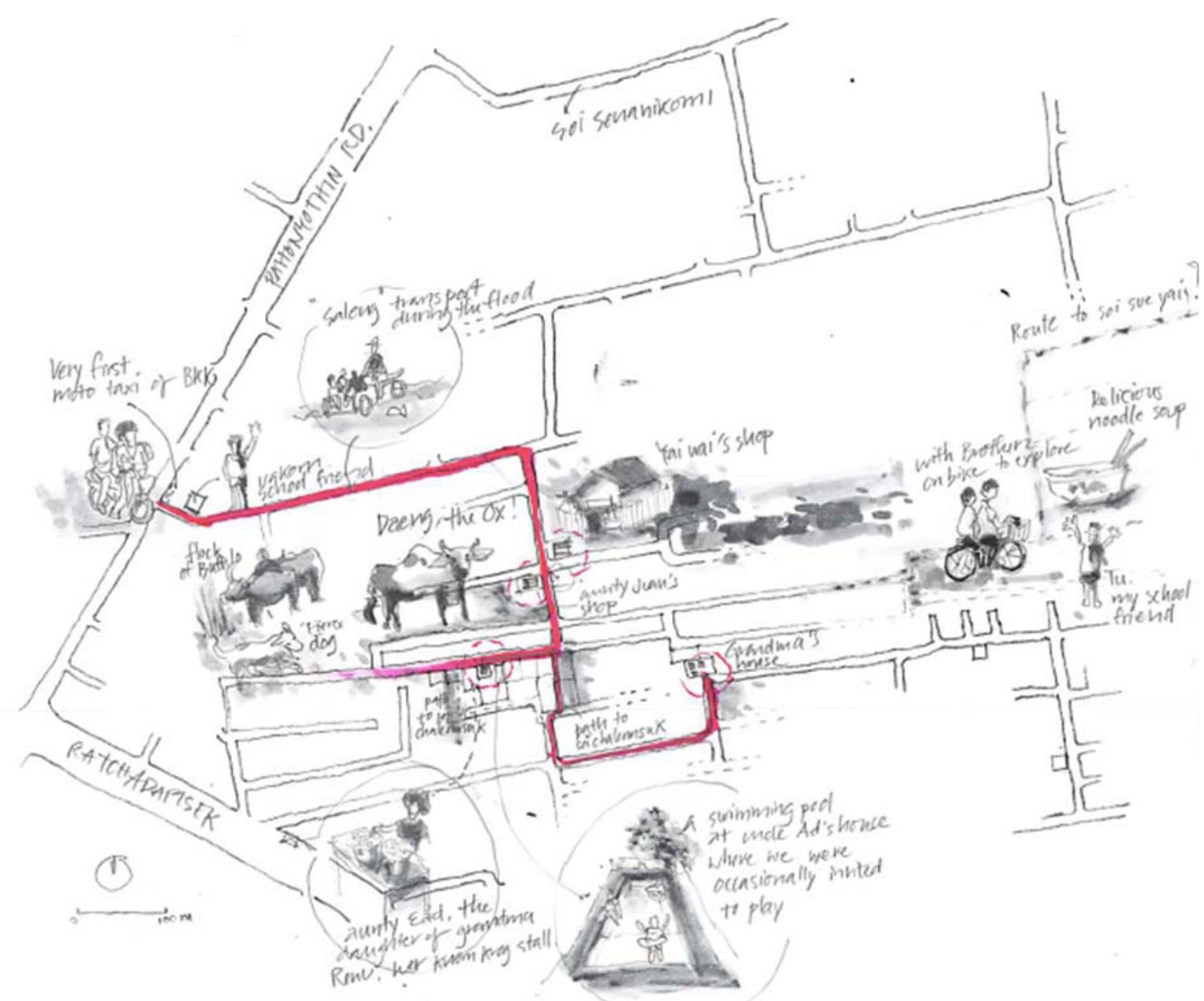

Fig. I. SKETCH - mapping narrative of my eldest brother

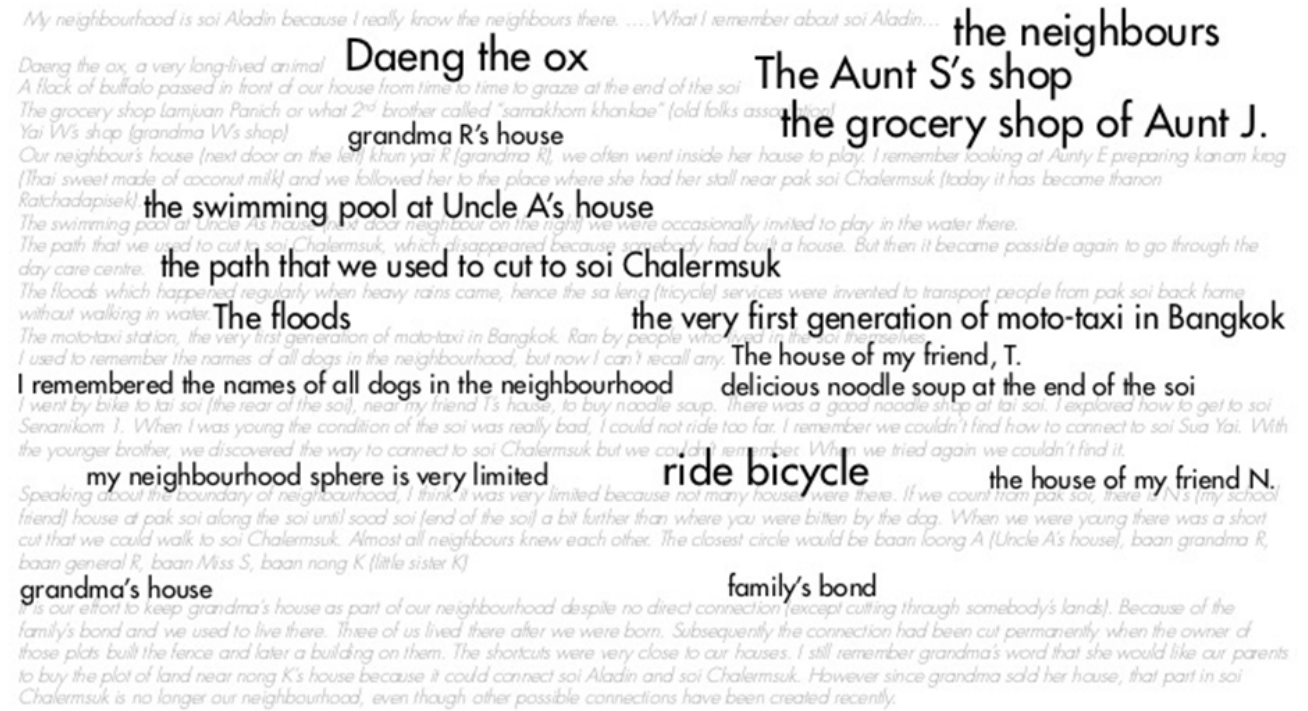

Fig. 2. SCRIPT - the narrative of my eldest brother with the highlights of important keywords (the bigger size of words represent the aspects that are common and found in other narratives). 


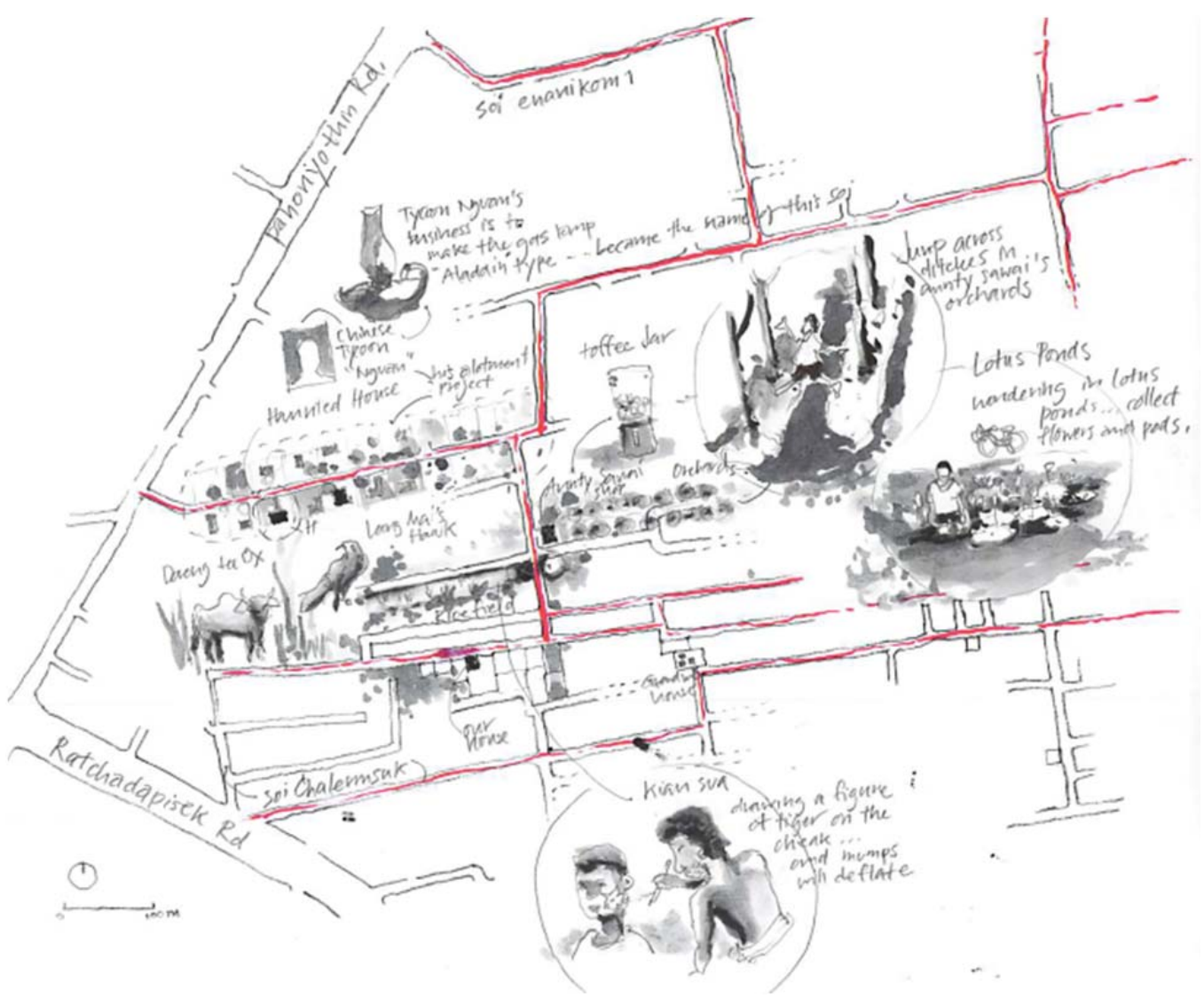

Fig. 3. SKETCH - mapping narrative of my elder brother

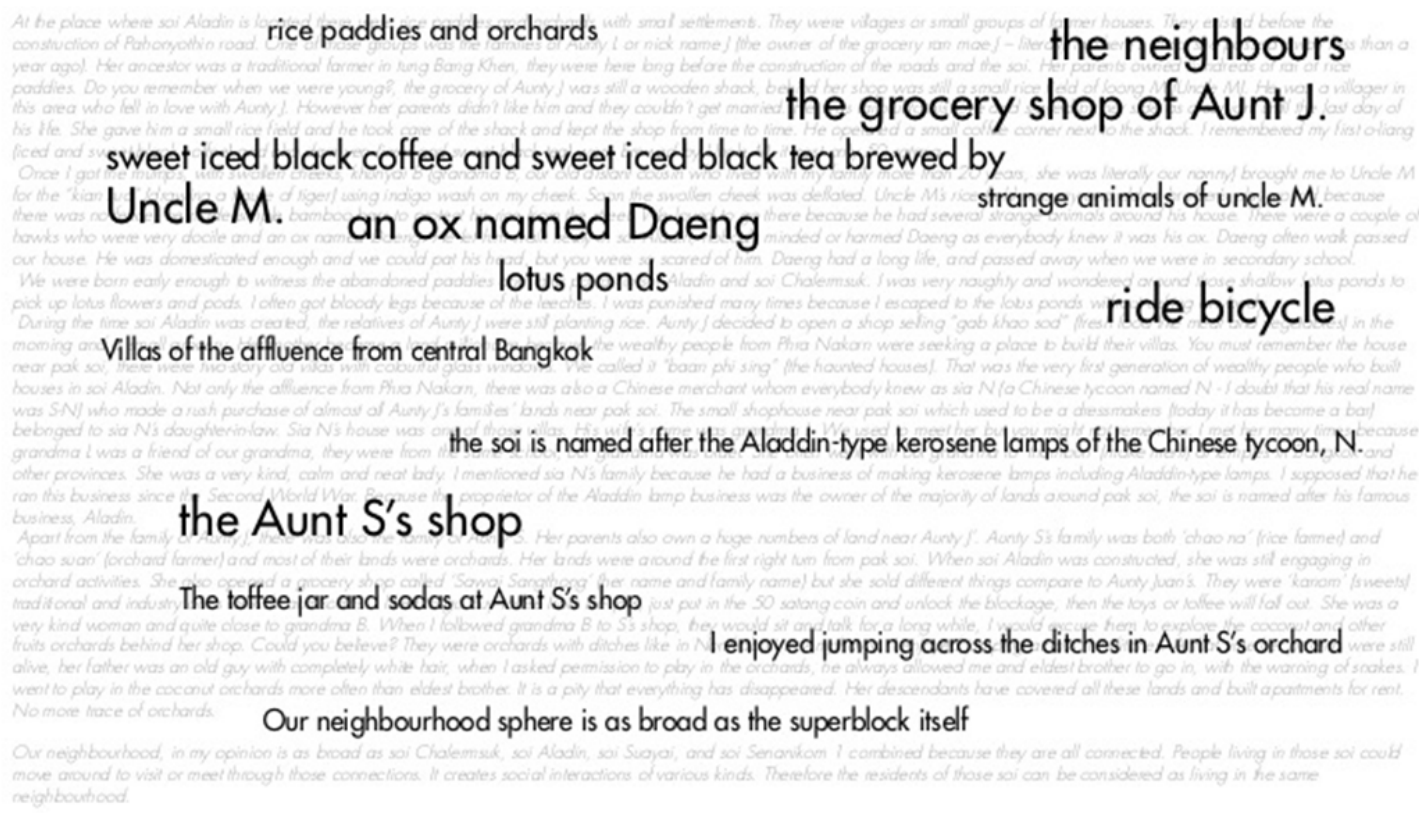

Fig 4. SCRIPT - the narrative of my elder brother with the highlights of important keywords (the bigger size of words represent the aspects that are common and found in other narratives). 


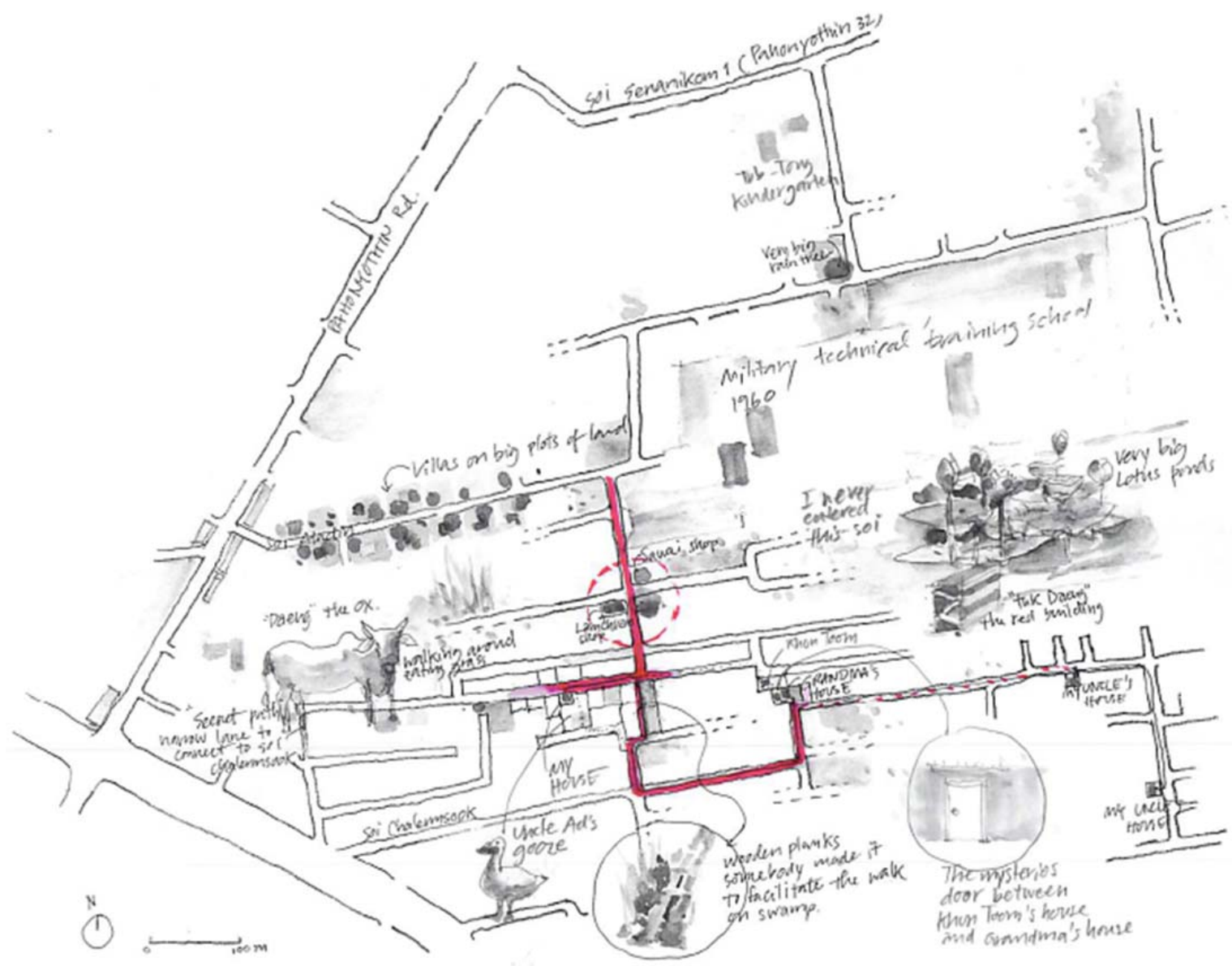

Fig. 5. SKETCH - my mapping narrative

\section{the walk to my grandmother's house}

The short cut through the empty plots of land
the secret path
a fierce goose
the mysterious door
Uncle M

the swimming pool at Uncle A's house

The floods

lotus ponds
Daeng the ox

\section{Aunt S's shop the grocery shop of Aunt J.}

the neighbours

\section{learning to ride bicycle}

the noise of cats fight

the boundary of my neighbourhood changed through time

Fig. 6. SCRIPT - my narrative with the highlights of important keywords (the bigger size of words represent the aspects that are common and found in other narratives). 


\section{Discussion}

Maps assist me in reading soi as the spine of our neighbourhood. The group of farmers' houses (Aunt J's and Aunt S's families) is the historical core of this neighbourhood. The narratives suggest that both of them are entitled to be credited as community founders. The North-South axis of soi Aladin, is the vertebral colon of the neighbourhood. This is the traditional and symbolic centre of space prior to the arrival of the soi itself. The semirural atmosphere around the junction $\mathrm{J}$ and $\mathrm{S}$ shops could resist the fierce urban development for several decades, but nothing lasts forever in Bangkok.

\section{I) Childhood - Neighbourhood}

Examining the personal attachment to the neighbourhood of soi Aladin, my brothers and I share strong attachment to the neighbourhood of our childhood. Many scholars who study the importance of childhood neighbourhood confirm that the street and path, and in my case the soi can "allow children to develop social competencies and to perform or enact their growing maturity through movements in and away from the home and their neighbourhood" (Christensen and O' Brien 2003). The bicycle routes that my brothers took allowed them to "explore their local place, and by accumulating such knowledge they gained confidence and could become the users of the city" (ibid).

Soi Aladin offered us an array of places to explore. We could acknowledge the rice paddies, the lotus ponds, and the orchards as sensed, perceived and experienced reality; they are stored within our bodies as tactile knowledge and a "community of senses" (Rasmussen and Smidt 2003). We were making meaning of our environment through our bodies and their movements. This neighbourhood provided "the emplaced knowledge in localities through a multitude of places, items and people" (ibid). All the aunties and uncles of the neighbourhood were the persons with whom we established social connections outside the family and school units. Animals, trees, ponds, and ditches were items that our bodies interacted with. Rasmussen and Smidt conclude the importance of childhood and neighbourhood nicely as:

The neighbourhood is perceived by the children through a number of concrete parts, where social, cultural and physical elements are inseparable and interwoven. The children are present in the neighbourhood, and they have the neighbourhood 'under their skin'.

(Rasmussen and Smidt, 2003).

\section{2) Neighbours}

Neighbourhood is all about neighbours and those face-to-face relationships. In those narratives several names were repeated. The closest ones are next door, close enough that we could penetrate into their private realm. The key people in the neighbourhood are important, in our narratives, Aunty J, Aunty S, and Uncle $M$ were the main characters and my brother and I interacted with them closely during our childhood.

As kids, my brothers and me addressed them in the Thai way using the terms we call our relatives (brother, sister, aunt, uncle, grandma etc.) Knowing neighbours and having an established relationship is the first step to feeling and creating the neighbourhood. However, not all neighbours had a good relationship. 


\section{3) Permeability}

Social space doesn't always need to be in the public space, as for soi Aladin, there is no other public space except the alley itself. The alley allows connections to happen. But with good social contact, the barrier between public alley and private realm can be permeated; like my brothers who could get into the rice field and orchards of the neighbours, or mysterious doors which allowed neighbours to cut across each other's property to connect across the soi. Was it possible only when we "knew" and "trusted" our neighbours? Was it possible only for the past generation; during the time when everybody knew everybody and when soi Aladin was still more of a village than a city? The shop of Aunty J was a shack without fence and completely open. There were big trees on both sides of the alley. There were benches for anybody to sit and buy drinks. This is the way of traditional life in a village. Her family houses were the centre of this settlement. This openness also invited customers and passer-by to come in and go out easily, or sit for a while.

The permeability is also applied to the path or short-cut on un-built land to cut across the two sois. People in the soi share that tactile practice. Especially when we live on the edge of a superblock, only locals know how to get out to the main street using these secret paths.

\section{4) Realm of Neighbourhood}

The narratives and mappings above demonstrate the impossibility in finding the cohesion of the exact neighbourhood sphere among the family members. Even people from the same family with the same background perceive the realm of their own neighbourhood completely different. This could support the frustration that scholars encounter while they agree upon a single definition of this construct. The sense of neighbourhood is definitely non-measurable; this slippery term is as complex as the city itself. In spatial terms, my siblings and I could not agree on one exact boundary of our neighbourhood but through their descriptions, our realm of neighbourhood is linear. It was constructed linearly and it stays linearly in our mind.

Unlike the moobanchadsan (housing estate or gated community) where the association of residents and common facilities are formed and active (Askew, 2002), soi Aladin doesn't have any of those. There were no official organisation and no common spaces, we only have the ordinary and mundane soi. The social structure of soi Aladin is invisible, but if I may point out the node of intensity of our social interaction, it would be at the corner shop of Aunty J. The history and the formation of this soi evolved around her and her family's lands. In this context, when an epicentre of a neighbourhood is formed around a unique person, that neighbourhood is socially quite vulnerable. Since Aunty J closed her shop and later passed away, the heart of this fragile community has vanished.

My eldest brother and I agreed on the deflation of our personal realm of neighbourhood. That tactical connection through somebody's land is also a weak connection. It confirms that in the case of soi Aladin, as many other soi in Bangkok, the private interest usually comes before the collective one. The path that has been collectively built and used for almost twenty years can be easily blocked and disconnected. Because of this simple gesture, the path that could ease the bond between families has been cut. 


\section{References}

Arkaraprasertkul, N. (2010), "Dynamic Soi: Neighbourhood and urban life" in Rian Thai: International Journal of Thai Studies, Vol. 3/2010, Bangkok: Institute of Thai Studies, Chulalongkorn University.

Askew, M. (2002), Bangkok: Place, Practice and Representation, London: Routledge.

Boontharm, D. (20I2), "Sketch and Script: made in/of Split", in Radovic D., Boontharm D., Kuma K., Grgic A., Split Case : Density Intensity, Resilience, Tokyo: Flick Studio and IKI, pP. 64-7I.

Boontharm, D. (20I3), "Bangkok Spontaneous Urbanism : Threat or Treat?" In the journal CONTESTI: Cities, Territories and Projects, Volume I/2012, Department of Urban and Regional Planning, University of Florence, pp.75-82.

Charmes, E. (2002), «La trame viaire périurbaine de Bangkok face aux théories dominantes de l'action collective», Autrepart, 21 : 17-26. DOI : 10.3917/autr.021.0017.

Christensen, P., O'Brien M., ed. (2003), "Children in the City, Introducing new perspectives" in Children in the city, Home neighbourhood and community, London: Routledge.

Jumsai, S. (1997), Naga: Cultural Origins in Siam and the West Pacific, Bangkok: Chalermnit Press and DD Books.

Lefebvre, H. (1974), La Production de l'espace, Paris: Anthropos.

Nims, C. (1963) City Planning in Thailand, Bangkok: City Planning Office, Ministry of the Interior.

Pichard-Bertaux, L., (20II) « Le tout et son contraire : une lecture de Bangkok», Moussons [Online], Online since 19 November 2012, accessed on 20 June 2016. URL: http://moussons.revues.org/757.

Polakit K., Boontharm D. (2008), "Mobile vendors: persistence of local culture in the changing global economy of Bangkok" in Local Sustainable Development in Global World, HEBERIE L., OPP S., (eds.), Pp. 175-202, Ashgate.

Radović, D. (20I4), Subjectivities in Investigations of the Urban: the Scream, the Mirror, the Shadow, Tokyo: flick Studio.

Radović, D. (2016), "Measuring the non-measurable: On mapping subjectivities in urban research", in City, Culture and Society, 7(I), pp. 17-24, Elsevier.

Rasmussen, K., Smidt, S. (2003), "Children in the neighbourhood: the neighbourhood in the children" in Christensen P., and O'Brien M., (ed.), Children in the city, Home neighbourhood and community, London: Routledge.

Sintusingha S. (2006), Sustainability and urban sprawl: Alternative scenarios for a Bangkok superblock, Urban Design International. 


\title{
Urban morphology and the post-industrial city: commercial space in Manchester
}

\author{
Eamonn Canniffe \\ Manchester School of Architecture, UK \\ e.canniffe@mmu.ac.uk
}

\begin{abstract}
The contemporary post-industrial city has developed within a system where every square metre of its area might be assessed for its economic productivity and market value. Retail space, leisure space, even public open space, as well as housing and work environments are quantifiable and comparable in financial terms as the ultimate test of their value. This conception of urban space as units of capital has its origins in the industrial development of centres such as Manchester where, largely unencumbered by earlier urban patterns, the idea of the modern city could thrive. As a 'shock city' Manchester, during the peak of its industrial growth in the early nineteenth century was an object of fascination and repulsion to the visitors it attracted. Opinion and rhetoric dominated social, economic and political debate, but dispassionate spatial analysis was rare. In the view of contemporary authors the town had few significant public spaces, instead being largely comprised of the vast industrial structures that crowded around the roads and canals. The mills were assessed for legal and insurance purposes, however, at a time of rabid competition and the prevalence of industrial accidents. The surveys that have survived provide the first opportunities to assess these examples of new urban space. The image results of a settlement composed of a single type, the mill or warehouse. Ancillary structures, most especially the workers' housing did not merit recording. In these products of spatial calculation the Manchester mill can be seen to set the pattern both for the productive spaces of industry and the spatial framework of the contemporary city, where the public space is one of consumption rather than community. The supervised and privatised public space of the contemporary city finds its genius loci in the industrial typology of its commercial origins.
\end{abstract}

Keywords: laissez faire; Manchester; morphology; regeneration.

\section{To cite this article:}

Canniffee, E. (2016). Urban morphology and the post-industrial city: commercial space in Manchester. The Journal of Public Space, I(I), 53-62, DOI: I0.5204/jps.v liI.IO

This article has been peer-reviewed and accepted for publication in The Journal of Public Space. Please see the Editorial Policies under the 'About' section of the journal website for further information.

\section{cc) (1) \$}

This work is licensed under a Creative Commons Attribution - Non Commercial 4.0 International License. https://creativecommons.org/licenses/by-nc/4.0/ 


\section{'the Utopia of Bentham' \\ (Leon Faucher Manchester in 1844)}

The history of a city, even merely of the architecture of a city, can never present a definitive picture. When that city is itself in a self-conscious state of transition, with the apparent discarding of many traces of its own history and heritage as so much dross, one can seemingly be engaged on a particularly futile task to document that transition. Yet the recording and the assessing of such a recent phase as the two decades since 15 June 1996 when the city of Manchester suffered substantial physical damage to its commercial core seems worthwhile because the effects of the I.R.A. bomb on that date and the strategies (or lack of them) adopted in its aftermath were profound. The change in the visual appearance of the city, coinciding with transformations in urban policy which changed other northern English cities as well, represents the greatest rupture in the continuity of Manchester's urban development since the Second World War. (Rogers et al. 1999). On the near side of such a breach, with all context affected, it is often difficult to recall what it was like on the far side, in an industrial past the circumstances of which have clearly been abandoned forever. But we need to know why we are where we are to be confident that we know where we are going.

It was a salutary experience to observe the relatively low status of the built environment in Manchester's official repository of record. In 20I4, in the newly reopened Central Library, the Local History section's holdings on architecture in Manchester account for considerably less shelf space than the ghost-written biographies of local television celebrities, even only those associated with one particular long-running soap opera. The plain truth is that Manchester, in general, has little regard for its architecture and is only begrudgingly concerned with it. The literature on the subject of Manchester's architecture is sparse and, despite some academic interest, reflects a general lack of concern with the built environment (Parkinson-Bailey, 2000; Hartwell 200I). This is something of a paradox since the city is extremely aware of its image, and its architectural character, both historically and contemporaneously, is how the city represents itself to outsiders. It is the contention of this paper that this disinterest shown internally within the city, outside of the professions in architecture and the built environment, is the result of the history of its industrial development and the ruthless economic basis of its recent regeneration. The purpose of this paper is to explore some examples of how Manchester looks and is proposed to look, in its new buildings and public spaces, and how the promotion of the regenerated city seems at odds to the experience of residents and visitors alike. As an academic working in the city I am often asked by visiting colleagues to account for the discrepancy between the generally laudatory literature available and the somewhat disappointing reality that literature claims to represent (RIBA \& Manchester City Council 2004). It therefore seems important to provide an alternative account, partial, personal and maybe even provocative, which could help illuminate the puzzling reality of the city. The pattern that the early phase of industrialisation established, however, was one where production and its requirements took a clear lead over any aspect of life that was noncommercial, be that spiritual, cultural or even defined by concerns over social welfare. The significance of Manchester is less its endlessly rehearsed pre-eminence in industrialisation but rather the typicality of its experience and its rapid imitation by other towns and cities to which its global trade connected it. Despite its provincial location its 
rivals were, self-consciously, not the other British industrial centres but the cities of the states whose symbols adorned the painted ceiling of the Great Hall of Alfred Waterhouse's Manchester Town Hall completed in 1877. The scale of Manchester might be outstripped by other industrial centres in the later nineteenth century, but once she had her own global shipping route with the opening of the Manchester Ship Canal ( 1894) a new phase of expansion presented itself which it took the outbreak of the Great War to arrest. Other cities might prefer to see their own significance as resting on stronger cultural aspirations but Manchester's confidence rested on the firm foundation of its global commercial origins, and that attitude prevails to the present day.

The naked industrial environment of the growing town had been observed during Karl Friedrich Schinkel's English journey in 1826, which brought him into direct contact with the technological progress of Britain in many sites across the country. (Bindman \& Riemann, 1993) However, his small sketch of the mills of Ancoats, with crude brick mills stacked up like so many boxes by the side of the Ashton Canal brought an abrupt urban scene to the mind and eye of an architect whose oeuvre grew out of a theatrical attitude to the beautification of the Prussian capital of Berlin in which he was engaged. In the north west of England he was confronted with a shocking urban environment that owed nothing to images of Greece or Rome, or even the medieval period which was deemed quintessentially northern European in spirit. Here was a city in all but name that owed nothing from the real or imagined past but everything to the economic imperatives of the nineteenth century present. The finest architectural mind of his generation was at once fascinated and repelled, repelled enough to note that 'made from red brick for the bare necessity only, make a rather gloomy impression' but fascinated enough to take back to Berlin the germ of an idea which would be synthesised into the design of the Bauakademie (1832-36) and the customs warehouse, Packhof, (1829-3I) in Berlin. In Schinkel's Ancoats sketch, against the towering mills and the even taller factory chimneys and dwarfed by these brute examples of mechanical production, were the hovels in which the workers existed. Schinkel's pen, with a few strokes, suggested the hazardous nature of the dwellings, poorly built, lacking in weather tightness, barely lean-tos against the great sheer walls of the factories, the symbolic form of the industrial town.

An even more dehumanised representation exists in a manuscript survey (presumably for legal or insurance purposes) for the period circa 1822 'Plans of all the Spinning Factories in the Township of Manchester' which survives in the collection of the John Rylands Library in Manchester acts as an early study in industrial morphology, with numerous detailed examples (Walter, 1976). Take for example, the land owned by Roger Aytoun Esq. and occupied by Mr. Thackery in the neck of land between a bend of the River Medlock. Here a disparate group of one, two, three and four storey buildings illustrate the incremental nature of early industrial development. The presence on the plan of a 'Factory burnt down' adjoining the tallest structure indicates the ever present hazards of industrial development.

In contrast, the site occupied by Richard Rothwell positioned parallel to a canal and a 'New Street' was a single rectangular block the seven storeys of which, plus loft were proof of the rational possibilities of efficient design. What the plates in the manuscript fail to record is the presence of the factory workers, who simply do not figure, apart from the occasional references to a dwelling house, presumably occupied by a manager or overseer. At this date the factory owners were already living off-site, and the workers 
would have been living where they could, leaving a situation of unplanned zoning between wealthy districts, industrial areas and working class districts which Engels would document in subsequent decades (Engels (1844), 1987).

The urban morphology of the industrial environment was, of course, dependent on two distinct pressures, which still hold true today, external forces and internal logic. Externally the position of new structures within the town was a product of the availability of land and sources of power, generally watercourses for water and steam power in the initial phases of development. Navigable rivers and canals also provided an efficient means of transport. The internal logic was a product of, in the case of mills, the number of looms which could be powered from the energy source and the optimisation with which they could be serviced by their operators. The constructional limitations of cast iron and brick then came into play in what until the Factory Act of 1833, and other early pieces of legislation, was essentially unregulated development.

Notwithstanding the significance of internal industrial processes to the morphological development of Manchester the situations in adjoining areas within the city grew in quite distinct ways as a result of historical origins and circumstantial developments. In a survey carried out by English Heritage in 200I for example, under the subtitles 'An Outgrowth of Accident' and 'Built According to a Plan' the differing situations of Shudehill and the Northern Quarter areas were contrasted. In discussing the historical development of these districts (the latter only rebranded as such by Manchester City Council in 1993) the former adjacent to the medieval centre clearly continues to display the irregular street patterns and narrow plots despite industrial development having occurred there as long ago as 250 years. In the Northern Quarter in contrast there is regular grid planning in the area around Stevenson Square, laid out by the new land owner William Stevenson in 1780 in preparation for the northern wards expansion of the town. That street network has remained largely intact with most blocks occupied by nineteenth and early twentieth century warehouses and manufacturing buildings with grand frontages to major thoroughfares. This building stock would be readily convertible to use by design companies and residential development from the late 1990s to the late 2000s and indeed provide much of the architectural ambience of the fashionable NQ4 area. Shudehill's looser patchwork of smaller historical remnants, empty sites and anonymous contemporary residential developments surround significant pieces of transport infrastructure such as the Shudehill Interchange (lan Simpson / Jefferson Sheard, 2006). In microcosm the disparity between the survival of elements of the urban fabric in these two neighbouring areas betray much of the broader situation of Manchester as a whole, since curiously the area with the irregular plan and topography has seen more demolition for development than the one with more obviously commercial building plots.

What are the morphological constraints which might condition the present urbanity of development in Manchester and how might they be compared to the historic situation? The initial unifying factor might be deemed to be that the building obey only an internal logic of productive or lucrative space. The external factor of consistent height, which might have been subject to some control in the 1970s and 1980s is now seldom invoked as a cause to determine the exterior, indeed Manchester has no tall building policy. The maximising of building form positioned on the plot represents a return to the spatial model which was employed during the period of the 'shock city'. In that era the limits of engineering technology might modify the risk produced by creating more space to 
support more machinery but the speculative impulse of current city development provides few such rational limits. If you can borrow the money the building will be built, and this can be seen in recent developments such as Spinningfields and First Street and proposed developments such as St. John's Quarter and St. Michael's. Whether broader economic circumstances will then allow it to be let depends on the proliferation of that same mentality on neighbouring plots. This constraint is a phenomenon which is common to both the office and residential sectors in terms of the current market.

However the issue of external appearance is more clearly the subject of differences between the present city and the developing town. The typology of cast-iron structure and brick skins with regular openings, creating a uniform if monstrous townscape, has given way to an almost heedless variety of façade treatments. The notion of authenticity in architecture, perhaps always dubious, has been abandoned to an apparently random form of pattern making using façade systems which often bear no relation to internal use and everything to abstract external appearance. The freeing up of façade conventions which indicated positions of floor levels, which represented lines of structure or communicated anything other than wrapping, led to the ubiquity of the barcode façade and the frantic expression of individuality in building, appears to have become a key component in urban design. Double and triple skins of sealed units serve to divorce the occupiers from their contexts, especially in office environments. Conversely in the residential sector the ubiquitous motif is the balcony providing some space for external individual expression, but often because of their limited size reduced to little more than storage for the cramped apartments. Their existence, while providing some mark of individual inhabitation externally serves to emphasise the tentative nature of city centre dwellings represented by statement balcony furniture, the overcrowded storage area, or the abandoned balcony of the 'buy to leave' apartment i.e. unoccupied investment property bought by foreign buyers. The morphology of these small spaces reveals much about the nature of occupation in the overheated residential market in central Manchester.

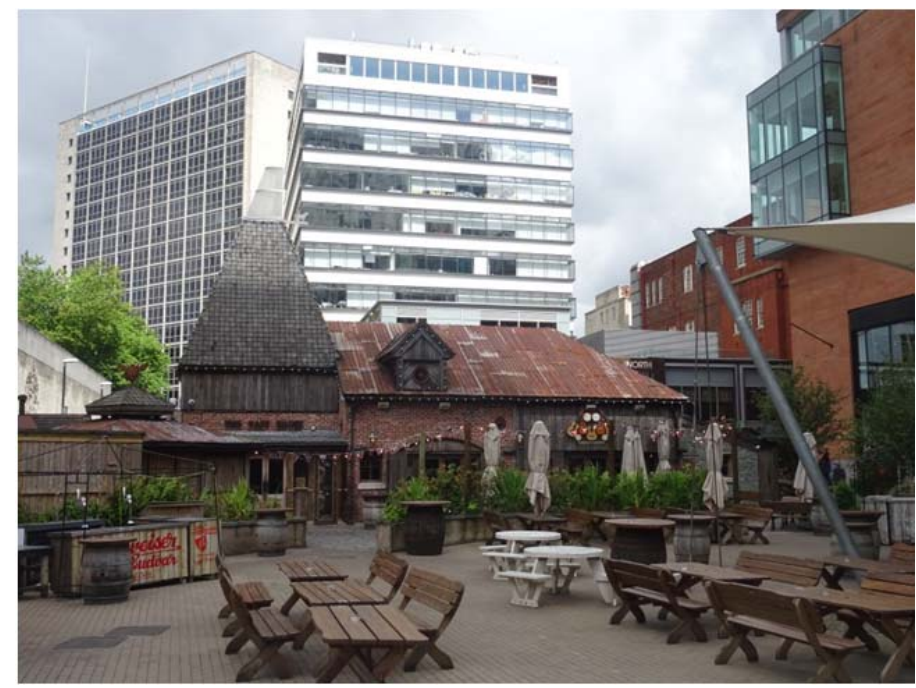

Fig. I. The Oast House, Spinningfields, Manchester 20II. Photo: Eamonn Canniffe 


\section{'the Spirit of materialism and indifference to beauty' (Rowland Nicholas City of Manchester Plan 1945)}

There is perhaps a contradiction in the drift of morphology in contemporary Manchester, although both tendencies are rooted in the same commercial origins but differentiated in the scale of operation. Clearly the bundling of adjacent plots to create ever larger single blocks operates as a process of consolidation and amplification at the building scale. At the same time, and apparently in the opposite direction of travel, the hollowing out of blocks to create privately owned public spaces would seem to be eroding the morphology of the city and causing a highly confused pattern to emerge.

Were Schinkel to arrive today in Manchester, what would be seen in Manchester that could hold his attention? Yes the mills of Ancoats, preserved now as monuments to vanished enterprise, Schinkel's own part in the evaluation and appreciation of the industrial structures being a component in the heritage impact narrative. He might draw instead a low and ramshackle hovel, sheltering beneath anonymous office buildings with no sense of connection but instead a strange co-dependency of purpose. The industrial workers have been replaced by office workers who live in the suburbs but require diversion and distraction which can be provided in a fake agricultural barn in an environment where no building is older than 1957. Schinkel's imagined sketch would depict The Oast House (Figure I) a piece of fictional heritage created in 20 I I on an empty site in a new business district in the city, Spinningfields. It is curious to speculate, whether this represents a falsification of urban history or its continuity in another guise. The mill owners of the early industrial period often used to dole out wages in public houses, which they also often owned, ensuring the dependence of the workforce whose wages would return to the paymaster. Today the urban economy is perhaps more complex but developments like Spinningfields make up the shortfall in return on investment by providing more and more places for drinking in what was planned before the economic crisis of 2008 as a work environment for the financial sector. (Canniffe 20I4).

Having endured a very deep recession in the period since the new business district's buildings began to be completed; the success of the development must be viewed as questionable. The residential component, the substantial wall of the Left Bank apartments, contains an unanticipated mixture of permanent residents, tenants of buy-to-let landlords, students and apartments let only at weekends for the growing stag and hen party trade. Some remain unoccupied having been bought as investments that, depending on the point in the economic cycle at which they were purchased, may or may not provide a good return. Several buildings were designed with the financial and banking sector in mind, which was particularly badly affected during the economic crisis. However, in 2014, with a limited amount of economic confidence returning, plans were announced for further construction at Spinningfields, with buildings planned for the empty site adjacent to the Civil Justice Centre, and the announcement that Quay House, a 1970s block adjacent to The Opera House on Quay Street was to be replaced by a new office building by lan Simpson. Unexpected assurances were made about the maintenance of the private open space used temporarily for film showings, the viewing of televised summer sporting events and Christmas ice-skating. The appropriation of seasonal leisure provision by corporate providers, their temporary adoption and factoring into future plans is indicative of a fair 
degree of fragility in economic prospects, especially following the unexpected result of the Brexit referendum in June 2016.

Of course the period of the 'shock city' and the recent past were both times when internal migration played a strong part. The factories of the early industrial revolution were essentially constructed independently from existing populations that grew dramatically to work in them. The living accommodation of the workers did not concern the manufacturers, only their convenient location for labourers to work the machines. The economically defined industrial structure would therefore be accompanied by spontaneous settlements (to adopt today's terminology) which would be unplanned and often remain unrecorded. Engels's description in The Condition of the Working Class in England remains a valuable and critical account of conditions though its tone is somewhat unsympathetic to the unfortunate inhabitants. While living conditions have improved beyond compare, the morphological changes in the recent history of Manchester bear some similarity in that they represent a formless accumulation of dwellings which test the limits of acceptability for their inhabitants, either in the meanness of their interior arrangements, or the sheer size and proximity of buildings squeezed on available construction sites, evident in three other ongoing projects in the city.

One might wearily predict that there will be more of this type of development to come in the extension of Allied London's land holdings across Quay Street on the former Granada Studios site. The St. John's Quarter in central Manchester is perhaps indicative of the drift of urban design practice in the city after nearly two decades of market-led urbanism. The departure of Granada Studios to MediaCity:UK in 2013 made thirteen acres of land available between Castlefield and Spinningfields. (It is a paradoxical situation that when many other regional cities are pinning their economic hopes on the attraction of media companies, the City of Manchester has lost the presence and activity of both the BBC and one of the largest independent companies to neighbouring boroughs). The developers Allied London purchased the site and announced that the newly designated St. John's Quarter would be a residential led development complementing their existing office development across Quay Street in Spinningfields.

In early 2014 the developers unveiled a series of masterplan proposals for the site by ten design practices, and also hosted a community consultation event inviting ' stakeholders' to contribute ideas. Having been an effectively closed site during Granada TV's tenure since the 1950s the local residential community are essential to engage in the process, those in the existing apartments who might be expected to want more green open space and other social amenities, and local businesses concerned about the impact of new development. They are currently presented with a very dense residential project based around pedestrian alleys, and a series of glass office towers lining the frontage to the River Irwell. Cultural activities are intended to be housed in a new multi-functional space called The Factory won in competition by OMA in 2015 and partly funded to the tune of $£ 78$ million by central government in a clear attempt to pump the prime commercial development of this district.

At First Street an over-dense development of mediocre quality can be traced to its origins, where a campus style office building was placed in the middle of cleared brownfield site in early 1990s, only to be radically modified and expanded and used as the determining factor for the grim new buildings and mean privately owned public space which now surround it. 


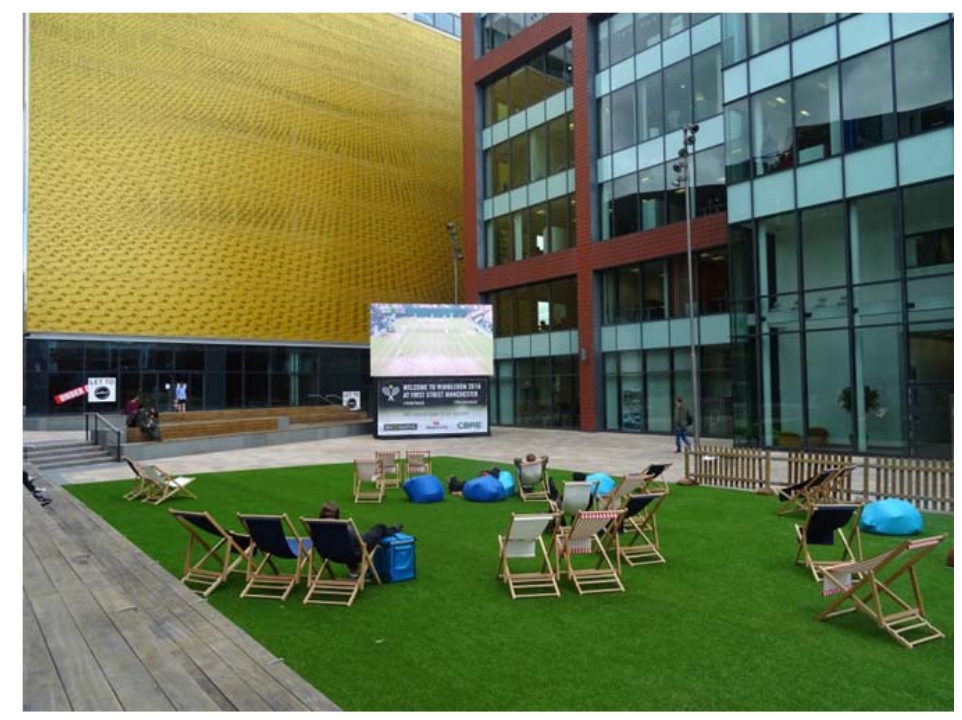

Fig. 2. Tony Wilson Place, First Street, Manchester. Photo: Eamonn Canniffe

The space itself, called with no hint of irony Tony Wilson Place, after the charismatic founder of the Factory Records label is under great pressure to earn its keep through monetisation via pop-up bars and temporary events, the activities which pass for the successful public realm in the characterless post-industrial city (Figure 2).

Spinningfields, St. John's and First Street largely effect former industrial sites, but in the thirst for development the civic core itself, is now threatened by over development. This tendency is exemplified by the proposal revealed in July 2016 for the redevelopment of a large block, called St. Michael's, mainly occupied by the redundant Bootle Street Police Station and the Manchester Reform Synagogue. What is at present a largely continuous perimeter block in an elongated rectangular form is set to have its form inverted by the introduction of a diagonal route between two black clad towers (designed by Make Architects) of $3 \mathrm{I}$ and $2 \mathrm{I}$ storeys respectively placed in a staggered arrangement on the site. The groundscape is advertised as new public space for the city, although it is effectively a partially covered commercial mall which negotiates a significant change of level, called in the enthusiastic local press Manchester's Spanish Steps. The enthusiasm is at least in part due to the leaders of the project being former Manchester United footballers Gary Neville and Ryan Giggs, this project one of a series of development projects which have brought the influence of the city's footballing wealth to bear on its urban form. In the long term this project poses a threat to the heritage amenity of the civic core, both because of the size of the two towers, but also the erosion of the street network's primary importance in this area of the city.

In the proposal, the north eastern corner of the block is left open to create a commercially active plaza intended to connect to Albert Square and Manchester Town Hall. However this new plaza is itself bounded on its southern edge by the shorter of the two towers, and therefore might be expected to be in shadow for much of the day and most of the year. A low pavilion attempts to provide some remnant of definition to the northern side of the plaza but appears to be only needed to mask the port cohere entrance to the larger tower. Given the need for drop off there and the inevitable delays, the street, Jackson's Row, which currently has a small amount of open space associated 
with the Synagogue, is likely to be reduced to a service zone, dominated as I will be by the lower storeys of the taller tower. The diagonal route, semi enclosed at its lower end before it connects to the plaza, is clearly intended to create a slice of mid-block townscape but will be essentially retail in character at the cost of severely compromising the life of the existing streets and their buildings, especially the historic Sir Ralph Abercromby pub which dates back to the industrial era and is currently proposed for demolition.

The general topographic situation of Manchester has offered little opportunity for the creation of dramatic urban ensembles and indeed the study of its history might suggest that such aesthetic sensibilities are alien to the genius loci. The city does contain notable individual works of architecture, but often placed in unsympathetic settings which diminished their apparent impact. However it is not beyond the collective imagination of the city to develop it with more of a sense of ambition and concern for its appearance. The city would have to adopt a physical plan which could be implemented over several decades. Such long term thinking has not been pursued since 1945, and the failure to fulfil that vision set the pattern for subsequent decades. It is, of course, an irony of history that the laissez-faire attitudes synonymous with Manchester liberalism in the nineteenth century are exactly at the root of the haphazard decisions regarding city planning which currently hold sway in Manchester. One can envisage three steps that could be undertaken to improve matters. One would be encouraging more transparency in the way decisions are made. The second would be adherence to some kind of standards for building height and volumetric expression which could impose a discipline on the more wayward proposals. And lastly an urban code could be developed over a five year period covering the whole of the city centre and treating it in a consistent manner derived from a close study of its morphology.

There is doubt in my voice mainly because what we see in Manchester's recent urban regeneration is so difficult to admire, presented through the marketing of the city as a great triumph over adversity, but in the experience of many visitors a completely generic experience providing a good range of international brands but increasingly few unique elements that might define urban quality. Quantity of buildings, of retail experiences and of anonymous spaces between them is the characteristics of the city which are being created.

\section{References}

Author unknown. c. (1822). Plans of all the spinning factories within the township of Manchester. Also some in which power looms are working, and a few occupied for other purposes, unpublished manuscript. John Rylands Library, Manchester.

Bindman, D.; Riemann, G. (1993). The English Journey: Journal of a Visit to France and Britain in 1826. New Haven and London: Yale University Press.

Canniffe, E. (20l4). Publoid space in the Microcosmopolis: two new business districts in Manchester and Salford, in M. Lansberger, M. Caja, M. Bovati, G. Floridi (Eds.). Cities in transformation. Padova: II Poligrafo, 199-206.

Engels, F. (1844) 1987. The condition of the working class in England. London: Penguin. 
Urban morphology and the post-industrial city: commercial space in Manchester

English Heritage. (200I). The Shudehill and Northern quarter area of Manchester 'an outgrowth of accident' and 'built according to a plan', English Heritage Architectural Investigation Reports and Papers B/066/200I.

Hartwell, C. (200I). Manchester: Pevsner architectural guides. New Haven, London: Yale University Press.

Parkinson-Bailey, J. (2000). Manchester: an architectural history. Manchester: Manchester University Press.

RIBA and Manchester City Council (2004). Manchester: shaping the city. London: RIBA Publishing. Rogers, R., et al. (1999). Towards an urban renaissance: final report of the urban task force. London: $\mathrm{E}$. \& F.N. Spon.

Walter, E. V. (1976). New light on dark satanic mills, Communication, Vol. 22-3. 


\title{
Temporary Public Spaces: A Technological Paradigm
}

\author{
Philip Crowther \\ Queensland University of Technology, Brisbane, Australia \\ Creative Industries Faculty, School of Design \\ p.crowther@qut.edu.au
}

\begin{abstract}
Contemporary cities no longer offer the same types of permanent environments that we planned for in the latter part of the twentieth century. Our public spaces are increasingly temporary, transient, and ephemeral. The theories, principles and tactics with which we designed these spaces in the past are no longer appropriate. We need a new theory for understanding the creation, use, and reuse of temporary public space. More than a theory, we need new architectural tactics or strategies that can be reliably employed to create successful temporary public spaces.

This paper will present ongoing research that starts that process through critical review and technical analysis of existing and historic temporary public spaces. Through the analysis of a number of public spaces, that were either designed for temporary use or became temporary through changing social conditions, this research identifies the tactics and heuristics used in such projects. These tactics and heuristics are then analysed to extract some broader principles for the design of temporary public space. The theories of time related building layers, a model of environmental sustainability, and the recycling of social meaning, are all explored. The paper will go on to identify a number of key questions that need to be explored and addressed by a theory for such developments: How can we retain social meaning in the fabric of the city and its public spaces while we disassemble it and recycle it into new purposes? What role will preservation have in the rapidly changing future; will exemplary temporary spaces be preserved and thereby become no longer temporary? Does the environmental advantage of recycling materials, components and spaces outweigh the removal or social loss of temporary public space? This research starts to identify the knowledge gaps and proposes a number of strategies for making public space in the age of temporary, recyclable, and repurposing of our urban infrastructure; a way of creating lighter, cheaper, quicker, and temporary interventions.
\end{abstract}

Keywords: assembly; disassembly; design; temporary; public space.

\section{To cite this article:}

Crowther, P. (2016). Temporary Public Spaces: A Technological Paradigm. The Journal of Public Space, I(I), 63-74, DOI: I0.5204/jps.vlil.I I

This article has been peer-reviewed and accepted for publication in The Journal of Public Space. Please see the Editorial Policies under the 'About' section of the journal website for further information.

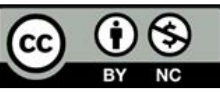

This work is licensed under a Creative Commons Attribution - Non Commercial 4.0 International License. https://creativecommons.org/licenses/by-nc/4.0/ 


\section{Introduction}

While much has been written about the changing nature of our cities and the increasing range of temporary public spaces within them, such writings are largely about the philosophy and planning policy of temporary public spaces (Bishop and Williams, 2012); little has been written about the architectural practicalities of making such spaces. 'Technical manoeuvres have not yet put together a consistent theory as a basis for the new paradigm of public space. The combination of urban tactics and the fear of climate meltdown may spawn a freak, only understood by ecologists and technocrats, which could reduce the design of public space to the basic issues of sustainability, viability, efficiency and durability' (Fernandez Per and Mozas, 2012: 19). With this is mind, this paper seeks to start the process of establishing the architectural needs of such temporary public space. It presents a general survey (through a number of case studies) of temporary public spaces and the architectural technologies that they utilise, to establish a theoretical understanding of the field and practical guidance for the creation of future temporary public space. The paper establishes a number of broad architectural and technological principles for designing temporary public space:

- a model of sustainment; environmental, economic, social

- the recycling of social meaning and sense of place through reused materials - 'spolia'

- time related building layers; the four dimensional city

The objective of this paper is to provide a theoretical analysis of the architectural strategies and technologies used in the creation of temporary public spaces, as illustrated in a number of case studies. This analysis then exposes the common approaches, solutions, and strategies implemented in the successful creation of public spaces. The paper presents a technological paradigm of temporary public space; a model or pattern of solution that has a belief system and a puzzle-solution (Dosi, 1982). This belief system incorporates an understanding of the psycho-social impact of public spaces when they change, and how the disassembly and deconstruction of public spaces can affect the meaning they embody (Denhart, 2009).

\section{The Temporary Nature of Cities}

In the final few decades of the twentieth century, and the first few years of the twenty first, it has become increasingly clear that cities and urban settlements are no longer designed and constructed with the same sense of permanence that is so evident in earlier constructed environments. Our buildings live shorter lives, being demolished after just a few decades to make way for bigger and better developments. The commercial realities of a capitalist society drive such private development at an ever increasing pace. In the midst of this private sector frenzy are the public spaces that we once took as permanent, but which now are likewise responding to a quickening pace of development. Although this phenomenon of shorter lived temporary buildings is more evident now than ever, it is not unique to our contemporary cities.

'Temporary use is not a new social phenomenon: temporary ventures have always been a feature of cities that were conceived and built for the long-term' (Senatsverwaltung für Stadtentwicklung and Denton, 2007: 21). Even whole cities that we tend to think of as permanent or long-lived environments were not always so. Indeed 'history abounds with examples of mighty cities that turned out to be temporary' (Bishop and Williams, 2012: 
12). Even when significant portions of cities survived for decades or centuries, other parts were less long-lived. It is perhaps because those parts have long gone that we tend to focus on the surviving structures.

What appears to be happening in our contemporary cities is however a much more widespread activity of temporary use and short lived constructions. 'Buildings are designed to last 70 to 100 years, yet today buildings with an age of only 15 years are demolished to give way to new construction' (Durmisevic and Yeang, 2009: 134). While buildings have a shorter life expectancy that they did a hundred years ago, the materials and components will last much longer. The city is no longer fixed in time; it is now a four dimensional city (Bishop and Williams, 2012:19). We are experiencing a significant paradigm shift in how our cities are designed and used (Mclntyre, 2009); what Bauman (2000) refers to as 'liquid modernity'.

'The way in which 'public space' is viewed is also changing from a traditional focus on formal squares, parks and pavements to a broader conception that recognises the value of less formal 'left-over' spaces and the everyday uses that occur there' (Bishop and Williams, 2012: 87). Public space is no longer only provided by governments for purposes of social control, but is now about the strategies and tactics used by those who occupy it. Public space is now characterised by freedom of action rather than stringently designed forms; a freedom that recognises the importance of social sustainability, indeterminism, and the importance of the temporary. Cities must now concern themselves with public spaces that operate on ever shortening time scales that accommodate the casual impromptu situation (Fernandez Per and Mozas, 20I2: II-I7). This shift in attitude to the casual, temporary, and publicly determined, evident in numerous governmental changes to legislation (Gerend, 2007), represents a new belief system in the technological paradigm of public space.

\section{Reuse of Construction Materials}

'Nothing is lost, nothing is created, everything is transformed.'

Antoine Lavoisier (French chemist), 1793.

The reuse of building materials and components has always been an important construction strategy. Since ancient times we have salvaged materials from demolished or temporary buildings for use in new construction. 'Buildings have long been mined and harvested for their materials' (Easterling, 2010: 266). There has however been a marked change in the reasoning behind the re-use of construction materials and components over the past two thousand years. Such disassembly and reassembly has been variously motivated by simple economic reason or material shortage, respect for craftsmanship, aesthetic taste, theories of bricolage, desire to express cultural domination or links to past glories, tradition, a desire to restage the past, connection to a sense of place, and most recently by ecological awareness (Meier, 20l I).

Unfortunately with the increasing pace of development and the shortening life span of buildings, we are seeing reducing amounts of reuse and recycling, and increasing amounts of construction and demolition material going to waste. 'The building sector alone absorbs up to $50 \%$ of all material resources globally used, while generating a similar proportion of construction and demolition waste' (Angelil and Siress, 2010: 254). The 
separation between our appreciation of materials in the natural realm and those in the constructed realm is changing. The natural realm is no longer seen as an endless resource and the constructed realm is no longer seen as an everlasting cultural artefact. For example there is now more copper to be found in buildings than in the ground (Ruby and Ruby, 2010: 243). In Europe, the "building industry accounts for 40 percent of waste production, 40 percent of energy consumption and $\mathrm{CO}_{2}$ emissions, and 50 percent of material resources taken from nature' (Durmisevic and Yeang, 2009:134). At the moment only $25-30 \%$ of construction and demolition waste is recycled, but this figure could be as high as 75\% (Leigh and Patterson, 2006: 217). We already have the ability to achieve such levels. 'The impediments to the reuse of construction components are rarely technical or economic. Instead, they are mostly based on organizational, contractual and social structures' (Gorgolewski, 2008: 175). In contemporary industrialised societies there is a widespread disapproval for the reuse of 'second-hand' materials.

It should not however be so. 'Transforming an existing building is not only economically more sound, but also socially more sustainable because one does not need to replace historically developed identities overnight by manufacturing new ones' (Ruby and Ruby, 2010: 245). Not only can we recycle and reuse materials, we can recycle and reuse the social significance embodied in those materials. Such appropriation of historic significance in building materials and components has been practiced for centuries in the form of spolia; the incorporation of fragments of demolished buildings and monuments into new buildings, primarily in order to borrow their cultural significance (Brilliant and Kinney, 20II).

While such reuse is not currently common, there is a slowly increasing awareness of the potential that could be realised in materials and component recovery. 'Building subtraction... is an emergent and aggressive enterprise, within which negative development is a lucrative means of mining the city' (Easterling, 20I0: 265). While the idea of the 'creative destruction' of the built environment and the reuse of existing structures as a resource is being explored (Paterno, 20I2), there is not yet a developed theoretical grounding for its application.

\section{Methodology and Case Studies}

Given the objectives of this research, to develop a new technological paradigm for understanding temporary public space and identifying strategies for achieving such spaces, the research methodology being employed is not one of positivist hypothesis-testing research. Rather the research is guided by a philosophy of soft systems methodology (Checkland and Scholes, 1990). In this approach the research is of an exploratory nature with a less clear vision of predetermined specific outcomes. Such an approach sits well with the goals of this study, the development of value systems and heuristic principles. Soft systems methodology is a way of looking at research into open-ended problems. Checkland and Scholes (1990: 5) define soft systems methodology as 'a process of tackling real-world problems in all their richness... which enables lessons to be learned... and... enables it to be used descriptively to make sense of a complex situation'.

Bearing in mind that it is not the purpose of soft systems methodology research to provide truths and solutions, but rather to investigate problems in a holistic and 
qualitative way, 'lessons to be learned' is a valuable outcome. The use of soft systems methodology to investigate building disassembly and materials recycling has already been used by researchers in this field. Golton, Hiley and Frost (1994: 265) used this methodology to 'assemble the fragmented information and place it in a framework' that relates it to the construction industry. Their proposal to develop a 'model' is consistent with the aims of this paper in developing strategies and a framework; a technological paradigm.

The case study projects that constitute this research are more numerous than can be presented here in full. What follows is a selection of projects that illustrate significant pieces of 'fragmented information'. Overall, analysis has been conducted on the following:

- fun fairs and circus tents

- temporary sport facilities; Olympics, motorsport street-races

- music concerts in stadia

- world Expos; I85I, 1970, 1988, 1992

- community occupation of vacant space, community gardens and similar

- political rallies

- religious or community festivals

- street markets

- a range of longer-term but temporary or adaptable public space buildings, such as; Centre Pompidou, IRCAM Paris, Sainsbury Centre for the Visual Arts, Kentishtown Interaction Community Centre, MOMI tent, Karaza mobile theatre

- a range of unrealised/experimental propositions or research projects, such as; Archigram plug-in City, Fun Palace, Temporary autonomous zones: TAZ (Bey, 199I), Free zone Berlin (Woods, 199I), The Cronocaos project (Koolhaas, 20II) A full review of all types of historic temporary buildings that have been designed for future disassembly has been conducted and presented elsewhere (Crowther, 1999). This paper presents an updated review of case studies with a specific focus on temporary public spaces. Data has been collected primarily from published information, drawings, and photographs of the projects, and where possible first hand from site visits and/or conversations with the designers and builders of the spaces. Case studies have been reviewed for recurrent themes in the approach to the making of public space, and recurrent technical solutions. A form of grounded theory analysis has allowed such recurrent themes and strategies to be exposed.

In particular this research explores what the economist Giovanni Dosi (1982) refers to as a technological paradigm; a model or pattern of solution that has a belief system and a puzzle-solution. In this particular instance the belief system is explored through the facets of a model of sustainment (social, economic, and environmental), and the recycling of social meaning. The puzzle-solutions are explored through the technological strategies for creating temporary public space.

\section{A Model of Sustainment}

Any new paradigm for the built environment cannot fail to consider the current state of society and the environment in regards to future sustainability. As such a model for temporary public space must deal with, or offer guidance on, the sustainment of environmental, economic, and social systems. For example the master planning and major 
stadia for the London Olympic Games of 2012 were based on a philosophy of temporary structures that could be disassembled and reused, and leave an appropriate legacy for the local community. 'The widespread use of temporary buildings as sporting facilities was truly radical, part of a sustainability strategy that argued it was wrong for a city to burden itself with facilities it didn't need' (Slavid, 20I2). The London stadium was designed specifically to be partly disassembled in order to down-size the stadium capacity after the games. The stadium was the lightest Olympic stadium to date according to the Olympic Delivery Authority; requiring approximately only one quarter of the structural steel used in the Beijing Olympic Stadium (Olympic Stadium, 20I2). The embodied energy in a stadium (as a building type) is typically much higher than other building types, due to the infrequent use of the stadium. Embodied energy can be as much as $60 \%$ of the lifetime energy load (Olympic Stadium, 20I2); as such it was important to seek ways to recover and reuse that embodied energy through reuse of materials and components.

Not only were environmental and economic concerns driving this design decision, the London Olympic Committee specifically set up a 'Legacy Board' that looked at the future of the temporary facilities as well as the future of the site itself from a social and community perspective. As such, the three dimensions of sustainability were engaged.

\section{Recycling of Social Meaning through Material Reuse}

Although this consideration of social meaning is related to the third dimension of sustainability presented above, it is worth a separate discussion as it is a very much overlooked aspect of the use and reuse of temporary materials and components (Denhart, 2009: 196). The deliberate appropriation of cultural significance from the reuse of building materials and components (traditionally significant stone sculptures and reliefs, columns, decorative elements, and the like) has a long and ancient history (Brilliant and Kinney, 20II). The archaeological term of 'spolia' is given to this practice; the term deriving from the appropriated goods (typically weapons) taken upon winning a battle. While there are numerous ancient examples of this practice its contemporary equivalent is less understood, though none the less significant.

The social meaning held in places, and in the building materials and components of those places is well described by the group of academics and students who disassembled and recycled an important 'public' structure in an African American community in South Carolina U.S.A. The participants noted that it was 'a cultural object' for which there would be 'political implications', and that there was an 'underlying belief that the site had more presence in the community than simply the material at hand' (Erdman, 2006: 19). When the large sail-like canopies from the temporary World Expo of 1988 in Brisbane, Australia, were disassembled for reuse in new public spaces across the city, they took with them a cultural memory of the Expo itself; the new locations became associated with the Expo (Expo Pavilion Recycling, 1991). This was not just the capturing and recycling of the physical structures, but also of the social meaning in them. Just as we might capture and recycle the embodied energy, we can capture and recycle the social energy (Meier, 20II). 


\section{Time Related Building Layers}

The idea that all buildings are impermanent and that different parts have different life expectancies has been well explored and documented (Brand, 1994). How this understanding relates to, or should relate to, the design of temporary buildings has also been explored (Crowther, 2009). 'Cities are formed by highly heterogeneous material composites made from a range of partially incompatible parts, all transforming at different rates of velocity in mutually dependent flows' (Angelil and Siress, 20 I0: 254). This incompatibility of the parts means that they should be designed to be separated on different time scales. The importance of designing buildings in which we separate the structure, the cladding, the services, the internal space planning, and the furniture has been well documented (Duffy and Henney, 1989).

The theory has not however been well developed to accommodate public spaces, neighborhoods, suburbs, and cities; the broader layers of the built environment that sit beyond the scale of the single building. There have been hypothetical explorations of public spaces at the larger scale, such as those of the Archigram group in the 1960's (Cook, et. al. 1972), but no empirical research into temporary public spaces, despite recognition for the need for such an understanding (Mclntyre, 2009). The very short time frame of most temporary public activities, sits in stark contrast with the relative permanence of the space itself. 'Right now, the capacity to occupy public space is immediate. The time factor of tactics has changed as the time scales are shorter' (Fernandez Per and Mozas, 2012: 17). Now, more than ever, there is a need to design public spaces as temporary spaces.

\section{Strategies and Tactics}

Consideration of the case studies against these overarching issues (belief systems) reveals a number of commonly occurring technological strategies that have facilitated the assembly and disassembly of temporary public spaces. Below are a number of such strategies that can be used to guide the design and construction of such public spaces. These strategies have also been shown to facilitate lighter structures, constructed with cheaper budgets, and assembled and disassembled in quicker time.

\section{Minimise the number of different types of building components}

This strategy has the potential to reduce time and cost during both assembly and disassembly through the economy of repetition in these procedures. While it is important to limit the number of different types of components in the whole building, it is more important to limit the number of different types of components in each individual timerelated layer of the building. If different layers are disassembled at different times, there is less benefit to be gained in the layers using the same limited pallet of components.

\section{Use mechanical not chemical connections}

The use of mechanical connections will allow for repeated and easier assembly and disassembly of components for maximum resource and component recovery. This is one of the more important principles that will require one of the greatest departures from the current construction practice of glues and chemical connections. There is however likely to be an increase in time and cost both during assembly and disassembly; but this is 
offset by significant reductions in time and cost in the reuse of components or whole building systems.

Use an open building system

An open building system (one in which parts of the structure can be interchanged and are not bespoke to just one function or location) will facilitate broader compatibility and greater opportunity for component reuse in other temporary projects and in different location on the same project, to facilitate maximum resource reuse after disassembly. There is also the increased opportunity for minor building alterations during the operation of the building with only minimal impact on cost and material consumption.

\section{Use modular design}

Dimensional and functional modularity will greatly reduce the time for assembly and disassembly (and reduce cost through reduced labour time). It will also increase the opportunity for component reuse between different buildings to maximise resource reuse. There may however be times when components may need to be made larger than optimal to comply with acceptable modular standard dimensions. Such minor increases will result in increased use of materials and increased weight; these increases must be balanced against the benefits of modular design.

\section{Use common tools and equipment}

The use of common construction technologies, those widely used within the current building industry, will increase the efficiency of assembly and disassembly. While some current technologies may use slightly more materials and be heavier, it is likely that the savings in time and cost will be greater. Decisions about such technologies require careful life cycle consideration and must be taken with potential and likely future technological developments in mind; and the associated potential savings in material, cost and time.

Provide access to all parts of the structure Increased access will make assembly and disassembly easier and is likely to produce increased levels of future resource recovery. The provision of such access may however, particularly if from the inside of the structure, result in the need for additional space and increased floor area. While examples show that significant levels of access can be achieved with only minor increases in the scope or scale of construction, consideration needs to be given to the desire to minimise materials, time and cost in the initial assembly stage.

Make components sized to suit the means of handling Increased ease of handling, though the reduction in weight or size, will make the future option of disassembly more attractive and increase the ability to maximise material reuse. Consideration should also be given to the cost and time impacts associated with the means of handling, both during assembly and disassembly. Different sized components may allow, or require, different means of handling that will negatively affect time and cost. 
Provide a means of handling and aligning components

There are likely to be few negative impacts associated with this principle. Just minor changes in the form of components will greatly increase the ability to repeatedly handle them and increase the ability to maximise reuse and reduce cost and time.

Provide realistic tolerances for repeated use Increased dimensional tolerances (beyond standard construction practice) will reduce the potential for damage to components during repeated assembly and disassembly. This will encourage the repeated cyclic reuse of components to maximise cost savings. Increased tolerances may require connection systems beyond the scope of common building practice. As such there may be a conflict with the desire to use common tools and equipment (see earlier strategy). It is also possible that increased tolerances may have an increased negative impact during the operational stage of the space, where durability and operability are major concerns. Any significant departures from common practice will require full life cycle consideration.

Use a minimum number of connectors

A reduction in the number of connectors will reduce the time and therefore cost required for the assembly and disassembly process. In order for components to be securely fixed with fewer connectors it may however be necessary to increase the structural capacity of some component. This would have an associated increase in material and weight and this would need to be evaluated against the benefits.

Use a minimum number of different types of connectors

Reducing the number of different types of physical operation needed to achieve assembly and disassembly will reduce time and cost. Such standardisation will also reduce the need for multiple types of tools and reduce the training of builders and users. It is however likely that optimisation of connectors will be compromised, and that some connections will be over designed for their intended function in order to comply with a limited pallet of component connectors. There may be some minor weight increase impacts associated with this compromise.

Design to withstand repeated reuse

Designing joints and connectors to withstand repeated reuse is likely to involve increased durability through increased structural capacity, which may increase the weight of the component. Any such increase must be balanced against the advantages of repeated life cycle reuse of such components and the associated ability to minimise material use in the longer term.

Allow for parallel assembly

Designing for parallel assembly and disassembly, the ability to remove various components in parallel rather than having to disassemble them sequentially will make access and disassembly easier, and therefore quicker and cheaper. There are however likely to be significant redundancies introduced into the design. In a scenario similar to the separation of time-related building layers, such as the separation of structure and cladding, it is likely that increased parallel assembly and disassembly will require increased building 
infrastructure such as support frames and multiple connection systems; all with an associated increase in weight.

Provide identification of building component type

The ability to easily and accurately identify components will reduce the time and cost of assembly and of sorting and re-processing components after disassembly. It will also allow for confident reuse of components, knowing their structural or functional capacity, thereby reducing material use in the longer time frame. Provision of such information should have very minimal negative impact.

\section{Use a standard structural grid}

The use of a dimensional structural grid, and its repetitive nature, will allow for faster assembly and also will facilitate better levels of disassembly through improved relocation compatibility. The grid should relate to the optimal structural capacity of materials and components to reduce material consumption and reduce weight. This may however conflict with a grid set out related to the functional use of the spaces of the building. Such conflict could result in the inefficient use of space and materials, and the inability to minimise resource consumption during the construction stage.

Use prefabrication and mass production

The off-site production of components in factory production facilities has the potential to produce lighter weight components that maximise material efficiency. Manufacture in such factory conditions is also usually faster and cheaper than on-site construction. There is also the opportunity to optimise the use of materials and energy during the stage of production, as well as during construction and deconstruction. Prefabrication and mass production should also be compatible with the use of an open building system and modular design. As such the associated impacts of those strategies must also be considered.

Use lightweight materials and components

The use of lightweight materials will result in lightweight components that are easier and quicker to assemble and disassemble. It is however necessary to consider the full life cycle impacts of the lighter material selection. The lightest appropriate material may have significant negative environmental impacts associated with its manufacture, use and disposal. A full life cycle assessment is required to establish optimal material selection to ensure full protection of the natural environment.

\section{Identify points of disassembly}

Accurate and reliable information of points of, and procedures for, assembly and disassembly will reduce the risk of component and material damage during repeated handling, and increase the potential for recovery to maximise material reuse. The provision of such information should have only minimal negative impact.

Sustain all information about the building/space

The retention of all information relating to public space structure, its component and materials, and their potential reuse and recycling is important in order to realise the full 
potential of future disassembly. Such information will ensure fast and cost effective disassembly of the structure. While such information retention will require careful consideration during the development, planning, design, and construction stages of the project there will be only minimal negative environmental impacts associated with this information management.

\section{Conclusion}

What we discover from the case studies and the derived strategies is that it is very difficult to maximise all three aims of lighter, cheaper, and quicker. In most instances, high achievement in one of these areas comes at the expense of the others, or at the expense of the quality of the public space itself. That is to say in order to achieve all three to a high level it is likely that there may be compromises in how well the space performs architecturally. While it is possible to produce a quality temporary public space that is light, cheap, and quick to create, this will require careful consideration of the above strategies and awareness of the issues of sustainability, varied time-related building layers, and the importance of social meaning and embodied cultural memory.

With the shortening life span of 'permanent' buildings and the increasing number of temporary public spaces, the architectural profession 'is currently mutating from a producer of monuments to a curator of their transformation' (Ruby and Ruby, 2010: 246). Designers need to develop a different understanding of how to make public space for transient use; how to engage with a new technological paradigm with facets of belief systems and technical solutions. 'Interim uses have beautified lots, revitalised neighbourhoods through active uses, and restored nature to stark urban landscapes' (Gerend, 2007: 26), but architects, planners and other designers must now engage with a deeper understanding of the social, cultural, economic and environmental impacts as well as maximising technical solutions.

\section{References}

Angelil, M. and Siress, C. (20I0). "Re: Going Around in Circles". In Ruby, I. and Ruby, A. (20I0). Re-Inventing Construction. Zurich: Holcim Foundation for Sustainable Construction.

Bauman, Z. (2000). Liquid Modernity. Cambridge: Polity Press.

Bey, H. (199I). T.A.Z.: The Temporary Autonomous Zone, Ontological Anarchy, Poetic Terrorism. Brooklyn: Autonomedia.

Bishop, P. and Williams, L. (2012). The Temporary City. London; New York: Routledge.

Brand, S. (1994). How Buildings Learn: What Happens After They're Built. New York: Viking.

Brilliant, R. and Kinney, D. (20I I). Reuse Value: Spolia and Appropriation in Art and Architecture from Constantine to Sherrie Levine. Farnham: Ashgate.

Checkland, P. and Scholes, J. (1990). Soft Systems Methodology in Action. Chichester: John Wiley \& Sons.

Cook, P., Chalk, W., Crompton, D., Greene, D., Herron, R. and Webb, M. (eds.) (1972). Archigram. London: Studio Vista.

Crowther, P. (1999). "Historic Trends in Building Disassembly". In Technology in Transition: Mastering the Impacts - ACSA/CIB 1999 International Science and Technology Conference, June 1999, Montreal, Canada. 
Crowther, P. (2009). "Designing for Disassembly”. In Newton, P., Hampson, K., and Drogemuller, R. (Eds.) Technology, Design and Process Innovation in the Built Environment. Abingdon: Taylor and Francis, Pp. 224-237.

Denhart, H. (2009). "Deconstructing disaster: Psycho-social impact of building deconstruction in Post-Katrina New Orleans". In Cities. 26 (2009): 195-20I.

Dosi, G. (1982). "Technological Paradigms and Technological Trajectories”. In Research Policy, no. II, Pp. 147-162.

Duffy F. and Henney, A. (1989). The Changing City, London: Bulstrode Press.

Durmisevic, E. and Yeang, K. (2009). "Designing for Disassembly (DfD)". In Architectural Design. 79 (6): I34-I37.

Easterling, K. (20I0). “Architecture to Take Away”. In Ruby, I. and Ruby, A. (20I0). Re-Inventing Construction. Zurich: Holcim Foundation for Sustainable Construction.

Erdman, J. (2006). "Studio South: Recycling an African American Landmark". In Journal of Architectural Education. 59 (4): 19-25.

“Expo Pavilion Recycling”. (199I). In Building Construction Materials and Equipment. 32 (I5): 8-9.

Fernandez Per, A. and Mozas, J. (20I2). Strategy and Tactics in Public Space. Amsterdam: A+T.

Gerend, J. (2007). "Temps Welcome: How temporary uses can revitalize neighborhoods". In Planning. December 2007: 24-27.

Golton, B. L., Hiley, A. and Frost, S. (1994). "Development of a Model of Environmental Impact Use and Recycling of Building Demolition Materials". In Sustainable Construction, Proceedings of the CIB TG 16 conference, November 6-9, Tampa, Florida.

Gorgolewski, M. (2008). “Designing with reused building components: some challenges”. In Building Research \& Information. 36 (2): I75-I88.

Koolhaas, R. (201I). "Cronocaos". In Log. Winter, 21: II9-123.

Lavoisier, A. (1793). Traite Elementaire de Chimie. Paris: Cuchet.

Leigh, N.G. and Patterson, L. M. (2006). "Deconstructing to Redevelop". In Journal of the American Planning Association. 72 (2): 217-225.

McIntyre, A. (2009). "paraSite: Repurposing Suburbia”. In Dimensions. 22: 175-I84.

Meier, H. (20II). "Spolia in Contemporary Architecture: Searching for Ornament and Place". In Brilliant, R. and Kinney, D. (20II). Reuse Value: Spolia and Appropriation in Art and Architecture from Constantine to Sherrie Levine (pp. 223-236). Farnham: Ashgate.

“Olympic Stadium Populous Architects”. (2012). In Architectural Record. 200 (6): 92.

Paterno, D. L. (2012). "Recycle and/or Restore: "Re-Cycle: Strategies for Architecture, City, and Planet," Museo Nazionale delle Arti del XXI secolo (MAXXI)". In Future Anterior. 9 (2): I I2121 .

Ruby, I. and Ruby, A. (20I0). "Mine the City". In Ruby, I. and Ruby, A. (20I0). Re-Inventing Construction. Zurich: Holcim Foundation for Sustainable Construction.

Senatsverwaltung für Stadtentwicklung, and Denton, J. (2007). Urban Pioneers: Berlin: Temporary use and Urban Development in Berlin. Berlin: Jovis.

Slavid, R. (2012). "Pavilions and Temporary Buildings". In Architects' Journal. 10/4/20I2: 58-59.

Woods, L. (199I). Free Zone Berlin. Berlin: Aedes. 


\title{
The Social Life of Gas Stations
}

\author{
Giulio Giovannoni \\ University of Florence, Italy \\ Department of Architecture \\ giulio.giovannoni@unifi.it
}

\begin{abstract}
Literature on gas stations is limited to a handful of approaches: the nostalgic/historical approach concerning the first vernacular manifestations of such roadside artefacts; the bleak approach, stressing the character of 'non-places' of these spaces; the obvious technological and functionalist approach; and a few other minor ones. Almost never gas stations are considered as public spaces. However gas stations, as well as other kerbside artefacts, abound of social life. This is particularly true in Italy, where thanks to the post-war tradition of Autogrill, gas stations are often much more than just a place to fill up a car. They provide coffee shops, restaurants, pastry shops, as well as newsstands, stores, food vendors, not to say more recently the inevitable Mac Drives. All activities that are accessible, with easy parking, and in many instances open 24/7, in a country which shuts at $7.00 \mathrm{pm}$, or at best at $9.00 \mathrm{pm}$. Therefore, gas stations become the crossroads of many social interactions, especially - but not only - of youth subcultures. For these reasons gas stations deserve being studied for what they are, avoiding both nostalgic and bleak approaches. This paper presents the first results of an ongoing research on the social life of gas stations in central Italy. It is structured in five main sections. Section one synthesizes the main theoretical positions on gas stations, from the pessimistic ones equating gas stations to nonplaces, to the more optimistic framing gas stations within street and car cultures. Section two frames the relevance of gas stations within the wider transformation produced on cities by the advent of car. Section three provides an historical framework in order to explain today's social relevance of gas stations in Italy. Section four presents the research findings on the social life of such 'architectures in motion', confirming the importance of gas stations for public life. The final section of the paper draws policy implications of such findings claiming the necessity of explicitly designing gas stations as places for public life.
\end{abstract}

Keywords: public life; gas stations; suburban life; non-places; public spaces.

\section{To cite this article:}

Giovannoni, G. (2016). The Social Life of Gas Station. The Journal of Public Space, I (I), 75-94, DOI: 10.5204/jps.vlil.I2

This article has been peer-reviewed and accepted for publication in The Journal of Public Space. Please see the Editorial Policies under the 'About' section of the journal website for further information.

\section{(c) (i) (8)}

This work is licensed under a Creative Commons Attribution - Non Commercial 4.0 International License. https://creativecommons.org/licenses/by-nc/4.0/ 


\section{A hated-loved object}

Since their appearance gas stations have been loved and hated: loved by street culture enthusiasts, especially in their first manifestations; hated by those adverse to car culture and its impact on contemporary cities. In any case, the importance of gas stations in everyday life goes well beyond its mundane role. Several researchers consider infrastructure-related spaces as 'non-places'. The concept of 'non-place' was introduced by the French anthropologist Marc Augé (1995) to describe what he defines as the typical space of hypermodernity. According to Augé hypermodernity is an historical moment characterised by excesses: excess of time, being time "overloaded with events that encumber the present along with the recent past" (p. 29); and excess of space, growing the Earth smaller and allowing us "an instant, sometimes simultaneous vision of an event taking place on the other side of the planet" (p. 3I). Such overexposure makes us lose the sense of time and the sense of space. Being manifestations of a condition of separation from time and space, 'non-places' are condemned to the impossibility of being arenas of social life (p. III):
Since nonplaces are the space of supermodernity, supermodernity cannot aspire to the same ambitions as modernity. When individuals come together, they engender the social and organize places. But the space of supermodernity is inhabited by this contradiction: it deals only with individuals (customers, passengers, users, listeners), but they are identified (name, occupation, place of birth, address) only on entering or leaving. Since non-places are the space of supermodernity, this paradox has to be explained: it seems that the social game is being played elsewhere than in the forward posts of contemporaneity. It is in the manner of immense parentheses that non-places daily receive increasing numbers of individuals.

In Italy Augé's position is shared by Paolo Desideri (1995); Desideri describes an autogrill, the typically Italian motorway restaurant with annexed gas station, crowded with an heterogeneous metropolitan population arrived there to eat ready-made sandwiches. $\mathrm{He}$ misses the time when "at night, in towns, in main streets, in nice Italian piazzas, we met to add our own history to the collective one" (p. 13). According to Desideri, "the collective actions going on in a 'non-place' perpetually remains the summation of single individualities never arriving to express themselves as the integral of a shared public identity (p. 77). But nevertheless Desideri admits that keeping on with applying to this 'tinplate city' the spatial configuration categories of the historical city only produces "effects of complete desolation and of stronger bewilderment" and that it's necessary to open-mindedly design the spaces of a civitas which is essentially made of travellers and of consumers.

Obviously, the way gas stations and infrastructure-related spaces are perceived depends on the cultural context. Northern American scholars are generally more interested in street cultures and its manifestations; in particular, the tradition of cultural landscape studies attributes great dignity to all kind of spaces that have an impact on everyday life, even if with no real architectural value, including spaces related to the typical streetscape generated by car culture. The same spaces which are classified as 'non-places' by Marc Augé, become both socially and culturally interesting locales. For example, parking lots are defined by Kunstler (1994: 136) the "most common little dead 'non-places' of the postwar streetscape”; John Brinckerhoff Jackson (1997: 76, in Eran Ben-Joseph, 2012) instead argues: 
I am tempted to dwell on the importance of the parking lot. I enjoy it as an austere but beautiful and exciting aspect of the landscape. I find it easy to compare it with such traditional vernacular spaces as the common: both are undifferentiated in form, empty, with no significant topographical features to determine use, both easily accessible and essential to our daily existence. But on another level, the parking lot symbolizes a closer, more immediate relationship between various elements in our society: consumer and producer, public and private, the street and the dwelling.

Furthermore, the way gas stations and infrastructure-related spaces are perceived has changed considerably in time. In post World War II, when the car was almost anywhere a symbol of liberty and wealth, gas stations had a positive meaning much more than they have today. However, already in the 1960s, bleak depictions of that spaces were emerging. A view of motorway restaurants as alienating and homogenizing places is conveyed for example by the 1963 movie Ro.Go.Pa.G. At that time in Italy the motorway restaurant, commonly named autogrill, was an incredibly powerful symbol of modernity and affluence (see $\S 3$ ). In the episode II pollo ruspante (The ground-raised chicken), directed by Ugo Gregoretti, the stop at the autogrill during a Sunday trip literally transforms visitors in battery chickens, oblivious of the liberty of their ground-raised ancestors, and only interested in mass consumption. While the leading actor buys useless goods and eats a standardized meal together with his family, Professor Pizzorno, a renowned Italian sociologist, holds a conference on consumption, where he invites "to always study new advertising campaigns in order to stimulate new desires, new needs, so to create a sort of systematic dissatisfaction in consumers". The episode ends with a scene in which the actors, sitting at table in the motorway restaurant, are transformed in battery chickens.

Although many consider infrastructure related artifacts only as a manifestation of the worst aspects of modernity, these artifacts can provide in many places opportunities of urban embellishment. In the words of Oriol Bohigas (1986, quoted in Ingersoll, 2006):

It is necessary to interrupt the old and counterproductive dichotomy between urbanism and the politics of public works, which has given a schizophrenic tone to the development of our cities. While the urbanists analyzed and planned, looking for a new method to work on the city, the technicians of public works continued to work in the healthy tradition of constructing the city realistically, but without an integrated vision of its areas ... or devoting themselves unilaterally to traffic engineering. It is time to approach urbanism with the tools of public works; build an urbanism that is capable of uniting and harmonizing the projects of urbanization. Designing and realizing plazas, streets, boulevards, ramblas, intersections, pedestrian paths, street furniture, street signs, monuments.

Also in the last decades there was a growing awareness about the possible role of transportation networks as structuring elements of social spaces. Infrastructural interventions realized in Barcelona under the direction of Oriol Bohigas between 1980 and 1992, offered the opportunity of rethinking in an integrated fashion the system of public spaces, globally redesigning the city aspect and style. However, apart from the aforementioned cases, the so-called 'non-places' are rarely designed with explicit attention to the public life which they can possibly host. This is true also in the case of gas stations, whose literature deals mainly with three approaches: a historic/nostalgic approach concerning the first vernacular incarnation of such roadside artifacts; the aforementioned bleak approach stressing their character of 'non-places'; and the obvious 
technological/functionalist approach of engineering character. Gas stations are almost never considered as public spaces, but gas stations, as other roadside artifacts, abound in social life. This is particularly true in Italy, where thanks to the post-war tradition of Autogrill and Ristoragip, gas stations are much more than places to fill up vehicles.

\section{Gas Stations, the Car and the City}

The urban and social importance of gas stations should be framed contextually to the transformations produced by the car in cities and in everyday life. In preindustrial cities, but more precisely before the advent of the car, thoroughfares coincided with the mostly crowded and vibrant public spaces. Before the car era the subsequent equation was true:

$$
\text { [COMMERCIAL SPACES } \equiv \text { THOROUGHFARES } \equiv \text { PUBLIC SPACES] }
$$

Commercial spaces, thoroughfares, and public spaces tended to coincide. The advent of the car made all of that impossible. The car was too big and fast to fit in the public spaces of cities which had not been explicitly designed to hold it. In the beginning the coexistence was forced and there was no way out of congestion. That was the time the urban crisis exploded. This happened earlier in the biggest northern American cites, later on in European and Italian cities.

Afterwards urban managers and politicians started coping with the new situation. On the one hand some great urban utopias envisioning a global revolution in cities were developed; on the other hand practical policies were developed to ease the situation of existing congestion in cities. Regarding the car/city relationship, these policies are in a range between two extremes. At one extreme we have policies aimed at adapting the city to the car; various contemporary versions of Haussmann's approach whose most famous cases probably are the Boston Central Artery and Robert Moses' interventions in New York, but which with various degrees have been adopted in almost every American and European city. In this case the aforementioned relationship becomes:

\section{[COMMERCIAL SPACES $\equiv$ PUBLIC SPACES] - THOROUGHFARES}

The single hyphen linking both commercial spaces and public spaces to thoroughfares means the relationship at the same time of spatial proximity and of physical separation. Public spaces and commercial spaces, instead, still tend to coincide as before.

At the opposite extreme the car was completely banned from cities separating residential zones and public spaces from traffic. Being accessibility vital to commerce, the separation of traffic from public spaces also implied the disconnection of the latter from businesses, being this in fact non separable from the main thoroughfares. This solution was adopted in many modernist plans, which devised residential neighbourhoods equipped with pedestrian public spaces and commercial areas astride the same neighbourhoods and the main thoroughfares. The aforementioned equation was then changed into the subsequent:

$$
\text { PUBLIC SPACES - COMMERCIAL SPACES - THOROUGHFARES }
$$

In this case commercial spaces are in a relationship both of spatial proximity and of physical separation (single hyphen), with thoroughfares and with public spaces at the same time. Public spaces instead are completely separated from thoroughfares. 
Between these two extremes, in which the governance dimension is in a sense predominant, is a complex reality produced by the natural tendency of the market and by the almost unrestricted freedom of movement made possible by the car. This tendency had been largely foreshadowed by Frank Lloyd Wright, who envisaged the sprawl of residential settlements in the countryside and the creation of the social, cultural and commercial centres necessary to community life in close proximity to the thoroughfare network. Although Wright's Broadacre City was a completely utopian and impractical social and political project, it was in some respects prophetical, having many of the spatial configurations envisaged in it actually come true, on a large scale in the U.S. and quite extensively also in Europe. Indeed at least in one regard was Wright's proposal very realistic and pragmatic, that is in assuming the centrality of the car in contemporary life. For this reason, the urban reorganization planned by Wright largely came true by itself, as an effect of interactions among individual preferences, market trends, and local planning systems. As Fishman (1990: 37) states:

Wright also had a remarkable insight into the highway-based world that was developing around him. Above all he understood the consequences of a city based on a grid of highways rather than the hub-and-spokes of the older city. Instead of a single privileged center, there would be $a$ multitude of crossings, no one of which could assume priority. And the grid would be boundless by its very nature, capable of unlimited extension in all directions.

Apart from the United States, this out-and-out explosion of the centre envisaged by Wright came true also in European cities, whose commercial, social and cultural centres got dispersed in a multitude of shopping malls, multiplexes, conference centres, sports facilities, entertainment facilities, gas stations, almost always in close proximity to mobility infrastructures. Old historical centres are no more at the top of the urban and regional hierarchy, but are just one of the numerous nodes of a basically non-hierarchical network. A special function was assigned by Wright (1963, 192-193) exactly to gas stations which were supposed to become real community centres dispersed in the region:

One more advance agent of reintegration, an already visible item in the coming decentralization of the City, may be seen in any and every roadside service station happening to be well located along the highways. The roadside service station may be - in embryo - the future city-service-distribution. Each station may well grow into a well-designed convenient neighbourhood distribution centre naturally developing as meeting place, restaurant, restroom, or whatever else will be needed as decentralization processes and integration succeeds. Already, hundreds of thousands occupy the best places in the towns or, more significantly, pretty well outside the towns. Eventually we will have a thousand new city-equivalents at work detracting from every small town or great city we now have. Proper integration of these would help overcome the super-centralization now trying to stand against human freedom.

According to Wheeler (1960, 174), Wright designed for the first time an ideal gas station in the beginning of the 1920s and later incorporated the design in his project for a model community - the Broadacre City. In 1958 Wright himself engaged in the realization of a gas station in Cloquet, Minnesota. Set among the conventional dwellings and small-town business establishments of Cloquet, the gas station had a cantilevered copper roof protecting the filling area and was equipped with large service areas including a restaurant, an observation lounge, and a rest area for travellers. On the top of the roof a lighted 
pylon stood out in the skyline, making of the gas station an urban landmark visible from far away. Each building's detail had been designed by Wright himself. It was complete, among other things, of plant racks and ceramic tiles, and cost more than ordinary gas stations. However, it was conceived for serial production, and scale economies should have lowered its cost per unit.

Also in the case of gas stations, Wright's hypotheses proved to be prophetic and many of these structures are assuming the features of authentic small community centres, for example the already mentioned Autogrill and Ristoragip in Italy.

\section{Autogrill and the Italian Gas Station}

Italy has a peculiar history in terms of gas stations, for two main reasons. The first is related to the partnership formed after World War II by the biggest food companies and the main oil companies, a partnership which led to an early 'implosion' (Ritzer 1999) of the boundaries between restaurants, supermarkets, entertainment facilities, and gas stations. The second reason is the important role played by Enrico Mattei's Eni in building a national energetic policy and in the commitment of Agip - an Eni's controlled petrol company - to create a filling station network also integrating restaurant and bar facilities. The history begins in 1947, with the opening of the first rest station built by Mario Pavesi in close proximity to the Novara exit of the Torino-Milano highway, not too distant from the Pavesini biscuit factory and aimed at its promotion. In 1949 a big arch over the highway was built to mark the station, with a hanging aerostat and the writing Biscottini di Novara Pavesi (Pavesi Novara Cookies). Between 1950 and 1952 the building was expanded realizing an auto-grillroom, a deli-restaurant for motorists. The project was entrusted to the Architect Angelo Bianchetti, who designed a single store building overlooked by a huge concrete arch, with the writing Bar-Autogrill-Restaurant Pavesini Biscuits placed on it together with a greasy pole made of anthropomorphic Pavesinibiscuits and of fluctuating egg. To motorists, then used to eating home-made-sandwiches, a modern and 'American' rest-station was now provided.

With the Novara autogrill starts the adventure of the Pavesi, one of the biggest Italian food industries at that time, in the world of highway restaurants. In 1955 the Bergamo autogrill was opened, and three years later the ones in Lainate and in Ronco Scrivia. The land was owned by Pavesi and the filling stations, which were to be rent to petrol companies, were developed subsequently to the rest area. The entrusted architect is again Angelo Bianchetti, who was awarded the golden award at the ninth Premio nazionale della pubblicità (National Advertisement Prize) for his work on gas-stations. The building is at the same time a commercial totem and a regional landmark. In Lainate and in Ronco Scrivia the fabric has a circular plan overlooked by three big arches converging towards a centre upon which the Pavesi logo is raised up to 5I meters (167 feet). As in the case of Wright's gas station in Cloquet, Minnesota, Bianchetti's project is total, controlling the interior and the exterior of the building, from graphics to signage, from tools to decorations. Such design creates a corporate image, but also symbolising the mass motorization and mobility revolution in Italy, as well as the birth of modern marketing and the advent of mass consumption.

Later on the Pavesi company will make a partnership with the American Esso and will import to Italy the bridge restaurant developed by the Fred Harvey Company, based in 
Chicago. The first autogrill to be realized according to this model was opened in Fiorenzuola d'Arda in 1959. In these new generation of autogrill, restaurants provide menus specifically conceived for motorists under the supervision of the Institute of Physiology of the University of Milan and made of "light, nourishing, healthy and genuine [food], ready at any time, day and night".
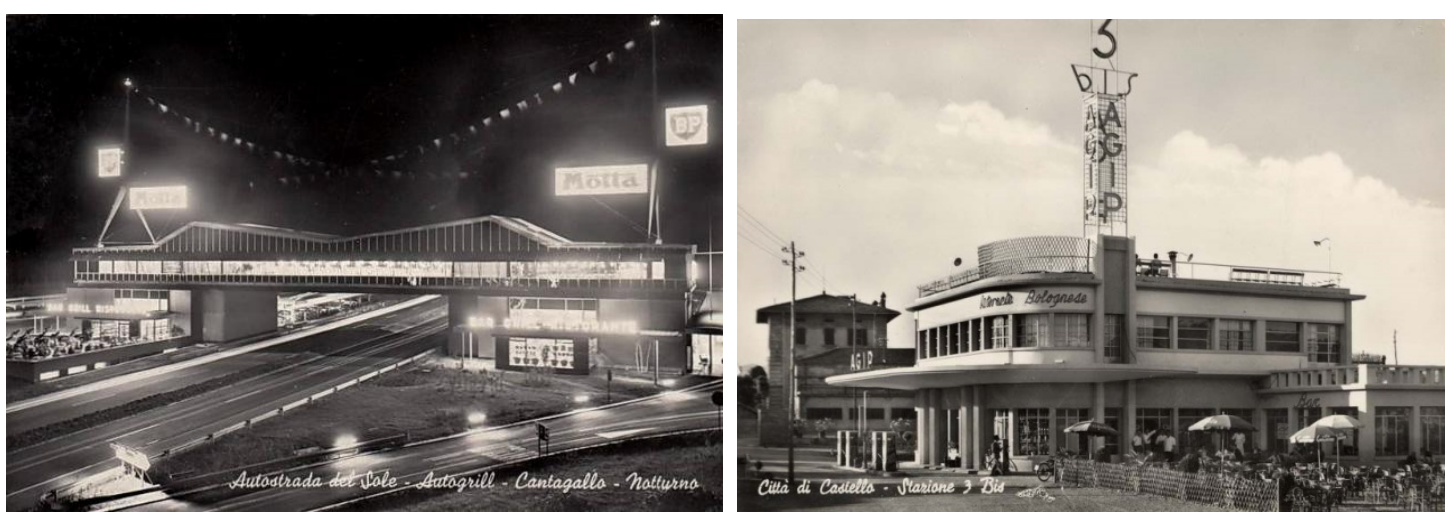

Fig. I. On the left: Cantagallo City. Old postcard (author's collection).

Fig. 2. On the right. Città di Castello. Stazione 3 Bis. Old postcard (author's collection).

The Motta company, a competitor of the Pavesi and the biggest food company in Italy, will enter the competition creating a partnership with the British BP and developing the famous Mottagrill in Cantagallo (BO), the biggest in Europe, also called 'Cantagallo City' (fig. I) The entrusted architect, Melchiorre Bega, interprets the bridge as a huge advertising emblem: glazed walls with big sunscreens, advertising pennons 30 meters high, and a roofing reminding the letter $M$, initial letter of Motta. The complex hosted a restaurant, a book-and-souvenir shop, a branch of the Banca Commerciale Italiana (a major Italian bank), and a branch the of the Ufficio del Turismo of Bologna (the local tourist office). The Mottagrill in Cantagallo becomes in these years a true landmark, also thanks to engagement of the talented cook Marco Bazzani, who raises the profile of the restaurant to nationwide reputation. 'Andare al Cantagallo' ('going to Cantagallo') was in great fashion also among famous personalities, including Frank Sinatra, Brigitte Bardot, Gregory Peck, so to seriously compete against the most famous restaurants of Bologna (Variante di valico, 2013).

From the beginning of the 1950s, also Enrico Mattei's Agip invested several resources in the commercial network, which was in charge of conveying the corporate image of the company: architectural models were developed, large investments in station-managers' training were made, corporate periodicals were created such as "Buon lavoro, Amici!" and "Il Gatto Selvatico". In one of these magazines it was possible to read in 1956: "Rests in the middle of nowhere no more exist. Beside filling stations arouse bright rooms, equipped with the most modern facilities, real residences, open 24 hours a day, in all climates. They are agile and slim structures, they make you think to a happy season, to trades getting crowded with new signs, with new homes for people" (Parrella, 1956). To the Pavesi's American style, Mattei opposed a local prototype based on a new national identity. After the advent of the autogrill also Agip entered the Market forming a partnership with Alemagna, a competitor of Motta and Pavesi. The result of this 
partnership were the autobar, whose sobriety was shown by the absence of table service. These were mainly prefabricated buildings assembled at the Nuovo Pignone, a company taken over by Eni in 1954, and hosting in a single block both the bar and petrol pumps. The simplicity of Agip gas stations makes you think to a catholic Eni, devoid of the typically American redundancies: they display a sort of ideological aesthetics flattering national self-regard.

The cultural importance of autogrill should be understood within the tremendous transformations undergone by Italian society in the post Second World War era. The 1950s are the years of the economy car, television, and the advent of mass consumption. In 1954 Fiat launches the Seicento, and the year after 126.000 models are registered, despite its price being equivalent to a one year blue-collar wage. The economy car transforms free time and is a symbol of liberty and escapism. In 1954 also start in Italy TV broadcasting and its widely enjoyed Caroselli, the famous advertising shorts interpreted by the best actors of that time. The first Carosello to go on air will be the advertisement of an oil company, Shell, although all the main protagonists of highway rest will be largely screened: from the "healthy, light and nourishing Pavesini ("Pavesini: sani, leggeri e nutrienti”), to Alemagna's greasy poles.

In these years autogrill consolidates as one of the major symbols of the so-called 'Italian economic miracle' and of the new bourgeois consumption. Its symbolic importance is demonstrated by many opening ceremonies, which are attended by the highest political and religious authorities. The opening ceremony of the Cantagallo Mottagrill, on April 29 ${ }^{\text {th }}$ 196I, for example, was attended by the undersecretary of Ministry of Education Elkan, and by the Archbishop of Bologna Lercaro, who even compared it to a small rest stop existing in Galilee in the time of Jesus. Even the journal Life International, in its September $26^{\text {th }} 1960$ edition, reported on the autogrill phenomenon:
Nowhere in Europe is the new prosperity more spectacularly evident, afloat and ashore, than in Italy. [...] Now Italy produces luxuries for home consumption and imports them as well. In Milan [...] alone, 350,000 citizens have passports; 10 milion radio sets and 1.6 milion television sets help Italians spend their leisure time when they are not at the theater, the movies or a football game. Usually they ride to their entertainment, often pausing to enjoy the allurements of an «autogrill», or roadside restaurant. The establishment brightening the night (above), one of I 3 in Italy, offers lunch or dinner for $\$ 1.20$, a bar and a wide variety of objects for sale including «exclusive» american bags (below) at a little more than $\$ 2$ each. The Pavesi Biscuit \& Cookie Co., which operates the grills, stuffs the pocketbooks, picnic baskets and beach bags that it displays with Pavesi products, some of them imported, others homemade, but all of them silently eloquent reminders of Italy's new standards of life and living.

Although the first autogrills took inspiration from some Northern-American examples, the happy alliance between food industry and oil industry is a typically Italian phenomenon which has no equivalent for its dimension in any other country in the world. The biggest highway-restaurant market in Europe is still the Italian one, and Autogrill SpA, the key player emerged after a long merging and restructuring process in the sector, is nowadays a global player producing $70 \%$ of its sales abroad with over 4.800 branches and 51.000 employees.

Thanks to the success of this experience - initially developed only in close proximity to the highway network in order to make it autonomous from inhabited areas - the union 
between gas distribution and food services became a widespread phenomenon in Italy, from the small filling station in the country in partnership with the coffee and pastry shop, to the station with annexed bar/restaurant in the urban peripheries, to the one with annexed pizzeria and small supermarket in medium-distance roads (fig. 2). Thanks to prolonged opening hours and to excellent accessibility, this secondary distributive network is becoming an important social infrastructure. In order to understand this network, gas station cannot be interpreted following the bleak visions of 'non-places', a structured research on uses and actors of these only apparently unusual small community centres is needed to unpack their true nature.

\section{The Social Life of Italian Gas Stations}

Our empirical analysis focused on two gas-stations in the South-west periphery of Florence, both owned by TotalErg, an oil company borne in 2010 after the merging of the French Total-Italia and the Italian Erg Petroli. They have been selected through a survey of gas stations in the Florence Area; selection of case studies was based on mixture of functions, accessibility, opening time, as well as likelihood of becoming spaces for social interaction.

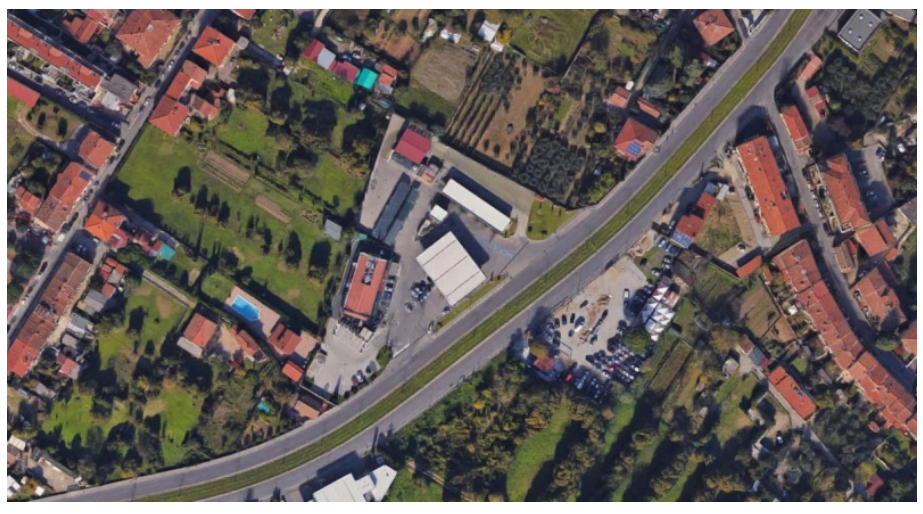

Fig. 3. Google Maps.

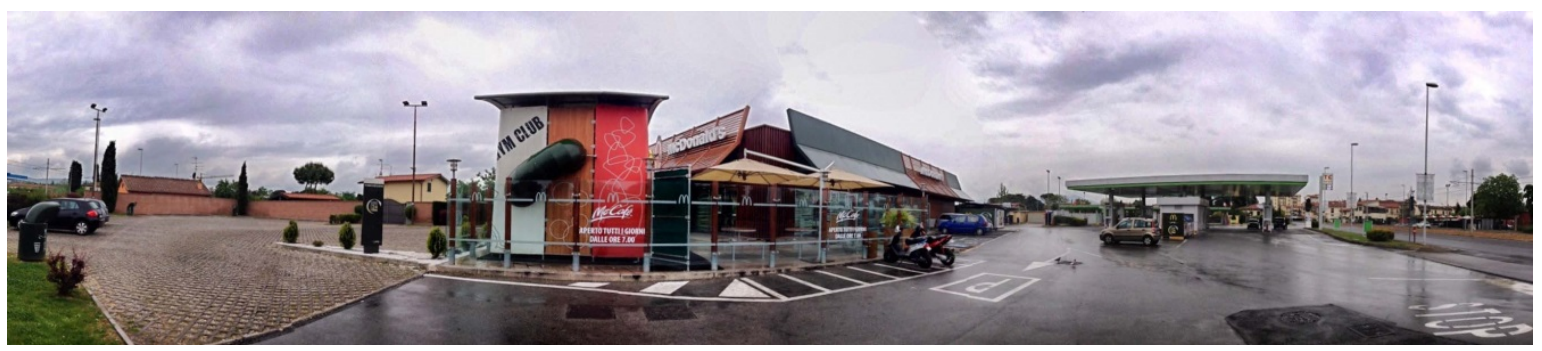

Fig. 4. Photo: Giulio Giovannoni

In the selected area, there are different types of gas stations, from small installations in the compact city with I-2 pumps to medium size stations with bar and restaurant, mainly located in the suburbs, to large Autogrills on highways. The two medium-size suburban gas stations selected for our research are both with bar/restaurant open 24/7. From a social point of view this is probably the most interesting type as it intercepts a local population in an area with scarce public places. 
The first station is located on the Viale Nenni, a four-lane-urban road lined by the Firenze-Scandicci tramway, constituting the main axis connecting Florence to Scandicci, a big residential neighbourhood South-West of Florence with a population of about 60.000 inhabitants. This gas station is also equipped with a large car-wash service, a parking lot, a MacDonald's and a McDrive, the latter two open until II p.m. on weekdays, 24 hours on weekends. In reporting the results of the analysis I will indicate this case study as the McDrive Gas Station (MDGS) (fig. 3-4).

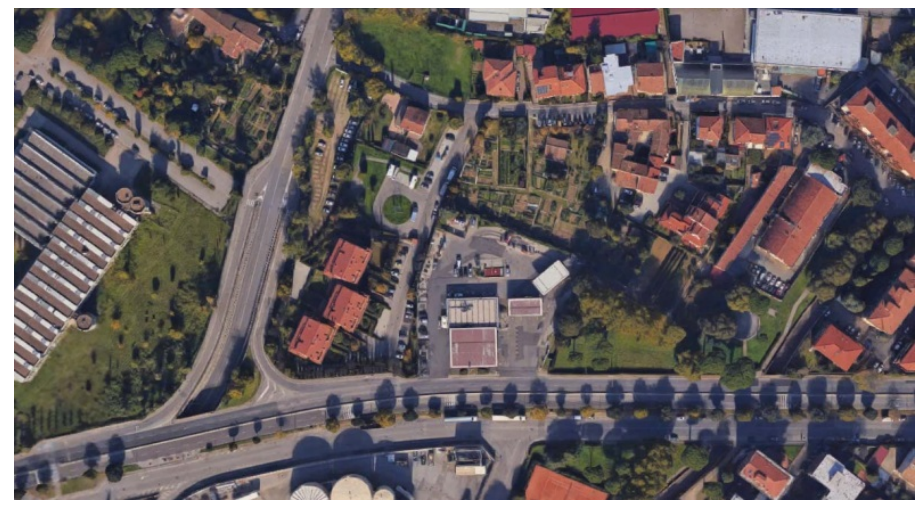

Fig. 5. Google Maps.

The second case is located on a four-lane-urban road that feeds into the Firenze-PisaLivorno highway. The gas station is equipped with filling facilities, coffee-pastry shop open 24/7 with also newspapers sale, parking lot, car-repair service, car-wash service, and natural gas station. In reporting the results of the analysis I will indicate this case study as the Pastry Shop Gas Station (PSGS) (fig. 5).

\section{I. Research Methods and Goals}

This section describes the research questions and aims of the empirical study carried out on the two gas stations and explains the methods used to answering such questions. The analysis used a range of tools, from long term observation to interviews to mapping techniques. The research was designed to include the following aspects:

- social life of the gas station in different times of the day and of the week;

- spatial and social relationship between the gas station and its neighbourhood;

- relationships and synergies between the various activities hosted by the gas station;

- city 'à la carte' and urban routines;

- gas station's publicness.

Social life of the gas station in different times of the day and of the week. In order to understand and to describe the social life of the gas stations we investigated the following questions (cfr. Gehl \& Savarre 2007):

- How many people and what kind of people (by age, gender, ethnicity) are there in each sub-unit of the gas station in different times of the day and of the week?

- What are they doing?

- For how long? 
This in vivo study of public space has found a growing legitimacy in the theoretical debate on territoriality in recent years. This view was fostered, among others, by Sack (I 986 p. 19), who defined territoriality as the "attempt by any individual or social group to affect, influence, and control people, phenomena and relationships by delimiting and asserting control over a geographical area". On this topic see also Brighenti (2010). The notion of territory understood as a bounded and controlled space has been questioned by highlighting the fluid and changing nature of territorial appropriations (e.g. Delaney 2005, Brighenti, 20I0; Kärrholm, 20I6). It became clear that territories, conceived as socially produced spaces, continuously change both their shape and content. In our case, the gas station and its sub-units are lived by different publics in different times. Therefore, understanding the social life of a gas station means describing how its publics and their performances change in space (sub-units) and in time (daytime, weekdays). We used structured observation methods (Gehl \& Savarre, 2007; Gillham, 2008) to understand such variations. In order to count users and to register their activities, we adopted a 'time sampling' technique with a time period of ten minutes. By 'time sampling' we mean observation at regular intervals for short periods of time (Gillham, 2008: 14-18); this approach makes the different measurements comparable. During the observation pedestrian movements were also mapped. This quantitative measurement was integrated with more properly ethnographic work, which consisted in participatory observations within the gas station. Short unstructured conversations were held with managers and with other customers. We kept these conversations as the most spontaneous as possible, while trying to direct them towards the areas of interest for the research.

Structured observations were carried out in April 2014. We first checked the place out in different moments of the day, observing differences in the use of gas stations in the morning, afternoon, and evening. We then developed an observation sheet which covered the different moments of the day in both working days and weekends. Altogether, 24 hours of observation were conducted in each petrol station, for a total of 48 hours. The stations were divided into sub-units, which were observed separately.

Spatial and social relationship between the gas station and its neighbourhood. Gas stations we surveyed are architectures on the road located in an urbanized environment; being on the road they are designed to be reached by car; belonging to an urban environment, although fragmented and suburban, they lend themselves to be used as neighbourhood facilities. One of our goals was investigating to what extent the gas stations are used by local residents. To accomplish this, we first observed the number of users who reach the gas station on foot. We also tried to establish if there was a significant percentage of users driving to the gas station and living nearby or going there on a regular basis. While the number of people going on foot to the station can be easily determined through observation, establishing how many motorists live in the neighbourhood requires more in depth investigations, which were outside the initial scope of this research. Partial data about provenience of users were acquired through unstructured interviews with gas stations attendants, who have some general knowledge of their regular customers.

Relationships and synergies between the various activities hosted by the gas station. The gas stations host several activities that can work independently of each other; for example, there may be people who go to the gas station only for petrol, and people who go to the 
gas station only for the bar or for the McDonalds. However, there may be people who simultaneously use more than one of the services offered by the station: for example they fill up, they wash the car, and then they go to the bar or to McDonalds to have a good time. This 'complex' usage of the gas station can be done individually or in group. In the case of a family, just to make an example, the father can fill up and wash the car, while the mother and the children wait for him at the McDonalds. It is important to evaluate these interactions/synergies as they are one of the features of public spaces. The evaluation was done through direct observation by estimating the percentage of people, or groups of people, simultaneously using two or more of the services offered by the station.

City 'à la carte' and urban routines. The contemporary city is featured by a widespread and pervasive use of the car. Robert Fishman (1990) effectively defined it 'city à la carte'. In fact, thanks to the freedom of movement made possible by the car, people decide their routes and their stops in the same way in which they order their food at the restaurant. That being the case the stop at the gas station is normally just one of the stops along a more articulate individual (or group) journey. Urban sociologists (e.g. Cohen \& Taylor, 1992) use the term 'urban routine' to indicate those systems of moves/stops that become a regular occurrence in the daily lives of people. During the anthropological phase of the fieldwork we investigated the urban routines of gas stations' users.

Gas station's publicness. In terms of ownership gas stations are obviously private spaces. However, they offer public services and raise no particular access restrictions. So the problem of how evaluating their publicness is being raised, which is far from trivial. The traditional dichotomous distinction between public space and private space is simplistic and largely outdated. Kohn (2004) argues that there are several hybrid forms of public/private spaces and that the "progressive blurring of the boundaries makes it necessary to develop a flexible definition of public space.” Marcuse (2004: I I3, note 32') identifies six legal forms of space which depend on the public/private nature of three distinct variables: ownership, function, and use. Petrol stations equipped with coffee shops/restaurants open 24/7 clearly fall into Marcuse's category 'private ownership/private function/public use'. Shopping malls as well as many other private facilities also belong to this category. However, whereas literature on shopping malls is quite extensive (e.g. Parlette Cowen, 20I I; Staeheli and Mitchell, 2006; Miller et al., 1998; Backes 199; Crawford, 1992), given their relevance in the urban structure and in everyday life, petrol stations have never been studied as socially relevant artefacts.

But the problem is more general; research trying to define and to measure urban-spacepublicness is very scarce and applies to situations that are quite different from the context of our research. Van Melik et al. (2007) developed a model to measure publicness which is visually represented by a cobweb diagram. It is designed for themed/secured urban spaces and has six rays, each corresponding to a 'dimension' of publicness, and three concentric circles, each corresponding to a measurement level (high, medium, low); Three of the six rays/dimensions are dedicated to secured public spaces (surveillance, restraints/loitering and regulation), and three to themed public places (events, fun shopping, pavement cafés). Giving a high/average/low score each to each axis/ray cobweb figures are produced that graphically show the degrees of securedness and themedness. Németh and Schmidt (20II) developed a model in which publicness is defined and 
measured in relation to three axes: ownership, management, and uses/users. Both aforementioned models are deficient, since they do not take into account the design and the localization of the spaces which they intend to assess. This bias is particularly relevant to our case. In fact, as we demonstrated in the historical section of this paper, the social significance of contemporary hybrid public/private spaces, such as gas stations and shopping malls, is largely determined by their location on the road and highway network or in close proximity to it. Although designed for the measurement of publicness in urban waterfront environments -that is in spaces that are quite different from ours- the star model conceived by Varna and Tiesdell (2010) is better suited to our purpose and adopts criteria which appear to us overall more balanced. In fact, compared with the aforementioned models developed by Van Melik et al. (2007) and by Németh and Schmidt (20II), it introduces parameters which measure centrality, access, and possibilities for active and passive engagement with the site.

Importantly, all measurement models of publicness found in literature, including that of Varna and Tiesdell (2010), which we actually used, are inductive models which study public space as something external to people. The assessment is done by the researcher and is based on the attribution of a value to each of the valuation parameters. Since this process is largely subjective, we tried to give adequate reasons for the values that we assigned. However, we argue that this bias is also offset by having used a number of complementary research methodologies (historical framing, structured observation, ethnographic observation).

\subsection{Research findings}

Social life of the gas stations in different times of the day and of the week. The structured observation of the two gas stations clearly shows that their social life and their publics deeply change across time, both during the day and during different days of the week (working days/weekends). So we can talk of multiple productions of space, which change both in space (parts of the gas station being lived) and in time. At the MDGS mornings are quite calm on weekdays, but quite crowded on weekends. People's activities, however, are mostly confined to car maintenance and social interactions are scarce. Lunchtime instead seems to be one of the most socially interesting periods in any day of the week. People appear to be very mixed in terms of group-size (from large groups arriving in several cars, to families, to individual users), of ethnic backgrounds, and of social classes (evaluated on the basis of the kind of vehicle driven). The late afternoon is markedly different from the lunch hours. Traffic diminishes, and a different type of user appears. On Saturday afternoon, we observed several groups of at least 4 teenagers arriving on foot, plus another middle aged man. The clients were generally young, from 16 to 20 years old, and there were few families. The early part of the evening is one of the busiest times, with the McDonalds filling up around 6.30 and the car wash in full function until dark. In general, the dinnertime atmosphere around the restaurant is different from lunchtime, as there are fewer families and elderly, but more young people and middle aged without children. In the evening the McDonalds becomes a meeting point for local teenagers. We observed many that did not enter inside, but used the parking as a meeting place. There were also older people using the parking lot as a social area. For example, some 30-yearold males were gathered around the modified car of another, examining it and eating their hamburgers. 
Analogous space-time variations of social life were registered at the PSGS. This is particularly active during night-time, especially on weekends. The pastry shop is a true landmark for younger people. On weekends it is largely used as a place both to start the night (before going to disco, to the movie theatre or to amusement centres) and to end the night (e.g. having pastry after disco in the early morning). Even on a Monday night many young people, up to 40 years old, were observed standing in front of the pastry shop, drinking, and talking relaxed. Reviews posted by gas station's customers on social networks, confirm its relevance for this kind of public. After all, as one of its night customers argued, the TE Pastry Shop is "the only place open at night in the Isolotto neighbourhood". Compared to the MDGS however the PSGS appears to be more physically disconnected from the neighbourhood and no single person was observed walking to it.

Spatial and social relationship between the gas station and its neighbourhood. Going even beyond our expectations, both gas stations resulted having a relatively strong social connection to their surroundings. Most of the McDonalds clients are local, and come there often. This was clearly stated by an attendant who said: "most of the clients are from the neighbourhood, we know many of them by name - there are few tourists here". Although they come mostly by car, as coming on foot is not very convenient, we were surprised observing several groups of teenagers walking here from the neighbourhood on a Saturday afternoon. The station is in fact located in a very dispersed area, and there are only few inhabitants in the space of at least two hundred meters. In the case of the PSGS we should distinguish between its spatial relationship and its social relationship to the neighbourhood. The station is in fact quite physically disconnected from the neighbourhood, being located on a thoroughfare on one of its edges, and being almost impossible to get access to it on foot. However, its social relationship to the neighbourhood appears to be strong, especially for younger people. Also, as one of its night users observed the gas station is "the only place open at night in all the Isolotto neighbourhood".

Relationships and synergies between the various activities hosted by the gas station. As we started our empirical analysis we expected to find strong synergies between food and gas. Instead we found that both in the MDGS and in the PSGS people using the gas station for car-related activities tend to be distinct from people using it for food-related activities. Only a small number of users take advantage of both functions. These findings surprised us and are in a sense counter-intuitive. However, a deeper analysis reveals that strong synergies between food and gas still exist. For example, although at the PSGS most of the pastry shop customers don't refill their car, they take great advantage of the oil company's parking areas and cantilever. Its location under the cantilever makes the pastry shop enormously more usable: it is always safe and lighted, always covered from rain, always easy to park. This explains why the gas station filling cantilever tends to become in certain moments an outer extension of the venue. Also the pastry shop gains a lot in terms of visibility, especially at night, thanks to the oil company's visual signs. At the MDGS the situation is quite different. The McDonalds in fact tends to be an enclave: it has its own outer space equipped with tables, but this is accessible only from the inside of the venue. However, in the MDGS some outer social spaces are spontaneously created as 
well, independently from the McDonalds. The most evident is the scooter parking area in front of McDonalds, which transforms into a meeting place for teens, who then stay there, blocking foot and car traffic. At various times, different areas of the parking lot are also used for social activities, particularly in the evening (fig. 6-7).

City 'à la carte' and urban routines. The gas stations evidently play a different role in people's routines on weekdays and on weekends. On weekdays at the MDGS we saw many small groups of people who were obviously taking their lunch break there. The most conspicuous was a group of about 25 firefighters, all dressed in fluorescent orange, and making a lot of noise. Interestingly individual users were almost absent. On weekends the picture is much richer.
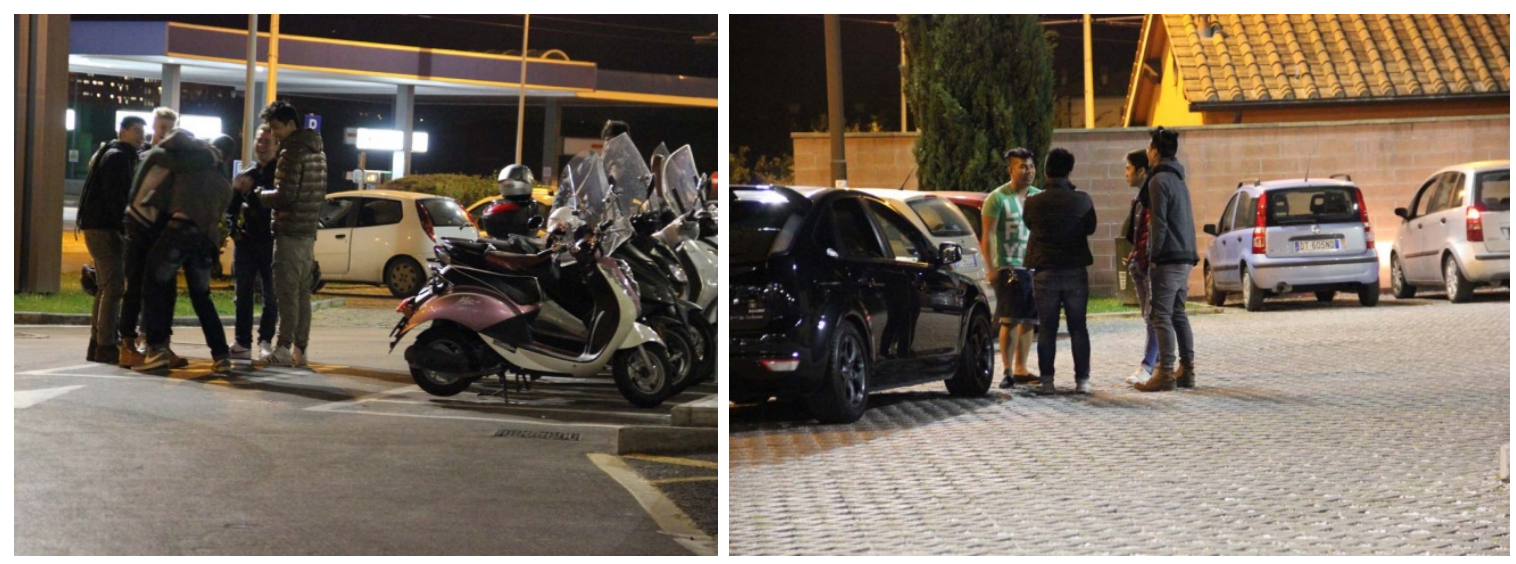

Fig. 6-7. Photos: Giulio Giovannoni.
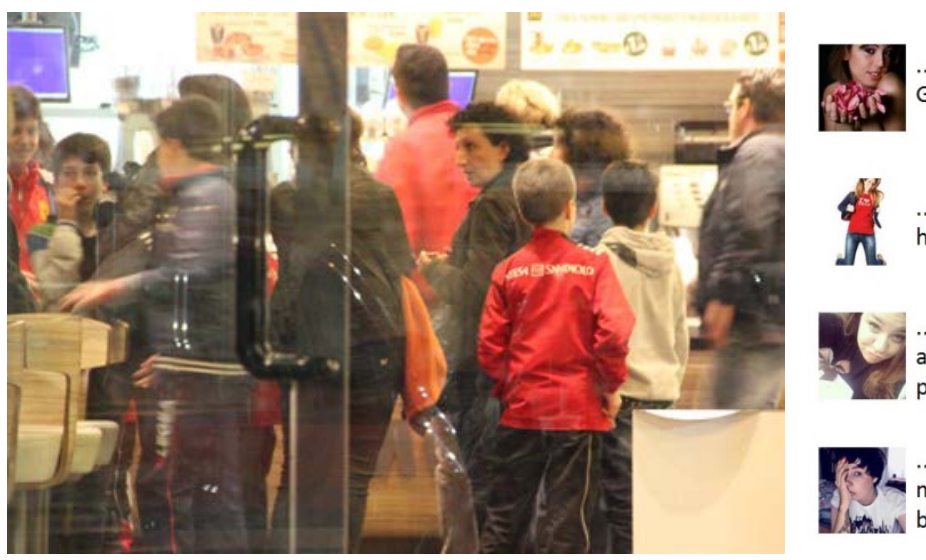

...this place is a hoot for night Gourmands!

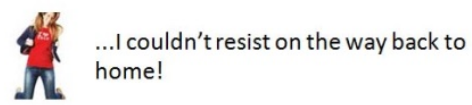

Fig. 8-9. Photos: Giulio Giovannoni.

On the right: comments of some young users of the PSGS on Yelp! http://www.yelp.com/biz/pasticceria-ergfirenze, accessed on April II, 2013.

In the late afternoon we noticed many parents coming with their children, mostly male, after football or other sporting activities. At night, a worker told us, many people that stop there are on their way out for other destinations. Our observations of clothes and other signs confirmed this. The employee also said that after the clubs close, many people pass through the drive through on their way home. We saw two women, aged 30 , 
obviously dressed to go out, arrive at about I0pm, on their way into Florence. We spoke with a 17-year-old from Calenzano, who had been waiting there for at least 30 minutes before his friends arrived. When they arrived, the group remained outside, saying that they had no intention to go to McDonalds, but would go somewhere else. So, the parking lot area is both a social space for them, as well as a departure point for whatever other activities they would be doing that evening. The situation is not too different at the PSGS, which is also much used by youngsters during their nightlife routines, especially on weekends (fig. 9).

Publicness. The variety of uses visible at the gas stations can lead one to conclude that the exterior spaces here are essentially public spaces in terms of active control. There is nobody there to stop you from doing whatever you want. The space is accessible to all, and used by a wide range of people. The constant presence of others and the tight, awkward spaces almost police themselves. Still, there are no rules to which you must conform, other than the general ones that govern you in any place. We could say that these gas stations, and particularly the areas around McDonalds and the pastry shop, are automatically policed by the large amounts of users that pass through. In that sense, they are very public - the large amount of users at key times is typical of an urban public space. But differently from other more traditional urban spaces which have an almost continuous presence of people, social life at the two gas stations lights up especially at certain times: at lunchtime, in the afternoon, and at night, particularly on weekends. Some of the other areas are less frequented, and hidden by buildings, but we observed no illicit users taking advantage of the privacy.

In order to make our analysis more specific and to provide a measurement of publicness we applied Varna and Tiesdell's (2010) model. This model consists of five dimensions whose values range from one (low publicness) to five (high publicness). The lowest score, according to this model, is five (lowest score in all variables), and the highest one is twenty-five (highest score in all variables). The first variable to be considered is ownership. The model attributes three points to situations like ours. The criterion is: 5 points in case of public ownership; 3 points in case of public/private partnership, transit interchange, retail premise; I point in case of private ownership. The second variable is control. The two opposites considered by the model are the 'big father' situation, protecting the freedoms and liberties of citizens (five points), and the 'big brother' situation, protecting the interests of the powerful (one point). The first is featured by no visible/overt control, no CCTV cameras evident, regulations enacted only in the interests of the community. The second is characterized by highly visible expressions of control presence (especially security guards), many CCTV cameras evident, regulations enacted in a narrower private interest. In our gas stations we have no visible/overt control, no particular regulations enacted in the private interest (such as in many shopping malls), and just a few scarcely visible CCTV cameras. Therefore, we give four points to this parameter. The third variable is civility. In this case a high level of publicness depends on the space being well kept and cared for, and on being provided of basic facilities such as toilets, shelters, food vendors, seats, and lighting. As we already discussed, in the PSGS the space in front of the pastry shop is very well equipped: it is sheltered, it has toilets, it has food, it has some seats available on the outside, and it is very well lighted (fig. I0). 


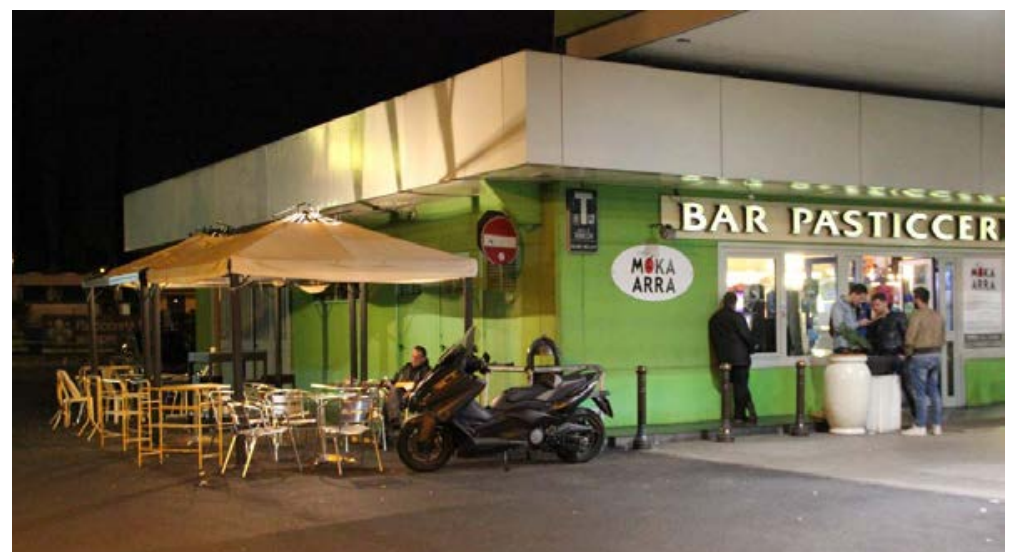

Fig. 10. Photo: Giulio Giovannoni.

The area in front of McDonalds in the MDGS is also well equipped but is more enclaved and therefore less public. Both gas stations are also very well kept and maintained. We give five points to the PSGS and four points to the MDGS. The fourth variable is physical configuration. A high score is determined by centrality/connectedness, by visual permeability, and by the absence of thresholds and gateways. Centrality is defined in terms of good location 'within the overall movement network', whereas being visually permeable means having 'strong visual connections with external (surrounding) public realm'. Both gas stations are highly central within the overall movement network, have strong visual connection with the surroundings, and have no thresholds or gateways limiting access to them. We could argue that these facilities are punctual and isolated, but in our mind this only holds true only if you are a pedestrian, not if you act as a driver, as most of their users do. We give five points to the variable 'physical configuration'. The fifth and last variable is animation, measured in terms of opportunities for active and passive engagement, and of opportunities for discovery and display. According to the model, opportunities for passive engagement are determined by reasons for peoplewatching, and by multiple and varied formal and informal seating.

Opportunities for active engagement are considered to be provided if there is high density of active frontages, and diversity of events and activities occurring spontaneously or through programming. Finally, opportunities for discovery and display are provided by loose, adaptable spaces, which can be used in multiple ways. On this variable our gas stations are weak. There are no particular events being held there, apart from the aperitif events organized at the pastry shop, the density of active frontages is not high, and there are not too many seating opportunities. Also space is not particularly adaptable: we ever observed people playing football or doing similar things. However, gas stations offer interesting opportunities for people-watching, there being continuous flows of users of any kind. We cautiously give one point to this variable. Finally, the MDGS scores 17 points, and the PSGS scores 18 points out of 25 in terms of publicness. With all the limits already highlighted in the methodological section ( $(4.1)$ the application of Varna and Tiesdell's (2010) model is quite useful in determining gas stations' strengths and weaknesses. The strengths of the two gas stations which we investigated are that they offer important facilities (food, toilets, light, shelters, and places to sit), that they are safe and controlled, well maintained, highly visible and accessible, they pose no particular 
restrictions to what people can do. Their weakness is that they pose no sufficient incentives to doing a range of different activities.

\section{Conclusions}

In this paper I tried to demonstrate that gas stations are central spaces in contemporary cities. The topic has been approached reviewing the main positions on gas stations, from the pessimistic views which equate them to nonplaces, to the enthusiastic ones which glorify their value in relation to street cultures.

Then I started examining the main causes which make gas stations important. These causes are mainly related to transformations induced by the car on cities, and hold equally good in all countries. Such transformations led F.L. Wright to the visionary proposal for a gas station conceived as a dispersed community center within the Broadacre City. Beyond these causes there are historical and economic reasons that make the social function of gas stations generally more important in Italy than in other countries. These reasons, examined in the paper's third section, are related to the partnership formed after WWII by food industry and oil industry. This partnership started with autogrill in close relationship to the highway network. Later on - thanks to the smaller and more dispersed stations realized first by Agip and then by all the other oil industries - the marriage food + gasoline had a widespread diffusion. The 'implosion' of the gas station into the restaurant/coffee shop together with its high accessibility made of the gas station the place of numerous social interactions.

After having supported the hypothesis of the centrality of gas stations within social contemporary life through historical analysis, I started checking it through fieldwork. Two gas stations in the periphery of Florence were chosen which looked promising, and various analytical and observational tools were applied to them. In both cases the initial hypothesis was confirmed. Both the gas station with annexed a McDonalds and the one with annexed a pastry shop are true social landmark for the inhabitants of the area. Their function goes well beyond the temporary and transient stop, contributing these places to their neighborhoods' identities and being at the core of stable and continuing interactions, especially for younger generations. Of course we can't expect gas stations to be the equivalent pedestrian squares located in the historic city center. Their social live is not as continuous, being intense only in particular times of the day and of the week.

Nevertheless, four out of five of the criteria established by Varna and Tiesdell's model are largely satisfied, and this explains why gas stations are socially active. The application of that model also highlights their main weakness, which comes from the limitedness of the range of activities that can be done over there. However, in a city which is more and more complex and diverse, gas stations can play an important role and this role should be clearly recognized by planners, by designers and by politicians. The policy implications of this analysis are clear and important. It's necessary to go beyond the dominant idea that gas stations necessarily are alienating spaces, or at best just technical artefacts. They are complex structures and as such they need to be designed thinking to the important social function which they detain in contemporary society and life. If we understand the potential of gas stations they can sure become, more than they already are, great places for public life and positively contribute to the provision of services in suburban areas. 
But the implications of our research go far beyond that. Rethinking gas stations is part of a wider process of rethinking public life and public spaces in contemporary human settlements. Although cities underwent radical transformations in the last century, our way of looking at urban life is still closely related to traditional public spaces such as squares and streets. We provide a background and conceptual positioning for the argument of gas stations as public spaces, and a method for their empirical investigation. These can usefully be applied to the study of other spaces which also play an important role in contemporary life but which have been scarcely investigated so far. We argue that developing new research in this direction is vital for overcoming still dominant urban paradigms and for creating the cultural and cognitive conditions for more finely tuned governance of contemporary human settlements.

\section{Acknowledgements}

A conversation held with Marco Cenzatti, at University of California Berkeley in Spring 2013 helped me understanding the relationship between autogrill and contemporary gas stations in Italy. The case study analysis takes advantage of empirical investigations done by students of the course "Rethinking Nonplaces", at the Department of Architecture, A.Y. 20I3-14, under the guidance of me and of Prof. Paolo Costa. Particular thanks to two anonymous reviewers for their valuable comments.

\section{Note}

(I) «One might thus conceive of six legal forms of ownership of public space. Here I provide a typical example of each of the six legal forms of ownership of public space:

- Public ownership, public function, public use (streets);

- Public ownership, public function, administrative use (city halls);

- Public ownership, private function, private use (space leased to commercial establishments);

- Private ownership, public function, public use (airports, gated communities, zoning bonus private plazas, community benefit facilities);

- Private ownership, private function, public use (cafes, places of public accommodations); and

- Private ownership, private use (homes)»

\section{References}

Augé, M. (1995). Non-Places. Introduction to an Anthropology of Supermodernity. London: Verso.

Backes, N. (1997). "Reading the Shopping Mall City". In The Journal of Popular Culture 3I(3), pp. I17.

Bohigas, O. (1986). Reconstrucción de Barcelona. Barcelona: MOPU.

Brighenti, A. M. (2010). "On territorology, towards a general science of territory". In Theory, Culture and Society (27), pp. 52-72.

Brinckerhoff Jackson, J. (1997). Landscape in Sight: Looking at America. New Haven: Yale University Press.

Cohen, L. and Taylor, L (1992). Escape Attempts. The Theory and Practice of Resistance to Everyday Life. 2nd ed. London: Routeledge.

Crawford, M. (1992) "The World in a Shopping Mall". In Sorkin, M. ed. Variations on a Theme Park: The New American City and the End of Public Space. New York: Hill\&Wang, pp. 3-30.

Delaney, D. (2005). Territory. Oxford: Blackwell. 
Desideri, P. (1995). Città di latta. Favelas di lusso, autogrill, svincoli stradali e antenne paraboliche. Milano: Costa\&Nolan.

Eran, B.J. (2012). Rethinking a Lot. The Design and Culture of Parking. Cambridge (MA): The MIT Press.

Fishman, R. (1990) “Megalopolis Unbound”. In The Wilson Quarterly I4 (I): pp. 24-45.

Gehl, J., and Svarre, B. (20I3). How to study public life. Washington, DC: Island Press.

Gillham, B. (2008). Observation Techniques: Structured to Unstructured. London: Continuum.

Ingersoll, R. (2006). Sprawltown. Looking for the City on its Edges. New York: Princeton Architectural Press.

Life International (1960). "Italian Luxury for Export and for Those at Home, too". 26 Sept., p. 17.

Kärrholm, M (2016). "The temporality of territorial production - the case of Stortorget, Malmö". In Social \& Cultural Geography, forthcoming.

Kohn, M. (2004). Brave New Neighborhoods. The Privatization of Public Space. London: Routledge.

Kunstler, J.H. (1994). The Geography of Nowhere. New York: Touchstone.

Marcuse, P. (2004). "The 'threat of terrorism' and the right to the city". In Fordham Urban Law Journal 32(4), PP. I0I-II9.

Miller, D., et al. (1998). Shopping, Place and Identity. London: Routledge.

Németh, J., and Schmidt, S. (20I I). "The privatization of public space: modeling and measuring publicness”. In Environment \& Planning: Planning \& Design 38, pp. 5-23.

Parlette, V., and Cowen, D. (20II). "Dead Malls: Suburban Activism, Local Spaces, Global Logistics". In International Journal of Urban and Regional Research 35(4), pp. 794-8I I.

Parrella, M. (1956). "Stazioni di servizio crocevia della vita moderna". In II Gatto Selvatico II(6), pp. I2-I3.

Ritzer, G. (1999). Enchanting a Disenchanted World: Revolutionizing the Means of Consumption. Thousand Oaks, London, New Delhi: Pine Forge Press.

Sack, R.D. (1986). Human Territoriality: Its Theory and History. Cambridge: Cambridge University Press.

Staeheli, L. A., and Mitchell, D. (2006). "USA's Destiny? Regulating Space and Creating Community in American Shopping Malls." In Urban Studies 43(5/6), pp. 977-992.

Van Melik, R., Van Aalst, I., and Van Weesep, J. (2007). "Fear and fantasy in the public domain: the development of secured and themed urban space". In Journal of Urban Design I2(I), Pp. 25-42.

Variante di Valico (20/3). "A Cantagallo lo chef da Oscar". 8(2), p. 6. Available at: https://www.autostrade.it/documents/10279/4150I/newsletter-33.pdf. Accessed 10 August 2016.

Varna, G. and Tiesdell, S. (2010). "Assessing the Publicness of Public Space: The Star Model of Publicness". In Journal of Urban Design I5(4), pP. 575-598.

Wheeler, R.C. (1960). "Frank Lloyd Wright Filling Station, 1958". In Journal of the Society of Architectural Historians 19(4), pp. 174- 175.

Wright, F.L. (1963). The future of architecture. New York: Horizon Press.

94 | The Journal of Public Space, I(I), 2016 | ISSN 2206-9658

(C) Queensland University of Technology 


\title{
Guerilla Eats and Bicycle Espresso. The Changing Contemporary Food Culture of Urban Helsinki
}

\author{
Mika Savela \\ Canadian Centre for Architecture, Montréal, Canada \\ mika@mikasavela.com
}

\begin{abstract}
The Finnish urban food culture traditionally differs from continental European traditions.

Restaurants, bistros, eateries or street food have never been similarly integral to everyday life as perhaps in many world cities. In Helsinki, the relatively young urban history, strict regulations on the sales of food and alcohol, diminishing food traditions, modernist urban planning and strong public control of the cityscape, have all contributed in limitations regarding urban food culture. However, since early 2000s, demand for more diverse urban food and restaurant culture has surged among the younger generations along with a rediscovery of domestic culinary traditions. Public debates and activism concerning the rigid bureaucracy related to food culture have resulted in culinary culture strategies and re-considering food as part of the urban culture, contemporary practices, and development of urban districts. For Helsinki, the relative success of these changes has been integrally connected to citizen campaigns and information distributed in social media, as well as previous stagnation of both urban food culture and public policies. The paper looks into small-scale citizen-led cases of urban food culture development in Helsinki over the past years, with focus on the story of "Restaurant Day", its origins as an illegally organized temporary event turned into a global phenomenon - before its obliteration in a post-temporary reality. The cases are set against histories of Finnish food culture and current viewpoints on foodways as generators of urban groups and new identities. By reviewing the handling of contemporary Helsinki-based food practices, especially in media and public documents, the paper evaluates how urban food culture and the sense of ownership in public space and the city at large have activated communities and created actual policy changes.
\end{abstract}

Keywords: urban culture; food; Helsinki; events; public space; urban foodways; Restaurant Day.

\section{To cite this article:}

Savela, M. (2016). Guerilla Eats and Bicycle Espresso. The Changing Contemporary Food Culture of Urban Helsinki. The Journal of Public Space, I(I), 95-I I2, DOI: 10.5204/jps.vlil.I3

This article has been peer-reviewed and accepted for publication in The Journal of Public Space. Please see the Editorial Policies under the 'About' section of the journal website for further information.

\section{(i) \$

This work is licensed under a Creative Commons Attribution - Non Commercial 4.0 International License. https://creativecommons.org/licenses/by-nc/4.0/ 


\section{Introduction}

The image, identity, history, and soul of many American cities can be captured in the foods that have come to define their unique culinary landscapes. It is almost impossible to envision these cities without the sights, smells, sounds, textures, and tastes of the edible environment overtaking the individual: the charred-molasses barbecue of Kansas City, the heft of a golden Chicago pizza, the feel and peel of a spicy New Orleans crawfish boil. Perhaps nowhere else in the United States is this more the case than in New York.

The above quote from the preface of Gastropolis (Hauck-Lawson and Deutsch, 20I0), a book on New York and the American urban food culture, exemplifies the starting point of this overview of Helsinki's contemporary culinary setting in multiple ways. Firstly, it serves to remind of the sheer difficulty in finding similar popular, not to mention global quotes related to Helsinki. Secondly, whatever might constitute as Finnish food culture, does not traditionally stem from cities, or a particular Finnish urban culture or history, but instead from a rural past and its later idealizations. Thirdly, as the quote speaks volumes of the power of food in capturing the soul and essence of cities in a popular manner, it perhaps to an extent validates the attempt of this paper in tracing shifts in the food culture related to what could be described as a larger urban soul-searching of the Finnish capital in the recent years. Helsinki, after all, is one of the still growing, young metropolitan regions in Europe (Laakso, 2012), and its cultures and urban identities are still in a constant flux. In general, the theme of food in cities or urban foodways has surfaced into the mainstream culture in several ways. While definitely a global issue, food has also become central to current lifestyles, especially in the Western world. Slow food, supper clubs, urban agriculture, local production, farmers' markets, food waste and street food have all become increasingly vibrant practices - with much emphasis on the pleasure of food as part of daily life - contributing into the role of food in new urban identities. (Levi, 2015: 233). Origins of food, its production, aesthetics, authenticity, healthiness, smartness, traditional values and even the related social networks and contexts have played into the current changes in the contemporary urban food culture in many cities globally.

Furthermore, food has become central in creative urban economies, foodism and even spatial practices, turning into forms of community participation and "DIY urbanisms". Over the recent years, such themes have been increasingly covered in research as well as by several design practices that have begun to work with the theme of food. (e.g. Zeiger, 20II, or Miazzo \& Minkjan, 2013; Taussig, 2016) However, as interest in food has started to display public and urban dimensions, various policies and the politics of food have become increasingly urgent, as is the case with Helsinki.

While the focus of this paper is in contemporary urban developments related to food in Helsinki, elements of the city's history as well as traditional Finnish habits and practices should be first understood, as they offer insight into the currently undergoing cultural changes. The paper attempts firstly to specify, why contemporary urban food culture has had such a fertile ground in Helsinki, and how the urban way of life in Finland in general has differed from a more general European or Western contexts. Here, the concepts and terminology regarding foodways as urban culture and heritage are also discussed.

Another history the paper touches upon, relates to the strong regulatory and bureaucratic history regarding Finnish restaurant culture, food safety, alcohol serving and consumption at various levels of government. These topics are vital to understanding the currently 
popular de-regulation rhetoric concerning urban food culture of Helsinki, as so many of the recent developments have resulted in historically unprecedented public resistance towards food-related guidelines. At the same time, the modernist origins of such sanitary regulations, state control and nation-building ideals still form the basis of Finnish urban planning and the welfare state project. As such, changes in urban food culture seem to be both signaling and catalyzing larger changes that are taking place in urban Finland. Against these histories and themes, the paper continues to look into case studies of recent urban food culture developments in Helsinki over the past years, with focus on the relative success story of Ravintolapäivä (Restaurant Day), which started in $201 \mathrm{I}$ as a oneoff protest event, eventually turning into a prize-winning globally celebrated food festival, utilizing design and technology as effective means for networking and urban participation, and also manifesting as spatial urban interventions. Other recent cases, such as the Camionette café truck or other mobile installments have brought the issues of aesthetics, use and control of Helsinki streetscape under a new kind of public consideration. In addition, entirely new events, institutions and planning strategies are spreading and signifying that these changes have not yet reached their saturation point among the great public and that new forms of creativity, culture and economic activities are still created around the theme of food and the city.

Finally, the paper proceeds to evaluate if such described developments are in effect part of a larger cultural shift in urban Helsinki - and how the city is currently positioned in the viewing of urban foodways, and "food and cities" as a thematic. A further consideration is the dual role of food-related practices in contemporary Helsinki as a non-confrontational "training ground" for building and expressing new and more diverse urban identities, also in relation to people's right to the city, and the design of public services and urban governance.

\section{Food as Urban Culture}

While the general understanding of "food as culture" is almost universal, the relationship of food and the city has not become such a socially or culturally nuanced topic until recently. With ever-increasing global urbanization, the everyday connection of food and urban people has also received more critical dimensions. Characterized as urban foodways, the varied patterns of food in the city have been defined readable as forms of human communication and intangible cultural heritage, where issues like identity, race, ethnicity, gender, class, ideology and social relations have an impact. (Lum \& de Ferrière le Vayer, $2016,1-2)$ While urban research related to foodways has relatively often focused on cultural heritage reinforcing ethnic identities in multicultural settings (Brulotte \& Di Giovinc, 20I4, 3), considering food as heritage is known to have socio-cultural impacts that in turn generate all kinds of groupings and identities. (lbid., 18) Of course, what such readings suggest is a much more varied study of urban food culture, far beyond the history of restaurants or elements of the local cuisine. In these aspects, critical considerations or updated views on Finnish urban food culture still remain few in numbers.

In the Finnish language, the word ruokakulttuuri (food culture) is commonly used as a way to describe heritage, but as such it lacks urban connotations, referring more plainly to domestic traditions and habits related to food. Compared to the idea of urban foodways, ruokakulttuuri remains tied to a rural or semi-urbanized Finnish landscape, where 
celebrated food items such as cloudberries, venison, wild salmon or bear meat have almost nothing to do with everyday urban lifestyles or living traditions, serving more as markers of a claimed identity or self-exoticization. (Kolbe, 2005) In fact, if studied as foodways, the heritage suggested today by ruokakulttuuri can be seen as a rather problematic collection of different cultural, historical and ethnic varieties, served as a single, national culture of food. On the other hand, due to the exact constructed and preserved homogeneity of modern Finnish society and its relative isolation, the culture of food in Finland has in turn been very homogenous, making it impossible to study as an urban melting pot.

Yet, the traditional narrow definitions of ruokakulttuuri have become increasingly obvious in the urban context. In the past decades, Helsinki has continued to grow, as well as becoming increasingly diverse. (Erjansola \& Haukkavuo, 2016) Here, it should be accentuated, that by European standards this late and somewhat subdued development towards globalization and multi-culturalism is entirely different from many world cities, or even neighbouring capitals. Thus, for Helsinki, as projected by the definitions of urban foodways, similar to many other urban dynamic forces, it could be said that food has slowly started to manifest itself in previously non-existing social and material ways, forming new group identities and becoming a site of intergroup communication. (Lum \& de Ferrière le Vayer, 2016, 6) Indeed, the growth of urban diversity along with globalized urban lifestyles could be seen as one of the special reasons as to why changes in the urban makings of Helsinki have recently manifested themselves especially in relation to food.

\section{Brief Urban Food History of Helsinki}

Kaupunki on muuttunut / mutta ei järin paljon / muistamme sen värin / joka oli harmaampi / silloin ei ollut yhtään eurooppalaista vaateliikettä / olutta oli vain ruokailijoille / koko paikka muistutti Neuvostoliittoa

The city has changed / but not that much / we still remember its color / far more gray / without a single European fashion chain / beer was only served with food / it was just like Soviet Union

Excerpt with translation from "Helsinki” (1996) a pop song by Ultra Bra. Lyrics by Anni Sinnemäki

To understand exactly why contemporary urban lifestyles and public events have driven changes in practices related to food in today's time, the history of urban Helsinki and the history of its food culture should be explained further. For instance, at a glance, visual historical evidence like $19^{\text {th }}$ century photos of Helsinki will set a scene similar to almost any Western European small city, equipped with restaurants, bakeries, cafes and park pavilions. The turn-of-the-century food culture appears as "urban" as it probably ever was at the time. However, the pre-WWI Helsinki, is in many ways not a reflection of the mono-cultural narrative that Finland as a nation would built for itself in the modern era. Instead, urban life in the $19^{\text {th }}$ and early $20^{\text {th }}$ century Helsinki was entirely dependent of one's social class, language, wealth and even nationality. This is why in the context of Helsinki, there exists no direct lineage between historical manifestations of urban food culture, and how the contemporary food scene has come to look like. Instead, these histories should be understood as chapters with certain discontinuation points. 
Helsinki was originally founded as Helsingfors in 1550 off-site from its current location by the order of King Gustav I of Sweden. Intended as a Swedish-ruled rival for burgeoning Hanseatic trading posts like Tallinn, it failed to gain momentum, even struggling to exist for centuries to come. However, in 1748 plans were made for a sea fortress outside of the modern-day Helsinki. During the decades long construction work, the Sveaborg island, destined as a stronghold against Russia, developed into a much larger and vibrant "city" than Helsingfors ever was. Thus, Swedish navy officers, some of who had served abroad in France or England, were the originators for an international urban food culture in Helsinki (Soini, 1963, 240-24I), which at a time, was a mere peripheral "colonial" $18^{\text {th }}$ century township next to a major military installation, with almost no Finnish-speaking (or Finnishidentifying) population - let alone a sense of a Finnish urban culture.

After Finland's 1809 annexation to Russia from Sweden, Helsinki became the capital of the Grand Duchy of Finland in 18/2. The establishment of this brand new centrality in the Baltic region provided opportunities for many European merchants to arrive and set up or expand their businesses in close proximity of bustling St. Petersburg, half-way to Stockholm. (Soini, 1963, 30I) The steady flow of immigrant entrepreneurs produced a cosmopolitan atmosphere, where in fact non-Finnish speakers would be a majority. (Sillanpää, 2002, 254) From this era, the imagery of food in the city, is extremely similar to many European capitals at the time. Hotels, restaurants, Swiss confectioneries and cafés catered to foreign residents or predominantly Swedish-speaking upper classes. Restaurants would also serve especially tourists and travelers, such as Russian aristocracy or visitors to the "far North". At major railroad junctions and visiting destinations, restaurants of high international quality popped up, employing Swedish or German staff and catering French menus. (Ruokatieto, 2016) The common people in Helsinki, would instead buy groceries from the markets, farm, fish or cook in primitive conditions at home, or find a selection of street food vendors and worker's eateries (Nevalainen, 2013).

Throughout industrialization, and especially after Finland's independence from Russia in 1917 and the following civil war, the Finnish-speaking population of Helsinki would grow into a ruling majority. (Erjansola \& Haukkavuo, 2016) Existing urban food culture and restaurants, which could have otherwise continued along their European style existence, with newly urbanized rural Finns possibly adopting previous habits and diets, suffered an almost deadly blow with the alcohol probation law, in place from 1919 until 1932. In hindsight, it has been estimated that the probation era resulted in a somewhat warped role for restaurants in the food culture of Finland, lasting well into the 1990s. (Sillanpää, 2002) Due to the temperance movement's strong social narrative, restaurants became synonymous with social and urban ails. For instance, women could not enter restaurants unless in company of men, suggesting that restaurants were, deep down, sinful establishments. This was not helped by the fact that alcohol was still served in secrecy, distilled at home and smuggled in massive quantities. Restaurants came to be considered places appropriate for moderate celebration or occasional dining, but not belonging to the "real" everyday life, where sober, plain and frugal choices would be the celebrated norm. In fact, well into the $20^{\text {th }}$ century, city life altogether was considered morally inferior to living with nature. (Tani, 1995) As a result, even after the probation era, restaurant sales or consumption of alcohol was dealt with suppressing ideological ethos and fear for societal problems, heavy supervision, and spatial regulation for restaurants - instead of normalizing wine or beer as parts of the food culture. Thus, issues related to alcohol 
consumption became overtly central in the Finnish restaurant culture, turning the restaurant space into a legislative device of regulation. (Sillanpää, 2002, 222)

During WWII, Helsinki experienced a sudden return to a more rural production and dependency of basic farming produce. Food was rationed and store shelves remained empty of import products. Finnish traditions of foraging, fishing and hunting became valued forms of coping with the demands of wartime. On the other hand, the urban relationship with food, continued to be highly divided by wealth, limiting the choices and menus of working class families. Urban poverty with homogenous post-war culture and ideals meant that the urban foodways of Helsinki were in effect limited in diversity and choice.

(Kokkinen, 2012) In the process of paying massive war compensations to the Soviet Union, good housekeeping and self-sufficiency was valued more than fine dining, snacks or street food, and many Helsinki families would continue to bring back food from the countryside, as Finland as a country was only in the process of urbanization. In such context, few could afford to perceive restaurants or food culture in Helsinki as a particularly urban experience or delight, enabled by the life in the city.

It might sound bold to state, that because of these histories, no classic "Finnish cuisine" truly developed. Food remained tied to local traditions rather than city consumption. The short jump from a predominantly rural existence into modernist urban setting generated a societal narrative. Health and sobriety were encouraged, and "Finnishness" was defined through active relationship with nature and participation in a harmonious and uniform welfare state. Considerations such as restaurant culture were not a shared generational experience. (Sillanpää, 2002, 225) Finnish ruokakulttuuri became a selection of food items that enforced the storyline built the country, its deep connection with nature, unique and pure ingredients. In reality, a loss of traditions, uniformity of society and modernization were already affecting the society, as entire generations started to move to cities, and Helsinki was receiving thousands of new residents per year. Furthermore, a strong consumer cooperative movement gained momentum, and started operating a variety of convenience stores, small eateries, cafés and large scale eateries - while in some ways enforcing food culture as social issue, rather than an urban phenomenon. School meals, too, would contribute towards a Finnish monoculture of food. In their normal lives Helsinki residents of the 1960-70s would retain a modest menu of fish, meat, potatoes, bread and porridges and would only slowly begin to explore food and cooking as part of a lifestyle choice. Slowly throughout the 1980s, larger chain stores would spread to suburbs and some ethnic variety would emerge, and expediting the supply and demand for imported products. Street food would be modestly available in general. Towards the 1990s, the first wholly urban Finnish Helsinkians caught first glimpses of a revival of international restaurant culture, only to be faced with the heaviest economic recession since the 1930s in 1991.

In today's Finland, the market share of the largest consumer cooperative supermarket chain is around $45 \%$, with the main competing group controlling a $35 \%$ share. (Peltoniemi, 2013) Such supermarkets in varied sizes, have today replaced almost every small food stores in Helsinki. The gradual build-up to such an extreme duopoly of food retailers have made the everyday experience of grocery shopping highly uniform all around the country - muddling the differences between an urban and rural selection of food. As supermarkets have overtaken the food sales, traditional food markets of Helsinki have diminished in size, having partly given away to tourism, selling less and less fresh produce for actual day-to- 
day consumption. Together with high taxation on food, labor and services, the general prices for food have stayed relatively high (Eurostat, 2016).

\section{The New Urban Identities}

Finland is a country with thousands of lakes and deep forests. Its northern location makes winters long and summers short. The growing season is also short, and accordingly, when fresh produce, vegetables and fruits are in season, they are prized and served in abundance. Almost every household does some preserving for winter, be it homemade strawberry jam or pickled cucumbers. Most households have freezers where they can store produce from their own garden. (Taimi Previdi.

The Best of Finnish Cooking, 1995, Hippocrene books, New York)

The quote above represents an international-style "cookbook description" of Finnish food culture. While somewhat truthful in describing past Finnish generations and their rural or semi-urban roots, in today's view, talk about "almost every household" making preserved produce from their gardens is mostly inaccurate. This is the result from continued urbanization, where today a significant number of Finns are now second and third generation city people compared to their parents. While Finnish attitudes related to food are undoubtedly changing and following international trends, Helsinki metropolitan area as home to about $30 \%$ of the country's population (City of Helsinki, 20I6) is naturally showing the most visible signs of this development. Thus, new kinds of observations and concerns related to food culture have become more prominent among urban Helsinkians. While positioning high in many life quality and livability rankings compared to the availability of street food in cities such as New York, Helsinki has never truly produced such world-classics as hotdogs or bagels. Having no Chinatown or Little Italy, alongside the comparatively very small number of immigrants - still at around I3\% of population (City of Helsinki, 2016) - has made also the ethnic variety of food scarce. Thus, as urban generations are growing in numbers, the lack of variety and the increasingly voiced comparisons with other cities and countries have resulted in frustration with urban management, decision-making and future planning, seen as slow and bureaucratic processes, discouraging global-style urban experiences. A sentiment shared by many Helsinki residents today, has been that city life in general should come with the perks and benefit of urban density. Popular Facebook discussion groups such as "More City in Helsinki" or blogs like "Urban Finland" and "Helsinki Cyclists" have formed, asking for more value in the urban existence, through better planning, more variety, creativity and sustainability. (Boyer and Hill, 20I3) It is in this mixture of calls for quality urban life that also food-centricity and the appearance of urban foodies, food magazines, TV-cooking shows, online culinary maps and recipe blogs have also reached the Finnish cultural mainstream. In the course of a mere generation, global food culture along with a global understanding of the "urban" has opened up for many Helsinki residents in an unprecedented way. New restaurants have been opened by first generations of chefs returning after apprenticeship stints abroad. New corner stores, downstairs bakeries and neo-Finnish local food markets, and organic options have become sought after among younger families who unlike their parents, now prefer to live in predominantly urban districts and demand them to be planned accordingly, and in many ways. (Lindblom \& Mustonen, 2014 \& 2016) 


\section{Urban Movements and New Technology}

...stop treating Internet like it's a different thing and start focusing on what you actually want your society to look like.

Peter Sunde, co-founder of now defunct "The Pirate Bay" file-sharing website. Vice Motherboard, December II, 2015

If only some years ago tactical or guerilla urbanisms were described happening wherever "residual urban sites and industrial lands have been occupied and converted into new uses by citizens and communities" (Hou, 20l0, 2), today the simple act of "occupying" or "hacking" is perhaps developing towards "disrupting" or overriding old practices of spatial and cultural production. (Zeiger, 20I2) As the historical limitations of participating in the public sphere have already expanded (Hou, 20l0, 4), the significant power of social media as a more inclusive platform has been displayed, compared to traditional methods of sharing information about urban events or planning. Digital communication has increased the accessibility of urban information, and widened its public reach across different ages and social groups.

Finland adopted the use of mobile phones and internet relatively early. The widespread access to technology and the concentration of well-educated urban population in Helsinki, have also contributed in the formation of new types of urbanisms in Helsinki. Social media has enabled an extension to the public sphere, where large enough groups of people can be formed as to give an impression of movements. While many of the fundamentals of social media today can be criticized for their corporate-driven, popularity-based and commercially-biased viewing of the world, for dispersed and traditionally "weak" urban cultures such as experienced in Helsinki, outlets like Facebook have offered new opportunities. Digital technology has made it possible to gather or "hang with friends" despite the grim realities of the Nordic climate conditions that limit the use of traditional public space. It can be said that the critical masses of "followers" enabled by social mediarelated events alone in many recent urban movements in Helsinki have outweighed the traditional planning participation or opinion polling, or any other means of distributing "urban information".

Since the early 2000 s, Helsinki has experienced a strong rise of pop-up events and festivals and to a large part, much of the reach of information of such events has been based on social networks. This type of event economy and hosting activities as consumable urban experiences has worked as a response to a public yearning for urban content. In the hands of the new urban class, these events have also been turned into campaigns and creative practices that have then found support in popular outlets and audiences. (See, Jyrkäs and Luoto, 2014 or Niemi, 20I4) It could also be argued that current activities in Helsinki food culture are not merely about reclaiming public spaces with expectations on food but introducing and trying out new forms and models of production of urban culture, space and practices.

The de-facto role of social media in such developments in Helsinki has been particularly central in especially two cases related to urban food culture that are studied next. Both have already received interest in their early stages from various observations of creative 
urbanisms (Boyer and Hill, 20I I), but considerations on their longer term impacts are worth further discussions.

\section{Pop-Up Case: The Restaurant Day}

The Restaurant Day (Ravintolapäivä) has been one of the most successful urban events to come out of the contemporary Helsinki, eventually becoming "the biggest food event in the world". (Ravintolapäivä, 2016) Started in 20I I as illegally organized low-key event dubbed by the media at the time as "Internet mutiny", it quickly grew into an international brand - and perhaps as such, out of its original setting. The origins of the event were very simple as the first Restaurant Day was run merely as a public Facebook event, orchestrated by three individuals Timo Santala, Antti Tuomola and Olli Sirén, who had teamed up after sharing frustrations of friends and acquaintances over the many regulations of running a restaurant in Helsinki. The three men themselves decided to try and sell food and drinks in the streets from the back of a bike as a protest against the regulations, inviting others to do the same, and enjoy food without restrictions for a day. The call was popular and on May 21 st, $201 \mathrm{I}$, some 45 "restaurants" were opened. They came in all forms and levels of ambition and it seemed that people had a good grasp of what the event was about. Prior to the day, the idea had garnered wide media attention, because of its "guerilla" mentality. While people were accustomed to May Day picnics or sampling market food, the idea of selling food to others without permission seemed somehow radical. People knowingly did something that was technically illegal, yet fun and desirable. Semi-serious speculations were made over what would happen. Would there be arrests or raids by the health inspectors? Would the police intervene? Would people be fined or arrested? In the occasion, newspapers and media would pitch stories on how difficult for an entrepreneur it was to open a restaurant and how debilitating the web of regulations seemed. At the end of the day, no one was arrested. The organizer's own restaurant, selling tapas from a bike, as well as event itself were declared a success. On the second Restaurant Day in August 201 I, 190 restaurants in Finland and some abroad were opened. After two years of gaining momentum, the day held in May 2013 had already gathered over 1,700 one-day restaurants in 30 countries, cementing its popular success and spawning several write-ups in the press. Over the years, restaurants were crafted with all kinds of spatial and conceptual ideas and various levels of professionalism. The event was fixed to run every three months, happening in all seasons and weather conditions, while the figures of pop-up restaurants per event day still remained above I,000. (Restaurant Day, 20 I I-16)

Once started, the Restaurant Day quickly became a media darling and also the recipient of many awards, some juries rewarding its merits in promoting food culture, some seeing it as an urban intervention citing its positive influence to communities and contributions to a self-made food culture. In 20II the Ministry of Education and Culture of Finland awarded the organization with the Finland Prize, positioning it on par with notable national artists and cultural figures. The City of Helsinki that had originally advised against the event, started to use its media buzz in its own marketing. The awards and recognition provided unprecedented validation for an event that had sprung from a Facebook activity only some years earlier. 
After a successful run of five years, in May 2016 the Restaurant Day published a statement on their Facebook page, which quoted founder Timo Santala:

While the international food carnival is a great event, it no longer serves the original purpose of Restaurant Day. We wanted to show people that a pop-up restaurant can be opened anywhere and anytime. At this point, an enormous amount of pop-up restaurants are opened worldwide four times a year, but only a handful outside those days. Restaurant Day has never asked - or gotten - any kind of special permits or exceptions to regulations. All pop-up restaurants participating in Restaurant Day can be realized on any given day. Therefore, from now on, every day is Restaurant Day.

Thus, in a timespan of five years, the temporary urban event had become popular enough that it seemed to have served its purpose, in introducing the anti-bureaucratic tool for adding "fun" in to the city it had originated from.

In hindsight, there are many reasons as to why the Restaurant Day became such a phenomenon in the eyes of the great public. A simple reason, evident especially when viewed against the culinary histories and urban culture of Helsinki, was that the event seemed to present a simple solution to difficult questions: how to claim back the city, how to enjoy urban life, how to start-up new vibrant urban practices. It should also be noted that throughout its existence, the event organization has operated without the exchange of money and event sponsors have been turned away. The anti-commercial and anticorporate quality of the Restaurant Day has also been factor in its success, making it both extremely easy and desirable to participate in a people-centered form of urbanism.

Certainly, the directness of action has worked against the frustration of many contemporary Finnish city-dwellers over the regulated and monopolized culinary culture. For the average Helsinkian, the collection of new food experiences and a sense of urban happening have been undoubtedly most welcome.

Furthermore, a sizable portion of all the restaurants that have popped up during the years in Helsinki have been ethnic-themed. Often simple staple dishes from other cultures have made their brief appearance. For some, the day has offered a first opportunity in trying typical dishes from other food cultures and urban settings, for others it has provided the consolation of experiencing a decent specimen of a typical international treat, otherwise unavailable in Helsinki. The popularity of ethnic varieties in the Restaurant Day is telling of an unfulfilled potential diversity of food and cultures in Helsinki, as many cuisines and cultures are currently underrepresented, yet familiar and popular in many world cities. In retrospect, Timo Santala as one of founders has even stated his travel experiences as inspiration for the Restaurant Day, observing a more liberal street culture in Central and Latin America: "I felt that something was missing, that the rules and bureaucracy prevented people's creativity from being unleashed, and a lot of good ideas don't come to light because things are just too difficult or they're not allowed." (Bosworth, 20I5) In short, Restaurant Day's history touches upon many of elements, developments and concerns mentioned in the past chapters on regulations and the Finnish society, and with hindsight, the ultimate success of the event seems an almost self-fulfilling prophecy in these aspects. Here, echoes of past generation's fears of the negative social effects of restaurants, and potential anarchy caused by de-regulation can be heard in the first reactions and media responses. However, the Day's development also provides a case in how its success is connected to accessible modern technology and good understanding of contemporary urban culture and event economy. While first seen as an act of civil 
disobedience, the Restaurant Day was instigated by young urban professionals working in event production, equipped with skills and understanding of how popularity might work in advancing a thought into a public opinion. Utilizing personal connections of creative networks, many elements of the event and its promotion happened quickly, and at a low cost. A fully-fledged website was created for free by people interested in the project, enabling credible and visually pleasing communication with the global audience. A smartphone application was developed with volunteers as well as integration to locationbased services, so that the pop-up restaurants could be pinned on map services. Weaving existing technologies, design and social media into the event has been executed as in any professional project. As such, the Restaurant Day became technologically the most impressive public service of Helsinki, whereas anything provided by the city government at the time, seemed backwards, hindered, and out of touch with what the citizens seemed to be already navigating at ease. The technological success is also a sizable demonstration of how capable normal individuals were in using the tools available, suggesting that almost everyone could start urban movements. This has become well-observed in many recent urban protests. But it can also be suggested that social networks are in any case very much connected with urban foodways today, as they naturally intersect with the "information ways" of contemporary urban life.

As the Restaurant Day was seen maturing, its novelty factor started to naturally stall. Other urban events were taking elements from its operating model and technological prowess and the culture of pop-ups has in general become more mainstream. Still, its legacy over contemporary Finnish urbanism and urban food culture remains undeniable. Undeniably, for Helsinki, the Restaurant Day remains one of the first examples of how contemporary urban movements could be started, orchestrated, and designed, and how added value in urban life could be produced through forms of low-threshold activism.

\section{Mobile Case: The Coffee Truck and the Espresso Bike}

Signifying how detailed the clashes between regulations and transforming food culture have become, are some specific cases related to mobile devices and structures for setting up a food establishments. The most famous example in Helsinki in a particular era was arguably the Camionette coffee truck, a vintage van first acquired and restored by a young entrepreneur Tio Tikka, with the aim of selling coffee and crepes on the streets 24 hours a day. He had seen similar trucks elsewhere in Europe and saw the idea as sympathetic novelty if brought in Helsinki, lacking anything of the sort. After spending time and money in the project and with initial positive talks with the city, Tikka received information that his sales permit was denied. The Public Works department had stated that his mobile kiosk would cause negative effects in the "city image" (kaupunkikuva) and "cause disturbances for traffic".

After the negative response, the entrepreneur decided not to complain about the decision to the Public Works department but instead to make his case public, using the tools he had available. After starting a campaign on Facebook - a means available to any young Helsinkian - in matter of days the project page had gathered over 10,000 supporters, who unanimously agreed that the city was being absurd in its claims and the coffee truck was instead exactly the kind of activity that was missing from the "city image". The success prompted also the traditional media to inquire responses from politicians in the city 
council, who could mostly only concur, with promises to look into the matter. Tikka's campaign continued to post photos to the public of his coffee truck parked in various spots in Helsinki streets, introducing a stark comparison with the existing, undeniably uglylooking but purportedly regulated streetscape. Facing elections, and the overwhelming public opinion, the political pressure ultimately turned around the decision and the truck started operating at a fixed location in the summer of $201 \mathrm{I}$.

The reasons first cited for denying permits for mobile kiosks by the city resembled quickly formed panic reactions as the issue was faced for the first time in the modern era. Historically, unregulated food stalls had been part of urban Helsinki in the early $20^{\text {th }}$ century, but had disappeared by the 1960s with expanding sanitary regulations. It seemed as though over the years the city had comfortably been adding regulations, with the thought that it was according to the people's will. When confronted, worries for the cityscape and traffic arrangements served as scapegoats for a lack of new strategy. However, after the initial shock and a certain awakening to the public opinion, in the following summer the city had already started to overhaul its strategy for food trucks even though the concept was entirely unknown in contemporary Helsinki. Unlike in many American cities, for instance, there was no existing framework for operating such businesses and many city officials would truly be unfamiliar with the concept, without knowledge or examples on how food trucks could be managed and what they would look like. A “kiosk-on-wheels” didn't even exist as a category for food permits and there was no expertise in evaluating such projects.

Since early 2014, the Public Works department has come to introduce "agile kiosk activities" (ketterä kioskitoiminta) into their latest suggestion of revised kiosk regulations. Today, some specific areas in central Helsinki are designated for food and coffee trucks, whereas everywhere else agile kiosks can be operated quite freely. In the instructions, a mobile kiosk carries the definition "registered vehicle or carriage." At first, with hopes of selling coffee from a bicycle equipped with gas-powered espresso makers, some entrepreneurs were left disappointed as bikes would not fall under the definition of registered vehicles, leaving such sales to be regulated by the stricter national food legislation. Again, such novel ideas of entrepreneurs were almost thwarted simply because they could not have been anticipated by the officials. Today, selling coffee from a mobile bike in Helsinki requires no permit, but the challenges are more related to establishing a culture of mobile kiosks, beyond the idea of doing so based on imported examples.

\section{Conflicts, Policy Changes and Legacy}

What remains as the most interesting outcome of these perhaps most famous cases in recent events in urban food culture of Helsinki - the Restaurant Day and the coffee truck - is their quick effect on city policies. In both cases the conflicts arising from old regulations and new endeavors became escalated in social media to such an extent that denying the will of the public change would have been politically impossible. For the average Helsinki resident craving for more urban food variety in the city and less regulation over urban opportunities, the conflict between the views from the administration and the prospect of missing out on yet another urban experience quickly began to dominate the discussion. Today, the set-up of new trendy urban projects similar to urban agriculture, activism, reclaiming or reusing and appropriating public space tends 
to align, similarly positioned as the opposite of bureaucratic sounding policies and planning. Bringing regulations under public examination has provided a precedence for social media commentators, news outlets and different organizations to take a stance in their evaluation of any new developments in the urbanism front.

What is also remarkable is that the Restaurant Day has today become an official anomaly within the city management culture. On multiple fronts city departments have listed the day as a special item in their policies. Today, the Public Works Department of Helsinki publicly states it "doesn't want to hinder the popular event" offering only advice for restaurant keepers on tidiness. The city's Environment Centre, responsible for health inspections today lists a specific chapter on the Restaurant Day type of events on their website, stating that sales of food and beverages is allowed during the one-day festival and no hygiene requirements are imposed during the event. The Centre also recognizes popup restaurants in general in its statement, offering further advice in their organizing. This change of tone has also been visible in statements made by the police authority and Valvira, the National Supervisory Authority for Welfare and Health. In 20 I , the first year of the Restaurant Day event, the authorities co-released statements reminding that the sales of alcohol remained prohibited outside actual restaurants. The wordings again echoed of a past era fears of "unlawful sales", "disturbances" and even "societal problems." On the second year the same statement had transformed into a simple information bulletin for the event participants. On the third year, no further statements were given. Such processes are telling of how Finnish officials seemed at first to be hiding behind citing rules, but with continuous positive public feedback, they ultimately took a more active role in enabling events that were proven to work. In the case of the coffee truck, the real change of policies and views came from the introduction of the novel concept of mobile vending platforms, and the respective missing regulations.

\section{Aesthetical and Spatial Considerations}

For urban Helsinki, new lines of thinking and evolving city governance have happened roughly in two fronts: what has been designed and produced as cultural production, and what has been regulated as urban activities. With increasing interest in food and contemporary tactical urbanisms, the aesthetic appeal and the spatial production of almost any new creative project, automatically seems to speak to current urban cultural consumers, whereas the regulations set by city officials have seemed mostly to gather less enthusiasm and face even hostile campaigns, sometimes unfairly.

This division becomes visible, for instance, in comparing aesthetics produced by different sets of rules. From the beginning of 2014, Helsinki introduced new instructions for outdoor serving areas (terassiohjeet). While the aim of the instructions booklet was to provide clear rules for what is visually allowed and what is demanded for restaurant terraces in the city, taking into account different legislations and accessibility requirements, the instructions were met with anger from the restaurant industry, escalating to threats of removing all existing terraces as a protest because of high costs to the restaurants for meeting the new standards. At the same time, on the other end of the spectrum there would exist a small summer café run perfectly legally from a metal container and hosting a free-form lounge terrace in Kalasatama, an old harbor area waiting for redevelopment. 
The difference between these two aesthetics is that former is seen as permanent, whereas the latter is a designated temporary use.

There remain some unresolved problems in this division. On one hand, undoubtedly for contemporary Helsinki, events and pop-ups have already become a method for contemporary place-making. As a whole they have become the bars, clubs, restaurants, shops, galleries and workshops that have been missing from the cityscape, often taking advantage of the cross-over potential of contemporary urban space, street art and of course, their own particular concepts. In relation to urban food culture, they have become collaborative venues with custom made identities and products, incorporating local talent and production capabilities, fostering an ecosystem of food-related events, rather than displays or offerings of food itself.

These changes are interesting in the sense that, in the realm of traditional urban planning and design, it has been customary to merely wish for things to happen and to fill renderings with people, cafés, exhibitions, parks and multi-use open spaces. It has been easy to declare urban areas as citizen plazas or stages for all kinds of public use. But if thought as contemporary practices, the difference between producing a pop-up venue and wishing for things to pop up in traditional urban design, is that temporary venues have often successfully overruled the original design intentions. In Helsinki, it could be said that food pop-ups in particular have been able to take whatever is wrong, and use it as a starting point for desirable urban culture.

It might also be tempting to see examples of the "reckless" behavior of many pop-ups as purely experimental, and of use only in the special context of festivals and happenings, where the temporariness ensures us that there is no need for concern even though rules and regulations are violated. But if temporariness might become one of the rules, then at the very conceptual level, events like Restaurant Day also signify a shift towards a posttemporary city, where simply a curated or designed flow of urban events happens, and cultural content and public culture gets produced. Of course, at the same time, traditional frameworks, urban foodways and other forms of production should be maintained, as the backlash effect of gentrification or producing overtly engineered events is equally subjected to public opinion as the original popularity of pop-ups.

\section{Further Developments and Strategies}

Ultimately, the recent developments in Helsinki have not only consisted of isolated projects successful in their own right. Instead, what has happened on the strategic level of planning is that food has been put into the programming of the city, and used as a means of achieving development goals. The role of Restaurant Day in this development appears as a significant catalyst. But regardless of the event's popular note, it proves that the policy changes forced down by previous examples of developing urban culture have had a deeper effect on the thinking of what constitutes as strategic design for cities.

While evaluating where the current development is heading is still a work in progress, much of the activities that have been started after and during the Restaurant Day have inevitably benefitted from its working model and the established public and political momentum. As pop-up restaurants or any other events as such are not anymore new - in fact they've become also ordinary and mainstream - the following phase of development in urban contemporary food culture of Helsinki seems to be a shift towards a more 
professional outlook on the subject. Continuous pop-up production has produced experts in the related technical solutions, content, cultural management, consulting and research everything required in generating urban events. However, perhaps due to likeability and the positivity of food, many of these developments have been food-centric and building on the "post-pop-up" atmosphere of urban Helsinki.

As an example, in March 20I4, a new Streat Helsinki event launched street kitchens and block parties in central Helsinki for 20,000 visitors. During two days the event provided sampling of a variety of food created specifically or made available during the event, gathering "exhibitors" from famed restaurants and well-known food operators, from Finland and abroad. It received wide sponsorship from companies and organizations that saw image value in cooperation with the urban food theme, already popular in Helsinki. Taking the event a step further was a miniature conference in the form of food talks that gathered well-known pioneers in the street food scene, who have independently created success stories of food festivals, sandwich trucks, temporary culinary gatherings, in combination with representatives from cities with progressive street food policies and food strategies. However, instead of activists or social media campaigners, the event was crafted by City of Helsinki's Food Culture Strategy team with partners in both public and private sectors. This well exemplifies the current state of Helsinki's urban food culture, where the creation of street food carnival as an event that captures the essence of popular contemporary urbanism and also develops into an international platform, is in essence an urban project that spans into producing, marketing, branding and design, further labeling the city as a contemporary culinary hub, listing "500 conference guests, countless new contacts, new ideas and initiatives" as its achievements.

In a rather poetic turn of events, the Food Culture Strategy originally laid out as a project for 2009-2012, eventually hired Restaurant Day founder Timo Santala as its head in 2015. Today, the strategy unit has at least seemingly become a facilitator in all-around activities governing food and the city. Operating under a city unit called Tukkutori (named after a traditional local wholesale area), the strategy has come to include both the new events and traditional forms of food sales and markets. New start-up concepts include Teurastamo (Butchery) that has been developed as a more permanent food hub hosting restaurants, events and activities, following examples and popularity laid out by pop-up activities. Questions remain whether the adoption of these strategies by the city government will in the long term be able to innovate and keep up with the public demand, or will they also become stagnated as their more regulatory predecessors were.

\section{Conclusions}

The recent fast cycle of culinary culture related developments in Helsinki reflects an ongoing change in the relationship with food and urban space. The path from organizing homegrown illegal guerilla-restaurants to swift policy changes, popular approval and incorporating tactical urbanism tools in city strategy-building, seems to suggest that Helsinki - as the central scene for Finnish urban life is perhaps experiencing a wider change in the valuation of urban lifestyle with kinship towards larger and more international cities. Food culture and urban foodways are changing in accordance with several other new urban signalers, such as the emergence of event economy or smart solutions. Examples of start-up style technological development of events and models of cultural production, such 
as pitching talks or market fair platforms suggest some likeness to the American contemporary urban development rather than the Central European tradition concerning food and the city.

The fact that much of the current Helsinki activities have circled around food, is perhaps partly accidental, but also following a global trend, as food touches everyone in cities and matters related to its production and quality have also become a worldwide phenomenon. In the case of Helsinki, food events instead of art fairs, biennials or fashion weeks, have served as platform for achieving fast changes in the urban culture and space, available to a large number of people. Food has become an easy and benevolent way of expressing expanded urban identities, allowing also culturally more diverse urban displays than what perhaps has been the case previously. As a result, the general Finnish ruokakulttuuri has quickly gone through changes that can partly be attributed to the urban food phenomenon, such as many deregulatory efforts and a surge in restaurant eating, affecting also coming generations who will undoubtedly have different conceptions about food and drink than their parents. This observation alone is already a clear change that has happened during a single generation of Finnish urban dwellers.

Ultimately, events such as the Restaurant Day have provided a framework where creative participation and even social inclusion have taken place. Cases such as the Camionette coffee truck have made city governance more perceptible to ideas and changes in regulatory culture. A combination of popular online platforms such as Facebook, increased closeness with the all-around contemporary urban culture and trends as well as poignancy in aesthetic and technical production, has contributed to the success of urban food events in Helsinki. Sense of empowerment through technology, the explicit and direct public experiences of stronger and more varied urban cultures, have already become more valuable to the general public than observing planning regulations created in the past with only societal well-being and ideological modernist state-building in mind. Risks in this development relate to heavy reliance on events and happenings as a source of liveliness and urban experiences, as well as the relationship of perceived event popularity in social media vis-à-vis the publicness or true social inclusivity of such practices.

So far, the positive aspects of the urban food culture development have been welcomed by the both the Helsinki residents and the city officials and a new wave of planning and management has been formulating as a result. The development and urban experiments in food culture have clearly offered desirable remedies for a particular longing for more urban and more international lifestyles in Helsinki. In essence, urban foodways have become forms of urbanism and urban practices that are familiar to today's Helsinkians. The popularity of "guerilla" food culture or grassroots movements has also driven the institutionalization of urban food, as has been signified by adopting of food strategies and design concepts. What remains to be seen, is how the current development will be positioned beyond the urban cultural shift, and whether it will induce lasting changes, or even becoming an exportable cultural product or a true import replacement for the Helsinki urban setting. What is clear already, is that Helsinki has - with gusto - taken a path of convergence to urban event tactics, food strategies, planning and design. Following these developments in the future should provide an interesting view on how urban foodways may shape current and upcoming urbanisms, and the makings of Helsinki streets. 


\section{References}

Boyer, B and Hill D. (20/3). Brickstarter. R. Hyde (Ed.). Helsinki: Sitra, Finnish Innovation Fund.

Boyer, B. and Hill, D. (20I I). Helsinki Street Eats. Helsinki: Sitra, Finnish Innovation Fund.

Bossworth, M. (20I5, March 4). Helsinki: trail of the unexpected. High Life. Retrieved I August, 2016, from http://highlife.ba.com/articles/helsinki-restaurant-day

Camionette - Café et Crêpes. (20II). In Facebook [Café]. Retrieved May I2, 20I4, from http://www.facebook.com/kahviauto

City of Helsinki Culinary Culture Strategy. (2009). Helsinki: City of Helsinki.

Comparative price levels for food, beverages and tobacco. (2016) Eurostat. Retrieved August I, 2016, from http://ec.europa.eu/eurostat/statisticsexplained/index.php/Comparative_price_levels_for_food,_beverages_and_tobacco

Erjansola, J. \& Hiekkavuo, A. Eds. (2016) Population with foreign background in Helsinki 2015. Statistics, 2016:2. Helsinki, City of Helsinki Urban Facts.

Every Day Is Restaurant Day Now. (2016, May 18).[Press release]. Retrieved August 8, 2016, from https://www.facebook.com/notes/restaurant-day/every-day-is-restaurant-daynow/I0568/208773/043

Hauck-Lawson, A. and Deutsch J. (2008). Gastropolis : Food and New York City. New York, NY, USA: Columbia University Press.

Helsingin ruokakulttuuristrategian vuosikatsaus. (201 I). Helsinki: Tukkutori, City of Helsinki.

Helsingin Tukkutorin toimintakertomus 2013. (2014). Helsinki: Tukkutori, City of Helsinki.

Helsinki - Tallinn. Facts and Figures 2014. (20I4). Helsinki: City of Helsinki Urban Facts. Tallinn: The Development Service of Tallinn City Office.

Hou, J. (20I0). Insurgent Public Space : Guerrilla Urbanism and the Remaking of Contemporary Cities. Routledge. Retrieved 22 April 2014, from http://www.myilibrary.com?ID=2586I0

Jyrkäs, P. and Luoto, K. (Eds.). (20I4) Opas kaupunkiaktivismiin - uutta kaupunkikulttuuria luomaan. Helsinki: Prototype Helsinki.

Food trucks. (2016). Helsinki: Public Works Department, City of Helsinki. Retrieved August 8, 2016, from http://www.hel.fi/www/hkr/en/permits/kiosks_sales_spots/food_trucks

Kokkinen, A. (2012) Miten Suomi nousi köyhyydestä? Tieto \& trendit, I/20I2. Helsinki: Statistics Finland.

Kolbe, L. (2005) Kotimaista ruoka- ja juomakulttuuria. Suomalaisten symbolit. Ed. Tero Halonen \& Laura Aro. Jyväskylä: Atena.

Laakso, S. (20I2) Helsingin seudun ja Helsingin väestökehitys - Toteutunut väestönkasvu ja projektiot vuoteen 2050. Helsingin kaupunkisuunnitteluviraston yleissuunnitteluosaston selvityksiä 20I2:3. Helsinki: City Planning Department, City of Helsinki.

Levi, J. (2015) Ethical Gastronomy: Organic Food, Markets and Marketing. Markets: Proceedings of the Oxford Symposium on Food \& Cookery 20 I 4, ed. Mark McWilliams, 232-240. Totnes, Devon: Prospect Books.

Lindblom, T. \& Mustonen, P. (20I4) Ruokamaku ja legitiimit ruokatyypit helsinkiläisten 25-44 vuotiaiden keskuudessa. Kvartti I/20I4.

Lindblom, T. \& Mustonen, P. (20।6) Kantakaupungissa asuu tyytyväisiä lapsiperheitä. Kyselytutkimus asumistyytyväisyydestä ja asumisvalinnoista Helsingissä. Kvartti I/2016.

Lisää kaupunkia Helsinkiin. (20I2) In Facebook [Group]. Retrieved May 12, 20I4, from https://www.facebook.com/groups/ /840850736I7/

Nelimarkka, M. (20I4) Ravintolapäivä karnevalisoi syömisen. Retrieved May 12, 20I4, from http://www.visithelsinki.fi/majoitu-ja-nauti/syo/ravintolapaiva-karnevalisoi-syomisen

Nevalainen, L. (2013) Torit ja kauppiaat. Keittoja, vellejä, muhennoksia: Työläisten ruokailu teollistuvassa Suomessa. Helsinki: Hotel and Restaurant Museum. Retrieved I August, 2016, from http://www.tyovaenruokailu.fi/p/torit-ja-kauppiaat-2_I.html 
Niemi, J. Starting Succesful Urban Movements. Steep Insights I/20I4 · 28 February 20I4. Retrieved May 12, 20I4, from http://www.steep.fi/research/2014/02/starting-successful-urban-movements/

Peltoniemi, A. (20I3). Ruokakorin hintakehitys. Kuluttajatutkimuskeskus, työselosteita ja esitelmiä I44 - 2013. Helsinki: Consumer Society Research Centre, University of Helsinki.

Poliisi varoittaa Ravintolapäiviä: Alkoholin myynnistä ei selviä rikesakoilla. (20I2, May 14). Iltasanomat. Retrieved May 12, 2014, from http://www.iltasanomat.fi/kotimaa/artI288469043050.html

Pop up -ravintoloissa ei saa myydä tai anniskella alkoholia ilman lupaa. (201 I, November 9) [Press release]. Retrieved May 12, 20I4, from http://www.valvira.fi/valvira/lehdistotiedotteet/pop_up_ravintoloissa_ei_saa_myyda_tai_anniskella_alkoholia_ilman_lupaa

Ravintolapäivä 2014. (2014). [Website]. Retrieved May 12, 2014, from http://www.hel.fi/hki/hkr/fi/ajankohtaista/ravintolapaiva_20I4

Restaurant Day. (20II) [Website]. Retrieved May 12, 20I4, from http://www.restaurantday.org/en/info/about/

Richards, Greg \& Palmer, Robert. (2010). Eventful cities: cultural management and urban revitalisation. [Books24x7 version] Retrieved May 12, 20I4, from http://common.books24x7.com.easyaccess I.lib.cuhk.edu.hk/toc.aspx?bookid=40I54

Ruokakulttuuristrategian raportti. (20I2). Helsinki: City of Helsinki.

Ruokamyynnin sääntely kypsytti Ravintolapäivän. (20I I, November 9). Helsingin Uutiset. Retrieved from http://www.helsinginuutiset.fi/artikkeli/79069-ruokamyynnin-saantely-kypsyttiravintolapaivan

Ruokatieto / Finfood - Finnish Food Information. (2016). Ravintolaelämä käynnistyy keisarikunnassa. Retrieved August 8, 2016, from http://www.ruokatieto.fi/ruokakulttuuri/gastronominensuomi/ruokakulttuurin-muutos-helsingissa/ravintolaelama-kaynnistyy-keisarikunnassa

Salomaa, M. (20।3, December 13). Helsinki heltyi: Kahvila-autoille vihreää valoa. Helsingin Sanomat. Retrieved May I2, from www.hs.fi/kaupunki/a I 386476562992

Sillanpää, M. (2002). Säännöstelty huvi: Suomalainen ravintola 1900-luvulla. Helsinki: Finnish Literature Society.

Street Food Circled the Helsinki City Hall. Streat Helsinki Exceeded All Expectations. (20I4, March 26). [Press release]. Retrieved, May 12, 2014, from http://streathelsinki.com/press

Tani, S. (1995) Elokuvien maaseutu suomalaisena mielenmaisemana. Maaseudun uusi aika : maaseutututkimuksen ja -politiikan aikakauslehti. Vol. 3, No. 2. 38-47.

Taussig, M. (2016) Let Us Now Praise Famous Seeds. L'Internationale. Retrieved August 8, 2016, from http://www.internationaleonline.org/research/politics_of_life_and_death/72_let_us_now_praise famous seeds

Terassiohjeet Helsingissä. Ulkotarjoiluun käytettävien katuterassien ohjeistus I.I.20I4 alkaen. (20I3). Helsinki: Public Works Department, City of Helsinki.

Verkkokapina tuo Suomeen yli 40 piraattiravintolaa. (20II, May 19). Kauppalehti. Retrieved May I2, 20I4, from http://www.kauppalehti.fi/etusivu/verkkokapina+tuo+suomeen+yli+40+piraattiravintolaa/201 I05 75603

Zeiger, M. (20I I, September) The Interventionist's Toolkit: 3, Our Cities, Ourselves. Places Journal. Retrieved August 5, 2016, from https://placesjournal.org/article/the-interventionists-toolkit-ourcities-ourselves

Zeiger, M. (2012, March 27) The Interventionist's Toolkit: 4, Project, Map, Occupy. Places Journal. Retrieved May 12, 2014, from https://places.designobserver.com/feature/the-interventioniststoolkit-part-4/32918/ 


\title{
Public Space for Street-Scape Theatrics. Guerrilla Spatial Tactics and Methods of Urban Hacking in Brisbane, Australia
}

\author{
Christopher Cox, Mirko Guaralda \\ Queensland University of Technology, Brisbane, Australia \\ Creative Industries Faculty, School of Design \\ christopher.cox@connect.qut.edu.au|m.guaralda@qut.edu.au
}

\begin{abstract}
It could be argued that architecture has an inherent social responsibility to enrich the urban and spatial environments for the city's occupants. However, how we define quality, and how 'places' can be designed to be fair and equitable, catering for individuals on a humanistic and psychological level, is often not clearly addressed. Lefebvre discusses the idea of the 'right to the city'; the belief that public space design should facilitate freedom of expression and incite a sense of spatial ownership for its occupants in public/commercial precincts. Lefebvre also points out the importance of sensory experience in the urban environment. "Street-scape theatrics" are performative activities that summarise these two concepts, advocating the 'right to the city' by way of art as well as providing sensual engagement for city users. Literature discusses the importance of Street-scape Theatrics however few sources attempt to discuss this topic in terms of how to design these spaces/places to enhance the city on both a sensory and political level. This research, grounded in political theory, investigates the case of street music, in particular busking, in the city of Brisbane, Australia. Street culture is a notion that already exists in Brisbane, but it is heavily controlled especially in central locations. This study discusses how sensory experience of the urban environment in Brisbane can be enriched through the design for busking; multiple case studies, interviews, observations and thematic mappings provide data to gather an understanding of how street performers see and understand the built form. Results are sometime surprisingly incongruous with general assumptions in regards to street artist as well as the established political and ideological framework, supporting the idea that the best and most effective way of urban hacking is working within the system. Ultimately, it was found that the Central Business District in Brisbane, Australia, could adopt certain political and design tactics which attempt to reconcile systematic quality control with freedom of expression into the public/commercial sphere, realism upheld. This can bridge the gap between the micro scale of the body and the macro of the political economy through freedom of expression, thus celebrating the idiosyncratic nature of the city.
\end{abstract}

Keywords: urban hacking; street performance; baskin; urban design; Brisbane.

\section{To cite this article:}

Cox, C.; Guaralda, M. (2016). Public Space for Street-Scape Theatrics. Guerrilla Spatial Tactics and Methods of Urban Hacking in Brisbane, Australia, The Journal of Public Space, I (I), I I 3-I 28, DOI: 10.5204/jps.vlil.I4

This article has been peer-reviewed and accepted for publication in The Journal of Public Space. Please see the Editorial Policies under the 'About' section of the journal website for further information.

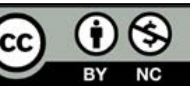

This work is licensed under a Creative Commons Attribution - Non Commercial 4.0 International License. https://creativecommons.org/licenses/by-nc/4.0/ 
Public Space for Street-Scape Theatrics.

Guerrilla Spatial Tactics and Methods of Urban Hacking in Brisbane, Australia

It could be argued that architecture has an inherent social responsibility to enrich the urban and spatial environments for the city's occupants (Deslandes, 20 I3; Jubany, 20I2), but how we define quality, and how 'places' can be designed to be fair and equitable, catering for individuals on a humanistic and psychological level is debated in the literature (Holt-Damant, Guaralda, Gomez, \& Miriam, 20I3), which often deals with these problems on a very analytical level. Public places are idealistically egalitarian and for all citizens in society, but as Orwell (1946) famously suggests, some are "more equal" than others. Architecture, as a politically informed profession of design, urban planning and placemaking, has the opportunity and the responsibility to consider public space with an egalitarian ethic. Certain failings in modernist architecture have demonstrated that humans need more than the mere fulfilment of their basic needs (Orom \& Cervone, 2009). This has been exemplified by Pruitt-Igoe, an infamous housing project which attempted to artificially contrive an environment for the low socio-economic class; once seen as a beacon of hope, the project was a tragic failure in terms of poverty, crime, suicide and segregation (Heathcott, 20I2).

This paper presents a pilot research grounded in the Lefebvrian idea of the "right to the city" and in the notion of idiosyncrasy, a structural or behavioural characteristic peculiar to an individual or group ("The American Heritage Dictionary of the English Language, Fourth Edition," 2009; Coleman, 2013); playfulness and idiosyncrasies transcend preconceived notions of governance, fear and pre-determination. They facilitate freedom of expression and incite a sense of spatial ownership; this will be defined as street-scape theatrics. Public spaces are a stage that demonstrates an intrinsic relationship between idiosyncratic environments and human engagement bringing about a sense of urban theatre. The street, an actor of public space, possesses an infinity of beautiful details, 'each so different from the other that one never encounters the same objects [...] one always finds something new' (Hays, 1998, p. II). This research has been designed to investigate, on a theoretical and practical level, to what extent architectural design can have a sympathy, or consideration, for the user on an idiosyncratic level through harnessing street-scape theatrics. The purpose of this research is to address the value of street expression in both an abstract and literal sense taking musical performances in Brisbane, Australia, as a case study to gather preliminary understanding on how public space identity can be enriched through unstructured activities like busking.

\section{Literature Review}

Public space design is inherently political because it attempts to find a platform for which a collective of individuals can exercise their right to be free (Mensch, 2007). But many spaces today are sterile, devoid of character, and are disjointed from the actual needs and desires of urban dwellers (Borden, $200 \mathrm{la}, 200 \mathrm{lb}$; Gehl, 20I0). Different theories are discussed in literature to deal with a civil and democratic approach to the design of urban environments (Hou, 20l0). Humanism, for example, seeks to establish the best possible life for the largest amount of people possible (Power, 2010). The concept of "greatest happiness for the greatest number" is also an underpinning belief of utilitarianism (Ralws, 1972: 22, cited in MacKenzie, 2009, 76). MacKenzie (2009) states that historically, justice and equality have been mutually exclusive. The fact that equality is now synonymous with 
justice is a modern concept and this has a deep impact in the way we consider contemporary public spaces (Harvey, 20I2). Ultimately MacKenzie highlights how the capitalist idea of satisfying the majority does not necessarily encompass the complex needs of all citizens. Pertaining to the seminal Orwellian text, Animal Farm, classes and different levels of "equality" are regarded as a prevalent human condition. The initial "seven commandments" or for arguments sake, ethical rules of society, are reduced down to a single phrase, 'All animals are equal, but some animals are more equal than others' (Orwell, 1946). As Wilkins (2007) contends architecture can marginalise certain sects of society or socio-economic class whilst "activist" forms of expression shape and sustain communities with regards to the ideologies formed, transmitted, and embedded into the built environment. However, as we see in the production of public space, inherent inequalities can exist based upon the lack of empathy for the user in the planning process. 'The view that planning is, above all else, a political activity [...] has only recently and grudgingly been accepted [...] this was because the professional ideology was essentially one that claims the planning was objective, technical, and as such not political' (Goldsmith, 1980: 126). There are certain behavioural sets involved in the analysis of planning policy. This can serve as a basis for generalization about the embedded political processes and their subsequent effect on planning policy (Torgovnik, 1990).

Gehl (1987) focuses his research on different types of activities within the urban realm and points out how social activities require suitable settings to foster interaction. The underpinning sociality of urban space creates a diversity of social roles and relationships, along with "institutional arrangements" that create social networks essential to efficient social order (Agiurre, 2007). Dangschat (2009) contends that a theory of space is needed by which it is possible to explain the inner logics of socio-spatial exclusion. This is with reference to the social inequalities that exist through respective power relations. Lefebvre (199I) offers some pivotal theories with regards to social space. He states that social space cannot be reduced to the "rank" of a simple object as it is the outcome of a sequence and set of operations. "Not a thing among other things, nor a product among other products: rather, it subsumes things produced, and encompasses their interrelationships in their coexistence and simultaneity - their (relative) order and/or (relative) disorder' (Lefebvre, 1991: 73).

Lefebvre contends that space is not only a product to be used; he suggests that social space is inherently fluid rather than rigid. Further, he observes that repetition in the capitalist city has, for him, 'defeated uniqueness' insofar as the artificial and contrived have driven all 'spontaneity and naturalness' from the fields of architecture and urbanism which should have led to increased levels of diversity. These notions of "spontaneity", "diversity", and the exchange and appropriation of "social space" are all conditions of the street. Miles (1997) contends that the professions of art and architecture align their ideologies to the needs of developers to create "enclaved places". These places are set against the natural evolution of a city in which its dwellers 'determine or at least influence its values and forms' (Miles, 1997: 109). The civic role of public art in providing a voice and a way of expression for citizens is debated in literature (Stevens, 2007); Miles (1997) states that art encourages the use of public places and that making a 'place' for art in the city gives it identity (Miles, 1997: I 17). In Spaces of Hope, by David Harvey (2000) it is proposed that if any political ideology or plan is to work, it must take account of our human qualities. He maintains 
Public Space for Street-Scape Theatrics.

Guerrilla Spatial Tactics and Methods of Urban Hacking in Brisbane, Australia

that, in a utopian sense, we need to learn how to bridge the gap between the personal micro-scale of the body and the macro-scale of the political economy. Through design we must give the individual the right to affect and temporarily personalise their own space within the public domain. This could embellish a renewed right to urban life and the celebration of street-scape theatrics.

The importance of street culture is its ability to reflect societal values on all socioeconomic levels (Gehl \& Gemzoe, 2004). Streets and sidewalks, as juxtaposed to buildings, inherently contribute to the workings of a city through the interconnection of nodes of activity. They serve other purposes than wheeled traffic (Jacobs, 196I). They are the main public places of a city and serve as vital organs for its vibrancy. In many ways the city can only be as good as it streets aesthetically, creatively, and functionally (Jacobs, 196I). Streets are the space where the consciousness of a city can express its self, exchange ideas, and portray a "buzz". It can change the way we think about space because it can promote spontaneous, democratic, and intimate encounters on a human level (Simpson, 2012: 416). This is a level of experience that transcends the city as a consumerist entity. On the streets we can see political protest, social encounters, places of pleasure, places of anxiety, and places of resistance (Simpson, 2012, p4I6). Streets can also be places of performance.

As stated by Cohe and Greenwood (198I: II) 'Street life is a characteristic of cities and towns' this is something that has tended to be undervalued. It can be argued that too much emphasis is placed on the buildings themselves rather than 'the spaces in between then where people interact'. Street-scape theatrics in itself is not a novel idea. It dates back to antiquity, and was highly valued as a form of communication and social interaction (Baird, 2000). Examples of street-scape theatrics are public performances in ancient Rome, renaissance France or modern England (Cohen \& Greenwood, 198I). The tradition of busking, and of human expression in a socio-political context, continues in a modern setting; busking groups are useful in showing 'street tradition as an organic and living thing' (Cohen \& Greenwood, 198I: 18I). However, technological development, to an extent, is the antithesis of musical buskers; this is because music can now be digitally projected into spaces. Music is often used as a commodity, rather than a means of expression and human engagement, often for the purpose of marketing and psychological influences for capitalism. However, the design of urban places and spaces could potentially revitalise the sharing of music in a less consumerist sense and enrich the urban environment.

\section{Methodology}

Busking, as a form of street-scape theatrics, is the focus of this research. Busking, as a definition, will be used to describe musical performance in public space for income and/or pleasure for the artist (other reasons such as exposure, expression, enjoyment, and political motivation may prevail). The desired public space for busking could range from a small to a large area; however, the commonality between all types is a high degree of pedestrian movement and exposure, unless the artist is performing for solitary personal enjoyment. The theoretical analysis has brought to light the importance of Street-scape Theatrics however few sources attempt to discuss this topic in terms of how to design these spaces/places that enhance the city on both a sensory and political level. Therefore 
the research question is how can our sensory experience of the urban environment in Brisbane be enriched through the design for busking?

The research investigates the sensory experience and spatial quality of music in public space, in terms of scale, location and acoustics. The aim of this study is to explore ways to design for freedom of expression and "spatial hacking" through music. It is proposed that the design of public spaces/places could benefit from this way of thinking which attempts to maintain and celebrate the culture and idiosyncrasy of the street and broader urban environment. The methodology for this research is articulated through three different research methods as indicated in Table I.

\begin{tabular}{|c|c|c|}
\hline Method & Description & Aim \\
\hline Case Studies & $\begin{array}{l}\text { A qualitative analysis of public spaces that } \\
\text { have attracted high levels street } \\
\text { entertainment. }\end{array}$ & $\begin{array}{l}\text { I. To study the control over buskers } \\
\text { and street entertainers in } \\
\text { "successful" public spaces }\end{array}$ \\
\hline Interviews & $\begin{array}{l}\text { Multiple interviews with street performers } \\
\text { and musicians. Direct engagement and the } \\
\text { perspectives, experiences, and stories of the } \\
\text { buskers themselves, will provide valuable, and } \\
\text { otherwise un-obtainable, information. } \\
\text { Interview questions primarily relate to ideas } \\
\text { of spatial ownership, personal experience, } \\
\text { territoriality, street performance, unwritten } \\
\text { laws, and social perception. }\end{array}$ & $\begin{array}{l}\text { I. To understand the idiosyncrasies } \\
\text { of Busking to help inform design } \\
\text { decisions } \\
\text { 2. To understand the reasons for } \\
\text { street performance and the various } \\
\text { underlying motivation behind busking } \\
\text { as an activity and form of income }\end{array}$ \\
\hline Observations & $\begin{array}{l}\text { Observations of buskers in the inner city } \\
\text { areas of Brisbane. The types of urban } \\
\text { spaces/places in which these performances } \\
\text { occur will be recorded }\end{array}$ & $\begin{array}{l}\text { I. To identify prominent busking } \\
\text { sites in Brisbane, observe their } \\
\text { characteristics, and draw } \\
\text { relationships to its urban situation } \\
\text { and the spatial qualities that enhance } \\
\text { busking. } \\
2 . \text { To map the acoustic projection of } \\
\text { buskers in the city }\end{array}$ \\
\hline
\end{tabular}

Tab. I. Methodology summary

\section{Research Approach}

When thinking about designing for street-scape theatrics, it is not about contriving a "stage", but harnessing existing conditions favorable for good public interaction. In this way a spontaneous performance can be a product of a well-designed public space, without designing the stage per se. Therefore what elements of a public space contribute to making it a "successful" one? The first and most basic order of a public space is that people attract people. In this sense, a successful public space will have a compounding effect whereby the more people there are using the space, the more people who will want to use the space. Whyte (1980) offers some valuable insight about the general design factors of a successful public space as detailed in table 2 . 
Public Space for Street-Scape Theatrics.

Guerrilla Spatial Tactics and Methods of Urban Hacking in Brisbane, Australia

\begin{tabular}{|c|c|}
\hline Design Consideration & Description \\
\hline Sit-able Area & $\begin{array}{l}\text { Hospitable but come in a variety of combinations to give the sitter choice. } \\
\text { When considered on a human level, miscellany is more attractive than } \\
\text { regulation }\end{array}$ \\
\hline "Triangulation" & $\begin{array}{l}\text { Any element such as a sculpture, piece of art, or performance that can bring } \\
\text { people together into a critical mass. This could be anything that engages people } \\
\text { and stimulates interaction, contribution to the sociality of the space (Whyte, } \\
\text { 1980). }\end{array}$ \\
\hline $\begin{array}{l}\text { Connection with } \\
\text { Street }\end{array}$ & $\begin{array}{l}\text { A good public space has an open and lucid relationship to the street which is } \\
\text { essentially 'the river of life for a city'. A public space is to be a landmark, } \\
\text { something people walk past, point to, discuss, and orientate themselves }\end{array}$ \\
\hline Environmental & $\begin{array}{l}\text { Sun - Highly favourable in winter, natural light in general is important. Water - } \\
\text { stimulates the senses through sound, look, and feel. Water - If present it } \\
\text { should not be blocked off from interaction and use. Trees - shade and } \\
\text { presence of natural environment }\end{array}$ \\
\hline Scale & $\begin{array}{l}\text { If the space is over scale, it fails to bring together a critical mass of people } \\
\text { because people feel vulnerable in the middle of large public spaces }\end{array}$ \\
\hline Amenities & Toilets, Food/Refreshments \\
\hline Safety & To what extent does the public feel comfortable or vulnerable in a space \\
\hline Optional Activities & In public spaces, optional activities are the most prominent (see figure 6) \\
\hline
\end{tabular}

Tab. 2: General Design Factors for “successful” Public Space as set out by Whyte (1980)

The research introduces a theoretical approach based on the work of Whyte (1980), Foth (20II), MacKenzie (2009) and Guaralda (20I3). As detailed in Table 3, five paramenters are taken in considetion in discussing selected case studies. The socio-economic context is evaluated in order to contextualise the space analysed, understand its history, its uses and its general design. Busking is the main activity observed and evaluated in terms of its value as a placemaking exercise aimed to foster social interaction (Gehl, 1987). Activities in public spaces are often subject to a specific set of rules, guidelines and prescriptions. Governance of space has been investigated to understand the institutional framework within which buskers might have to operate. Physical layouts and spatial configurations are addressed to understand the actual design of a case, while soundscapes are evaluated to contextualise busking activity in the broader urban landscape.

\begin{tabular}{|c|c|c|}
\hline $\begin{array}{l}\text { Theoretical/Political } \\
\text { Consideration }\end{array}$ & Description & Method of Investigation \\
\hline Socio-economic context & $\begin{array}{l}\text { General information about the space } \\
\text { (History, Commercial/public/private) }\end{array}$ & Case Studies \\
\hline Busking & Provisions/Value & $\begin{array}{l}\text { Case Studies, Interviews, } \\
\text { Observations }\end{array}$ \\
\hline Control/Governance & $\begin{array}{l}\text { Levels of restriction over the way the } \\
\text { space is used with regards to authority, } \\
\text { permits, and sound levels. }\end{array}$ & Case studies, Interviews \\
\hline Spatial Characteristics & $\begin{array}{l}\text { The spatial elements of popular busking } \\
\text { locations }\end{array}$ & Observations, Interviews \\
\hline Social Preconceptions & Societal views about buskers & Interviews \\
\hline Sound projection & Audibility within City & Observations, Interviews \\
\hline
\end{tabular}

Tab. 3. Research approach 
This approach will be used to draw conclusions about how 'the right to the city' can be enhanced in a socially equitable way for the Brisbane CBD. Social Equity is intended as the idea that 'all social values - liberty and opportunity, income and wealth, and the basis of self-respect - are to be distributed equally unless an unequal distribution of any, or all, of these values is to everyone's advantage' (Ralws, 1972: 22 cited in MacKenzie, 2009: 76).

\section{Case Studies}

Different cities deal with busking in different ways. Melbourne and Brisbane in Australia have been analysed in terms of how their government regulates street-scape theatrics and the unstructured use of public places. Comparing policies and official documents provide an idea of how busking is not always perceived as problematic in the capitalist city (Brisbane City Council, 2012; City of Melbourne, 200I; Project for Public Spaces, 20I2). In Melbourne, buskers have to pass an audition to perform in Bourke Street Mall as 'live performances increase' (Gardiner, 20 I I). According to the City of Melbourne (20I I), a professional busker is a 'performer who busks as their main source of income, has a repertoire that would enable them to perform for at least 30 minutes without repeating a song, and has a website, YouTube, Facebook or other profile'. Despite an apparent high level of opposition to the plans to audition buskers, the resultant decision by the Melbourne council was that permit allocation will come under the scrutiny of a panel of council officials and an experienced busker. According to the city councillors, the Bourke Street buskers are required to demonstrate a higher than average level of accomplishment and a 'unique quality, subtle or dramatic, that gives them an interesting edge and makes them unlike other performers' (cited in Gardiner, 20 I I). Within the rest of the city, buskers must be judged only to make sure they are safe and not offensive. According to the City of Melbourne's Street Activity Policy (20II), it recognises the valuable contribution that street entertainment makes to the 'life and vitality of a city' and states that artistic and cultural life is integral to Melbourne as a creative city. Thus the city encourages performers from all 'backgrounds, abilities and through different mediums to showcase their craft' (City of Melbourne, 20II). The control measures have been introduced on the basis of providing a structured framework as to minimise the complaints, criticism, and other issues relating to the ambience and amenity of the city's public realm.

Queen Street Mall, is a commercial public space in Brisbane, Australia, and has traditionally been considered as the cornerstone of retail and fashion in Brisbane CBD. Queen St claims to attract 26 million visitors a year and contains over 700 retailers and is thus highly commercialised (bnecity, 20I2). Due to its high level of pedestrian traffic, Queen Street Mall has become a popular place for street entertainers and buskers alike. Akin to Bourke Street in Melbourne, Queen Street Mall also requires aspiring buskers to attain a licence for the privilege of using the space. According to the Brisbane City Council, busking licences are free; however performers are required to submit an application prior to attending an audition. Unlike Bourke Street, there are not any council restrictions on the general amount of buskers in the mall at any point of time. There are also no provisions for the length of performance and depth of performance material. A notable audition rule 
Public Space for Street-Scape Theatrics.

Guerrilla Spatial Tactics and Methods of Urban Hacking in Brisbane, Australia

is concerned with the neat appearance of the busker where preference will be given to buskers who are dressed appropriately for the act (Brisbane City Council, 20I2). In both cases performers are requested to possess a permit to perform in central locations; busking is recognised as an important activity to activate public spaces and make them a vibrant component of the urban life. Street performers and buskers will generally set up where a high level of movement already exists. However there is also an effect where buskers draw the public to a space that they otherwise would not have visited. This is particularly exemplified by world renowned public spaces such as Las Ramblas in Barcelona (Project for Public Spaces, 2012). The artful street culture creates an attractive and diverse experience for pedestrians and as a result of its social quality, it is described as the "emotional hub" of the city. This is a key factor for its high usage and for this reason Las Ramblas has become known as an international cornerstone of street art and performance. This effect is also noted in Bourke Street where the existence of cultural exchange brings about its high level of use. As discovered through the interview process, this is a dialectic effect which is not present in Brisbane because the provisions in the CBD do not enhance the notion of street-scape theatrics

The mechanics of the permits in central locations align with the image a city wants to project of itself. The quality of buskers is assessed in order to create a pleasant environment for the majority of city dwellers. While the selection process provides access to the urban stage for a variety of artists, on the other hand the permit structure has an impact on the right of citizens to access and express them in the public realm.

\section{Interviews}

With regards to permits and authority, all five interviewees (Brisbane based) claimed that their negative run-ins with authority are very minimal to non-existent. Therefore, the simple act of exercising common sense, without being publicly obnoxious will be generally accepted by authorities. Interviewee I claimed that he busked across Australia as mode of transience without a permit and recorded no negative run-ins with authorities. The general view is that there has to be some level of competency when providing entertainment in a public space because a performer is using it in "bigger ways" than the general public. Therefore there is a responsibility and onus that you are adding to the urban experience, not detracting from it. Further, there are musicians who busk as a large source of their livelihood as a refined art form. As stated by one interviewee, 'For someone to come out and be belligerent, and not have perfected their art, it's annoying'. Another prevalent point was that without permits, malls run the risk of becoming saturated with buskers thus desensitizing the public. Therefore, permits where seen as a good measure. With regards to Queen Street Mall, you have to attain a permit for the mall and there's no amplified busking. However, according to one of the interviewees (Interviewee 5), Melbourne and all other cities authorities allow amplified busking. These codes of written and unwritten laws relate to the idea of equity in a public space. People should have the right to express themselves but the concept of "greatest happiness for the greatest number" principle is an underpinning belief (Hutcheson, 1725). Thus quality control is a good notion for commercial public space but only if the power structures of the space meet halfway with the street performers to enhance the 
experience (Chambers, 20I3). None of the interviewees actually busked in Queen Street Mall because the sound gets lost for acoustic performers and amplified busking is not authorised. Therefore the commonality was to busk outside of the permit required zones and in places where sound dissipation was not as prevalent. If Queen Street Mall was to celebrate "street-scape theatrics" some provisions in terms of a more egalitarian distribution of spatial ownership would have to be made. This notion of spatial ownership can become quite complex especially regarding a commercial space such as Queen Street Mall. This can come in two levels, spatial ownership on a societal level (permits), or between competing buskers (Respect/Unwritten law).

A commonality between all buskers is that there is a strategy and relationship between the location and time to maximise exposure (Kushner \& Brooks, 2000). Therefore these locations would change throughout the day. Buskers often get more interest at night because people are out to be entertained whereas people generally have an agenda throughout the day. However, at an event such as a market place, the public tend to show higher interest. This would be due to a lower pressure of time. Also, certain areas where people are spilling out going between clubs, or having food provide good spaces for busking. Therefore, when considering a desirable location, it is important to think why the public occupy that space. Interviewee 2 made that comment that train stations were desirable because people were already shuffling through change in their hands. They would often see a busker and throw in some spare change. An interesting notion about busking is that it affects the space in ways which the public would not expect and therefore brings about a new value to the way the space is being experienced and manipulated. There exists the potential to make the public think or feel differently. An interesting statement was made by an interviewee regarding the ways in which the public interacted with his music:

Everyone would walk to the same beat, and I would actually find myself playing to that beat. But I found that if I played counter to that beat or changed it up it made people notice more. I thought that was pretty fascinating... Before $5 \mathrm{pm}$ and after $6 \mathrm{pm}$ so in that time it was just too intense, they couldn't see anything in front of them. People would need to be able to see you from at least 10 - 15 metres away and know that you were there so that they would make a conscious decision about if they were going to respond or not. (Interviewee 3)

Societal preconceptions and reactions play a major role in the notion of spatial ownership for a performer. To an extent, the more experience you have with busking, the more comfortable the performer will feel in public space. As stated by one of the interviewees, "I had been doing it for a long time I just felt like I was in my own space". The prevalent question in relation to social acceptance is whether the space being culturally enhanced or depredated. The general societal reaction towards busking is mostly positive, adopting a 'more music the better' attitude. However, playing in Melbourne was seen as preferable to playing in Brisbane indicating that Melbourne is a more culturally advanced city and spaces are more socially dynamic. It was also noted that there is a notion that busking in another city can be preferable to busking in your own city. In the process of busking, you can become a "Chameleon" insofar as an anonymous persona, however some buskers find it hard to adjust in your own city or places of prior associations. This indicates that there 
Public Space for Street-Scape Theatrics.

Guerrilla Spatial Tactics and Methods of Urban Hacking in Brisbane, Australia

are negative connotations that are associated with busking such as desperation or homelessness. However, interviewee 2 had the contrary view and used busking as way of socializing. He stated:

If you, in your mind think that busking is a form of begging then you might feel a sense of shame from that but I didn't, I felt like I was just being a street performer.

Predictably it was found that financial motivation is always a present factor for busking. The location for where a busker sets up is called a "pitch". However, most of the interviewees stated that the "pitch" is not the only factor and often not even the primary motivation. It was the combination between being able to express one's self and also achieve some financial gain that drives a musician to play in public space. The experience, promotion and practice were often equally as important as the finance.

Interviewee 2 claimed that he would make about $\$ 10$ per hour and thus it was not enough to consider a career pursuit... the best nights weren't the nights that we thought we made $a$ lot of money, it was the nights where there was a group... dancing around us, singing along to the cover songs... people would come from standing in line at a club or bar, and join along in the atmosphere. And it wasn't about the money... (Interviewee I)

Through the interview process key points of importance emerged.

- It can transpose the space from a means of going from $A$ to $B$ to a social space where interaction between people on a creative level can be valued.

- The cultural exchange is not predefined but can be surprising, irregular or make a pedestrian feel, see or hear something that they weren't expecting.

- Busking is inherently a mutual experience. The entertainment is offered before the payment, rather than a traditional performer who has a set fee agreed on before the performance. In this way the public will only pay if the art or circumstances are considered worthy of that payment.

- The general public can exercise a preconception of buskers as people begging for money, or engaged with low class activity.

- Permits are generally an accepted measure of quality control in busy commercial spaces.

\section{Observations and Mapping}

Building on the findings from the interviews, observations have been made in three locations within Brisbane CBD; preliminary data collections have allowed us to identify the main sites used by buskers, as summarised in Figure I. Detailed observations of them be conducted in three locations, one in Queen Street Mall, requiring the busker to hold a permit, and two in areas just outside the Mall. Spatial and environmental qualities have been surveyed. Sounds dispersion has also been measured to evaluate the potential of each site in providing good exposure to buskers. 


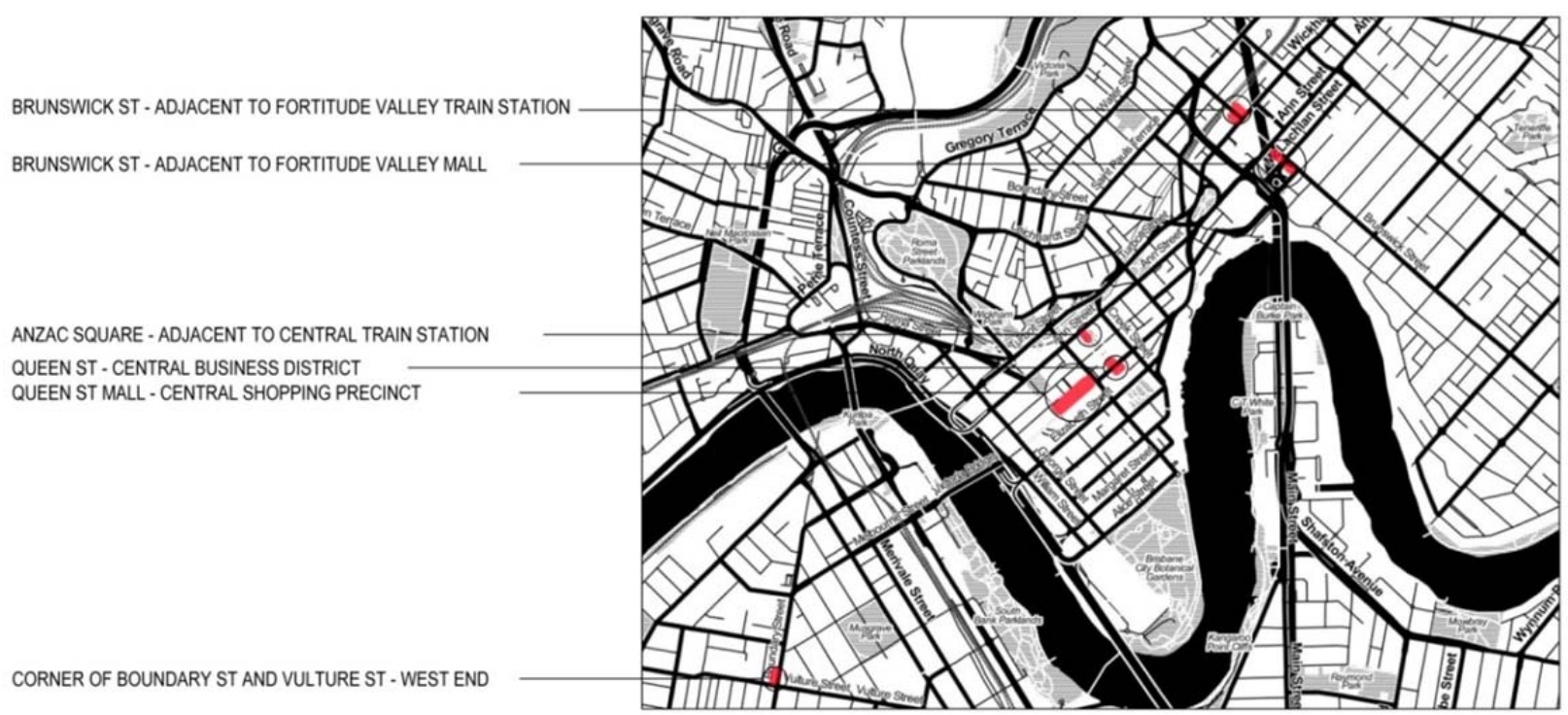

Fig. I. The preliminary mapping of busking sites in Brisbane

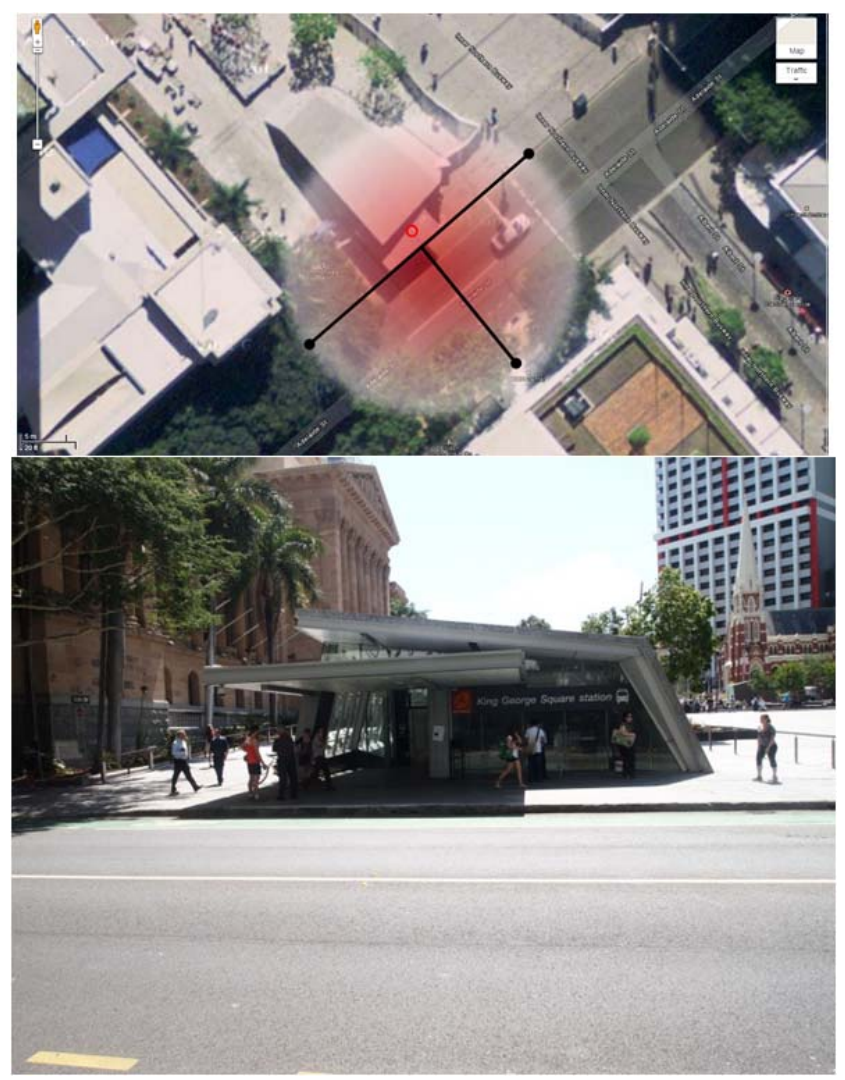

Fig. 2-3. Acoustic busking sound projection example I (base - Google Maps) 


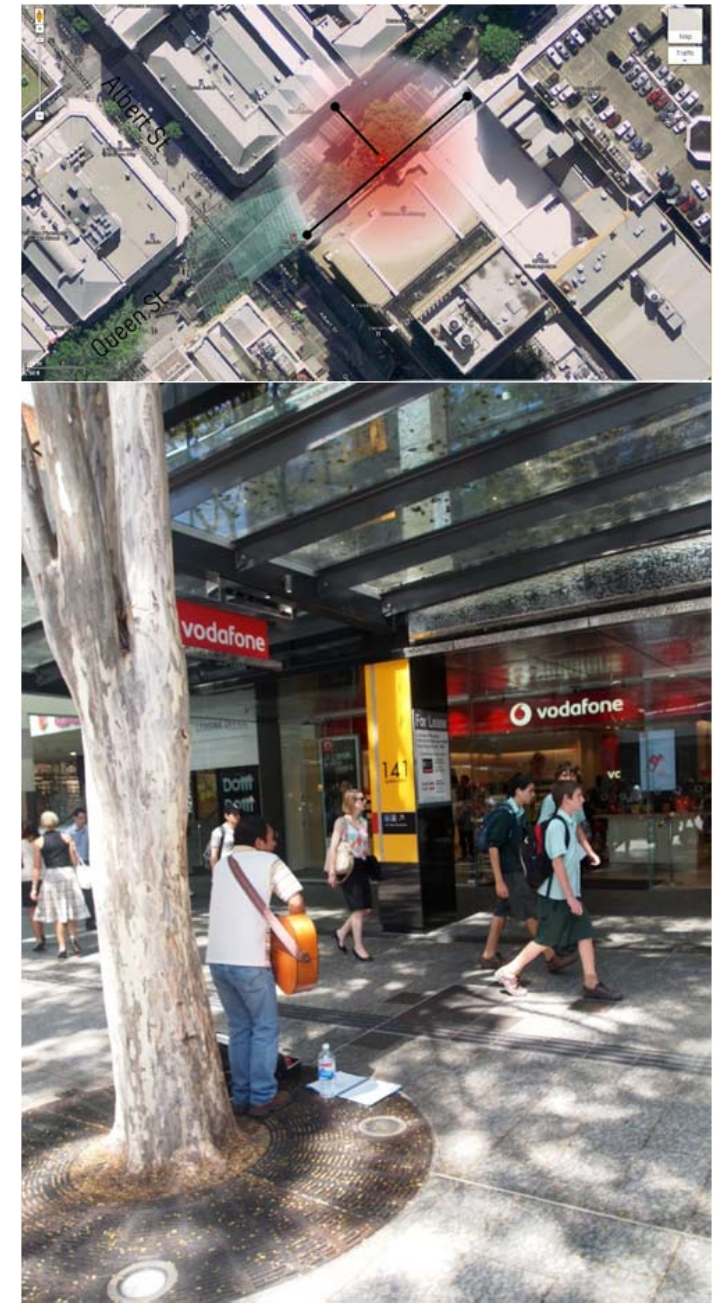

Fig. 4-5. Acoustic busking sound projection example 2 (base - Google Maps)

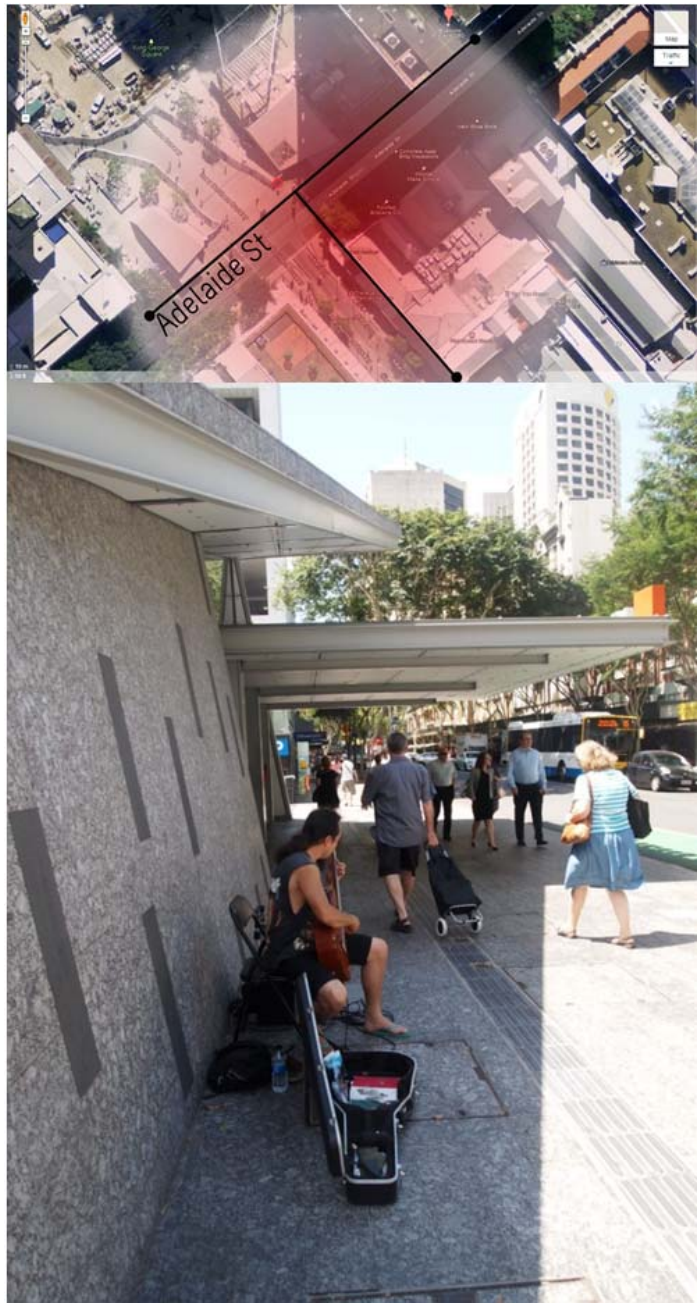

Fig. 6-7. Amplified busking sound projection comparative example (base - Google Maps)

\section{Discussion}

Through the literature review, interview analysis, and prior observations it has been identified that busking provides a valuable contribution to public space without compromising the individual liberties of the overall public. The sharing of music on the street induces the Lefebvrian notion of having a 'right to the city' as the performer can temporarily affect the sensory experience of public space and connect with people on a humanistic level. With this in mind the right for the public to express themselves through music in the Brisbane CBD could be improved by making the following provisions.

I. Allowing amplified sound in the city with appropriate sound levels and permits would be an appropriate measure for Queen Street in celebrating street-scape theatrics. As noted by the prior observations, amplified busking in Brisbane CBD achieves a sound projection of up to four times the radius of an acoustic busker. This is important for buskers in the city, as competing with ambient noise without amplification is difficult, and has been identified as the most difficult barrier to their art form. 
2. In a prominent section of Queen Street mall there exists numerous speakers positioned above the shop fronts projecting commercial music into the space. Not only does the Brisbane City Council disallow amplified busking in the mall, these speakers in the area outlined by figure $7 \& 8$ nullify opportunity for busking in this area of Queen Street This is at a place where people are not only passing by they are sitting and socialising at the Pig and Whistle Hotel. To nullify this ideal location for busking and street entertainment seems unnecessary being that Queen Street openly endorses street entertainment. As a notion, this reduces the public's 'right to the city' by way of art. As Interviewee 5 stated, this is not a notion that is experienced in Melbourne. He contends that 'I'm registered in the Burke St mall and because of the busking there they don't have any commercial music playing...'
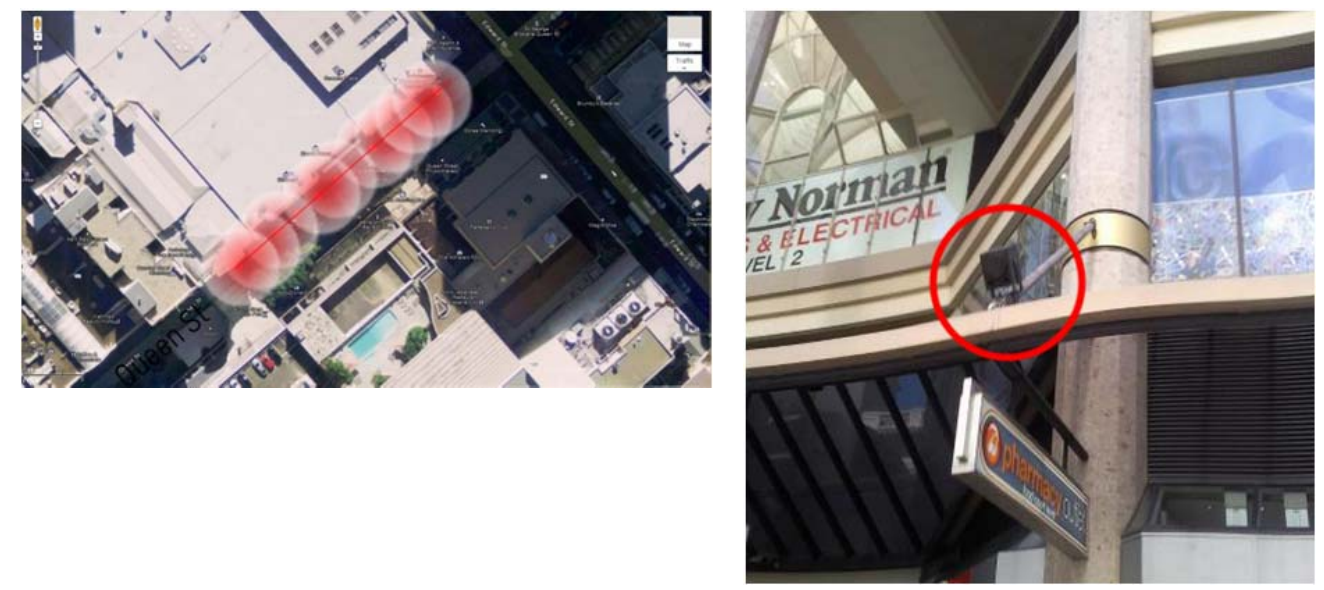

Fig. 7-8. Nullification of Busking in favourable public spaces

3. The third recommendation is the designation of discrete spots within a public space that facilitates buskers. In Melbourne the number and locations of buskers are regulated and this generally contributes to an overall engaging experience for city users, who are not overwhelmed by different auditory stimuli. As commented by Interviewee 5 , an experienced busker, 'People don't really take busking as an important part of designing the city but now it's starting to take shape... Melbourne has accommodated designated spots to busk, everywhere in Melbourne...' Therefore, if designated busking spots were provided in Queen Street mall along with the aforementioned provisions, the experience of public space could be enhanced with adequate quality control measures being taken. As stated by an interviewee involved in the audition and licensing process for buskers in Brisbane, busking has a positive impact on public space. 'If I see music anywhere, I'll stop and have a look and listen. And that's what the people do, people wandering around shopping' he states. Ideally, these busking spots could not only be designated, but designed into the leftover space within the urban fabric at specific locations that are desirable to buskers. These could be in the form of busking "spots" that could allow buskers to freely manipulate the conditions of the set area to improve the experience both functionally and aesthetically:

- Improve acoustic projection

- Very basic amenities including a power source and seating

- Incorporate miscellaneous seating arrangements if appropriate 
Public Space for Street-Scape Theatrics.

Guerrilla Spatial Tactics and Methods of Urban Hacking in Brisbane, Australia

- Aesthetic recognition of the value of street-scape theatrics

- These could serve a multitude of functions beyond busking that could extend into rallies and street forums

- Retain priced permits and auditions, but the money generated goes towards funding these provisions

Figure 9-II depict potential for designated spots to be incorporated into leftover urban fabric in locations conducive to busking. The design of these places is intended to evolve as its users refine the space.
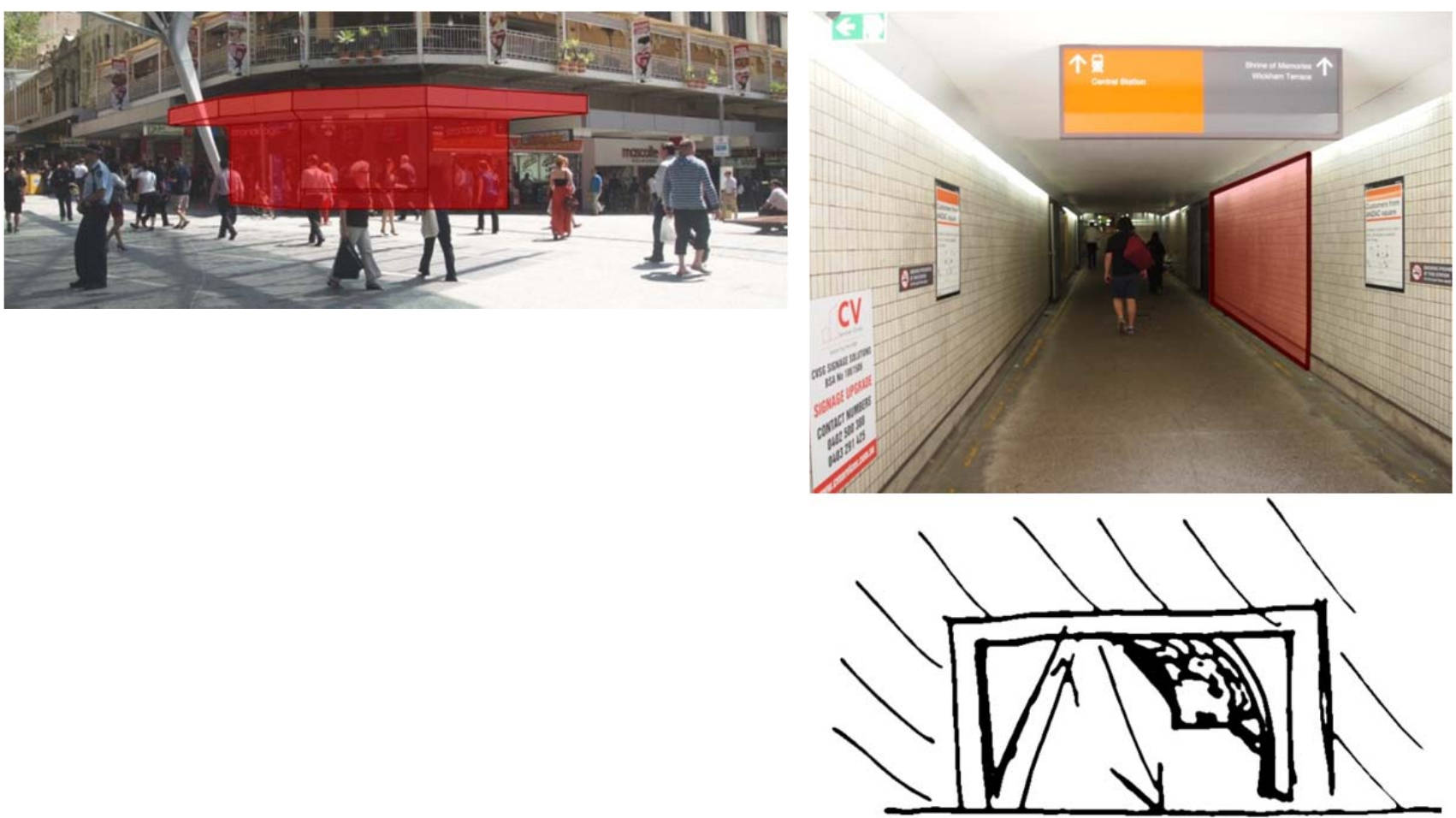

Fig. 9-10-II. Potential busking spots in Brisbane CBD.

\section{Conclusion}

The research has provided evidence that there are ways in which the Brisbane CBD can be enriched through an increased appreciation for street performance. Street culture is a notion that already exists in the Brisbane city but is repressed by over governance of public space. It is proposed that incorporating these suggestions into the design of public space both physically and politically would enhance the Lefebvrian idea of maintaining a 'right to the city'. There lies the potential to enhance the sensory experience of our public space. This leads to a determination of the practicality of designing busking into the leftover urban fabric and critical thought to the way the city is allowed to express itself in a sensory and experiential way.

Some limitations to this research have been prevalent. The first limitation is time. This research was conducted over a period of three months, a relatively short period of time 
for a complex issue. Therefore, the project contributes to a body of knowledge that aims to surface the idea of design for street-scape theatrics. Is not expected that this particular research would have immediate societal consequences that could involve redefining the way in which planning regulations may be developed or acted upon. However, what has been achieved is a body of ideas that demonstrates how public spaces can be enriched through retracting over-governance and over-organisation and giving the public the right to express themselves in public spaces in a way that does not compromise the individual liberties of others. It is crucial that the notion of ensuring a 'right to the city' by way of art is always prevalent in our public space. This can bridge the gap between the micro scale of the body and the macro of the political economy through allowing freedom of expression and thus celebrating the idiosyncratic nature of the city.

\section{References}

Agiurre, A. (2007). Urban Space. In G. Ritzer (Ed.), Blackwell Encyclopaedia of Sociology. Malden, Mass, Oxford: Blackwell. Retrieved from http://www.blackwellreference.com/public/tocnode?id=g978I405I2433I_yr20I2_chunk_g978I $40512433127 \mathrm{ss}$ I- 18

The American Heritage Dictionary of the English Language, Fourth Edition. (2009). Boston, MA: Houghton Mifflin Harcourt.

Baird, S. (2000). The History and Cultural Impact of Street Performing in America. In B. Franklin (Ed.), Street Performers and Buskers Advocates.

Bnecity (20I2). Queen Street Mall. http://www.bnecity.com.au/Storelnformation.aspx?id=35I2 (accessed 27th August 20I2)

Borden, I. (200 Ia). Skateboarders are essential for our cities Retrieved March I2th, 20I2, from http://www.independent.co.uk/opinion/commentators/skateboarders-are-essential-for-ourcities-69380I.html

Borden, I. (200 Ib). Skateboarding, space and the city: architecture and the body. New York: Berg.

Brisbane City Council. (2012). Busking Licences Retrieved 27th October 2012, from http://www.brisbane.qld.gov.au/laws-permits/laws-and-permits-for-businesses/mallsmanagement-markets/busking-licences/index.ht $\mathrm{m}$

Chambers, C. M. (20I3). Busking and the Performance of Generosity: A Political Economy of the Spiritual Gift. Performing Religion in Public, 256.

City of Melbourne. (200I). Bourke Street Mall busking permit Retrieved 2th November 20I2, from https://www.melbourne.vic.gov.au/enterprisemelbourne/industries/design/StreetEntertainment/P ages/BourkeStreetMallPermit.aspx

Cohen, D., \& Greenwood, B. (I98I). The buskers: a history of street entertainment. Newton Abbot: David \& Charles.

Coleman, N. (2013). Utopian Prospect of Henri Lefebvre. Space and Culture, 16(3), 349-363.

Dangschat, J. S. (2009). Space matters - Marginalization and its places. International Journal of Urban and Regional Research, 33(3), 835-840.

Deslandes, A. (2013). Exemplary amateurism: Thoughts on DIY urbanism. Cultural Studies Review, $19(1), 216-227$.

Foth, M. (20I I). From social butterfly to engaged citizen: urban informatics, social media, ubiquitous computing, and mobile technology to support citizen engagement. Cambridge, Mass: MIT Press.

Gardiner, A. (20II). Bourke St buskers risk being banned. http://www.heraldsun.com.au/news/victoria/bourke-st-buskers-risk-being-banned/storye6frf7kx-1226017347/27 (Accessed 27th October 20I2) 
Public Space for Street-Scape Theatrics.

Guerrilla Spatial Tactics and Methods of Urban Hacking in Brisbane, Australia

Gehl, J. (1987). Life between buildings: using public space, Reinhold Pub.Co.

Gehl, J. (2010). Cities for People. Washington DC: Island Press.

Gehl, J., \& Gemzoe, L. (2004). Public Spaces Public Life. Copenhagen, The Danish Architectural Press \& The Royal Danish Academy of Fine Arts School of Architcture Publishers.

Goldsmith, M. (1980). Politics, Planning and the City. GB: Routledge Ltd.

Guaralda, M. (20I3). Eye on the Street? Sensory Experience in Public Places. In_Bo Ricerche e progetti per il territorio, la cittá e l'architettura, 4(I), 7I-80. doi:I0.6092/issn.2036-I602/37II

Harvey, D. (2012). Rebel Cities: From the Right to the City to the Urban Revolution, Verso Books.

Hays, K. M. (1998). Architecture theory since 1968. Cambridge, Mass: The MIT Press.

Heathcott, J. (20I2). Planning note: Pruitt-igoe and the critique of public housing. Journal of the American Planning Association, 78(4), 450-45I.

Holt-Damant, K., Guaralda, M., Gomez, T., \& Miriam, N., Cindy. (2013). Urban jungle : making cities healthy places for Australians with neurodiversity. Paper presented at the 6th Making Cities Liveable Conference, in Conjunction with the Sustainable Transformation Conference, Melbourne, St Kilda.

Hou, J. (2010). Insurgent Public Space: DIY Urbanism and the Remaking of Contemporary Cities. GB: Taylor \& Francis Ltd - M.U.A.

Hutcheson, F. (I725). Inquiry concerning Moral Good and Evil.

Jacobs, J. (Ed.). (196I). The death and life of great American cities. New York: Vintage Books.

Jubany, H. L. (20I2). Design Intelligence. The Social Responsibility of Architects Retrieved March I5th, 2012, from http://www.di.net/articles/archive/the_social_responsibility_architects/

Kushner, R., \& Brooks, A. (2000). The One-Man Band by the Quick Lunch Stand: Modeling Audience Response to Street Performance. Journal of Cultural Economics, 24(I), 65-77.

Lefebvre, H., \& Nicholson-Smith, D. (199I). The production of space. Oxford: Blackwell.

MacKenzie, I. (2009). Politics: Key Concepts in Philosophy. London: Continuum.

Mensch, J. (2007). Public Space. Continental Philosophy Review, 40(I), 3I-47.

Miles, M. (1997). Art, space and the city: public art and urban futures. New York; London: Routledge.

Orom, H., \& Cervone, D. (2009). Personality dynamics, meaning, and idiosyncrasy: Identifying crosssituational coherence by assessing personality architecture. Journal of Research in Personality, 43(2), 228-240.

Orwell, G. (1946). Animal farm. New York, Book: Harcourt, Brace \& World.

Power, N. (20I0). Humanism. In M. Bevir (Ed.), Encyclopedia of Political Theory. Thousand Oaks, CA: SAGE.

Project for Public Spaces. (20I2). Las Ramblas Retrieved 7th August 20I2, from http://www.pps.org/great_public_spaces/one?public_place_id $=59$

Simpson, P. (2012). Apprehending everyday rhythms: rhythmanalysis, time-lapse photography, and the space-times of street performance. Cultural Geographies, 19(4), 423-445.

Stevens, Q. (2007). The ludic city: exploring the potential of public spaces. New York: Routledge.

Torgovnik, E. (1990). The politics of urban planning policy. Jerusalem. Lanham, Md: University Press of America.

Whyte, W. H. (1980). The social life of small urban spaces. Washington, D. C.: Conservation Foundation.

Wilkins, C. L. (2007). The Aesthetics of Equity. Notes on Race, Space, Architecture, and Music. Minneapolis: University of Minnesota Press. 


\title{
Private control and public openness. The development of London's public spaces since the Mayor's 2009 manifesto
}

\author{
Camilo Vladimir de Lima Amaral \\ University of East London, UK \\ School of Architecture \\ camilovla@gmail.com
}

\begin{abstract}
This research aims to analyse the ongoing privatization of public spaces in London. It also seeks to explore the impact of the 2009 Mayor's policy document named 'A Manifesto for Public Space - London's Great Outdoors' in this process. The manifesto argues in opposition to the growing 'corporatisation' and exclusion of privately controlled spaces and in favour of spaces that are open 'for all Londoners' and with a planning process overseen by the Public Sector. In order to understand if these goals were achieved, an initial inventory listed all the developments after 2009. The projects' examination made it possible to identify the most important cases in each group. This article analyses whether these developments are private public spaces or whether they remain genuinely public, thus examining the manifesto's effectiveness on London's lived spaces. In order to do that, a critical approach was constructed upon the literature review, in order to confront the ideas of public space with the spatial experience. This dissection demonstrated how recent complexity of urban space production has created new phenomena in the city, that can be assembled in the concepts of Velvet Ground, Tangled Orbits and Repeated Compulsion of Space Consumption. The concepts clarify the relationship between social control, the democratic openness of public space, and citizenship. The study concludes that a new form of privatized space is taking over the city, and the proposed policies were unable to stop this tendency.
\end{abstract}

Keywords: public space; urban policy; London; democracy; privatization.

\section{To cite this article:}

Amaral, C. (2016). Private control and public openness. The development of London's public spaces since the mayor's 2009 manifesto. The Journal of Public Space, I(I), I29-I46 DOI: 10.5204/jps.vlil.I5

This article has been peer-reviewed and accepted for publication in The Journal of Public Space. Please see the Editorial Policies under the 'About' section of the journal website for further information.

\section{cc) (1) \$}

This work is licensed under a Creative Commons Attribution - Non Commercial 4.0 International License. https://creativecommons.org/licenses/by-nc/4.0/ 
Private control and public openness.

The development of London's public spaces since the Mayor's 2009 manifesto

\section{Public Space and City Life}

In order to answer whether the Mayors Manifesto (Boris, 2009) had any impact on London's spatial production or not, a dialectical reflexion about public spaces will be conducted. The premise, on which this reasoning proceeds, is that perceptions are commanded by a priori ideas (or the so called 'natural interpretations', cf. Feyerabend, 1989). Firstly, we will investigate the relation between city life and public space, or the politics within the polis. Secondly, we will analyse how the city space role has changed, forming different public experience over the years. This analysis leads to the formulation of three concepts to describe the 'publicness' of the current spaces produced in London. Ultimately, the analysis reveals how these new spaces in contemporary London are producing an urban experience that eliminates the confrontation with difference, and instead, they are producing a constant feeling of shining, blurred, yet soft, stimulation in a new velvet social ground, controlled by entanglement and directed towards a compulsive form of spatial consumption.

The political role of public space in modern society is controversial and has been part of a historical process formed of both a history of ideas and a history of societies. For Neil Smith and Setha Low (2006), the definition of Public Space has been constructed as the opposite of Private Space. Therefore, both social constructions are the result of modern capitalist society. In this sense, this phenomena is the result of social struggles against the former feudalist spatial order, and it is even a progressive development from the Greek polis, which did exclude both slaves and women from its political space, the Agora. Thus, public space arises as a new set of social relations, articulating the power of civil society, the market and the modern State (2006: p. 4).

Sharon Zukin (2010: p. 129) argues that public space has had an important role in the democratization process. For instance, even before the French Revolution clashed against the previous classes' privileges, the mixture, promoted by the markets' space, was creating the basis for modern democracy and for city space to be open for all. Moreover, Zukin highlights that London and New York created public spaces in the $19^{\text {th }}$ century, such as libraries, parks and museums, even before the right to vote was available to everyone. Rather than just an effect or image, public spaces were also generating democracy and are, therefore, politics in praxis.

Specifically in London, the public ownership of the streets was the outcome of a long dispute that happened towards the end of $19^{\text {th }}$ century (Minton, 2012: 19-21). By this time, major squares of the city were enclosed, guarded by private security and surrounded by sentry boxes. After a conflict with guards resulted in a murder, social unrest and the involvement of the printed media resulted in two major parliamentary inquiries. These inquiries resulted in streets becoming 'adopted' by the local authorities, which were growing into power by this time. In this sense, the rise of the public space coincided and represented the construction of local democracy in London.

The end of the 1980's saw the birth of a new kind of space, as a result of political and economic reconfiguration. The metropolis in central economies faced a process of deindustrialization, with the increasing flexibility of work relations, the collapse of the Welfare State, which reframed the mass production economy into the so called toyotist economy (Harvey, 1992). For this new neoliberal economy, a new form of space was produced. 
In London, the paradigmatic example was Canary Wharf. Developed in an old industrial area, a vast new financial centre was designed from scratch, where the streets and squares were no longer 'adopted' by the weakening Welfare State, but, were controlled by a new entity: the corporation. For Smith and Low (2006: 14-16) as we watch the collapse of basic rights, public space emerges in the centre of the contemporary debate on democracy, as the production of space is a central strategy for the implementation of neoliberal concepts. For Smith and Low, this is the reason why political movements are always attached to places (the archetypical mass in a public space). As we will see, changes in the production and control of public spaces will also have implications on the political potential of those places.

Zukin (2010: 222) state that this is a long process that took place in the period after the great wars, creating what she called the 'corporate city'. This city has been produced by specific arrangements of: private capital investment, State specific policies and rules design, media image construction and direction of consumer's tastes (Zukin, 2010: 30). This new configuration of social space (capital, state, media) excluded civil society from the formula. Not surprisingly, the collapse of public spaces are accompanied by the collapse of democracy itself, as empirical studies demonstrate that political decisions are defined by corporation interests, and are no longer influenced by the public opinion (Gilens and Page, 20I4).

Zukin (2010: 145) argues that schemes of private city space management are a new form oligarchy. For instance, the votes and decisions in Business Improvement Districts are balanced by the size of ownership in the local arrangement, and usually the vote is proportional to the size of the property. Therefore, based on the argument that the State does not have funds in a moment of economic crises, those who have capital should rule. For instance, in this equation both homeless and unemployed simply do not exist. Smith and Low (2006: 15) reinforce the argument stating that this is the formation of a new apartheid, excluding the poor, the homeless and the immigrants out of the city spaces. In the middle of this debate, in 2009, the Mayor of London, Boris Johnson, published a policy paper named 'A Manifesto for Public Space: London's Great Outdoors'. In this text he argues:

"There is a growing trend towards the private management of publicly accessible space where this type of 'corporatisation' occurs, especially in the larger commercial developments, Londoners can feel themselves excluded from parts of their own city. This need not be the case.' (Boris, 2009: 8)

He then sets a series of strategies, which should be enforced in order to avoid this type of city space corporatization. The proposed strategies can be summarised as: (I) the respect of the London Plan's priorities; (2) the process overseen by the public sector; (3) the improvement of the urban context connection; (4) the flexibility and inclusive character ('for all Londoners'); and (5) the equity and affordability of developed spaces. Nevertheless, a new policy draft has been submitted to change London's Housing Strategies (Johnson, 20I3). This new document has strong contradictions with the former manifesto. The new policy aims to produce a great number of houses focusing on big developments, and strong partnerships between State and corporations, financing only big schemes. In order to bring forward land for development, the strategies articulate tactics 
Private control and public openness.

The development of London's public spaces since the Mayor's 2009 manifesto

of compulsory purchase and land assembly that overlaps the local scale. All those solutions setup a scale for the spatial production. As Zukin (2010: 222) asserts, we may have not seen the end of history, but we are certainly seeing the end of 'place-bound culture'.

\section{The Metropolis and Public Life}

In addition to the relationship between public space and democracy, many intellectuals have also observed a causal link between the production of city space and social freedom (Sennet, 2002; Berman, 1990; Simmel, 1903; Baudelaire, 1995; inter alia). Although this connection could hardly be dismissed, there is a great deal of complexity in the topic. This relationship has changed in different historical moments, and cities have had different roles in the formation of modern citizenship. It is important to understand these subtle differences and conceptualize the role of metropolitan space in the construction of contemporary public life. Consequently we should avoid simplifications and uncritical propositions, which are so common in contemporary architectonical technicism. Charles Baudelaire is perhaps the most cited author on the account of the modern construction of freedom through the experience of the city. In his literature he was able to express how the modern metropolis became an instrument to create an ephemeral and free spirit in the modern man (cf. Baudelaire, 1996). For Baudelaire (1995) the modern man is like the modern painter, who is able to design his own life, as freely as an artist design his paintings. This freedom was enabled by the sudden transformation of the small, closed and stable traditional space, into a multitude, and the constant changing fashion. This atmosphere was founded in the city itself, and was experienced by the flaneur attitude: a modern man that would engage in the news and movement of the city, connecting freely with the street's 'family of eyes', and swimming in the stream (Berman, 1990: 148-154).

Marshal Berman (1990) examines how different cities in the 19th century transformed the citizens' social perception. Contrasting the boulevard's experience in Paris with the Prospect's experience in Saint Petersbourg, Berman demonstrates the intimate relation between the social awareness and the city forms. Those spaces transformed the urban experience into a direct clash of different city's classes, into a social experience of the human condition in contrast with the social situation. For Berman, the city was the fundamental trigger of the most important social movements of that century. Moreover, Georg Simmel (1903), in a different perspective, analyses how the experience on the metropolis changes the modern men consciousness and, therefore, social relations. For Simmel, the modern city creates an intensification of 'nervous stimulation', a continuous confrontation with the unexpected, a highly impersonal relationship with others, an abstract mode of mediation (money) and, therefore, the necessity of fast reactions. That situation leads to the unconditional use or rationality. In other words, by these new features, the modern man is ripped apart from the old 'orbit' of the Feudal village, where he was guided by emotions and closeness. This orbit holds back individual progress, as they are founded in constant equilibrium, centrality and hierarchical order. Therefore, it is the metropolitan rupture that creates the modern man, guided by the use of rationality, rather than his heart. 
Therefore, Simmel argues that freedom is the fundamental achievement of the metropolis experience. But, this freedom is only achieved by an active operation of transcending this condition of displacement. According to him, it is not just because of mobility, the distance of the prejudices from the country, or the elimination of 'philistinism', but is also because the metropolis urges to the 'particularity' of each person to be 'actually expressed', confronting the citizens with the laws of his 'inner nature', confronting him with what makes his 'irreplaceability'. Simmel summarizes it as the condition that makes one sure that his mode of existence was not imposed upon him from outside.

In this sense, Monte-mór (2006) argues that the relations between urban experience and human condition are expressed by the common origin of many words. For instance, the notion of citizenship has an intricate relationship with city, as the condition of belonging to a civilization, sharing rights and rules. As the idea of urbis is connected with the urbanuum, the economic infrastructure that maintained the roman cities, and as the idea of polity is connected to the Greek polis. Therefore, when Henri Lefebvre (200I: 27-36) argues that, as philosophy and the polis had a special relation, where the former constructed the sense and the meanings of the experience of the second, we must make a similar effort to comprehend the contemporary city. Nevertheless, a philosophical system is not enough, as the contemporary conditions are formed by diversity, reflexivity, relativity, and its political complexity.

The modern metropolis has represented, therefore, the possibility of self-creation, awareness of social condition, the formation of a rational experience of the world, the accountability to each 'inner laws' and the possibility of encountering and existing among difference. Nevertheless, the ongoing process of privatization of public space threatens exactly the constitution of this freedom of modern urban life. Simmel argues that the feudal village was formed by a social 'orbit', i.e. a central and ordered overall rule. For him, this order was overcome by the free space of the metropolis. Nevertheless, today we are moving towards a new synthesis of those 'orbits', forming an urban space of several tangled social orbits, where several different rules overlap each other on the space, similarly to a Tangled Orbit. Therefore, as we will discuss next, the boundaries of the cities' spaces becomes a "blurred" impressionist picture, where the self is only completed through consumption.

\section{Beyond the Access Principle: Repeat Compulsion of Space Consumption}

The changes in contemporary metropolis' spaces can only be understood by the dialectic between the physical arrangements and the economic, political and social doctrines. The openness of the public space is not just a matter of barriers, cosy benches or fancy comfortable materials, but how the objectified social relations (Lefebvre, 200I; inter alia) awake citizenship roles in the space. These are the social codes and interpersonal rules that are graved in spatial elements. These objectified relations can be made by fences, doors, tables, or even grass and pavement, provided that they somehow direct behaviour. Citizenship roles are the activities people are expected and accepted to play in a specific place. Beyond the apparent accessibility of privatized public spaces, and beyond its physical beautification, the metropolitan space, once symbol of difference, rationality and freedom is being transformed into a space of fragmented orbits of control (social rules 
Private control and public openness.

The development of London's public spaces since the Mayor's 2009 manifesto

and behaviour control graved into fractal and cosy objects). In this new space, the only available roles for citizens are founded by consumer actions. Therefore, these spaces are now only mediated by a repeated compulsion to consumerism.

Despite all this contradiction, Latham and Koch (2013) argue that the ongoing process of transformation of the public space is the 'hard work of domestication'. They use the concept of domestication, against its former critical use (cf. Zukin, 2010). For them, the space has never been 'wild', because it is an artificial product. In this sense, it has neither been tamed, as it already is. Therefore, ignoring dissent, social conflict, politics and the history of mankind, they propose the domestication of urban space as "home-making", by blurring any social difference between private and public.

Whilst the use of the concept of domestication has a 'delightful' aspect, it is self-evident that it also has connotations of control, hierarchy and, even, the creation of domesticated specie of citizens. Nevertheless, despite domestication delightfulness, there is another powerful effect of the current trend. As Simmel (1903) asserted, the foundation of the modern rational freedom in the metropolis is based on the experience of abstraction, distance and difference that are made possible by the big city. In opposition to this modern space, the feudal city was exactly formed by a domesticated space, fully experienced by emotional relation to the place, mediated by the 'heart' and tradition, with the sensation of a cyclical and eternal stability, that can only be felt home. Therefore, the proposition of transforming the modern city into a home is, by logical conclusion, the proposition of destructing modern freedom as experienced in the metropolis.

Therefore, the domestication advocated by Latham and Koch (20I3), is both the beautification by delightfulness and the elimination of the abstract distance and solitude among the multitude that is so important to create the uncomfortable encounter with freedom. As Simmel argues, "For here, as elsewhere, it is by no means necessary that the freedom of man reflect itself in his emotional life only as comfort". In that proposition, architecture becomes the engineering death of city's freedom, as their enumeration of strategies to create comfort conditions, sounds like a Machiavelli project of difference and dissent anaesthesia. It is in this sense that these strategies transform the city spaces into a 'velvet ground': formed by comfortable, shining and blurred spaces.

On one hand, the domestication argument can be used to explain how intimate relations can be created between humans and other forms of life, or how animals used to social structures can adapt to live humans' relations. On the other hand, different approaches in ethnography and biology present a much more critical point of view. Velden (2009) argues that ethnocentric views of domestication have a particular conception of society, where public life is conceived as a hierarchical construction built aggressively, and the domestic and family life is conceived in a patriarchal structured order, taken to be the natural harmonic patter of human social behaviour. Therefore, sarcastically, the naive use of the domestication concept suits as a glove to the ongoing process: the blindness created by the concept towards the big picture alternatives mimesis the blindness created by the new public space towards the political dissent.

For instance, let's take the example of dogs in the Amazonia to create an alternative view of different species relations. Many studies have demonstrated how it is hard for dogs to adapt to these circumstances, as they became genetically addicted to human control (Velden, 2009), and totemic societies have a 'horizontal' cosmogony of they relations with 
animals (Vigne, 20 I I). Moreover, Velden (2009) argues that in the Amazonas rainforest wild animals were never domesticated, but introduced into the village life by the process of 'familiarization', in which the animals maintain their autonomy, in a non-subdued relation with humans. According to Vigne, domestication is a 'symbolic shift' with prehistoric origins, and overlaps the origin of divinities: the representations of people praying to a vertical order in the sky, as superiors to humans, happened in the same moment as other species were directed and controlled. For Vigne this is no coincidence: there is a spiritual and symbolic human thought in the origin of animal domestication. As domestication of animal do have many paths (Larson and Burger, 20I3), the domestication of urban spaces also does, and during this process, not only the spaces change in itself, but also the citizens who inhabit it. Much in the sameway that cattle domestication transformed human genome into lactose tolerant genes; today spaces are transforming democratic citizenship into control tolerant codes.

By contrast, other authors defend the recalcitrant nature of public space in democracy. For Zukin (201 I: I30) democracy is intrinsically loud, unruly, unpredictable and dangerous. Therefore, the calm business friendly environment of today, only exists through negation and disciplinary imposition of work ethics and state power, in order to hide any sign of its fragile social order. Rancière (2005: 18-26) stated that the Agora had and fluid existence sustained by the live words of the interlocutors, as a breath of life. The reality of the polis itself was like a dancing chorus, a dancing choreography made by the changing pace of Agora speakers. Richard Sennet (2002) also challenges the idea that the city should be seen as a uniform and calm space. For him, this idea of comfort is a social construction, which conceives citizens as passive elements, rather than the city as an instable arrangement and the citizens' individuality as an incomplete condition:

Intense civic bonds arouse from the very play of displacement (...) Yet the ancient city was itself not like a monument to stability. (...) It is a modern habit to think of social instability and personal insufficiency as pure negatives. (Sennet, 2002: 37I)

Therefore, to live in cities, is to confront ourselves with contradictory experiences that reveal our incompleteness and the cognitive dissonance of our senses (2002: 37I). He argues that, the move from Christianity to Modernity, changed rituals for labour and selfdiscipline, where comfort was directed to home and fatigue to the workplace, suspending the sensory of body. A passive relationship to environment was built by anaesthesia in home, on one hand, and discipline punishment in the street, on the other. Today we see the emergence of a new kind of sensory suspension, formed by both: a velvet discipline. Therefore, Sennet argues that the urge for comfort in the cities is a dangerous game. Too much protection of 'stimuli' can create a 'sickness of lack'. He argues that pleasure can only emerge as a distension of unpleasurable experiences, and that we need to confront ourselves with the 'reality principle', in order to acknowledge to which extension our mind is playing with our senses of pleasure and 'unpleasure'.

This idea is founded in Freud text 'Beyond the Pleasure Principle'(1962) where Freud argued that, although unpleasure and pleasure are important elements to understand mental life, it is the process of 'repression of desires' that is the key principle. Freud asserted that 'Most of the unpleasure that we experience is perceptual unpleasure', 
Private control and public openness.

The development of London's public spaces since the Mayor's 2009 manifesto

because our instincts and desires are repressed inside our unconscious by our social experience. This perceptual unpleasure is formed, in that case, by the 'expectations of unpleasure and dangerous', or by the pressure of 'unsatisfied instincts'. Therefore, a conflict emerges between the 'unconscious repressed' and the actual experience, creating a compulsion to repeat the manifestations of that repressed desire. Those manifestations can emerge as painful experiences or accepted social games. He explains this condition by describing a game played by a child. The child repeatedly threw a toy behind the bed, in order to enjoy the reencounter with this toy. By incessantly repeating the disappearance of the object and its reencounter, the child achieved a form of revenge and the feeling of mastery over his destiny. Therefore, the child regains control from the passivity of his experience only through the 'game activity' (Freud, 1962: 17).

As Latham and Koch (2013: 6) presents, in domesticated spaces, the passivity of the urban experience is overcome in their recount of the 'piano' happening. In a London regenerated square, a man sees a piano in the street, and asks the waiter if he can sit on the chair, only to be shown a sign 'Play Me. I'm Yours!' After playing some music, and being applauded by surrounding customers asking for "one more", the man leaves embarrassed. The passivity of his experience is overcome only through the game activity. Yet, a more subtle game is in play. In Privatized Public Spaces the anxiety of the experience (generated by the lack of publicness of public spaces) is only regained by consumption. The feeling of belonging is carefully orchestrated so one only feels suited to the space as he is engaged in the consumption game. Tables and chairs, views and pianos, are coordinated by business. In Simmel's metropolis, the mediation of relations was, indeed, commanded by money, that became 'the common denominator of all values'. However, in the modern metropolis, money worked as an abstract element to intermediate differences. In the contemporary space, money is not only the condition of existence in the space, but it is consumption (the act of expending money) which is the only valid platform of place bound. The former blasé abstract distance is transformed into domestic closeness through the repeated game of consumption (in other words, repeating incessantly the disappearance of money and its re-encounter, as a form of consumption and felling of place mastery).

For some authors there is no reason to be 'overpessimistic', and those who are have an 'idealized' concept of Public Space (De Magalhães, 2010: 560). It is just a matter of recognizing the natural necessity of the current developments, as the bankruptcy of welfare state is a fact. Therefore, the remaining action is to technically understand process and, therefore, control it. For De Magalhães, the ongoing process can be described as a simple 'contracting-out' of the public character of the cities' spaces, and the matter is to know how to make good contracts, balancing rights and duties. For him, this is not a history of 'corporate take-over' or 'exclusion' but a 'complex redistribution of roles'.

This multi-orbital space, formed of fractal rules, fragmented domestication and blurred shining aspect creates a paralysis of effective difference. Dissent, as the basis of the real polis (as Jacques Rancière, 2005, argues), is one of the first targets of these many rules. This de-politicization of public spaces, the forbiddance of politic in the polis, became evident during the occupy movements and is a fundamental shift in the character of public space, that cannot be undermined. Nevertheless, anesthetized by the constant vibration 
of the intertwined rules (tangled orbits), the wandering citizen repress his 'inner values' through experiencing the place only by repeating consumption, and he regains control only by playing games.

On one hand, the discussion is not about reaffirming the States' lost control of space. As Zukin (2010: 30) asserts, in the current situation the State plays a strong role in guaranteeing that big business gain control over the city. As she demonstrated in the case of WTC in New York, the State control can be even more repressive, ideological and even less representative than other kinds of spatial intervention (Zukin, 20I0: I50-I58). On the other hand, there are two dimensions of this 'contracting-out' of the public space. In one dimension, the social actors involved in the contract are very well informed about the elements and the rights been sold. And if this situation took place in the first place, it was certainly because of that awareness/consciousness. Therefore, the academic' formalization of the praxis has no effect into that reality. In the second dimension, the lived space, the reality is that the fragmentation of rules, promoted by these contracts transforms the public space in a tangled orbit of unconscious domesticated rules, which changes from place to place, square to square, street to street.

Arguably, in this condition, when a person walks through the city of London, his experience is not one of confrontation with difference, but a constant metamorphosis of its own character, becoming constantly more or less free, more or less at home, more or less active, more or less controlled. For those in the streets, the feeling is a constant shining, blurred, yet soft, stimulation of a velvet ground. This condition creates a new dimensionality to the city, which founds a new form of comfortable estrangement. Next, we will present how this process is happening in the city of London, representing this new way of experiencing public spaces with five representative examples. As we will see, this new experience of the public space is a mix of comfort through serenity and belonging through consumption, compulsively repeated in each step of the way.

\section{New Spaces in Town}

Pragmatically, the Ist stage of the research started with a quantitative analysis, based on two main themes (the impact on public realm, and the scale of privatisation of the public space). There is a conceptual difficulty in defining public space and how it relates to the promotion of social relations, and the related literature presents multiple methodologies that assess the 'publicness' of a place into divergent grids and concepts (Varna and Tiesdell, 2010, Benn and Gauss, I983, Kohn, 2004, Németh and Schmidt, 20I I, Németh, 2012, Lessing, 200I, Staeheli and Mitchell, 2008, Iveson, 2007). Thereupon, in a second phase, 20 representative spaces were investigated with a qualitative field investigation. The first phase of the research was accomplished by an initial inventory, conducted by combining information from various entities, including the planning portal of the UK government, the Greater London Authority website, the British Property Federation website, the New London Architecture organisation, and the websites of major property corporations and local authorities. From an initial list of 1024 projects, 708 developments were already completed. After that, the approval dates of the projects were searched. It was not possible to determine the approval date of 32 projects; therefore, these were eliminated from analysis. $10 \mathrm{I}$ projects fit the criteria of having been approved after the 
Private control and public openness.

The development of London's public spaces since the Mayor's 2009 manifesto

mayor's first policy documents were drafted. Of those, 25 were found not to enter the realm of public and private boundaries (being mainly internal refurbishments). The research combined this assessment with the analysis of the new strategies for 'public spaces' (Johnson, 2009) and the 'housing' policy proposed by the mayor of London (Johnson, 2013). The formulation of the investigation in these terms allowed investigation of how punctual actions related with the big picture.

The remaining 76 cases were initially analysed through their projects' online information. The following figure represents the degree of enclosure of these spaces. The first bar represents the scale of the public realm impact: $3 \mathrm{I}$ projects $(40.8 \%)$ made a large enclosure impact on the surroundings (red), 3 I projects (40.8\%) made small impacts (yellow), and 14 projects (18.4\%) did not impact the openness of the public environment (green). The second row represents the public space privatisation: 42 projects $(55.3 \%)$ resulted in large privatisations (red), 27 projects (35.5\%) privatised few aspects of the space (yellow), and 7 projects (9.2\%) privatised no aspect of public spaces (green). The last bar represents the sum of the two indexes (for each project), resulting in a diagram of the public space's 'coefficient of conversion' into privatised public space.
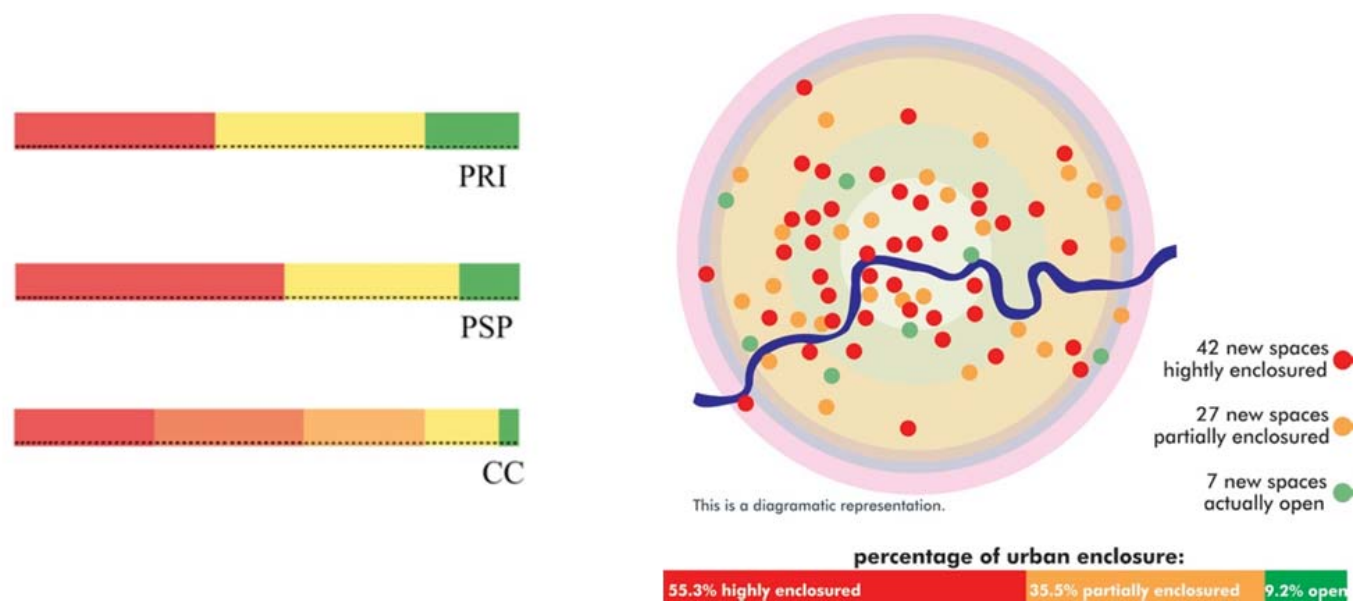

Fig. I. On the left: Public Realm Impact/ Public Space Privatization/ Conversion Coefficient.

Fig. 2: On the right: The degree of reification of public spaces in London. Source: the author.

The average of these three analyses creates the overall coefficient of privatization of public space; thus, the following diagram represents the general degree of enclosure of those public spaces in London.

In the second phase of the assessment, 20 spaces with different private/public arrangements were subjected to a field investigation that collected the information on 36 criteria developed upon state of the art research on public space'. For this reason, the field analysis involved a multi-layered methodology, registering different aspects of the space, aiming, on one hand, a rigorous analysis, and on the other hand, the observation of regular experience of common users. In this sense, the case studies were a mixed methodology, involving dialectical investigation, analytical techniques, behaviour and 
aesthetical observation, and critical synthesis. The observations of each case study were filled in a form, which divided the criteria in 5 main aspects:

(I) Descriptive and Informative elements

General information and data collection is important to interpret the impact of the developments in the city. This data was undertaken in a straightforward spirit and is the first moment of analysis, where the accumulation of pragmatic facts helps the observer to engage and get closer to the object of analysis. It also helps to keep the final conclusion in tone with the concrete experience, avoiding any excess of speculation and idealism.

\section{(2) Aspects of Territoriality}

In the field investigation, aspects of the construction of the site and the production of the territoriality are observed. Those aspects involve the production of a character/difference of the object in relation to its surroundings or regular spaces in the town. It is a subjective analysis not because of its imprecision, but because it depends on the interpretation of the impact of the object in the subject that observes it. It is an analysis of how the object presents itself as a phenomenon. It is specifically concerned with forms of creating boundaries and managing flows, as those aspects create the relation to the overall system of the city.

\section{(3) Mechanisms of Heteronomy}

This aspect is interested in how a series of apparatuses and 'invisible' machines are set into the place, transforming the territory in an instrument of controlled and directed experience. Signs, indications, directions, and regular furniture silently work together, creating patterns of behaviour and affecting a spatial protocol of exchanges and flows.

\section{(4) Observation of Public Experience}

This aspect is concerned with elements of affect involved in the sense of publicness of a place. It aims to assess how different perceptions and patterns indicate and create expected behaviours, how the space, the use, and the events indicate forms of possible subjectivities, actions, and actors, much in the sense of an althusserian 'interpellation' of space. Although it is a subjective element of experience, it can be registered through different concrete elements.

(5) Personal experience through photographical register

Finally, a personal experience, using critical and aesthetical techniques, aims to synthesize the overall experience of the site.

Following the collection of data, a series of "constant comparative analysis", as proposed in the Grounded Theory approach (Guest et al., 20I I, Glaser \& Strauss, 1967), aimed to develop theories on the basis of rigorous observation. This process of "grounding the theory" means the identification of main "codes" (patterns in general behaviour, segments of data, preliminary categories, and so on) in the case studies. The observations were assembled into preliminary main themes. Later, these themes were subject to field confrontation and debates with peers. 
Private control and public openness.

The development of London's public spaces since the Mayor's 2009 manifesto
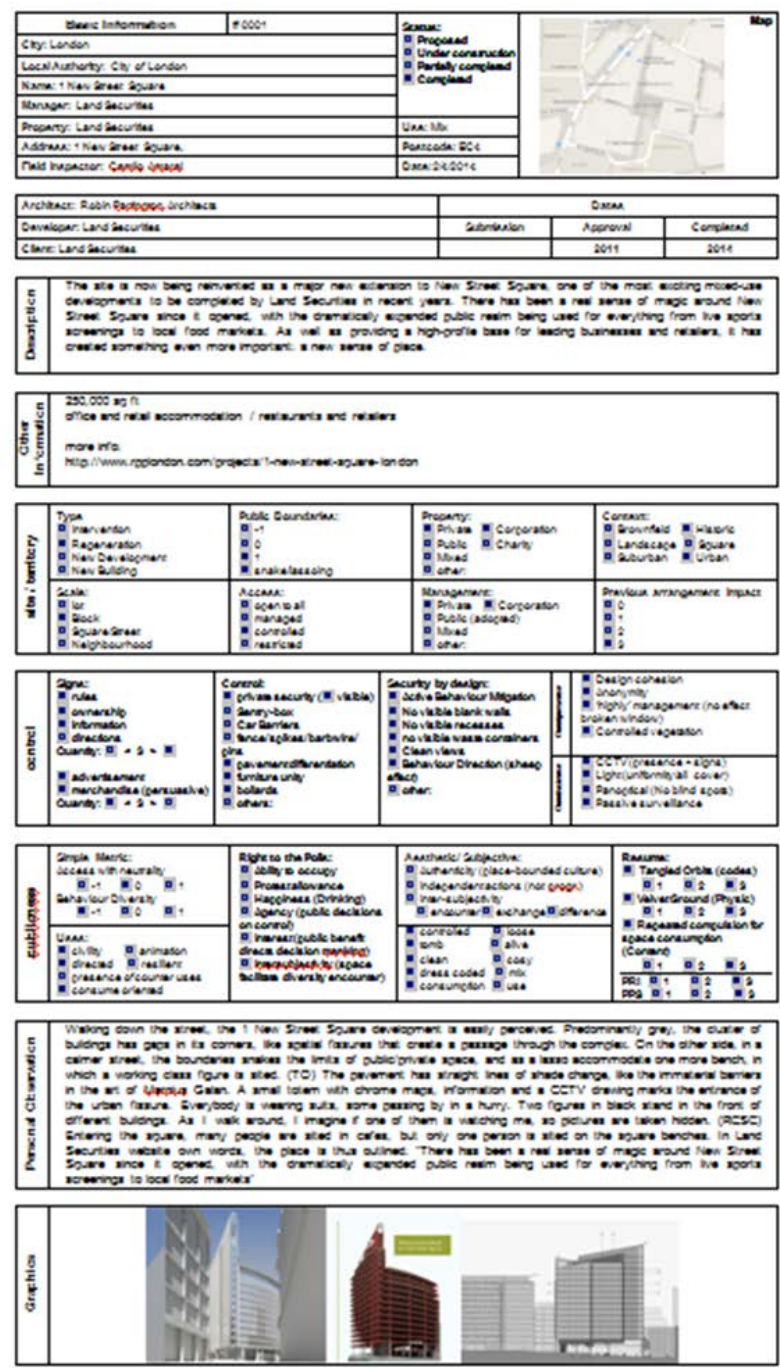

Fig. 3: Example of a Field Investigation form.

Finally, the systematization of this data made possible the development of three concepts to describe the new dimensions of these spaces:

(a) the sensation of a velvet ground, formed by a shining, soft and comfortable feeling, that transform the former freedom hard experience of cities into an anaesthetised soft experience;

(b) the formation of intertwined rules, in the form of tangled orbits, transforming the city spatial rules into a fragmented atmosphere, as if the 'lens' (a priori) we use to see a place have to be changed in each step of the way, maintaining a constant feeling of inability to use ones 'inner nature' to experience the space and, thus, handing control towards the place automaton fractal structure;

(c) and the anxiety produced by a new kind of displacement, where the architecture is no more appropriated by distraction (cf. Benjamin, 1986) as in the modern metropolis, but it happens only by the consumption of the place, where a subject only regain control of place experience through the game activity of consumption (what may be called the repeated compulsion of space consumption). 
The following lines will delineate these concepts among five of those spaces' experience, representing and describing five "gradations", from the most privatized space to the most public place (N.B.: the concepts do not emerge on the last example).
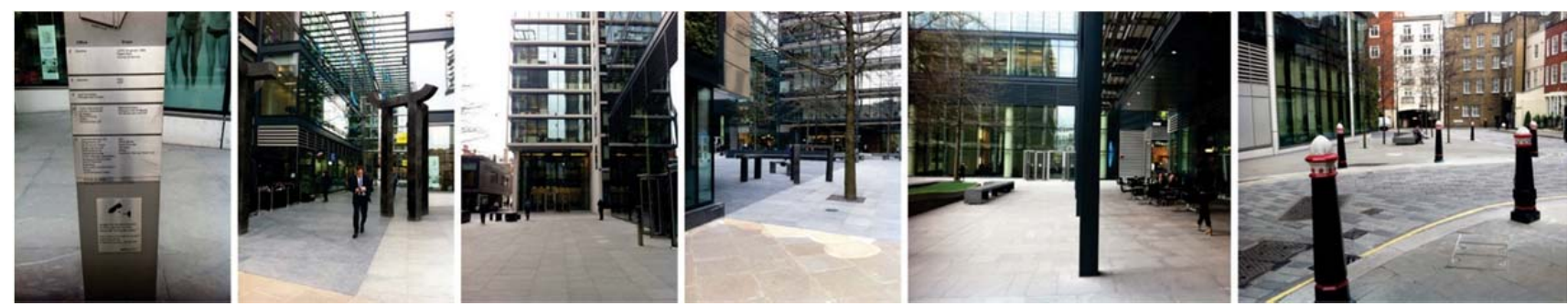

Fig. 4. I New Street Square. Photos: Camilo Amaral.

Number I New Street Square is utterly privatized. (Concept 'a') Walking down the street, the development is easily perceived. Predominantly grey, the cluster of buildings has gaps in its corners, like spatial fissures that create a passage through the complex. On the other side, in a calmer street, the boundaries snakes the limits of public/private space, and as a lasso accommodate one more bench, in which a working class figure is seated. (Concept 'b') The pavement has straight lines of shade change, like the invisible barriers in the art of Marcius Galan. A small totem with chrome maps, information and a CCTV drawing marks the entrance of the urban fissure. Everybody is wearing suits, some passing by in a hurry. Two figures in black stand in the front of different buildings. As I walk around, I imagine if one of them is watching me, so I take hidden pictures. (Concept ' $c$ ') Entering the square, many people are seated in cafes, but only one person is seated on the square benches. In Land Securities website own words, the place is thus outlined: "There has been a real sense of magic around New Street Square since it opened, with the dramatically expanded public realm being used for everything from live sports screenings to local food markets".
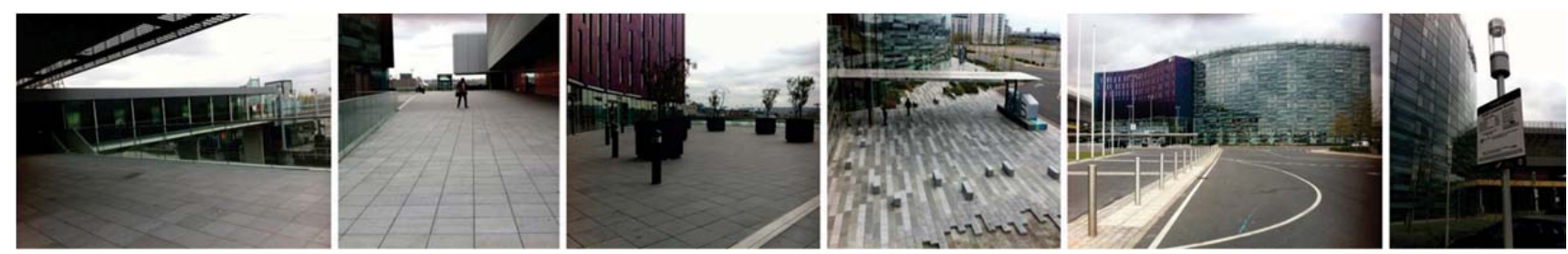

Fig. 5: Aloft Hotel. Photos: Camilo Amaral.

The Aloft development is also highly privatized. (a) In order to arrive at the Hotel, at the London's Docklands, pedestrians coming from the DLR must walk through a suspended platform, fluidly connected to the station and the Excel exhibition centre. A long smooth perspective connects the entrances without any stairs. In the way, the walker can see a square underneath. (b) A profusion of signs are attached to lampposts, with information rules and CCTV drawings reminding you are been watched. The myriad of bollards creates boundaries without barring you, composing a strange spatial choreography. In the same sense, benches seem to dance out of cracks in the pavement. The place appears 
Private control and public openness.

The development of London's public spaces since the Mayor's 2009 manifesto

overdesigned, as if the invisible hand of the architect was being corrupted by the dirty leaved by each footstep. (c) As a jewellery on display, the place seems more an object to be desired from the DLR windows, than a space to be actually consumed.
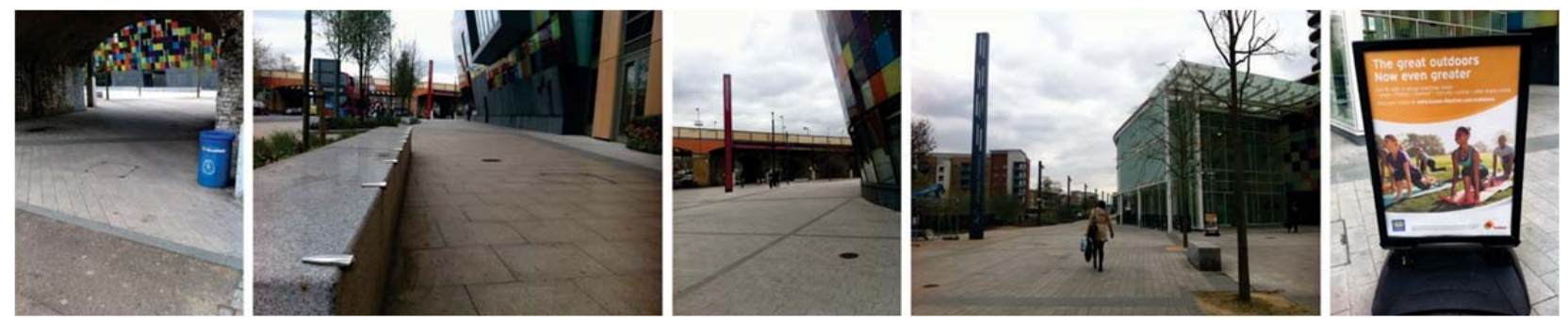

Fig. 6: Renaissance Development. Photos: Camilo Amaral.

The Renaissance development is moderately privatized. (a) Coming from the station, before arriving at the place, we first reach a square, passing through old brick arches. The reminiscence creates a tactile historicity, warming up the senses as we approach the colourful glass and metal building. (b) The shapeless of the square is subtly coordinated by a grid of squares in the pavement, giving command to what otherwise would be interstice. As in other places, the snake lines in the pavement are lassoing small objects, twisting from one side to the other of walker's trajectory. Furniture also presents itself as an omnipresent gesture of design. While pins in benches avoid skaters, massive totems are announcing information and the private/public partnership, nailing in the ground its own sense of place. (c) As many other new developments, Renaissance is a mix-use complex. In front of the cultural complex, a poster, from the Lewisham Borough in partnership with the Fusion Management Organization, proudly announces 'The great outdoors 'Now even greater'. Now, consumers can pay for group exercise class in the park backstreet. The Granary development is subtly privatized. (a) The analysis of public/private spatial relations on housing projects is of a more cautiously kind. House spaces are essentially domesticated, and this development is placed in a surround of calm streets, filled of smooth changes between public and intimacy. (b) Nevertheless, the streets on the new buildings have clear signs, showing its different private nature. The buildings in the block arrange an incisive frontier of prevailed pattern of solids and voids. (c) Another idiosyncrasy of the building among its neighbours is the fact of been connected to the Malthouse Creative Industries that, according to its website, work with 'ownership of ideas' and 'intellectual property'. The place is managed by an Arts Education charity, making it hard to simplify. Yet, we have the introduction of work into a domestic field.
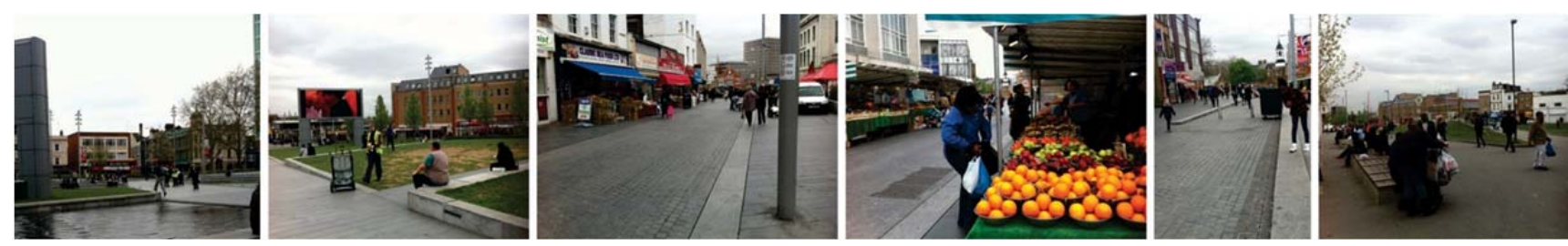

Fig. 7. Woolwich Squares. Photos: Camilo Amaral. 
The Woolwich are public spaces. Although, the massive screen gives a first impact of the squares becoming more or less equal to private public spaces, many aspects are different. The pavement has no snake patterns or shades of grey. The divisions are evident only between street and sidewalk. The square is unusually busy, with many kids, passers-by and people seated. The benches are formed of long plain lines emerging from the ground. Many people are seated. Two uniformed guards are on the street. Kids run on the fountain water, as parents tries to bring them back to their way. The stores in the side have merchandise and box in the sideway, causing a sensation of chaos. A sign in the lamppost indicates that dog walkers cannot take more than 4 dogs. A market is on the street, but market traders are not uniformed, and they chat more than work. A group of thirty-somethings drink beer seated on the benches, right in front of the officers, forming a strange combination with many others eating they own lunch.

\section{Conclusion}

The present article made an exercise of conceptual reflection on the practical experience of the new public spaces produced in London after the 2009 Mayor Manifesto. The analysis demonstrated a great trend towards the corporatisation of public spaces. The investigation demonstrated that the changes are not a simple contracting-out of roles between private and public actors, but a fundamental change in the experience of the city, suggesting a direct interference in citizenship conditions and in the freedom experienced in London.

These new spaces homogenize difference, transforming confrontation into game. Without a constant frame of reference, these multiple-layered spaces create a constant metamorphosis on the citizens' character, transforming the anxiety of the urban experience into a device for controlling diversity and directing social forces towards consumption. The urban space becomes a soft velvet ground, tangled by invisible rules. These spaces produce alienation by means of disorientation and comfort, repeatedly metamorphosing on each step one takes in his way through this new "velvet ground". Thus, the current production of social space is shaped by the dissolution of the rational and abstract conditions of the metropolis, provoking the accommodation of differences into an ethnocentric and hierarchical society. A new kind of domestication emerges from the corporations' bodiless. These contemporary spaces are formed by a new continuum of dissimilar repetition. As the examples demonstrated, the repetition of patterns does not build continuity, but displacement and anxiety, resolved only by spatial consumption. Therefore, citizenship is reified into consumerism. Therefore, theoretical approaches focused on the 'delightfulness' of urbanism cannot deal with the complexity of space and society. In contrast, it is important to investigate spatial alternatives: to imagine difference, autonomy and inner ruled citizenship; to imagine wilder and uncomfortable otherness similar to the 'familiarization' process.

The recidivism of Velvet Grounds and Repeated Compulsion of Space Consumption, do not represent a new uniformity. In contrast, creates an unpredictable 'heterogeneity' of sameness, by preventing the manifestation of inner values, and pragmatically autonomous interrelations other than consumption. The recidivism of Tangled Orbits occurs without formal centrality (as in Simmel's feudal cities, or in its metaphorical origin, the solar 
Private control and public openness.

The development of London's public spaces since the Mayor's 2009 manifesto

system). This new kind of circularity is timeless, perpetually cyclical, obscure and undetermined (blurred). Its complex knotted and twisted rules create a new kind of bird nest prison, which differs from the former means of control (panoptical and gridded). Cosy and kind, domestic and comfortable, this new form of control operate through disorientation and refuge, rather than discipline and punishment.

\section{Acknowledgements}

Support for this study was provided by "CAPES - Coordenação de Aperfeiçoamento de Pessoal de Nível Superior" for a PhD research at University of East London. I wish to thank Roland Karthaus, Anna Minton, Douglas Spencer, Peter Budd and Holly Brown for their careful review, contribution and discussions.

\section{Notes}

(I)The aspects and considerations derived for the observations came from the following studies: (I) Varna and Tiesdell (2010) characterized the conceptualization of publicness in two major effort groups: (a) Inductive: the quality of being public comes from external elements, physical properties, material elements, and barriers; (b) Deductive: comes from internal issues, symbolic interpretations, rules, and socially constructed meanings (in the eyes of the beholder). They propose a model for publicness interpretation by measuring: ownership, physical configuration, control, civility, and animation.

(2) Benn and Gauss (1983) propose three dimensions for the publicness examination: (a) Access: the ability people have to occupy the space, i.e., appropriate the space and recreating its function; (b) Agency: the examination of who defines how the space is controlled, i.e., if the rules have social accountability; and (c) Interest: the examination of the space management decision, interpreting if the 'rules' benefit the public or particular interests.

(3) Kohn (2004) uses three criteria for publicness: (a) ownership; (b) accessibility: the freedom, control, and neutrality of access; and (c) intersubjectivity: how the elements of the urban space facilitate or make difficult the encounter and interactions of people, allowing differences to emerge.

(4) Németh and Schmidt (20II) has used three axes to analyse publicness: ownership, management, and uses/users.

(5) Staeheli and Mitchell (2008) argued that a space is public when it can integrate the inhabitants into the creation and use of the space. For that, is important to analyse the receptivity, welcome, and comfort provided.

(6) For Iveson (2007), spaces become public through a process that engages people in the debate of the space's proprieties. Therefore, a place is public when subjected to public assessment or if it becomes a means of public conscience.

(7) Lessing (200I) creates a model of interpretation of the space, creating an interpretation grid drawn upon information networks' society. He uses three 'layers' for that: (a) Physical: the hardware are the material elements and infrastructure (as cables, mediums, objects); (b) Code: the laws, codes, protocols, and rules that mediate the exchanges; (c) Content: the actual information and elements involved in the transaction between people.

(8) Németh (2012) asserts that a "truly public forum is characterized by (relatively) open access, unmediated deliberation, and shared participation (...) Nevertheless, publicness is always 
subjective: whereas some might feel a space full of homeless persons is "truly public," this sight might drive other users away. (...) A simple metric might examine public space vis-à-vis' [a] Free Access and [b] Behaviour Freedom. He suggests a complete analysis should consider the following aspects: Physical (spatial programming, mobility, restrictions and aesthetic); Code (laws, regulations, policing, norms, language and guidelines); content (use, behaviour, symbolism meaning).

(9) For Zukin, S. (20I0), culture used to be place-bounded, and Public Space was connected to its history, but it is not anymore. Rather than preserve only the buildings, Public Spaces should also preserve the community that created the authenticity of the place. Domestication by cappuccino is a form of controlling the space by consumption taste. One should not miss the big picture: The issue is about capital granting incomes, controlling workers, associating with state to make profitable rules, and using media apparatus for managing consumers' tastes. Authentic democracy is loud, unruly, unpredictable, dangerous, undisciplined, independent, and non-programmed behaviour. Therefore, Public Spaces are understood as spaces free for protest, as the political aspect is one of most important elements of the polis.

\section{References}

Baudelaire, C. (1995) The Painter of Modern Life and Other Essays. Phaidon Press Ltd. London.

Baudelaire, C. (1996) Pequenos poemas em prosa [le spleen de Paris]. Florianópolis: Editora da UFSC.

Benjamin, W. (1986) Magia e Técnica, arte e política. Vol. I. São Paulo: Brasiliense, 1986.

Benn, S., and G. Gauss. 1983. The public and the private. In Public and private in social life, edited by S. Benn and G. Gauss, 3-30. New York: St. Martin's Press.

Berman, Marshal. (1990) All That is Solid Melts Into Air. 5th edition. London: Verso.

De Magalhães, C. (2010). Public Space and the Contracting-out of Publicness: A Framework for Analysis. Journal of Urban Design, Issue I5, pp. 559-574.

Feyerabend, P. Contra o Método. Rio de Janeiro: F. Alvez ed., 1989.

Freud, S. (1962) Beyond the Pleasure Principle. In Vol. 18. London: The Hogarth Press.

Gilens, M. and Page, B. I. (2014) Testing Theories of American Politics. Perspectives on Politic, Fall.

Glaser, B. and Strauss, A. (1967). The discovery of grounded theory. Chicago: Aldine.

Guest G., MacQueen, K., \& Namey E. (20II) Applied Thematic Analysis. SAGE Publications.

Harvey, D. (1989) The Postmodern Condition. Oxford: Oxford University Press.

Iveson, K. 2007. Publics and the city. Oxford: Blackwell.

Johnson, B. (2009) A Manifesto for Public Space: London's Great Outdoors. Mayor of London. Available from http://www.london.gov.uk/sites/default/files/Manifesto\%20for\%20Public\%20Space.pdf

Johnson, B. (2013) Homes for London: The London Housing Strategy. Draft for Consultation. Greater London Authority, November, 2013. Copies of this report are available from www.london.gov.uk

Kohn, M. 2004. Brave new neighborhoods: The privatization of public space. New York: Routledge.

Larson, G. and Burger, J. (20I3). A population genetics view of animal domestication. Trends in Genetics, April, 29 (4).

Latham, A. and Koch, R. (2013) On the hard work of domesticating a Public Space. Urban Studies, at 50(I) 6-2I, January.

Lefebvre, H. (200I) O Direito à Cidade. trad. R. E. Frias. São Paulo: Centauro. 
Private control and public openness.

The development of London's public spaces since the Mayor's 2009 manifesto

Lessig, L. 200I. The future of ideas: The fate of the commons in a connected world. New York: Random House.

Minton, A. (2012) Ground Control. London: Penguin Books.

Monte-Mór, R. (2006) A Cidade e o Urbano. in: BRANDÃO. As Cidades da Cidade. BH: UFMG, 2006.

Németh, J., and S. Schmidt. 20II. The privatization of public space: modelling and measuring publicness. Environment and Planning B: Planning and Design.

Németh, Jeremy. (2012) Controlling the Commons: How Public Is Public Space? Urban Affairs Review 2012 48: 811 .

Rancière, J. (2005) A Partilha do Sensível. Rio de Janeiro: Ed. 34.

Sennet, R. (2002) Flesh and Stone. London: Penguin Books.

Simmel, G. (1903) The Metropolis and Mental Life. In Kurt Wolff (Trans.) The Sociology of Georg Simmel, New York: Free Press, 1950, pp. 409-424.

Smith, N. and Low, S. (2006). The politics of Public Space. London: Routledge.

Staeheli, L., and D. Mitchell. 2008. The people's property? Power, politics, and the public. New York: Routledge.

Varna, G., and S. Tiesdell. (2010). Assessing the publicness of public space: The Star Model of publicness. Journal of Urban Design I5: 575-98.

Velden, F. F. V. (2009) Sobre cães e Índios. Avá, n. I5, Posadas dic, UNMT, Argentina.

Vigne, J. (20II) The origin of animal domestication and husbandry. C.R.Biologies, 334, p.I7I-I8I I.F.

Zukin, S. (2010). Naked City: Death and Life of Authentic urban Places. Oxford University Press. 
The Journal of Public Space

2016 | Vol. I, n. I

\section{VIEWPOINT}

\section{This is My City}

\section{Leonardo Parra-Agudelo}

Queensland University of Technology, Australia

Creative Industries Faculty, School of Design, Urban Informatics Research Lab I.parraagudelo@qut.edu.au | @Parra_Leonardo

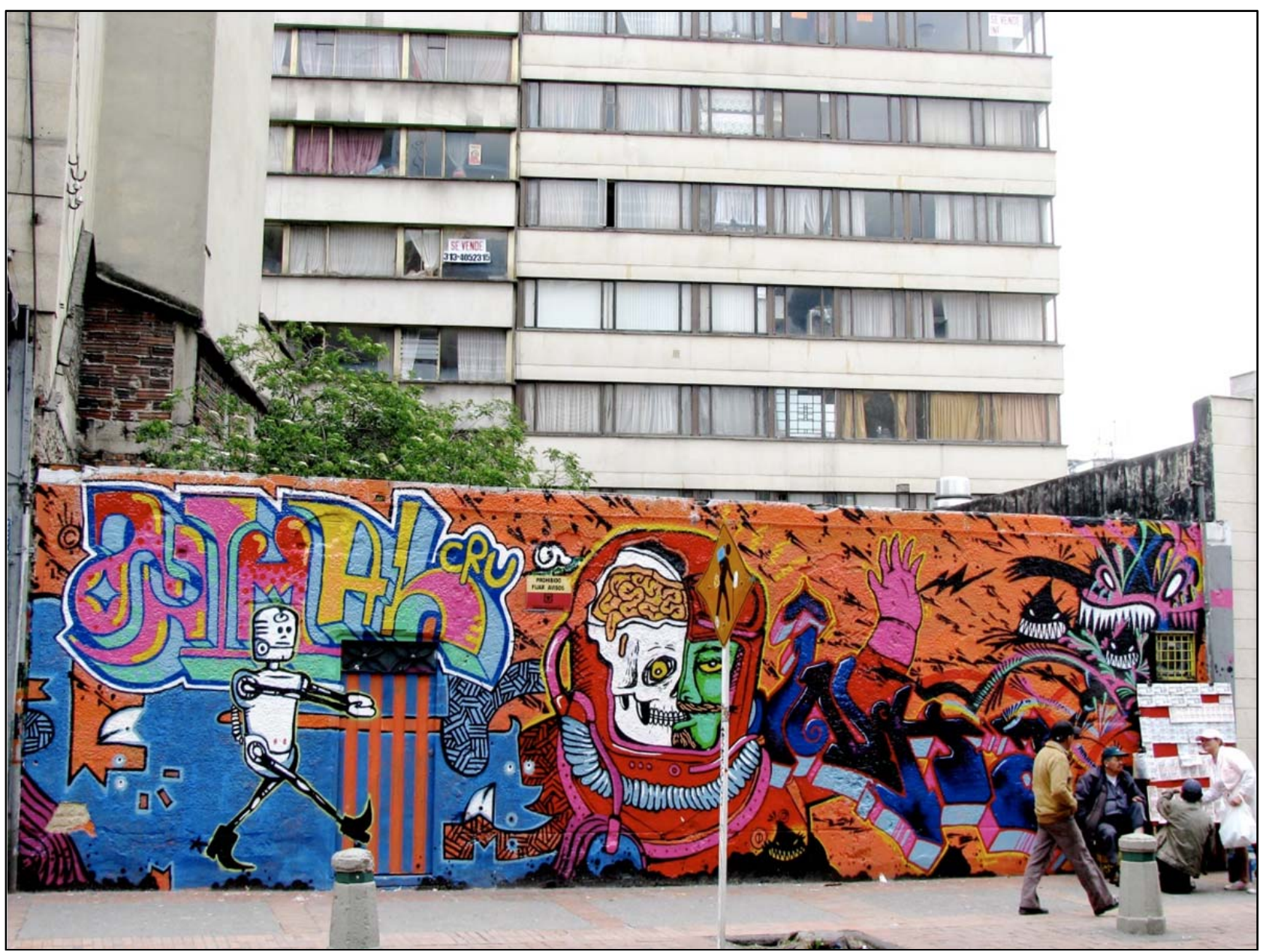

Wall painted in the context of the Scoundrel Memory Exhibition, Museo de Bogota by Buytronick, Chirrete, Mecamutanterio, Zas-Inha, Stinkfish, Juan Canales \& Jungla. Bogota, Colombia.

I would like to think l'm a good person. I've studied how to transform things with my hands, with projects, with words, with education. I was initially trained to solve problems by bringing new artefacts to existence; my training makes me shiver with distrust now. I walk with equal fascination through nature and urban environments and the clash 
between the two upsets me greatly. The depth and breadth of the human endeavour fascinates me and I'm saddened I will never have access to it all. Through my work I have embraced the good and the bad, in an attempt to understand myself and others. Conflict is at the core of what I do and sometimes I materialise it in ways that are not appreciated by others. A few years ago someone I regard highly said that I was interested in everything under the sun; it cannot be any other way.

I hold a bachelor's degree in industrial design from Universidad de los Andes (Colombia) and an M.F.A. in Design \& Technology from Parsons School of Design (US). I'm currently based in the Urban Informatics Research Lab, Queensland University of Technology (Australia) and I expect to finish a PhD in design for social change with a focus on South American cities this year.

For this issue, I was asked to provide a viewpoint on the experience of public space as someone that has been involved in graffiti and street art for more than ten years. My involvement with these two forms of street interventions, that for outsiders co-exist and for insiders collide, is mostly situated in Bogota, Colombia. The living conditions of the inhabitants of the capital city of a country embedded in more than fifty years of internal violence were, and still are, precarious for many but not so much for me. I was raised in a middle class home and was well taken care of.
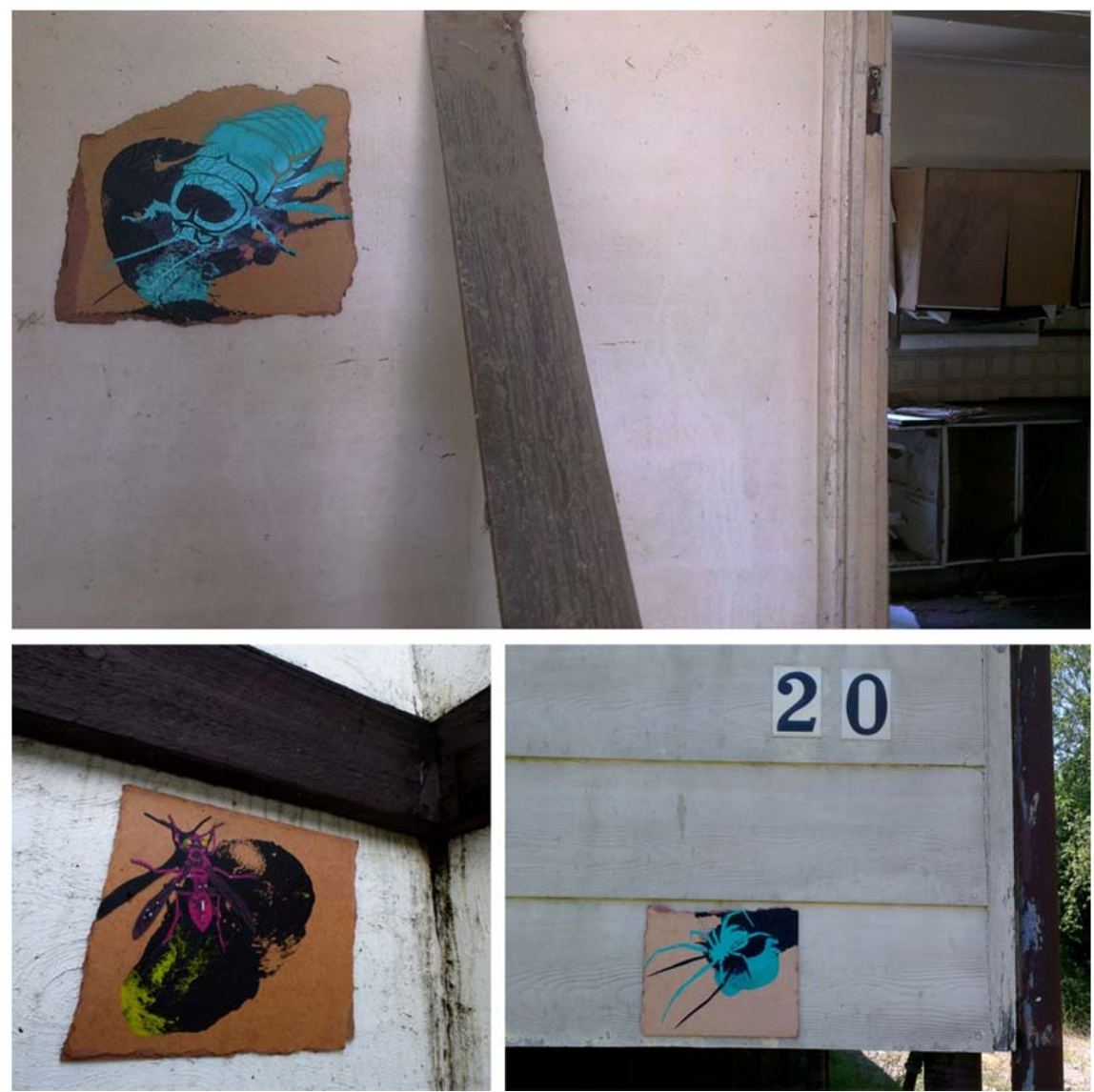

Upper picture: roaming around outer city suburbs like the two-layer Australian cockroach stencil. Bottom left: seven-layer wasp on discarded wooden board flies around an inner-city suburb. Bottom right: two-layer Red Back spider stencil in an abandoned house. 
Throughout my childhood I lived in gated communities and the entrapment in the city was palpable; we could not go anywhere. Gated communities were all I had. The city, the countryside, the country did not belong to me, I was there, but it was all borrowed from someone that could get rid of me without anyone knowing where I had gone. These things were beyond my reach and I complied. What I knew about the city were the things my parents knew were safe for me. I grew up protected and sheltered. I adapted to the situation, and then skateboarding appeared in my life. I had my own wheels, I could go places. I was chased by guards out of shopping malls and my understanding of the city changed. Where other people saw staircases I saw heel flips and tail grabs. I started to read public space as a playground, a nose slide here and a grind there. It was really fantastic. I developed a navigating sense based on the sites where tricks could be executed.
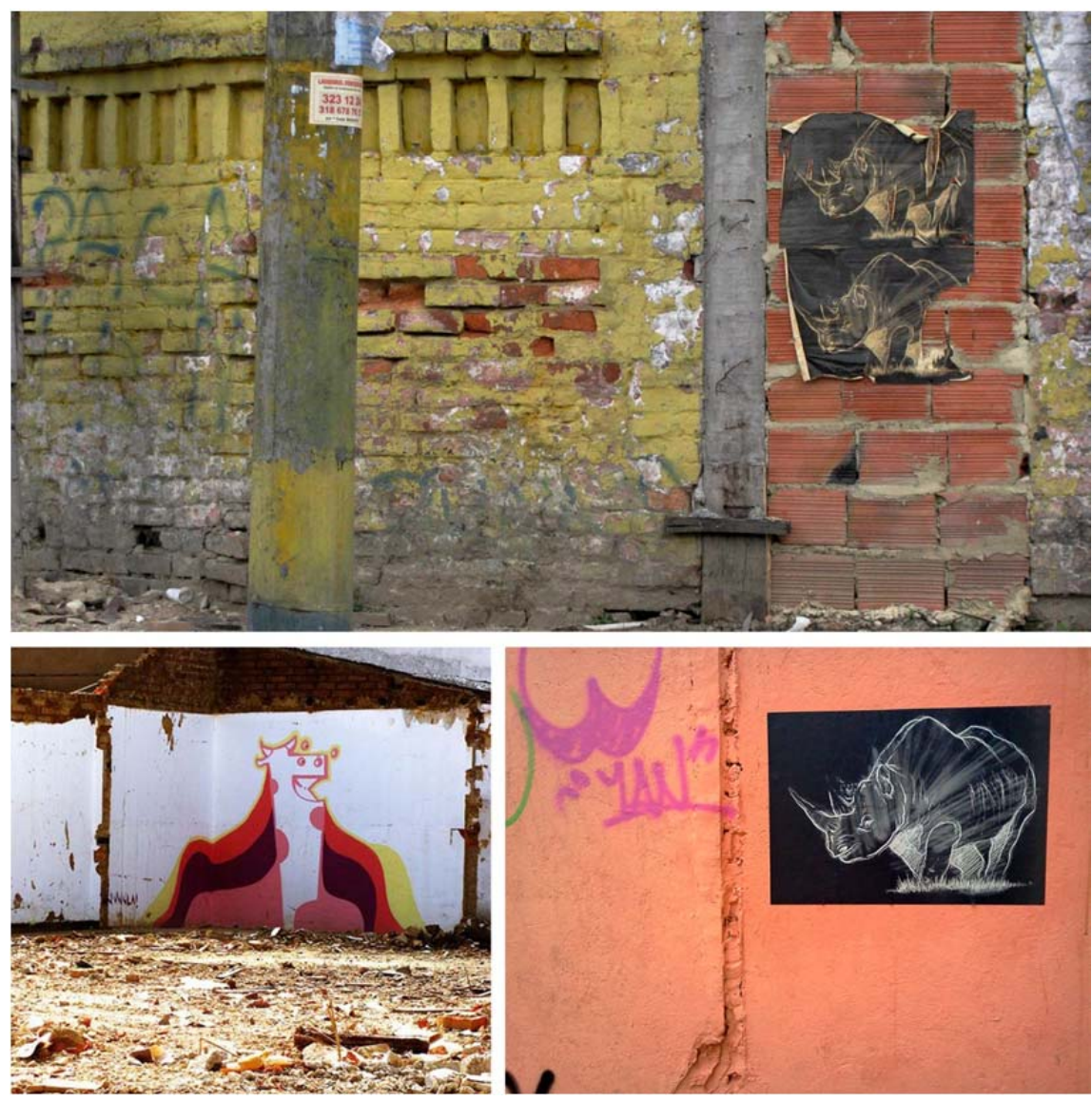

Upper picture: rhinoceros decaying as the building they're on. Bottom left: strength in numbers: 1000 rhinoceros were printed in newspaper paper. 200 have seen the city so far. Bottom right: Melting cow in a derelict area of northern Bogota.

Years later, after a two year absence, I returned to see Bogota covered in spray paint. I could not miss the opportunity to contribute; I had discovered my new skateboarding. I no longer needed wheels; I just needed a pair of cans of spray paint and a sketchbook. To this day I keep a record of the walls that need some colour. Perhaps I need to see colours 
in them; it really doesn't matter, I had the tools to take over of what was taken away from me when I was a kid. The chance to make my voice publicly heard had come and I was going to embrace it with a pair of runners, a black hoodie and a pink dot fat cap on my cans. I started my late night outings painting a set of smiling animals: cats, cows, bulls, rhinos, etc. I wanted to give back to the city that had given me so much after all, I had grown up there-, to its people, I wanted to tell them, and tell myself, that not everything was bad. I wanted to say that I was there to share happy thoughts. At the time I didn't know about old school bomber Pez from Barcelona and his happy schools of fish. Much has changed since early 2006 when I got interested in exploring my own voice through spray paint and homemade glue. The country is in much better shape now and the current peace agreements promise an enormous change, however, inequality and discrimination are still ubiquitous throughout and the transformation required calls for a lot of hard work. As an individual citizen, I saw public spaces as the platform from which to contribute to that transformation, even if that meant shattering the old through contested means. I still see public spaces this way, I still paint -and the country still makes me cry- and I own the spots where l've painted. The message is out there, even if only for a few days: this is my city, it belongs to you too, it's time to change it and what you see here is my colourful contribution towards that new Bogota.

\section{To cite this article:}

Parra-Agudelo, L. (20I6). This is My City. The Journal of Public Space, I(I), I47-I50, DOI: 10.5204/jps.vlil.16

This article has been accepted for publication in The Journal of Public Space. Please see the Editorial Policies under the 'About' section of the journal website for further information.

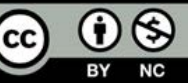

This work is licensed under a Creative Commons Attribution - Non Commercial 4.0 International License. https://creativecommons.org/licenses/by-nc/4.0/ 
The Journal of Public Space

2016 | Vol. I, n. I

\section{VIEWPOINT}

\section{Magic Carpet. \\ Re-envisioning Community Space in Hong Kong}

Hendrik Tieben

The Chinese University of Hong Kong, Hong Kong

School of Architecture

hktieben@cuhk.edu.hk

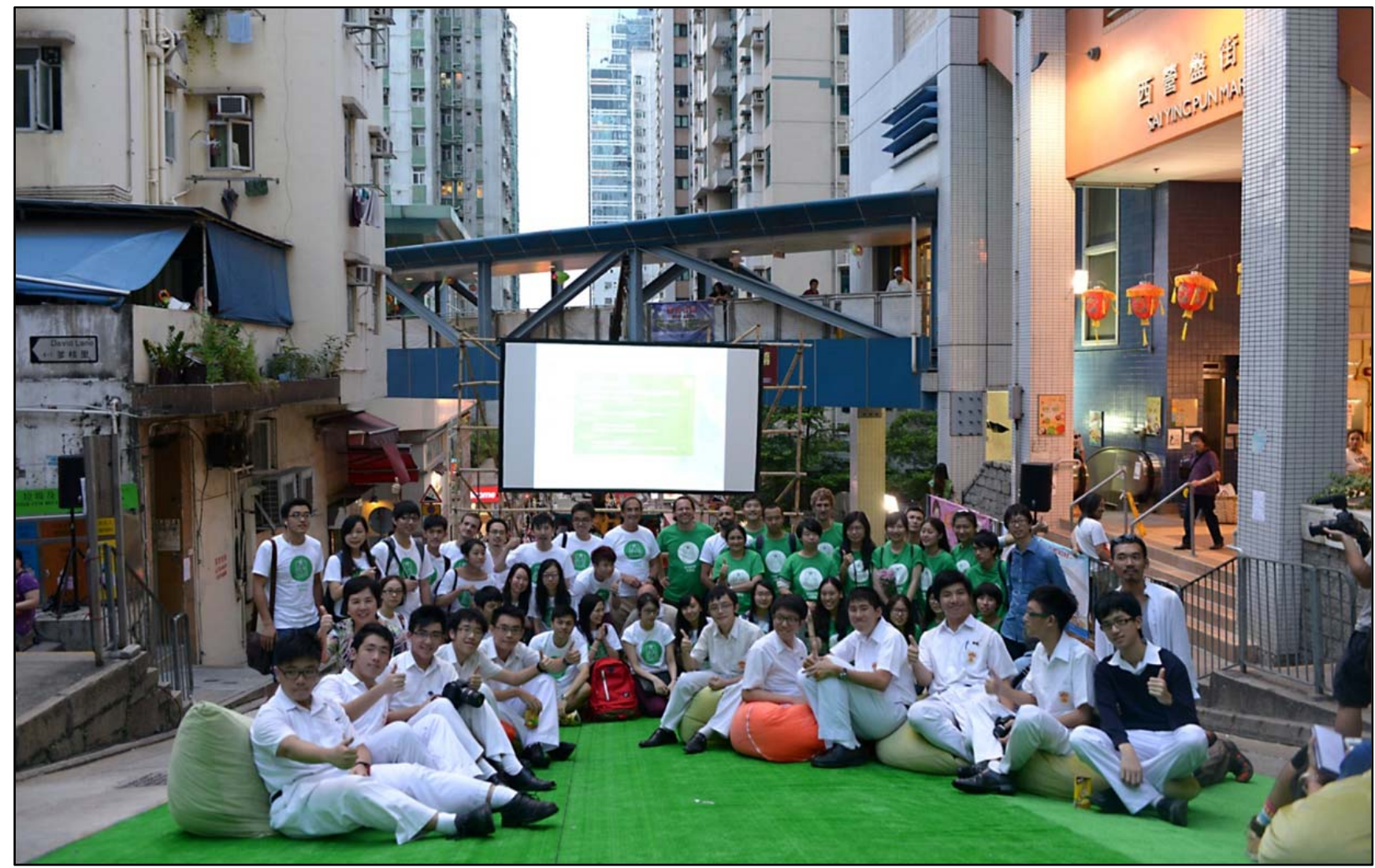

The Magic Carpet project team in Centre Street, Sai Ying Pun, Hong Kong, just few hours before the moonlight cinema event, Mid-Autumn Festival, 2013.

Magic Carpet was launched in 2013 by Hendrik Tieben of the School of Architecture and Anthony Fung of the School of Journalism and Communication at The Chinese University of Hong Kong, as an outreach program combining documentation of daily life, community engagement and urban design. The project was first held in Sai Ying Pun in 2013 and was subsequently brought to Tin Shui Wai (20I4) and To Kwa Wan (20I6).

Magic Carpet transforms a public space into an outdoor cinema in which movies about the neighbourhood are shown. The movies are produced by local secondary school 
students, following a series of workshops that prepare them to conduct video-interviews with the community.

At Magic Carpet, community members and the general public interact with each other, building a stronger bond between themselves while empowering them to re-envision the possibilities of public space together.
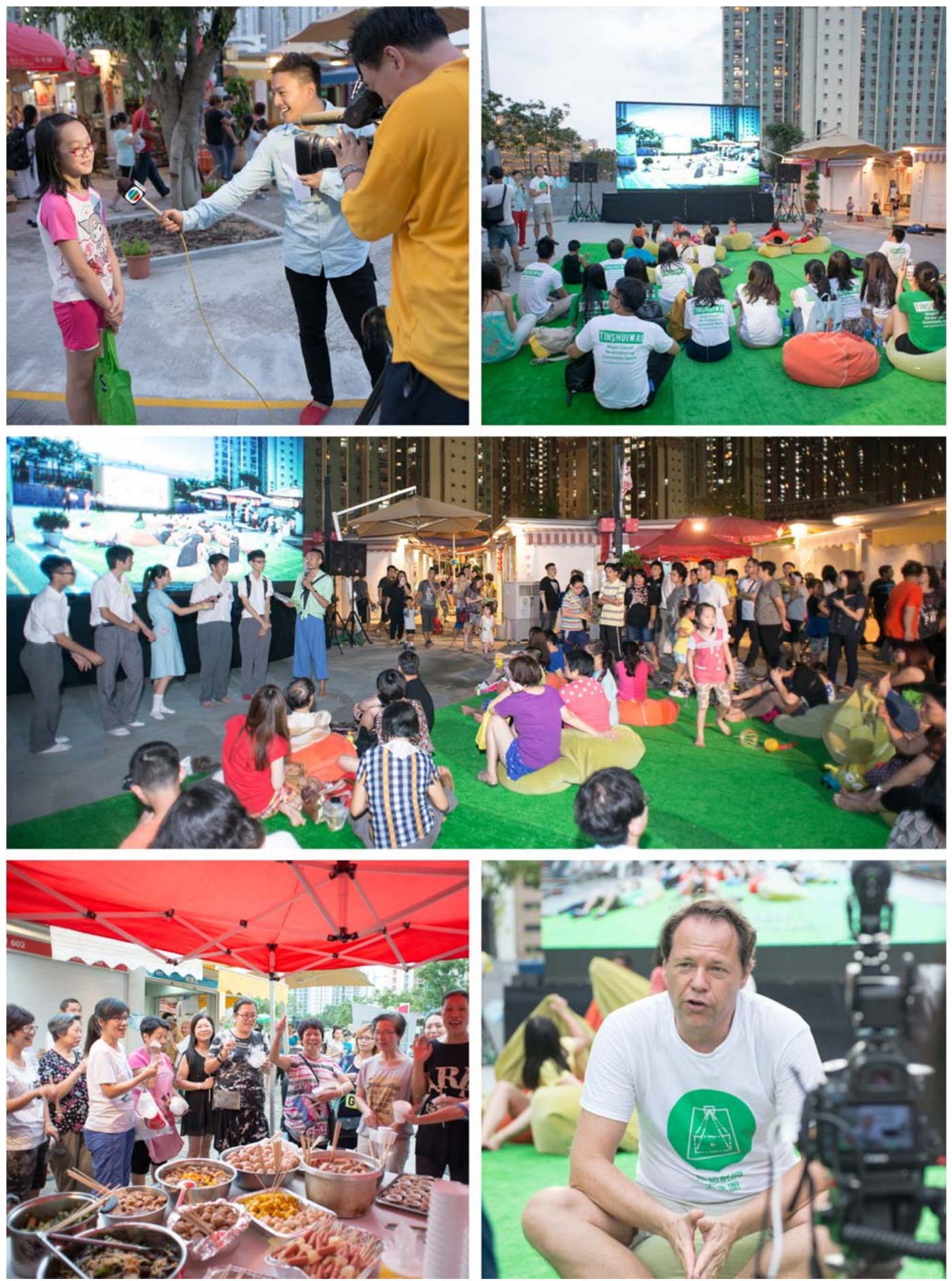

Pictures from the Magic Carpet event held in Tin Shui Wai in 2014.

I52 | The Journal of Public Space, I(I), 2016 | ISSN 2206-9658

(c) Queensland University of Technology 

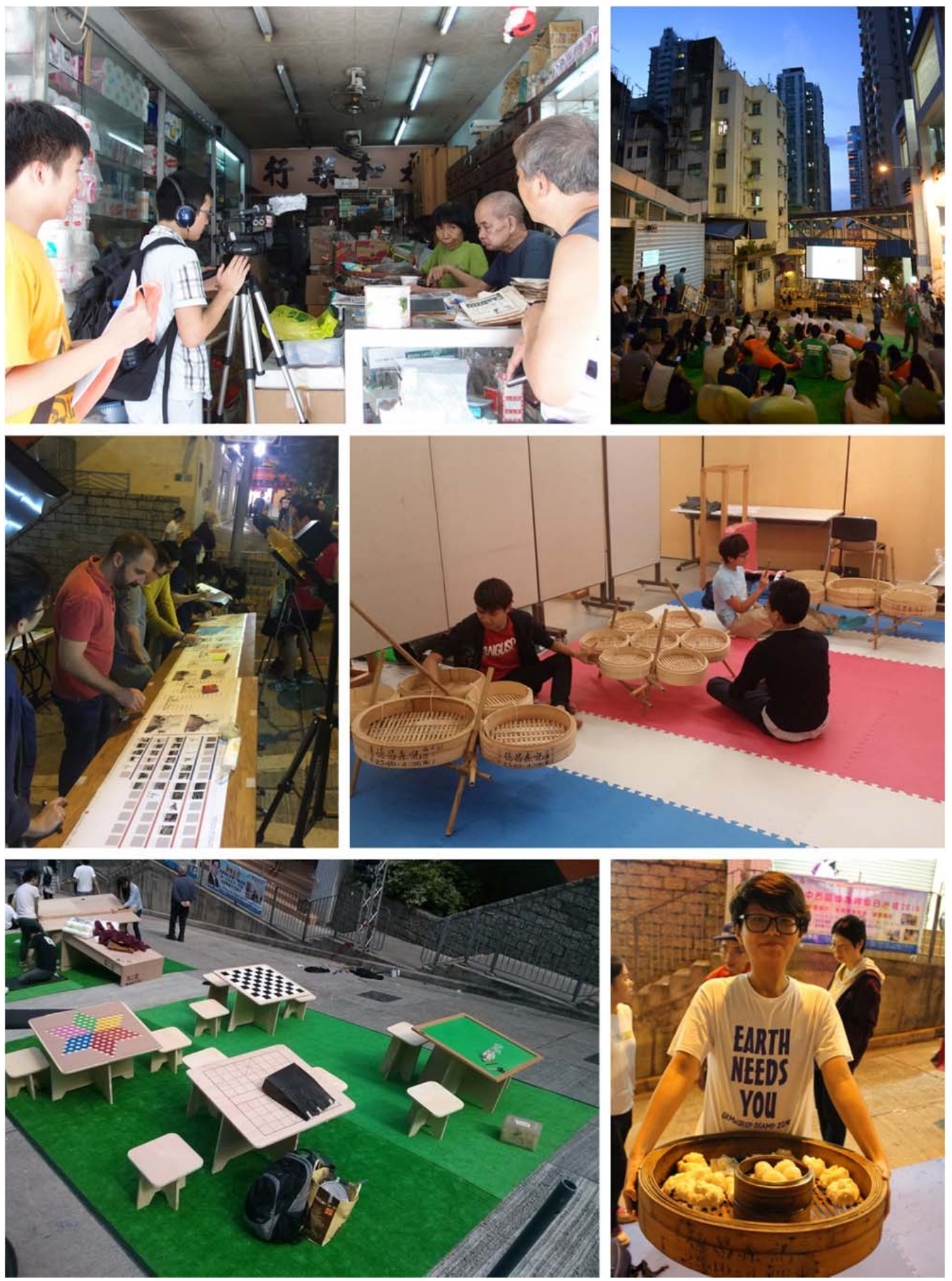

Pictures from Magic Tables, a design-build project + public event focusing on the making of community space. CUHK urban studies students collaborated with residents of different streets to engage in a friendly competition to "build" tables that allow stronger social interaction in the district.

Magic Carpet is one of a series of projects carried out by the same team to transform public space. A further initiatives has been Magic Tables - Remaking Community Space in Sai Ying Pun (20I5), in which Urban Studies students from CUHK built street furniture 
for social gathering. The latest Magic Carpet project focuses on the district To Kwa Wan, which is known for its grass-roots and migrant population and is currently transforming rapidly due to the construction of a new metro-line.

The Magic Carpet project has been supported by the Knowledge Transfer Fund of The Chinese University of Hong Kong and the Quality Education Fund, Hong Kong. Each project has been linked to studios of CUHK to engage urban studies and design students in community projects.

A parallel Magic Carpet project is organized by the National Taiwan University in Taipei. Results of both Magic Carpet projects will be discussed on a forthcoming book publication in late 2016.

\section{Credits}

Project initiator:

Hendrik Tieben, Associate Professor, School of Architecture

The Chinese University of Hong Kong

Project partners:

- Kwang Hwa Information and Culture Centre

- Conservancy Association Centre for Heritage

- Sai Ying Pun residents

Project team at CUHK:

- William Sin

- Janice Leung

- Francesco Rossini

- Yip Kai Chun

- Students of the BSSc in Urban Studies Program

Sponsor:

- Kwang Hwa Information and Culture Centre

Food sponsors:

- Pacific Island Hotel

- Sai Ying Pun Community

www.magiccarpet.hk

\section{To cite this article:}

Tieben, H. (20I6). Magic Carpet: Re-envisioning Community Space in Hong Kong. The Journal of Public Space, I(I), I5I-I54, DOI: 10.5204/jps.vlil.I7

This article has been accepted for publication in The Journal of Public Space. Please see the Editorial Policies under the 'About' section of the journal website for further information.

\section{(c) $\left(\mathrm{BP}_{\mathrm{NC}}\right.$}

This work is licensed under a Creative Commons Attribution - Non Commercial 4.0 International License. https://creativecommons.org/licenses/by-nc/4.0/ 
The Journal of Public Space

2016 | Vol. I, n. I

\section{VIEWPOINT}

\section{Pop-up City. Searching for instant urbanity}

\section{Luisa Bravo}

City Space Architecture, Italy

luisa.bravo@cityspacearchitecture.org

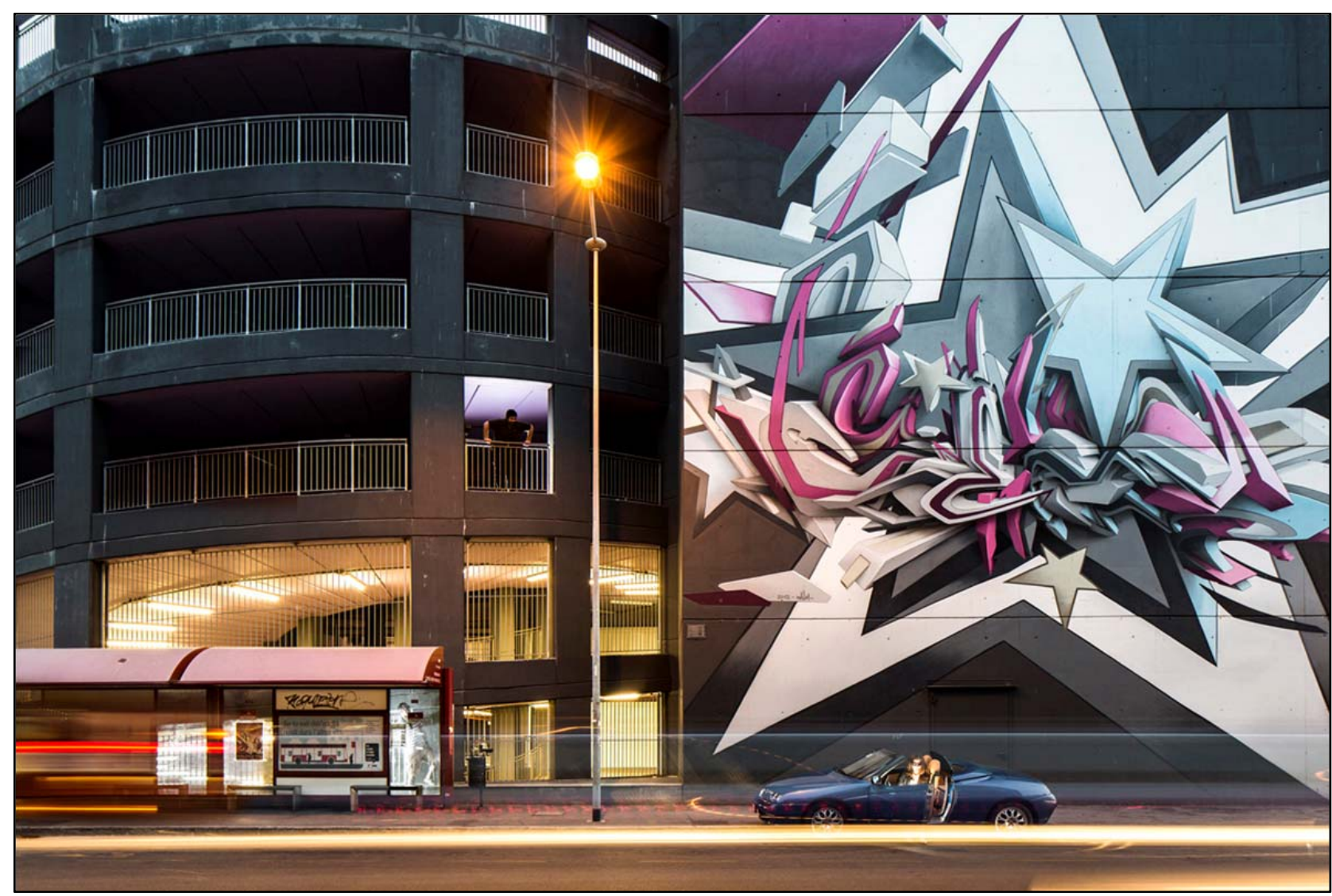

Multi-storey car park, via Fioravanti, Bologna. Photography: Fabio Mantovani.

Pop-up City is a photography research project initiated in 2013 in the city of Bologna, Italy. It works on perception and understanding of urban and architectural features of the existing city, trying to deliver new powerful images of the suburban world and to highlight existing places with a potential for public life. These places are generally disconnected from the mental representation of the urban narrative plot of public spaces: they are part of the everyday existence, but common people are accustomed to experience them as fragments, in a sort of jump-cut urbanism, affected by the use of cars.

Pop-up City is an attempt to make people look at everyday streets, places and spaces around them with different, conscious eyes, in order to embed them in their physical and 
emotional urban life. Pop-up City moves far away from the European mental attitude that immediately links the concept of "public space" to the idea of a traditional designed square, searching for that intangible dimension made of desires, dreams and passionate involvement, giving shape to imagination.

Pop-up City can influence the mental representation of different places and can foster a kind of imageability in the urban consciousness. This a means to discover invisible dimensions of an "ordinary magic" in the public realm, looking for the unexpected and the unseen, through episodes of instant urbanity related to our everyday existence.

Pop-up City is trying to document what is now largely undocumented. It represents the city of Bologna, but actually the Pop-up City could be anywhere.
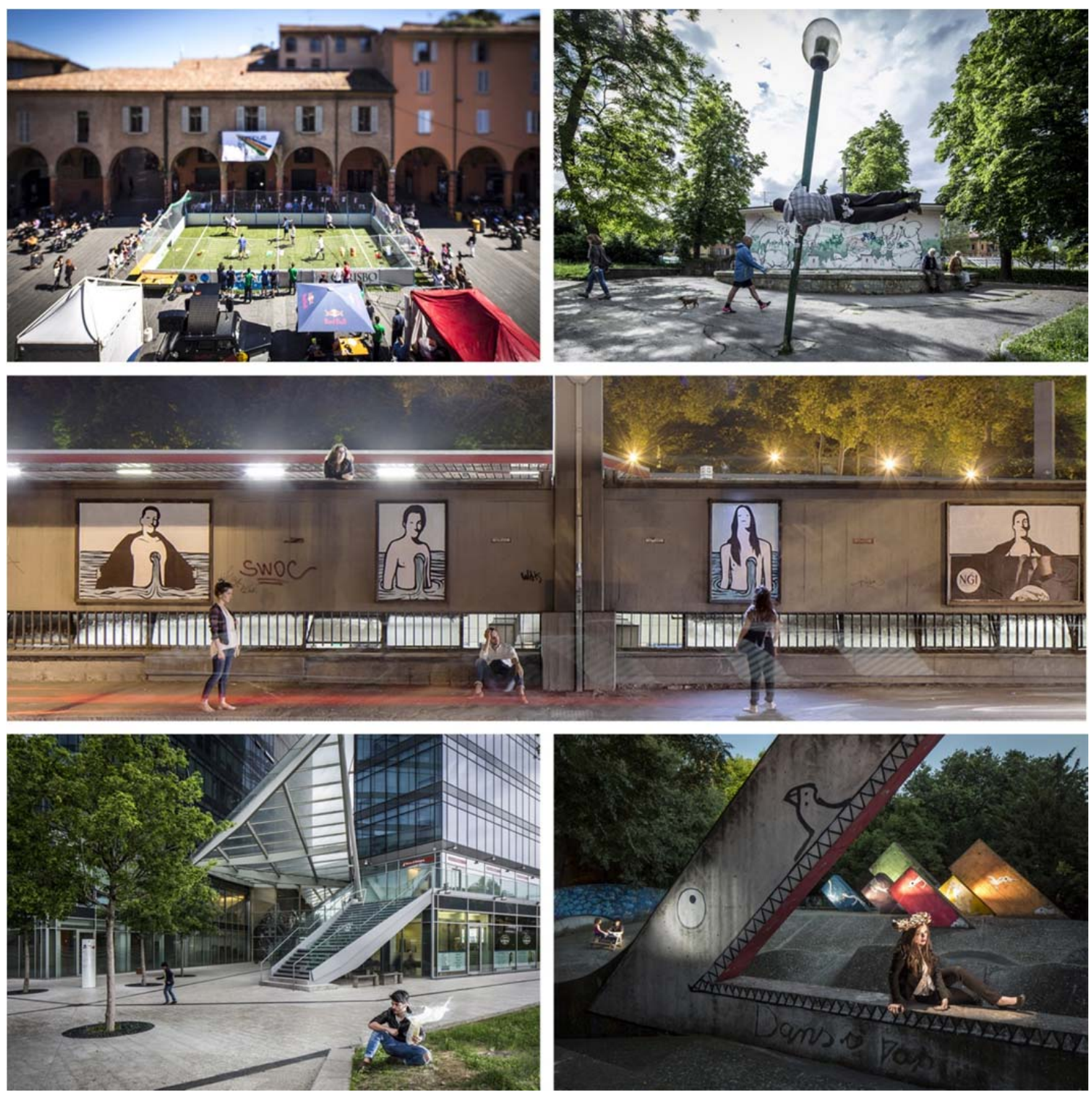

Top left: "Campus by night” event, Piazza Verdi, Bologna.

Top right: Lions' cage, Giardini Margherita, Bologna. Center: Bus Station, Viale Masini, Bologna. Bottom left: Piazza Liber Paradisus, Bologna. Bottom right: Giardino del Guasto, Bologna.

Photography: Fabio Mantovani.

I56 | The Journal of Public Space, I(I), 2016 | ISSN 2206-9658

(c) Queensland University of Technology 


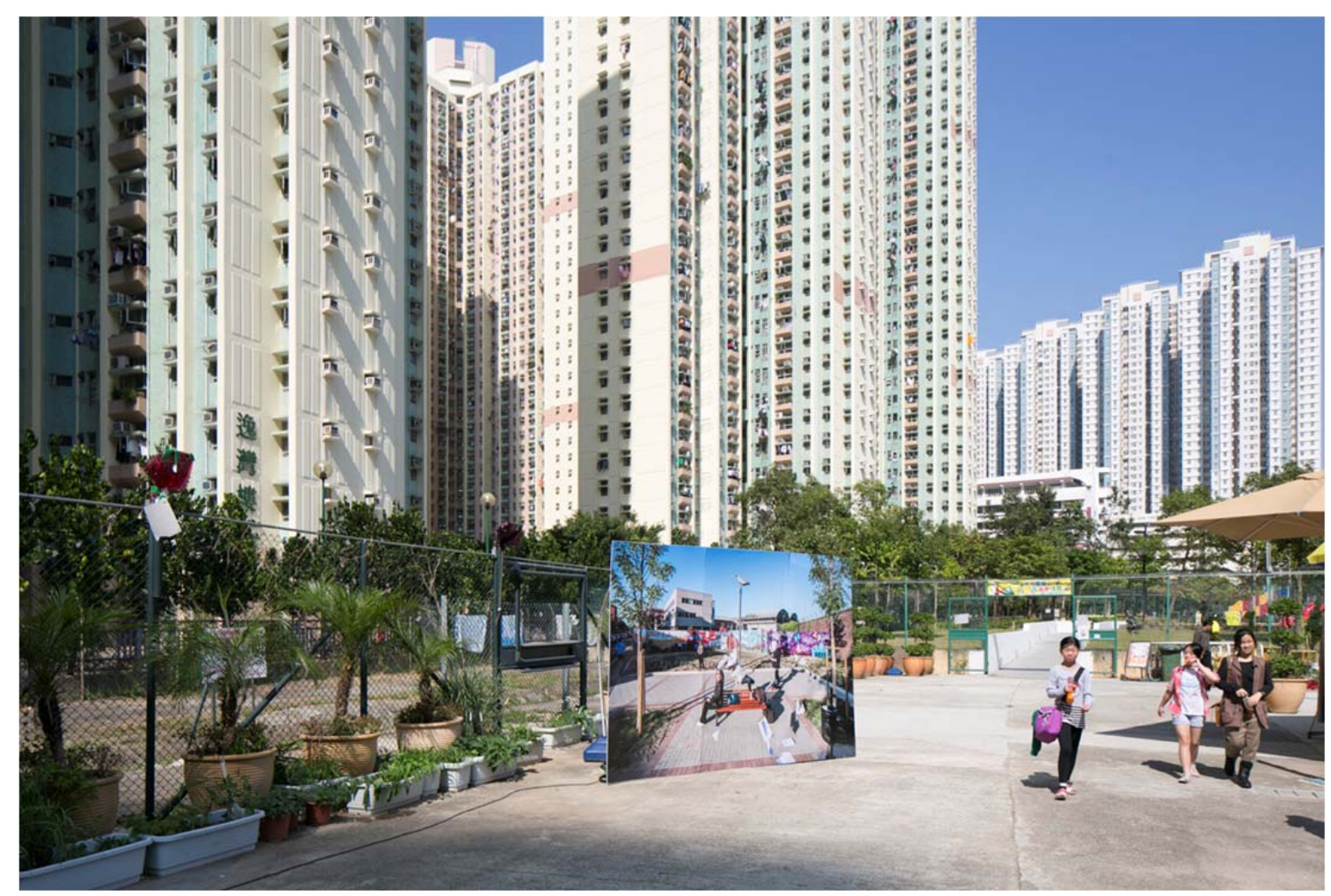

Pop-up City exhibition at Tin Shui Wai, Hong Kong, 20I4. Photography: Fabio Mantovani.

The Magic Carpet project team at The Chinese University of Hong Kong and Tung Wah Group of Hospitals Tin Sau Bazaar hosted Pop-up City in Tin Shui Wai in 2014. Like suburban Italian neighborhoods, Tin Shui Wai is located at the margin of Hong Kong; its space has no identity; it lacks street spaces for communal encounters and microeconomic activities. All these result in the stigmatization of Tin Shui Wai with problems such as social isolation and a high unemployment rate.

Bologna and Hong Kong share the same suburban reality, in a way that is not difficult to perceive: even if they are related to different geographical contexts and cultures, the two cities are dealing with living communities in new, large urban landscapes far away from the historic downtown district. The suburban world can be banal, sometimes ugly, not interesting, but full of life and can transform itself into an enchanting environment. People simply have to understand a new kind of urbanity, made of small, temporary, spontaneous and creative episodes of emotional exchange.

Through staging Pop-up City in Tin Shui Wai, the Magic Carpet project team and Tin Sau Bazaar created an opportunity to re-envision, activate, and transform the public space of the district, and thereby make the community more vibrant. In addition, the project aimed to foster art and cultural exchange and creative activities in Tin Shui Wai.

\section{Credits}

Curator: Luisa Bravo

Photographer: Fabio Mantovani

Pop-up City was exhibited for the first time at Palazzo Pepoli, Museum of the History of Bologna, Torre del Tempo, Bologna, June 27 - July 20, 20I4, as part of the 'Past Present and Future of Public Space' International Conference on Art, Architecture and Urban Design, June 25-27, 2014. http://www.cityspacearchitecture.org/?c=pop-up-city 

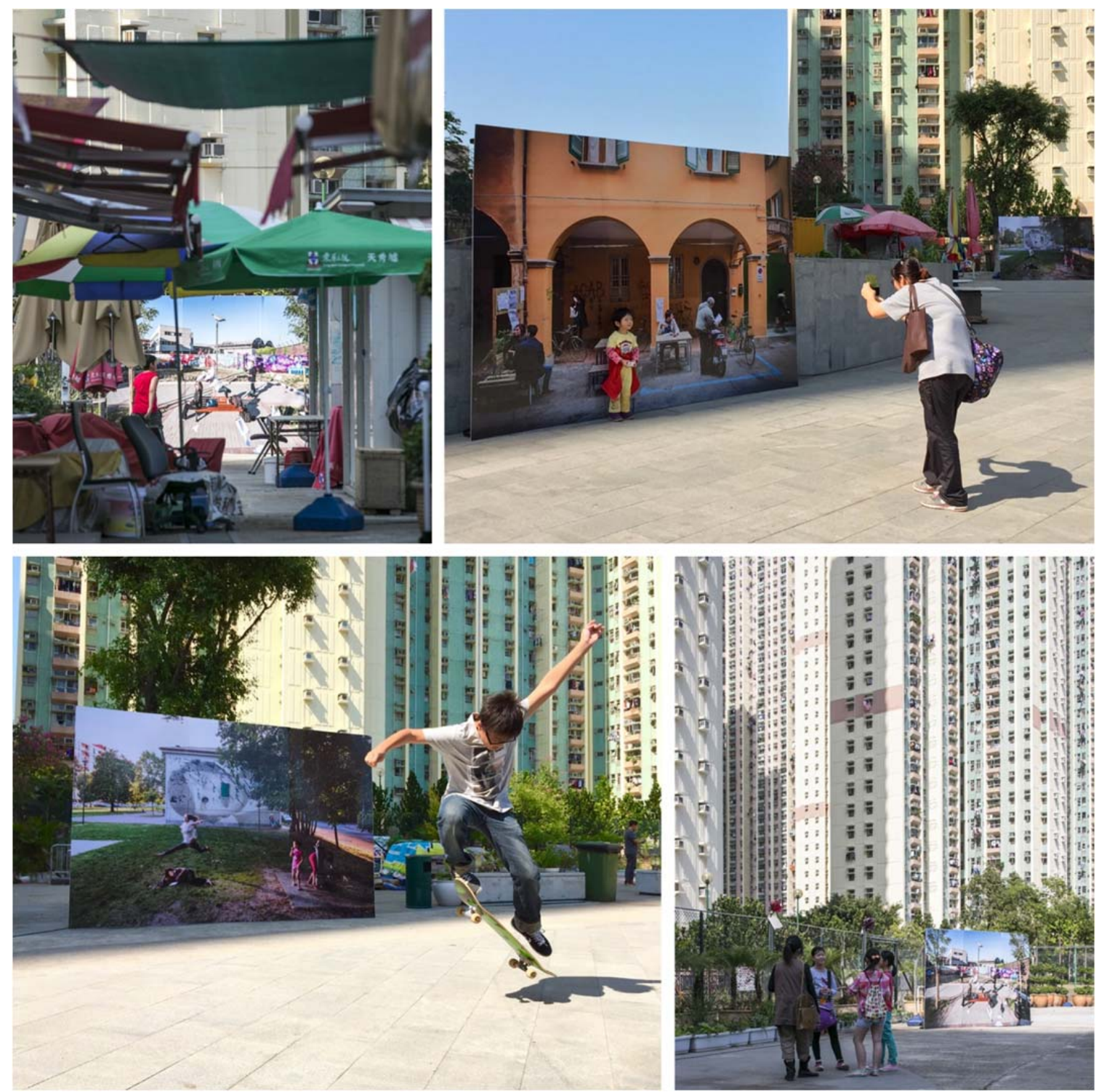

Pop-up City exhibition at Tin Shui Wai, Hong Kong, 2014.

Photography (top left and bottom right): Fabio Mantovani. Photography (top right and bottom left): Loiix Fung

\section{Acknowledgments}

Thanks to Hendrik Tieben, Francesco Rossini and Yip Kai Chun from The Chinese University of Hong Kong, School of Architecture for the valuable and generous support. Thanks also to Loiix Fung for the set-up in Tin Shui Wai.

\section{To cite this article:}

Bravo, L. (20I6). Pop-up City. Searching for instant urbanity. The Journal of Public Space, I(I), I55I58, DOI: 10.5204/jps.vlil.18

This article has been accepted for publication in The Journal of Public Space. Please see the Editorial Policies under the 'About' section of the journal website for further information.

\section{(C) (i) (2)}

This work is licensed under a Creative Commons Attribution - Non Commercial 4.0 International License. https://creativecommons.org/licenses/by-nc/4.0/

I58 | The Journal of Public Space, I(I), 2016 | ISSN 2206-9658

(c) Queensland University of Technology 
Thank you for reading!

The Journal of Public Space

ISSN 2206-9658

Founding Editors Luisa Bravo \& Mirko Guaralda

(c) Queensland University of Technology

https://www.journalpublicspace.org 